\title{
Functionally Graded Alumina/Mullite Coatings for Protection of Silicon Carbide Ceramic Components from Corrosion
}

Final Report

September 1996-November 2000

Prepared by:

Prof. Stratis V. Sotirchos

February 2001

Work Performed under Grant No.: DE-FG22-96PC96208

Performed for:

U.S. Dept. of Energy

University Coal Research Program

Pittsburgh Energy Technology Center

Pittsburgh, Pennsylvania

Performed at:

University of Rochester

Dept. of Chemical Engineering

Rochester, NY 14627 


\section{EXECUTIVE SUMMARY}

The main objective of this research project was the formulation of processes that can be used to prepare compositionally graded alumina/mullite coatings for protection from corrosion of silicon carbide components (monolithic or composite) used or proposed to be used in coal utilization systems (e.g., combustion chamber liners, heat exchanger tubes, particulate removal filters, and turbine components) and other energy-related applications. Since alumina has excellent resistance to corrosion but coefficient than silicon carbide, the key idea of this project has been to develop graded coatings with composition varying smoothly along their thickness between an inner (base) layer of mullite in contact with the silicon carbide component and an outer layer of pure alumina, which would function as the actual protective coating of the component. (Mullite presents very good adhesion towards silicon carbide and has thermal expansion coefficient very close to that of the latter.)

A comprehensive investigation of the chemical vapor codeposition (CVD) of alumina and mullite through hydrolysis of aluminum and silicon chlorides in the presence of $\mathrm{CO}_{2}$ and $\mathrm{H}_{2}$ as a route for the preparation of composite alumina/mullite coatings was carried out. The kinetics of the codeposition of silica, alumina, and aluminosilicates from mixtures of methyltrichlorosilane or silicon tetrachloride, aluminum trichloride, carbon dioxide, and hydrogen was studied experimentally. In order to elucidate some aspects of the codeposition process, the deposition of pure silica and the deposition of pure alumina from mixtures of methyltrichlorosilane or silicon tetrachloride and aluminum trichloride, respectively, with $\mathrm{CO}_{2}$ and $\mathrm{H}_{2}$ were also investigated. Kinetic data were obtained by carrying out chemical vapor deposition experiments on $\mathrm{SiC}$ substrates in a hot-wall reactor of tubular geometry, which permits continuous monitoring of the deposition rate through the use of a microbalance. Experiments were conducted over relatively broad temperature and pressure ranges around $1300 \mathrm{~K}$ and 100 Torr, respectively, and the effects of feed composition, flow rate, and distance from the entrance of the reactor on the deposition rate and deposit composition were investigated. Thermodynamic equilibrium computations were performed on the $\mathrm{Al} / \mathrm{Si} / \mathrm{Cl} / \mathrm{C} / \mathrm{O} / \mathrm{H}, \mathrm{Al} / \mathrm{Cl} / \mathrm{C} / \mathrm{O} / \mathrm{H}$, and $\mathrm{Si} / \mathrm{Cl} / \mathrm{C} / \mathrm{O} / \mathrm{H}$ systems at the conditions used in the deposition experiments, and the results were used to explain the observations made in the experiments. Among the most interesting findings of the kinetic studies was that in the codeposition problem there was a dramatic increase of the deposition rate of $\mathrm{SiO} 2$ in the codeposition process, relative to the rate seen in a silica deposition experiment through the hydrolysis of silicon chloride at the same conditions. This enhancement was accompanied by a reduction of the rate of deposition of $\mathrm{Al}_{2} \mathrm{O}_{3}$, relative to the deposition rate in an independent alumina deposition experiment at the same conditions. The overall deposition rate was by a factor of 2-3 higher than the sum of deposition rates that were obtained when only one of the two chlorides (chlorosilane or $\mathrm{AlCl}_{3}$ ) was present in the feed, and because of the enhancement of the deposition of $\mathrm{SiO} 2$ and the suppression of the deposition of $\mathrm{Al} 2 \mathrm{O} 3$, the deposit consisted mainly of $\mathrm{SiO}_{2}$ at reaction conditions that yielded 
similar deposition rates of the two oxides in independent deposition experiments. The behavior of mixtures with methyltrichlorosilane as silicon source was qualitatively similar to that of mixtures with silicon tetrachloride, but both the codeposition rate and the rate of deposition of $\mathrm{SiO} 2$ were much higher in the former case.

Detailed homogeneous and heterogeneous kinetic models were formulated for the deposition of $\mathrm{SiO}_{2}$ from $\mathrm{SiCl}_{4} / \mathrm{CO}_{2} / \mathrm{H}_{2}$ and $\mathrm{MTS} / \mathrm{CO}_{2} / \mathrm{H}_{2}$ mixtures and the deposition of $\mathrm{Al}_{2} \mathrm{O}_{3}$ from $\mathrm{AlCl}_{3} / \mathrm{CO}_{2} / \mathrm{H}_{2}$ mixtures. A complete mechanistic model for the water gas-shift reaction was included as a subset in the overall decomposition and deposition mechanisms. The kinetic models were introduced into the transport and reaction model of a plug-flow reactor, and the overall models were employed to investigate the sensitivity of the predicted deposition rates, surface coverages of adsorbed species, and gas phase composition on the operating conditions, the residence time in the reactor, and some key steps in the pathways of the homogeneous chemistry of the process. The results showed that in the absence of deposition reactions, the gas phase approaches equilibrium at residence times that are much greater than those typically encountered in CVD reactors. The concentrations of the gas phase species that are responsible for deposition of oxides are strongly influenced by the occurrence of the heterogeneous reactions, and this in turn leads to strong dependence of the deposition rate profile on the reactor geometry (deposition surface to reactor volume ratio). For $\mathrm{SiO}_{2}$ deposition, the concentrations of the deposition precursors are much higher when methyltrichlorosilane is used as silicon source, for comparable silicon and oxygen loadings of the feed, and thus, the rate of silicon oxide deposition from MTS can be higher by a few orders of magnitude. The overall transport and reaction model were found to be capable of reproducing, both qualitatively and quantitatively, all results obtained in our experiments on $\mathrm{SiO}_{2}$ and $\mathrm{Al}_{2} \mathrm{O}_{3}$ deposition. The two models were combined to formulate a model for the codeposition process, and the predictions of this model and the results of the experimental studies on the kinetics of codeposition process were used to identify operating conditions where deposition of coatings consisting of mullite or aluminarich mullite was possible. Deposition experiments were carried out at those conditions, and the results confirmed that it was possible to produce alumina/mullite composite coatings of any composition by manipulating some of the operating conditions. In general, the deposition of material having the composition of mullite $\left(2 \mathrm{SiO}_{2} \cdot 3 \mathrm{Al}_{2} \mathrm{O}_{3}\right)$ or alumina-rich mullite was found to be favored by low operating pressures, high Si:Al feed ratios, and low residence times in the CVD reactor. 
TABLE OF CONTENTS

EXECUTIVE SUMMARY ii

TABLE OF CONTENTS IV

1. BACKGROUND INFORMATION 1

2. WORK DONE AND DISCUSSION 5

$\begin{array}{ll}\text { BIBLIOGRAPHY } & 6\end{array}$ 


\section{BACKGROUND INFORMATION}

Silicon-based ceramic materials are used or being considered for use in a variety of applications related to coal utilization and other energy-related systems. In particular, silicon carbide ( $\mathrm{SiC})$, in monolithic or composite form, exhibits such a unique combination of high thermal shock resistance, high thermal conductivity, high strength, low weight, and high oxidation resistance at elevated temperatures that it appears to be the material of choice for a number of technological applications. These include structural components in advanced coal technologies, such as IGCC (integrated gasification combine cycle) and PFBC (pressurized fluidized-combustion) systems, components of advanced turbine systems (combustor liners and, possibly, turbine blades), parts in piston engines (valves and piston heads), ceramic tubes as heat exchangers in coal-fired boilers and industrial furnaces (glass melting and aluminum remelt operations), and ceramic filters for particulate from hot flue and coal gases.

Like Si itself and other Si-based ceramics and intermetallics (silicon nitride and molybdenum disilicide, for instance), the good oxidation resistance of $\mathrm{SiC}$ at high temperatures is due to the formation of a scale of $\mathrm{SiO}_{2}$, through which the oxidizing agent $\left(\mathrm{O}_{2}\right)$ must diffuse to reach unreacted material. $\mathrm{SiO}_{2}$ has one of the lowest diffusion coefficients of $\mathrm{O}_{2}$ (Jacobson, 1993), and as a result, this passive oxidation process is a slow process. At very high temperatures, formation of gaseous $\mathrm{SiO}$ becomes possible, and the oxidation process moves into a phase of active oxidation, where because of absence of a protective scale, the rate of the reaction is very high (Wagner, 1958; Pareek and Shores, 1992; Zheng et al., 1992; Sickafoose and Readey, 1993; Nickel et al., 1993). This pattern of oxidation is qualitatively the same for all Si-based materials, but the location of the passive to active oxidation transition boundary on the [oxygen partial pressure, temperature] plane varies with each material (Jacobson, 1993).

In a typical application, there are several trace components present in the combustion environment in addition to fuel and oxygen. Among the most important 
ones are alkalis $(\mathrm{Na}, \mathrm{K})$, halides $(\mathrm{Cl}, \mathrm{I})$, and sulfur $(\mathrm{S})$. All these pollutants are present in relatively large quantities in coal and other solid fuels (waste material, for instance), but even some of the cleanest fuels (such as, unleaded gasoline, commercial aviation fuel, and fuel oils) contain significant amounts of sulfur (0.05$1 \%$ ) and alkali compounds (4-20 ppm) (Jacobson, 1993). Sodium and halides may also be introduced in the combustion system through the combustion air, especially if combustion occurs in the vicinity of a marine environment. Corrosive degradation of ceramic components occurs by both gaseous and liquid species formed from the various alkali, halide, and sulfur precursors in the high-temperature environment.

Alkali-induced corrosion through liquid deposition of alkali metal salts and oxide slags is the major mechanism of corrosion. The main corrosive species is $\mathrm{Na}_{2} \mathrm{O}$ (or $\mathrm{K}_{2} \mathrm{O}$ ), formed from sulfites or other salts, which tends to react with the protective scale of $\left.\mathrm{SiO}_{2}\right)$ forming liquid sodium silicate species $\left(\mathrm{Na}_{2} \mathrm{O} \cdot\left(\mathrm{SiO}_{2}\right)_{\mathrm{x}}\right)$. In contrast to $\mathrm{SiO}_{2}$, this liquid layer is not protective because the diffusion coefficient of oxygen in it is much higher than that in $\mathrm{SiO}_{2}$ and because in the high temperature environment it is carried away from the surface through vaporization. The situation is exacerbated in the presence of moisture since more reactions that lead to formation of $\mathrm{Na}_{2} \mathrm{O}$ become thermodynamically more favorable (Van Roode et al., 1993). This corrosion process is not much different from the hot corrosion of turbine alloys that is observed under $\mathrm{Na}_{2} \mathrm{SO}_{4}$ generating conditions and the corrosion that occurs in $\mathrm{SiC}$ heat exchanger tubes when alkali halide fluxes are used in the aluminum remelt industry. Surface recession rates of almost $1 \mathrm{~cm} / \mathrm{yr}$ may be observed under these circumstances (Goldfarb, 1988; Van Roode et al., 1993).

Given the exceptional properties of $\mathrm{SiC}$ and of other silicon-based ceramics but their problematic performance in alkali and sulfur containing environments, a protective coating must be used on surfaces exposed to the combustion environment to protect them from corrosion. For proper performance, such a coating must have good oxidation resistance and chemical stability (up to at least $1300^{\circ} \mathrm{C}$ ), good adherence with the base material, and good tolerance to thermal cycling. Problem- 
free performance during thermal cycling requires that the chosen material must be such that it yields low residual stress at the interface, and this in turn necessitates that there is a good match between the thermal expansion coefficient of the substrate and that of the coating.

Alumina presents very good corrosion resistance against the various corrosive compounds that cause degradation of the silica scale that functions as a protective layer of Si-based ceramics (Goldfarb, 1988; Lawson et al., 1993). Under some conditions the presence of $\mathrm{Na}_{2} \mathrm{O}$ in the sodium salt melts can lead to formation of a $\beta / \beta$ "-alumina (Van Hoek et al., 1991,1992), but, as it is evidenced from the long-term, stable performance of $\beta$ "-alumina ceramics as electrolytes in $\mathrm{Na} / \mathrm{S}$ cells, further reaction between the $\beta / \beta "$-alumina and the sulfur and alkali compounds is practically absent (Gordon et al., 1992). Its high corrosion resistance combined with its relatively low cost makes alumina an ideal candidate as protective coating for silicon carbide, but the problem is that its thermal expansion coefficient is almost twice as large as that of the latter.

In such intractable problems such as joining dissimilar materials (metals and ceramics) and depositing adherent and crack-free films and coatings on substrates having significantly different thermal expansion coefficients, compositionally graded materials (CGM's) provide practical solutions (Ford and Stangle, 1993). In graded materials the composition is varied continuously or in steps between those of two outermost layers. The continuous change in the composition and, hence, microstructure of CGM's results in gradients in their properties, and this makes possible to develop coherent structures that present considerably different properties at the two ends of their thickness. Of particular interest for application to protective coatings is the ability of CGM's to bridge the difference in the thermal expansion coefficients of a base layer, which adheres well to the substrate and matches well its thermal expansion coefficient, and of an outer layer, which exhibits the desired properties of chemical stability and corrosion resistance. By spreading the mismatch of the thermal expansion coefficient over a finite thickness, the local thermal stresses 
- compressive or tensile depending on which thermal expansion coefficient is larger and in which direction the temperature is changed - are reduced and excessive damage to the coating is avoided (Ford and Stangle, 1993).

It is practically impossible to find a single material that matches the thermal expansion coefficient of the substrate material ( $\mathrm{SiC}$ for our studies), adheres well to the substrate, and exhibits good oxidation resistance in the presence of alkali, sulfur, and halogen compounds. Good oxidation resistance more or less requires that the coating be an oxide, but going through a database of thermal expansion coefficients of oxide ceramics, one soon comes to the realization that there is no oxide that both has thermal expansion coefficient matching that of $\mathrm{SiC}$ over the whole temperature range and provides acceptable protection against oxidation and corrosion. There is relatively good agreement between the thermal expansion coefficient of mullite and $\mathrm{SiC}$, but, even though mullite does not contain free silica, there is some evidence in the literature that it tends to form sodium aluminosilicates and silicates in an alkali and sodium environment (Dietrichs and Krönert, 1982; Van Roode et al., 1993). As we mentioned in the previous section, much better corrosion resistance is displayed by alumina, but its thermal expansion coefficient is almost a factor of 2 greater than that of $\mathrm{SiC}$. The above discussion points to the conclusion that a solution to the problem is offered by a compositionally graded structure, in which the composition varies smoothly between a base layer of mullite, used to provide good adhesion and matching of the thermal expansion coefficient, and an outer layer of alumina, which protects the substrate against corrosion and oxidation.

To reduce the mismatch between alumina and silicon carbide substrates, Federer et al. (1989) and Van Roode et al. (1993) produced graded coatings with composition varied in $25 \%$ steps between that of mullite (inner layer) and alumina (outer coating) using a plasma spraying method. Their corrosion tests showed that the mullite-alumina graded structures did very well during thermal cycling, showing no visible damage and developing only a few cracks. However, examination of the substrate-coating interface revealed the presence of sodium aluminosilicates 
$\left(\mathrm{Na}_{2} \mathrm{O} \cdot \mathrm{Al}_{2} \mathrm{O}_{3} \cdot \mathrm{SiO}_{2}\right)$ and, possibly, sodium silicates. Their conclusions were that the problem lied in the porosity $(10-15 \%)$ of the coating produced by plasma spraying and that denser coatings were needed for successful application of the graded coating concept.

The development of processing routes for the fabrication of mullite/alumina graded ceramic coatings through chemical vapor deposition (CVD) methods was the subject of this project. Silica and alumina were deposited using mixtures of their chlorides with $\mathrm{H}_{2}$ and $\mathrm{CO}_{2}$, and the results were used to identify ways in which the composition of the deposit could be varied normal to the surface. Experimental deposition studies were carried out in a hot-wall reactor coupled with a thermogravimetric analysis system. Detailed kinetic models of the deposition processes of silica, alumina and mullite were developed, and they were used to analyze the experimental data. The deposits were characterized using various methods, such as XRD, Raman spectroscopy, electron microscopy, and EDS.

\section{WORK DONE AND DISCUSSION}

The work that was done under this project is described in detail in six appendices that are attached to this report. These appendices correspond to six papers that were based on experimental and theoretical results that were obtained in this project. The first paper was published in Advanced Materials-CVD, the second in the Journal of the Electrochemical Society, the third was accepted for publication in Advanced Material-CVD, and the other three have been submitted for publication. It is expected that a few more papers (at least three) will be derived from results obtained under his project.

The titles of the six papers (appendices) are:

A. Codeposition of Silica, Alumina, and Aluminosilicates from Mixtures of $\mathrm{CH}_{3} \mathrm{SiCl}_{3}, \mathrm{AlCl}_{3}, \mathrm{CO}_{2}$, and $\mathrm{H}_{2}$. Thermodynamic Analysis and Experimental Kinetic Investigation

B. Chemical Vapor Deposition of Aluminosilicates from Mixtures of $\mathrm{SiCl}_{4}, \mathrm{AlCl}_{3}$, $\mathrm{CO}_{2}$, and $\mathrm{H}_{2}$ 
C. Effects of Residence Time and Reaction Conditions on the Deposition of Silica, Alumina, and Aluminosilicates from $\mathrm{CH}_{3} \mathrm{SiCl}_{3}, \mathrm{AlCl}_{3}, \mathrm{CO}_{2}$, and $\mathrm{H}_{2}$ Mixtures

D. Homogeneous and Heterogeneous Kinetics of the Chemical Vapor Deposition of Silica from Mixtures of Chlorosilanes, $\mathrm{CO}_{2}$, and $\mathrm{H}_{2}$. Model vs. Experiment

E. Development and Validation of a Mathematical Model for the Chemical Vapor Deposition of $\mathrm{Al}_{2} \mathrm{O}_{3}$ from Mixtures of $\mathrm{AlCl}_{3}, \mathrm{CO}_{2}$, and $\mathrm{H}_{2}$

F. Factors Influencing the Preparation of Mullite Coatings from Metal Chloride Mixtures in $\mathrm{CO}_{2}$ and $\mathrm{H}_{2}$

\section{BIBLIOGRAPHY}

Dietrichs, P., Krönert, W., INTERCERAM·NR. 3, 223 (1982).

Ford, R.G., Stangle, G.C., Proc. 6th Conf. Cer. Matrix Comp., p. 795 (1993).

Federer, J.I., Van Roode, M., Price, J.R., Surface and Coatings Technology, 39/40, 71 (1989).

Goldfarb, V., GRI Contract No. 5086-232-1274, Final Report (1988).

Gordon, R.S., Heavens, S.N., Virkar, A.V., Weber, N., Corrosion Science, 33, 605 (1992).

Jacobson, N.S., J. Amer. Cer. Soc., 76, 3 (1993).

Lawson, M.G., Pettit, F.S., Blachere, J.R., J. Mater. Res., 8, 1964 (1993).

Nickel, K.G., Fu, Z., Quirmbach, P., Trans. ASME, 115, 76 (1993).

Nitodas S. F., and Sotirchos S. V., Chem. Vapor Deposition (Adv. Mater.), 5, 219 (1999).

Nitodas, S. F., and Sotirchos, S. V., J. Electrochem. Soc., 147, 1050 (2000a). 
Nitodas, S. F., and Sotirchos, S. V., Nitodas S. F., Sotirchos S. V., to be submitted in Adv. Mater (2000b).

Pareek, V.K., Shores, D.A., Science, 48, 983 (1992).

Sickafoose, R.R., Jr., Readey, D.W., J. Am. Cer. Soc., 76, 316 (1993).

Van Hoek, J.A.M., van Loo, F.J.J., Metselaar, R., Key Eng. Materials, 53-55, 111 (1991).

Van Hoek, J.A.M., van Loo, F.J.J., Metselaar, R., J. Am. Cer. Soc., 75, 109 (1992).

Van Roode, M., Price, J.R., Stala, C., J. Eng. Gas Turb. Power, 115, 139 (1993).

Wagner, C., J. Appl. Physics, 29, 1295 (1958).

Zheng, Z., Tressler, R.E., Spear, K.E., Corrosion Science, 33, 545 (1992). 
Codeposition of Silica, Alumina, and Aluminosilicates from Mixtures of $\mathrm{CH}_{3} \mathrm{SiCl}_{3}, \mathrm{AlCl}_{3}, \mathrm{CO}_{2}$, and $\mathrm{H}_{2}$. Thermodynamic Analysis and Experimental Kinetic Investigation

Stephanos F. Nitodas and Stratis V. Sotirchos ${ }^{*}$

Department of Chemical Engineering

University of Rochester

Rochester, NY 14627

* to whom correspondence should be addressed (E-mail: svs2@ che.rochester.edu) 


\begin{abstract}
The codeposition of silica, alumina, and aluminosilicates from mixtures of methyltrichlorosilane, aluminum trichloride, carbon dioxide, and hydrogen is investigated in this study. In order to elucidate some aspects of the codeposition process, the deposition of pure silica and pure alumina from mixtures of methyltrichlorosilane and aluminum trichloride, respectively, with $\mathrm{CO}_{2}$ and $\mathrm{H}_{2}$ is also investigated. Kinetic data are obtained by carrying out chemical vapor deposition experiments on $\mathrm{SiC}$ substrates in a hot-wall reactor of tubular geometry, which permits continuous monitoring of the deposition rate through the use of a microbalance. Reaction rate data are presented for temperatures for temperatures between 1073 and $1373 \mathrm{~K}\left(800-1100{ }^{\circ} \mathrm{C}\right)$ at $13.3 \mathrm{kPa}$ (100 Torr) pressure for various feed compositions and various positions along the axis of the deposition reactor. Thermodynamic equilibrium computations are performed on the $\mathrm{A} / \mathrm{Si} / \mathrm{Cl} / \mathrm{C} / \mathrm{O} / \mathrm{H}$, $\mathrm{Al} / \mathrm{Cl} / \mathrm{C} / \mathrm{O} / \mathrm{H}$, and $\mathrm{Si} / \mathrm{Cl} / \mathrm{C} / \mathrm{O} / \mathrm{H}$ systems at the conditions used in the deposition experiments. The experimental observations are discussed in the context of the results of the equilibrium analysis and the results of past studies. Among the most interesting findings of this study is that the presence of $\mathrm{AlCl}_{3}$ has a catalytic effect on the incorporation of silica in the deposit, leading to codeposition rates that are by a factor of 2-3 higher than the deposition rates that are obtained when only one of the two chlorides $\left(\mathrm{CH}_{3} \mathrm{SiCl}_{3}\right.$ or $\left.\mathrm{AlCl}_{3}\right)$ is present in the feed.
\end{abstract}

$\underline{\text { Keywords: }}$ silica; alumina; mullite; protective coatings; chemical vapor deposition

\title{
SUMMARY
}

The codeposition of silica, alumina, and aluminosilicates from mixtures of $\mathrm{CH}_{3} \mathrm{SiCl}_{3}$ (methyltrichlorosilane), $\mathrm{AlCl}_{3}, \mathrm{CO}_{2}$, and $\mathrm{H}_{2}$ is investigated in a CVD reactor at high temperatures $(1073-1373 \mathrm{~K})$ and $13.3 \mathrm{kPa}$ total pressure. Results obtained from the investigation of thermodynamic equilibrium in $\mathrm{Si} / \mathrm{C} / \mathrm{Cl} / \mathrm{H} / \mathrm{O}, \mathrm{Al} / \mathrm{C} / \mathrm{Cl} / \mathrm{H} / \mathrm{O}$, $\mathrm{Si} / \mathrm{Al} / \mathrm{C} / \mathrm{Cl} / \mathrm{H} / \mathrm{O}$ systems are also presented. The experimental results show that the coexistence of $\mathrm{CH}_{3} \mathrm{SiCl}_{3}$ and $\mathrm{AlCl}_{3}$ in the feed leads to a dramatic enhancement in the rate of $\mathrm{SiO}_{2}$ incorporation in the deposit and an equally dramatic reduction in the rate of $\mathrm{AlO}_{3}$ deposition, relative to the rates observed at the same conditions when only one chloride is fed into the reactor. The suppression of alumina deposition in the presence of $\mathrm{CH}_{3} \mathrm{SiCl}_{3}$ is in agreement with the thermodynamic equilibrium results. 


\section{Introduction}

Because of their excellent chemical and physical properties, silicon carbide ceramics, in monolithic or composite form, are very attractive for use in high temperature structural applications such as advanced coal utilization systems, gas turbines, industrial furnaces, and aerospace transport. $\mathrm{SiC}$ and other silicon-containing ceramics owe their very good oxidation resistance at high temperatures to the formation of a scale of $\mathrm{SiO}_{2}$, which inhibits the diffusion of oxygen toward the substrate [1]. However, the integrity of the silica scale is compromised at high temperatures in the presence of alkali, sulfur, and halide species. For instance, $\mathrm{Na}_{2} \mathrm{O}$ or $\mathrm{K}_{2} \mathrm{O}$ tend to react with the protective $\mathrm{SiO}_{2}$ scale forming eutectic alkali silicate species (e.g., $\left.\mathrm{Na}_{2} \mathrm{O} x\left(\mathrm{SiO}_{2}\right)\right)$, which are carried away from the surface, allowing the underlying silicon-based material to be attacked by the corrosive gases $[2,3]$.

A protective coating must therefore be employed on silicon-based ceramics intended for use in high temperature corrosive environments. For satisfactory performance, the material of the coating must possess good oxidation and corrosion resistance, high temperature chemical stability (up to at least $1300{ }^{\circ} \mathrm{C}$ ), high strength and thermal conductivity, good adherence with the base material, and good tolerance to thermal cycling. Problem-free performance during thermal cycling requires that the chosen material be such that it yields low residual stresses at the interface, and this in turn necessitates that a good match exist between the thermal expansion coefficient (CTE) of the substrate and that of the coating.

Refractory oxides, such as alumina $\left(\mathrm{Al}_{2} \mathrm{O}_{3}\right)$, mullite $\left(3 \mathrm{Al}_{2} \mathrm{O}_{3} \cdot 2 \mathrm{SiO}_{2}\right)$, yttriastabilized zirconia $\left(\mathrm{ZrO}_{2}-\mathrm{Y}_{2} \mathrm{O}_{3}\right)$, and glass ceramics offer promising solutions for improving the environmental endurance of silicon carbide-based ceramics in corrosive atmospheres [1, 4]. Alumina presents very good corrosion resistance against the various corrosive compounds that cause degradation of the silica scale that functions as protective layer of Si-based ceramics [5, 6]. However, the thermal expansion coefficient of alumina is by almost a factor of 2 larger than the thermal expansion coefficient of silicon carbide, and therefore, relatively large thermal stresses develop at the interface between the alumina coating and the $\mathrm{SiC}$ substrate when the substrate-coating system is 
exposed to temperatures different from those used in the preparation of the coating. This is almost always the case when operation is carried out under condition of thermal cycling. Mullite adheres very well to $\mathrm{SiC}$ and matches rather well its thermal coefficient $[5,7]$, but the Si contained in it can lead to similar problems as those experienced by the $\mathrm{SiO}_{2}$ scale. A solution that combines the advantages of mullite and alumina is offered by graded coatings, of multi-layered [7] or functionally graded form, that is, composite materials with composition changing in steps or in a smooth manner between that of an inner layer of mullite in contact with the $\mathrm{SiC}$ substrate and an outer layer of alumina.

In order to provide information to those interested in preparing alumina, silica, and mullite (or in general aluminosilicate) coatings, in pure or composite form, for the protection of $\mathrm{SiC}$ ceramics or of other materials, the present study focuses on the kinetic investigation of the chemical vapor codeposition of alumina, silica, and aluminosilicates from mixtures of methyltrichlorosilane (MTS), aluminum trichloride, carbon dioxide, and hydrogen. Films of alumina, silica, and aluminosilicates can be prepared by several methods, but chemical vapor deposition (CVD) combines a number of advantageous characteristics. It is capable of preparing essentially nonporous coatings, can achieve compositional changes (for the preparation of graded coatings) over very small distances, offers the ability to control the microstructure and morphology of the coating by changing the operating parameters and conditions, and can be used to coat porous materials, such as filters used for particulate removal in advanced power plant systems based on solid fuels.

The deposition of silica from MTS- $\mathrm{H}_{2}-\mathrm{CO}_{2}$ mixtures and the deposition of alumina from $\mathrm{AlCl}_{3}-\mathrm{H}_{2}-\mathrm{CO}_{2}$ mixtures are also investigated, and deposition experiments are carried out for the three processes over rather broad ranges of experimental conditions. Deposition rates are measured gravimetrically using a tubular hot-wall reactor coupled to an electronic microbalance. In order to determine the effect of temperature and feed composition of the reactants on the equilibrium composition of the gas phase and to identify regions of the space of operating parameters in which deposition of silica, alumina and aluminosilicates can take place from the equilibrated gas phase, computations are carried out on the thermodynamic equilibrium of $\mathrm{Si} / \mathrm{C} / \mathrm{Cl} / \mathrm{H} / \mathrm{O}$, 
$\mathrm{Al} / \mathrm{C} / \mathrm{Cl} / \mathrm{H} / \mathrm{O}$, and $\mathrm{Al} / \mathrm{Si} / \mathrm{C} / \mathrm{Cl} / \mathrm{H} / \mathrm{O}$ systems at the conditions used in the deposition experiments.

Films of alumina and silica find applications in several other areas in addition to that of protective coatings such as in microelectronics, gas separations in high temperature processes, and hard coatings for cutting tools [8-12]. As a result, the chemical vapor deposition of alumina and silica has been investigated for various source gas mixtures in many past studies. Deposition of alumina from mixtures of $\mathrm{AlCl}_{3}, \mathrm{CO}_{2}$, and $\mathrm{H}_{2}$ is one of the most frequently employed routes of alumina film preparation, and it has been extensively investigated [8, 13-22]. Much less work has been done on the preparation of silica films through the hydrolysis of silicon chloride precursors, and almost all of the published studies refer to deposition using silicon tetrachloride as silicon source $[9,10,23,24]$. The same silicon source has also been employed in the few studies that have been presented on the chemical vapor deposition of mullite [25, 27].

MTS is used as silicon source in the present study because preliminary studies on the deposition of silica and alumina through hydrolysis of metal chlorides in the presence of $\mathrm{H}_{2}$ and $\mathrm{CO}_{2}$ revealed that the rate of silica deposition from MTS is much higher (by more than an order of magnitude) than the deposition rate from $\mathrm{SiCl}_{4}$ and comparable to the rate of alumina deposition from $\mathrm{AlCl}_{3}$, for similar metal chloride concentrations. This difference in reactivity between $\mathrm{SiCl}_{4}$ and MTS is most probably a result of the fact that the decomposition of the latter takes place faster than that of $\mathrm{SiCl}_{4}$, leading to higher concentrations of silicon-bearing radical species with high surface reactivity, such as $\mathrm{SiCl}_{2}$ and $\mathrm{SiCl}_{3}$.

\section{Thermochemical Equilibrium Analysis}

The mixture sent through the CVD reactor is assumed to consist of $\mathrm{H}_{2}, \mathrm{CO}_{2}$, and $\mathrm{AlCl}_{3}$, and MTS, with the last two species supplied simultaneously only for codeposition experiments. Hydrogen and carbon dioxide react to produce water vapor through the water gas-shift reaction, and deposition of silica, alumina, and aluminosilicates (e.g., $\mathrm{Al}_{6} \mathrm{Si}_{2} \mathrm{O}_{13}$, and $\mathrm{Al}_{2} \mathrm{SiO}_{5}$ ) takes place through hydrolysis of MTS and $\mathrm{AlCl}_{3}$. The overall reactions that represent these processes are 


$$
\begin{gathered}
\mathrm{CO}_{2}+\mathrm{H}_{2} \rightarrow \mathrm{H}_{2} \mathrm{O}+\mathrm{CO} \\
\mathrm{CH}_{3} \mathrm{SiCl}_{3}+2 \mathrm{H}_{2} \mathrm{O} \rightarrow \mathrm{SiO}_{2}+3 \mathrm{HCl}+\mathrm{CH}_{4} \\
2 \mathrm{AlCl}_{3}+3 \mathrm{H}_{2} \mathrm{O} \rightarrow \mathrm{Al}_{2} \mathrm{O}_{3}+6 \mathrm{HCl} \\
6 \mathrm{AlCl}_{3}+2 \mathrm{CH}_{3} \mathrm{SiCl}_{3}+13 \mathrm{H}_{2} \mathrm{O} \rightarrow \mathrm{Al}_{6} \mathrm{Si}_{2} \mathrm{O}_{13}+24 \mathrm{HCl}+2 \mathrm{CH}_{4} \\
2 \mathrm{AlCl}_{3}+\mathrm{CH}_{3} \mathrm{SiCl}_{3}+5 \mathrm{H}_{2} \mathrm{O} \rightarrow \mathrm{Al}_{2} \mathrm{SiO}_{5}+9 \mathrm{HCl}+\mathrm{CH}_{4}
\end{gathered}
$$

The species fed into the chemical reactor undergo a number of decomposition and recombination reactions, before they reach the deposition surface. The actual chemistries of the deposition processes are therefore much more complex than what the above overall reactions (equations (1)-(5)) suggest, involving several gas phase and solid phase (adsorbed on the deposition surface) species.

Thermodynamic equilibrium calculations were carried out on the $\mathrm{Si} / \mathrm{C} / \mathrm{Cl} / \mathrm{H} / \mathrm{O}$, $\mathrm{Al} / \mathrm{C} / \mathrm{Cl} / \mathrm{H} / \mathrm{O}$, and $\mathrm{Al} / \mathrm{Si} / \mathrm{C} / \mathrm{Cl} / \mathrm{H} / \mathrm{O}$ systems using a computational scheme based on free energy minimization. A variant of the STANJAN code [28] was employed for the computations, using about 250 gaseous and condensed (solid) species from a database of thermodynamic data compiled from various literature sources [29-32]. Calculations were performed over broad ranges of operating conditions (temperature, pressure, and feed composition) for deposition of alumina, silica and aluminosilicates from mixtures of MTS, $\mathrm{AlCl}_{3}, \mathrm{CO}_{2}$, and $\mathrm{H}_{2}$. The temperature was varied in the range $800-1500 \mathrm{~K}$, the cumulative mole fraction of the chlorides between 0.015 and 0.038 , the $\mathrm{CO}_{2}$ to chloride mole fraction ratio between 2 and 3, and the pressure between 2.66 and $101.3 \mathrm{kPa}$ (20 and 760 Torr). The loading of the reactor in each element was determined from the feed composition in aluminum chloride, methyltrichlorosilane, hydrogen, and carbon dioxide.

The thermodynamic analysis was carried out in three steps: The free energy minimization code was first used to compute the equilibrium of the gas phase in the absence of solid deposition reactions. The composition of the equilibrated gas phase was subsequently employed to assess the feasibility of depositing a certain solid species by examining the equilibrium constants of reactions leading to deposition of that species. Finally, the equilibrium constants of reactions among the solid species that could be deposited from the equilibrated gas phase were used to determine transition temperatures 
for these reactions and, in this way, assess the stability of the various solid species on the deposition surface. This three-step procedure is used because the reactions that are encountered in the gas phase are, in general, much faster than those involved in solid deposition; therefore, it is more likely within the residence times encountered in typical CVD reactors to have equilibration of the gas phase only. The attainment of complete gas-solid equilibrium requires that large amounts of mass be transferred from the gas phase to the solid phase, and this can happen only for unreasonably large residence times or deposition surface to volume ratios in the reactor.

\subsection{Results on Gas Phase Equilibrium}

The computations showed that 19 species were present at equilibrium in the reactor in significant quantities in the gas phase for the $\mathrm{Al} / \mathrm{Si} / \mathrm{C} / \mathrm{Cl} / \mathrm{H} / \mathrm{O}$ system, 13 for the $\mathrm{Si} / \mathrm{C} / \mathrm{Cl} / \mathrm{H} / \mathrm{O}$ system, and 13 for the $\mathrm{Al} / \mathrm{C} / \mathrm{Cl} / \mathrm{H} / \mathrm{O}$ system. The threshold mole fraction was taken as $10^{-6}$. These species are shown in Table 1. For the silica deposition from MTS and alumina deposition from $\mathrm{AlCl}_{3}$, representative results for the variation of the equilibrium mole fractions of the major gas species with the temperature are shown in Figures 1 and 2, respectively, at $13.3 \mathrm{kPa}$ (100 Torr).

It is evident from Figure 1 that almost complete decomposition of MTS takes place at equilibrium, especially at high temperatures. $\mathrm{The}^{\mathrm{SiCl}_{3}}$ and $\mathrm{SiCl}_{2}$ radicals are present in significant quantities, and since these species must exhibit high surface reactivity, they most probably are the main precursors for silicon incorporation in the deposit and, hence, silica deposition. $\mathrm{SiCl}_{2}$ becomes the main silicon-bearing species above $1200 \mathrm{~K}$. The role of $\mathrm{SiCl}_{2}$ as a major silicon deposition precursor has been established in experimental investigations of silicon deposition using silicon tetrachloride as source gas [33, 34]. $\mathrm{SiCl}_{4}$ and $\mathrm{SiHCl}_{3}$ are the two stable silicon chlorides that exist in appreciable quantities in the equilibrium gas phase composition. Because of their stable form, these species must exhibit much lower surface reactivities than $\mathrm{SiCl}_{2}$ and $\mathrm{SiCl}_{3}$, and therefore, their contribution to silicon incorporation in the deposit should be important only at low temperatures where their concentrations become much larger than those of $\mathrm{SiCl}_{2}$ and $\mathrm{SiCl}_{3}$. A similar observation applies to $\mathrm{CH}_{4}$ with regard to its role in carbon 
incorporation in the deposit, relative to other stable hydrocarbons and radicals [35]. $\mathrm{CH}_{4}$ is the only hydrocarbon found to exist above the mole fraction threshold $\left(10^{-6}\right)$ in the equilibrated gas phase.

Silicon monoxide $(\mathrm{SiO})$ is the most abundant silicon-bearing species at temperatures above $950 \mathrm{~K}$, its concentration becoming a few orders of magnitude larger than that of the next silicon-bearing species in the high temperature range. However, some studies have concluded that it possesses rather low surface reactivity [36, 37]. Most of the chlorine is present in the form of $\mathrm{HCl}$, one of the main products of the overall deposition reaction of $\mathrm{SiO}_{2}$ from MTS and $\mathrm{H}_{2} \mathrm{O}$. It must be noted that thermodynamic equilibrium computations were also done after including in the list of chemical species several $\mathrm{Si}_{\mathrm{x}} \mathrm{C}_{\mathrm{y}} \mathrm{O}_{\mathrm{z}} \mathrm{H}_{\mathrm{w}}$ compounds in addition to those covered in [29-32], using thermodynamic data reported in $[38,39]$. It was found that the only species that may be present at equilibrium in relatively high mole fractions at temperatures above $1300 \mathrm{~K}$ are $\mathrm{Si}(\mathrm{OH})_{4}, \mathrm{SiH}(\mathrm{OH})_{3}$, and $\mathrm{SiOSiO}$. When these three species were not considered, the results were found to be almost identical to those shown in Figure 1 (for $\mathrm{SiO}_{2}$ deposition) and Figures 3 and 4 (for codeposition) over the whole temperature range. Since our literature survey did not uncover any reaction pathways that could support high rates of formation of these species, it was decided not to include them in the computations we present and discuss here.

In contrast to the situation encountered in Figure 1, the results of Figure 2 show that $\mathrm{AlCl}_{3}$ is the main metal-bearing species at temperatures up to $1450 \mathrm{~K}$. Significant amounts of other aluminum species, such as $\mathrm{AlCl}, \mathrm{AlCl}_{2}$, and $\mathrm{AlOH}$, appear above 1100 K. However, because of their radical form, these species may possess high surface reactivities and, therefore, contribute more to the aluminum incorporation in the deposit. A much more interesting difference between the results of Figure 1 and Figure 2 is that in the latter the overall equilibrium concentration of the radical metal-containing species increases with the temperature and that the concentration of $\mathrm{HCl}$ at equilibrium is significantly lower. This difference suggests that the effects of temperature and $\mathrm{HCl}$ presence in the gas phase on the rates of the deposition of the single oxides may be markedly different. 
Results on the influence of temperature and initial concentration of the reacting mixture on the equilibrium composition of the gas phase for the case of the codeposition process are presented in Figures 3 and 4. The metal chloride loadings in Figure 3 are the same as those in Figures 1 and 2. The comparison of Figure 3 with Figures 1 and 2 suggests that the addition of $\mathrm{AlCl}_{3}$ in the mixture influences weakly the concentrations of the silicon species; however, the converse is not true. The introduction of MTS in the system leads to a dramatic reduction in the concentrations of the aluminum-containing radical species, such as $\mathrm{AlCl}, \mathrm{AlCl}_{2}$, and $\mathrm{AlOH}$. The concentration of $\mathrm{HCl}$ at all temperatures is similar to that in the $\mathrm{MTS}-\mathrm{H}_{2}-\mathrm{CO}_{2}$ system -- actually higher because of the introduction of additional chlorine in the system through $\mathrm{AlCl}_{3}$. By increasing the $\mathrm{Al} / \mathrm{Si}$ feed ratio from 0.8 to 2.5 (Figure 4), a marked increase in the equilibrium mole fractions of the aluminum-bearing radicals is observed, even in the low temperature region, and there is a significant decrease in the silicon species mole fractions, especially the mole fraction of $\mathrm{SiCl}_{2}$. $\mathrm{HCl}$ exists in Figure 4 at a level similar to that in the MTS$\mathrm{H}_{2}-\mathrm{CO}_{2}$ system, and the concentrations of the aluminum-containing radicals approach those seen in the absence of MTS only in the upper limit of the temperature range. Because of the rise in the concentration of $\mathrm{HCl}, \mathrm{AlCl}_{2}$ becomes the most abundant aluminum-bearing species in the presence of MTS.

\subsection{Thermodynamic Feasibility of Solid Deposition}

From the equilibrium constants of reactions leading to $\mathrm{SiO}_{2}$ and $\mathrm{Al}_{2} \mathrm{O}_{3}$ deposition, such as equations (2) and (3), it is concluded that the deposition of these two species is feasible at all temperatures in Figure $1\left(\mathrm{SiO}_{2}\right)$, Figure $2\left(\mathrm{Al}_{2} \mathrm{O}_{3}\right)$, and Figures 3 and 4 . In other words, any reaction leading to $\mathrm{SiO}_{2}$ or $\mathrm{Al}_{2} \mathrm{O}_{3}$ deposition and involving species present in the gas phase is favored to occur in the direction of solid deposition. The equilibrium constants of the reactions given by equations (4) and (5) or of other equivalent reactions show that the deposition of mixed oxides, $\mathrm{Al}_{2} \mathrm{SiO}_{5}$ and $\mathrm{Al}_{6} \mathrm{Si}_{2} \mathrm{O}_{13}$, is also feasible at the conditions of Figures 3 and 4. From the thermodynamic data of the literature [29-31], it was determined that at the conditions chosen for our study, the most stable forms of these oxides are andalusite $\left(\mathrm{Al}_{2} \mathrm{SiO}_{5}\right)$ and mullite $\left(\mathrm{Al}_{6} \mathrm{Si}_{2} \mathrm{O}_{13}\right)$. The fact 
that the oxides can be deposited from the equilibrated gas phase does not imply that this would also be the case under the conditions that prevail in a CVD reactor. For instance if $\mathrm{HCl}$ forms faster than $\mathrm{H}_{2} \mathrm{O}$, it is possible to have a situation where deposition of one or more oxides is not favored to take place.

The formation of the mixed oxides from the single oxides can be represented by the reactions

$$
\begin{gathered}
\mathrm{Al}_{2} \mathrm{O}_{3}+\mathrm{SiO}_{2} \rightarrow \mathrm{Al}_{2} \mathrm{SiO}_{5} \\
3 \mathrm{Al}_{2} \mathrm{O}_{3}+2 \mathrm{SiO}_{2} \rightarrow \mathrm{Al}_{6} \mathrm{Si}_{2} \mathrm{O}_{13}
\end{gathered}
$$

Figure 5 presents the activity-based equilibrium constants of these reactions as functions of temperature. It is seen that the formation of the mixed oxides is feasible at all temperatures. The question that remains to be answered is what transformations, if any, can take place among the single and mixed oxides and what are the transition (equilibrium) temperatures for these reactions. Two such reactions of interest for the deposition of mullite and their equilibrium temperatures are:

$$
\begin{array}{ll}
2 \mathrm{Al}_{2} \mathrm{SiO}_{5}+\mathrm{Al}_{2} \mathrm{O}_{3} \rightarrow \mathrm{Al}_{6} \mathrm{Si}_{2} \mathrm{O}_{13} & \mathrm{~T}_{\mathrm{eq}}=1128 \mathrm{~K} \\
3 \mathrm{Al}_{2} \mathrm{SiO}_{5} \rightarrow \mathrm{Al}_{6} \mathrm{Si}_{2} \mathrm{O}_{13}+\mathrm{SiO}_{2}(\mathrm{xbt}) & \mathrm{T}_{\text {eq }}=1260 \mathrm{~K}
\end{array}
$$

The variation of the equilibrium constant of these reactions is shown in Figure 5. Shown in this figure is also the equilibrium constant of the quartz (qrtz) to cristobalite (xbt) transformation,

$$
\mathrm{SiO}_{2}(\mathrm{qrtz}) \rightarrow \mathrm{SiO}_{2}(\mathrm{xbt}) \quad \mathrm{T}_{\mathrm{eq}}=1134 \mathrm{~K} \quad(10)
$$

as determined from thermodynamic data.

From the above results it is concluded that: a) for $\mathrm{Al}_{2} \mathrm{O}_{3}: \mathrm{SiO}_{2}$ ratio in the deposit below 1:1, the deposit will consist at equilibrium of $\mathrm{Al}_{2} \mathrm{SiO}_{5}$ and $\mathrm{SiO}_{2}$ up to $1260 \mathrm{~K}$, and $\mathrm{Al}_{6} \mathrm{Si}_{2} \mathrm{O}_{13}$ and $\mathrm{SiO}_{2}$ above that; b) for $\mathrm{Al}_{2} \mathrm{O}_{3}: \mathrm{SiO}_{2}$ ratio between 1:1 and 3:2, it will consist of $\mathrm{Al}_{2} \mathrm{SiO}_{5}$ and $\mathrm{Al}_{2} \mathrm{O}_{3}$ up to $1128 \mathrm{~K}, \mathrm{Al}_{2} \mathrm{SiO}_{5}$ and $\mathrm{Al}_{6} \mathrm{Si}_{2} \mathrm{O}_{13}$ between 1128 and $1260 \mathrm{~K}$, and $\mathrm{Al}_{6} \mathrm{Si}_{2} \mathrm{O}_{13}$ and $\mathrm{SiO}_{2}$ above $1260 \mathrm{~K}$; and c) for $\mathrm{Al}_{2} \mathrm{O}_{3}: \mathrm{SiO}_{2}$ ratio above 3:2, it will consist of $\mathrm{Al}_{2} \mathrm{SiO}_{5}$ and $\mathrm{Al}_{2} \mathrm{O}_{3}$ up to $1128 \mathrm{~K}$, and $\mathrm{Al}_{6} \mathrm{Si}_{2} \mathrm{O}_{13}$ and $\mathrm{Al}_{2} \mathrm{O}_{3}$ above that. Therefore, if one is interested in the deposition of mullite, temperatures higher than 1128 $\mathrm{K}$ must be employed if there is thermodynamic equilibrium among the deposited solid species. The picture provided by the reactions represented by equations (6)-(9) is 
relatively simple in comparison to that obtained through rigorous analysis of solid phase equilibrium in the $\mathrm{Si} / \mathrm{Al} / \mathrm{O}$ system, but it suffices for the purposes of our study since it provides results that are very close to those revealed by experimental and other thermodynamic studies. For instance, the estimated temperature of the "andalusite $\rightarrow$ mullite" transformation $(1260 \mathrm{~K})$ agrees well with the thermodynamic results of Davis and Pask [40] who reported that at atmospheric and subambient pressures andalusite is the stable aluminosilicate species for temperatures lower than $1300 \mathrm{~K}$, while near this temperature it transforms to mullite and silica quartz.

\section{Experimental Results and Discussion}

\subsection{Effects of Temperature}

Results on the effect of temperature on the deposition rates of $\mathrm{SiO}_{2}$ and $\mathrm{Al}_{2} \mathrm{O}_{3}$ in independent deposition experiments and on the codeposition rate are presented in Figure 6 in Arrhenius-plot coordinates, that is, as $\ln R_{d}$ vs. $1 / T$, with $R_{d}$ being the deposition rate and $T$ the absolute temperature in the reactor. To obtain these results, the temperature was varied between 1073 and $1373 \mathrm{~K}$ ( 800 and $1100{ }^{\circ} \mathrm{C}$ ) at $25 \mathrm{~K}$ steps. The mole fractions of the source gases were $0.011 \mathrm{MTS}\left(x_{\mathrm{MTS}}\right), 0.009 \mathrm{AlCl}_{3}\left(x_{\mathrm{AlCl} 1}\right)$, and $0.036 \mathrm{CO}_{2}\left(x_{\mathrm{CO} 2}\right)$. The midpoint of the substrate was located $7 \mathrm{~cm}$ from the top of the heating zone of the furnace, the total flow rate was $250 \mathrm{~cm}^{3} / \mathrm{min}$, and the operating pressure $13.3 \mathrm{kPa}$ (100 Torr). Since our objective was to investigate the feasibility of depositing aluminosilicate species, it was decided to operate under conditions giving similar rates of $\mathrm{Al}_{2} \mathrm{O}_{3}$ and $\mathrm{SiO}_{2}$ deposition. Preliminary experiments showed that comparable deposition rates of the two single oxides $\left(\mathrm{Al}_{2} \mathrm{O}_{3}\right.$ and $\left.\mathrm{SiO}_{2}\right)$ could be obtained in independent deposition experiments for similar values of mole fractions of the source gases $\left(\mathrm{AlCl}_{3}\right.$ and MTS). Thus, the $\mathrm{Al} / \mathrm{Si}$ feed ratio (0.8) was set equal to 0.8 .

The results of Figure 6 show that in all three cases the rate increases with increasing temperature. The rate of silica deposition in the single species deposition

process varies in the range $0.002-0.05 \mathrm{mg} / \mathrm{cm}^{2} \cdot \mathrm{min}$ for temperatures between 1198 and $1373 \mathrm{~K}$ (925 and $1100{ }^{\circ} \mathrm{C}$ ). Much lower values (lower than $10^{-3} \mathrm{mg} / \mathrm{cm}^{2} \cdot \mathrm{min}$ ) were 
observed at temperatures below $1373 \mathrm{~K}$. This observation is in agreement with the thermodynamic analysis of the $\mathrm{Si} / \mathrm{C} / \mathrm{Cl} / \mathrm{H} / \mathrm{O}$ system (Figure 1), if one assumes that $\mathrm{SiCl}_{2}$ is the main deposition precursor. The decomposition of MTS is thermodynamically favored throughout the entire range of temperatures examined, but $\mathrm{SiCl}_{2}$ becomes the dominant silicon-chlorine species above $1200 \mathrm{~K}$. Using linear regression, the apparent activation energy of the reaction of silica formation, the slope of the $\ln R_{d}$ vs. $1 / T$ curve, is found to be $26 \mathrm{kcal} / \mathrm{mol}$. There is no information available in the literature on the deposition of silica from MTS so as to compare this value with other reported activation energies.

In the case of alumina deposition, two temperature regions can be distinguished in the behavior of the reaction rate vs. temperature plot shown in Figure 7, which correspond to different slopes of the curve. Above $1223 \mathrm{~K}\left(950{ }^{\circ} \mathrm{C}\right)$, the rate of increase of the rate of alumina deposition with the temperature (slope of the curve in Arrhenius coordinates) is markedly higher than in the second region, i.e., between 1073 and $1123 \mathrm{~K}$. This difference can be attributed to the fact that at low temperatures, the water gas-shift reaction is very slow. In their experiments, Choi et al. [16] found that the nucleation and growth of $\mathrm{Al}_{2} \mathrm{O}_{3}$ are closely related to the production of $\mathrm{H}_{2} \mathrm{O}$, which was found to increase exponentially with increasing temperature. However, the deposition of alumina is not controlled by water formation in the gas phase since the activation energy for the homogeneous water gas-shift reaction (about $80 \mathrm{kcal} / \mathrm{mol}$ at temperatures from 1073 to $1273 \mathrm{~K} \mathrm{[41])} \mathrm{is} \mathrm{higher} \mathrm{than} \mathrm{the} \mathrm{reported} \mathrm{activation} \mathrm{energy} \mathrm{of} \mathrm{alumina} \mathrm{deposition,} \mathrm{which}$ varies from 16 to $57 \mathrm{kcal} / \mathrm{mol}$ [13-15, 17-20]. The experimental data of Figure 6 yield an activation energy of $19.6 \mathrm{kcal} / \mathrm{mol}$ for temperatures higher than $1223 \mathrm{~K}$. The differences in the activation energies obtained in different studies are not surprising considering that in almost all cases they correspond not to the true activation energy of the reaction, but they are apparent quantities that also account for the effects of the reactor geometry, flow and temperature field in the reactor, and residence time. Moreover, the overall deposition process is not represented by a single elementary irreversible reaction, which is the only case where the activation energy can be extracted from the $\ln R_{d}$ vs. $1 / T$ plot. 
The deposition rate of $\mathrm{Al}_{2} \mathrm{O}_{3}$ over the examined temperature range (1073-1373 K) varies from 0.002 to approximately $0.05 \mathrm{mg} / \mathrm{cm}^{2} \cdot \mathrm{min}$ (Figure 6). Temperatures higher than $1223 \mathrm{~K}$ should be employed in order to obtain relatively high deposition rates of alumina. This is consistent with the thermodynamic analysis of the equilibrium gas phase of the $\mathrm{Al} / \mathrm{C} / \mathrm{Cl} / \mathrm{H} / \mathrm{O}$ system (Figure 2), if $\mathrm{AlCl}$ and $\mathrm{AlCl}_{2}$ exhibit higher surface reactivities and, hence, higher $\mathrm{Al}_{2} \mathrm{O}_{3}$ deposition rates than $\mathrm{AlCl}_{3}$. Significant reduction of the equilibrium mole fraction of $\mathrm{AlCl}_{3}$ is observed only at temperatures above $1200 \mathrm{~K}$, which implies that alumina deposition is favored throughout this temperature region. Most past studies on the deposition of alumina from mixtures of $\mathrm{AlCl}_{3}, \mathrm{CO}_{2}$, and $\mathrm{H}_{2}$ employed temperatures higher than 1173 K. Park et al. [15] and Kim et al. [19] obtained results at experimental conditions similar to those used in this study $(13.3 \mathrm{kPa}, 0.005-0.01$ $\mathrm{AlCl}_{3}$ mole fraction, and 0.005-0.03 $\mathrm{CO}_{2}$ mole fraction). The reported values of deposition rate are in good agreement with our results for temperatures above $1000^{\circ} \mathrm{C}$, but they obtained higher deposition rates at lower temperatures. The actual precursors of deposition are not the gaseous species fed into the chemical reactor but rather the products of their decomposition reactions (see Figures 1-4), and the concentrations of the latter at the deposition location are influenced strongly not only by the operating conditions but also by the characteristics of the chemical reactor, the flow field in it, and the residence time. Thus, the differences between the results of this study and those of [15] and [19] are not surprising since, for instance, the flow rate in the latter was twice the value used here. Similar remarks generally apply to the differences among the results of other deposition studies.

Funk et al. [13], Colmet et al. [14], and Colmet and Naslain [20] also reported a sharp increase of the alumina deposition rate with the substrate temperature above 1223 $\mathrm{K}$. In the experiments of those studies, the total pressure was $6.6 \mathrm{kPa}$ (50 Torr), and the total gas flow rate 560,300 , and $300 \mathrm{~cm}^{3} / \mathrm{min}$, respectively. Their results are comparable with our observations even though they used lower pressure and different reactors. The apparent activation energies found in [13], [14], and [20] were larger than the values obtained here (40, 31.2 and $31.2 \mathrm{kcal} / \mathrm{mol}$, respectively). A high apparent activation energy $(76.5 \mathrm{kcal} / \mathrm{mol})$ was also calculated by Bae et al. [21] at an operating pressure of 
$13.3 \mathrm{kPa}$. This is the only reported value that is very close to the activation energy of water formation from $\mathrm{CO}_{2}$ and $\mathrm{H}_{2}$ and suggests that the water gas-shift reaction may be the rate-limiting step of $\mathrm{Al}_{2} \mathrm{O}_{3}$ deposition.

\subsection{Codeposition vs. Single Species Deposition}

The temperature has a strong effect on the rate of the codeposition process (Figure 6). The codeposition rate varies in the range $0.001-0.2 \mathrm{mg} / \mathrm{cm}^{2} \cdot \min$ (i.e., by more than two orders of magnitude) for temperatures between $1073 \mathrm{~K}$ and $1373 \mathrm{~K}$. Higher codeposition rates are observed for the codeposition process than for each of the single oxides in independent deposition experiments, with the only exception being at $1073 \mathrm{~K}$ where the rate of alumina deposition is larger. The codeposition rates are not only larger than those of the single oxides but also higher than their sum by a factor of 2-3 (composite curve in Figure 6). This is a surprising result considering that the concentration of each of the chlorides in the codeposition process was the same as that in the corresponding single species deposition experiments. Moreover, the same concentrations of $\mathrm{CO}_{2}$ and $\mathrm{H}_{2}$ were used in the single species experiments and in the codeposition experiments.

Since continuous monitoring of the deposition rate was employed in our experiments, it was possible to measure the rates of the codeposition process and the two single species deposition processes sequentially at each set of experimental conditions. Therefore, the differences seen among the deposition rates of the three processes in Figure 6 and in other figures reflect the differences in the gas phase composition and not in other operating conditions. Figure 7 presents the variation of the weight of the substrate with time in the three deposition processes, as they were performed sequentially at 1273 $\mathrm{K}$ at the conditions of Figure 6. It is clear from the results of Figure 7 that the deposition rate decreases significantly when one of the chlorides is removed from the feed. Experiments conducted over a long period of time at the same reaction conditions showed that the deposition rate remained constant. Typical results for the codeposition process 
are shown in Figure 8, at $1223 \mathrm{~K}$ and $13.3 \mathrm{kPa}$, where no noticeable variation in the slope of the curve - the dashed curve gives the straight line obtained through linear regression is observed over the whole time horizon of the experiment.

From a comparison of the individual deposition reactions in Figure 6, it is found that for temperatures up to $1200-1225 \mathrm{~K}$ the deposition of alumina proceeds at a higher rate than that of silica, whereas at higher temperatures the opposite situation prevails. If the relative rates of $\mathrm{SiO}_{2}$ and $\mathrm{Al}_{2} \mathrm{O}_{3}$ deposition in the codeposition process were proportional to those seen in the single species deposition experiments at the same conditions, one would expect the deposit to contain significant quantities of $\mathrm{Al}_{2} \mathrm{O}_{3}$ at all temperatures and its composition to be biased towards this oxide in the low temperature range. However, the analysis of the composition of the codeposited films, using energy dispersive X-ray analysis (EDXA), revealed that $\mathrm{SiO}_{2}$ was the main constituent, with its content exceeding $95 \%$ in many cases (on a weight basis). Table 2 shows results of the composition of the films at various combinations of operating conditions along with the rates measured for the codeposition and the single oxide deposition processes, and the deposition rates for the $\mathrm{SiO}_{2}$ and $\mathrm{Al}_{2} \mathrm{O}_{3}$ components of the codeposited films that were extracted from the values of the codeposition rate and film composition. Superscript ind is used to denote results from individual (single oxide) deposition experiments, and superscript cod to denote the respective quantities for codeposition experiments. It is seen that whereas the deposition rates from individual experiments predict $\mathrm{SiO}_{2}$ content in the range 35 to $58 \%$, the $\mathrm{SiO}_{2}$ content of the codeposited film is above $88 \%$ in all cases.

As the results of Table 2 indicate, the high silicon oxide content of the deposit is the combined effect of a dramatic enhancement in the rate of silica deposition and an equally dramatic decrease in the rate of alumina deposition. The decrease in the rate of alumina deposition can be explained on the basis of the thermodynamic results in Figures 2 and 3. As we remarked during the discussion of these results, the concentrations of 
aluminum-containing radical species in the equilibrated gas phase when $\mathrm{AlCl}_{3}$ and $\mathrm{MTS}$ coexist in the feed are much lower, for comparable $\mathrm{CO}_{2}$ and $\mathrm{H}_{2}$ concentrations, than those when $\mathrm{AlCl}_{3}$ is the only chloride fed into the system. On the other hand, the concentration of $\mathrm{HCl}$ is much higher and comparable to that in the $\mathrm{MTS}-\mathrm{CO}_{2}-\mathrm{H}_{2}$ system (Figure 1). Since aluminum-containing radical species are most probably the principal precursors of alumina deposition, and $\mathrm{HCl}$ is the product of almost every $\mathrm{Al}_{2} \mathrm{O}_{3}$ deposition reaction step that one may construct, the rate of the deposition of $\mathrm{Al}_{2} \mathrm{O}_{3}$ in the codeposition process should be much lower if the gas phase composition in the reactor behaves as that of the equilibrated gas phase. However, the thermodynamic equilibrium results cannot explain the enhancement in the rate of $\mathrm{SiO}_{2}$ deposition since the concentrations of the silicon-containing species in the codeposition process (Figure 3) are similar to (and in some cases lower than) those in the MTS- $\mathrm{CO}_{2}-\mathrm{H}_{2}$ system (Figure 1). The fact that the codeposition rate is greater than the composite deposition rate (sum of deposition rates of the two oxides) in independent experiments suggests that there must be steps in the chemistry of the codeposition process that involve both aluminum- and silicon-containing species. Since the enhanced codeposition rate is caused by increased silicon oxide deposition, one is led to conclude that the main deposition product of those additional steps must be silicon oxide.

The activation energy that corresponds to the Arrhenius-plot of the codeposition process (Figure 6) is $22.9 \mathrm{kcal} / \mathrm{mol}$. This value lies between the activation energies of the individual deposition processes and is three times bigger than the activation energy reported in [26] for codeposition from $\mathrm{SiCl}_{4}, \mathrm{AlCl}_{3}, \mathrm{CO}_{2}$, and $\mathrm{H}_{2}(7.4 \mathrm{kcal} / \mathrm{mol})$. Deposition of mullite was reported in [26] at conditions similar to those used here: temperatures between 1073 and $1323 \mathrm{~K}$ and 75 Torr pressure. It was reported that mullite did not form at $1073 \mathrm{~K}\left(800{ }^{\circ} \mathrm{C}\right)$, and that the deposition rate increased with increasing temperature above $1123 \mathrm{~K}$. The reported deposition rates are about one order of magnitude smaller than those found in this study, but this difference can be due to the different reactor configurations and deposition conditions and, more importantly, to the use of silicon tetrachloride as silicon source. Another interesting difference is that in [26] 
the deposition rate and the alumina content of the deposit increased with time, whereas in this study no changes were observed (see Figure 8 for the deposition rate).

\subsection{Effects of Feed Composition}

Results on the influence of the feed composition on the deposition rates are presented in Figures 9-12. The effects of $\mathrm{CO}_{2}$ mole fraction at 1223 and $1273 \mathrm{~K}$ are presented in Figures 9 and 10, respectively, for 0.011 MTS mole fraction and $0.009 \mathrm{AlCl}_{3}$ mole fraction. It is seen in both figures that an increase in the mole fraction of $\mathrm{CO}_{2}$ has a positive effect on the reaction rate of the codeposition process. A steep increase in the deposition rate is observed with increasing mole fraction for low mole fraction values. The codeposition rate appears to reach a "plateau" value as the concentration of $\mathrm{CO}_{2}$ increases, but at $1273 \mathrm{~K}$ (Figure 10), it shows a tendency to go through another increasing phase at the upper limit of the range of $\mathrm{CO}_{2}$ concentration covered in the figure. Codeposition rate vs. $\mathrm{CO}_{2}$ mole fraction data are shown in Figure 9 for two experimental runs, and it is seen that the experimental data are characterized by very good reproducibility.

Since the total flow rate is kept constant at $250 \mathrm{~cm}^{3} / \mathrm{min}$, the increase of the $\mathrm{CO}_{2}$ feed mole fraction is accompanied by a decrease in the $\mathrm{H}_{2}$ mole fraction in the feed. This decrease is relatively small, and therefore, it cannot account for the leveling off of the codeposition rate in Figure 9 as the $\mathrm{CO}_{2}$ mole fraction is increased. The thermodynamic equilibrium computations showed that the increase in the mole fraction of $\mathrm{CO}_{2}$ in the feed leads to a marked increase in the equilibrium concentration of $\mathrm{H}_{2} \mathrm{O}$. However, because of the larger amount of oxygen in the system, the concentrations of the various metal chloride species, especially those of silicon chlorides, are reduced. These results suggest that the leveling off of the deposition rate at high concentrations of $\mathrm{CO}_{2}$ is the result of the competition of the increasing concentration of $\mathrm{H}_{2} \mathrm{O}$ and the decreasing concentrations of metal chlorides.

In the case of silica deposition, the results in the variation of the deposition rate show that the increase in the mole fraction of $\mathrm{CO}_{2}$ has, in general, a negative effect in the deposition rate of silica, with the only exception being at very low $\mathrm{CO}_{2}$ mole fractions 
(0.004-0.008) and $1123 \mathrm{~K}$ (Figure 9). The variation of the deposition rate of alumina exhibits the same behavior as that of the codeposition rate (Figures 9 and 10). This suggests that the surface reaction steps that might be responsible for the enhanced deposition of silica in the codeposition process should be affected by the concentration of $\mathrm{CO}_{2}$ in a similar manner as the steps leading to the $\mathrm{SiO}_{2}$ deposition in the single species deposition process. The deposition rate of alumina appears to level off at lower $\mathrm{CO}_{2}$ mole fraction values than the codeposition rate, and this happens at higher $\mathrm{CO}_{2}$ mole fractions as the temperature increases. These trends are consistent with previous experimental studies on $\mathrm{Al}_{2} \mathrm{O}_{3} \mathrm{CVD}$ from $\mathrm{AlCl}_{3}-\mathrm{CO}_{2}-\mathrm{H}_{2}$ mixtures $[14,15,19]$ where both a maximum in the alumina deposition rate and a shift of the location of the maximum with the temperature were observed. These results led to the conclusion that the limiting mechanism in alumina CVD was the water gas-shift reaction. The production of water vapor from $\mathrm{CO}_{2}$ and $\mathrm{H}_{2}$ has been also suggested by Wong and Robinson [22] to be the rate-limiting step in the deposition of $\mathrm{Al}_{2} \mathrm{O}_{3}$. Funk et al. [13] found that the increase of $\mathrm{CO}_{2}$ flow rate had a positive effect on the deposition rate of alumina, but they did not examine the possibility of the occurrence of a maximum.

More results on the influence of the feed composition on the deposition rates are shown in Figure 11 which presents the variation of the deposition rate with the $\mathrm{AlCl}_{3}$ mole fraction in the presence or absence of MTS at 950 and $1000^{\circ} \mathrm{C}$, respectively. The $\mathrm{AlCl}_{3}$ mole fraction varied in the range 0.006-0.015, and this corresponded to a range of 0.55-1.36 $\mathrm{Al} / \mathrm{Si}$ feed ratio. The feed content in the other reactants was $0.036 \mathrm{CO}_{2}$ mole fraction and 0.011 MTS mole fraction, whereas the distance of the midpoint of the substrate from the top of the heating zone was $4 \mathrm{~cm}$. It is seen that an increase of the $\mathrm{AlCl}_{3}$ flow rate (via an increase in the flow rate of $\mathrm{HCl}$ sent through the chlorinator) leads to an increase in the rates of both deposition processes, and this effect intensifies with increasing temperature. As before, the rate of the codeposition is much higher than that of $\mathrm{Al}_{2} \mathrm{O}_{3}$ deposition. The results of past experimental studies on the chemical vapor deposition of alumina $[14,15,19,20]$ are in good agreement with those of the present study. Colmet et al. [14] reported that at low $\mathrm{AlCl}_{3}$ concentrations (close to the values employed in this investigation), the deposition rate first rapidly increased with increasing 
$\mathrm{AlCl}_{3}$ mole fraction, and then approached a limiting value. This was interpreted as an indication that the deposition rate of alumina was limited by mass transport in the gas phase. A trend to reach a limiting value is not observed in Figure 11, but this could be a result of the different reactor configuration and flow rates used in our experiments.

Kim et al. [19] found a maximum in the deposition rate for $\mathrm{AlCl}_{3}$ mole fractions in the 0.01-0.015 range. It was suggested that the decrease in the deposition rate at higher $\mathrm{AlCl}_{3}$ mole fractions may be caused by the increased concentration of $\mathrm{HCl}$ in the gas phase. In an effort to identify the cause of this decrease, Funk et al. [13] investigated the effect of $\mathrm{HCl}$ on the deposition rate of alumina, and found that addition of $\mathrm{HCl}$ to the feed mixture decreased the deposition rate. Since the increase of the mole fraction of $\mathrm{AlCl}_{3}$ is not accompanied by an increase in the mole fraction of $\mathrm{CO}_{2}$, the weakening influence of $\mathrm{AlCl}_{3}$ on the deposition rate of alumina and the codeposition rate could be due to the overall process becoming controlled by the supply of water through the water gas-shift reaction. According to Silvestri et al. [18], the dependence of the deposition rate of $\mathrm{Al}_{2} \mathrm{O}_{3}$ on both the $\mathrm{AlCl}_{3}$ and $\mathrm{CO}_{2}$ mole fractions is an indication that the process involves more than one rate-limiting step.

Figure 12 presents the effect of the MTS mole fraction on the deposition rate of $\mathrm{SiO}_{2}$ at two locations of the midpoint of the substrate, $4 \mathrm{~cm}$ and $7 \mathrm{~cm}$ from the top of the heating zone of the furnace. When the substrate is positioned at $7 \mathrm{~cm}$, an increase in the MTS mole fraction leads to an increase in the deposition rate, but the opposite behavior is observed at $4 \mathrm{~cm}$. The comparison of the deposition rates for the two locations shows that at the low end of the mole fraction range, the rate of silica deposition decreases with increasing distance from the top of the heating zone. Results on the effect of the substrate position in the reactor on the deposition rate of $\mathrm{Al}_{2} \mathrm{O}_{3}$ and the codeposition at 1223 and $1273 \mathrm{~K}$ for $0.009 \mathrm{AlCl}_{3}$ mole fraction, $0.011 \mathrm{MTS}$ mole fraction, and $0.036 \mathrm{CO}_{2}$ mole fraction can be extracted by comparing Figures 9 and 10 with Figure 11. (The deposition rates at $1273 \mathrm{~K}$ are reported in Table 2.) It is found that at $1223 \mathrm{~K}$, the two deposition rates decrease as the distance from the top of the heating zone increases, whereas at 1273 $\mathrm{K}$, both increase as the distance goes from 4 to $7 \mathrm{~cm}$. As the results of Table 2 show, the location of the substrate also affects the composition of the deposit. 


\subsection{Deposit Stoichiometry and Morphology}

The composition and morphology of the deposits were determined using energy dispersive X-ray analysis (EDXA) and scanning electron microscopy (SEM), respectively. Figures 13 and 14 show some representative SEM micrographs of silica, alumina, and codeposited films obtained at 100 Torr, $250 \mathrm{~cm}^{3} / \mathrm{min}$ total flow rate, 0.011 MTS mole fraction, $0.009 \mathrm{AlCl}_{3}$ mole fraction, and $0.036 \mathrm{CO}_{2}$ mole fraction at various locations and temperatures. The thickness of the films varied between 5 and $12 \mu \mathrm{m}$. The characterization of the silica deposits revealed that they consisted of amorphous $\mathrm{SiO}_{2}$, and their photomicrographic examination by electron microscopy showed that they were smooth and dense, having nodular morphology with average nodule size of approximately $13 \mu \mathrm{m}$ (Figure 13a). On the other hand, the alumina films were characterized by much larger nodule sizes, up to about $30 \mu \mathrm{m}$ (Figure 13b). X-ray diffraction (XRD) showed that alumina coatings consisted primarily of polycrystalline $\kappa-\mathrm{Al}_{2} \mathrm{O}_{3}$, but incorporation of the $\theta$ modification was also encountered. Annealing of the coatings in an inert atmosphere at $1400^{\circ} \mathrm{C}$ resulted in transformation of $\kappa-\mathrm{Al}_{2} \mathrm{O}_{3}$ to $\alpha-\mathrm{Al}_{2} \mathrm{O}_{3}$ (corundum).

The growth of $\alpha-\mathrm{Al}_{2} \mathrm{O}_{3}$ is often initiated by the $\kappa-\rightarrow \alpha-\mathrm{Al}_{2} \mathrm{O}_{3}$ transformation during the deposition process $[8,42]$, and $\kappa-\mathrm{Al}_{2} \mathrm{O}_{3}$ is the phase grown initially irrespective of the CVD process temperature. An increase in the deposition time leads to increased $\alpha / \kappa$ ratio. It has been reported that the appearance of the $\alpha$-phase depends on the deposition temperature, occurring earlier at higher temperatures. Specifically, it has been found that deposition for $5 \mathrm{hr}$ at $1233 \mathrm{~K}$ gave XRD peaks of $\alpha-\mathrm{Al}_{2} \mathrm{O}_{3}$ in the deposit with very weak intensities, whereas 15 min of deposition time at $1353 \mathrm{~K}$ was ample to yield deposits with intense $\alpha-\mathrm{Al}_{2} \mathrm{O}_{3}$ diffraction peaks [42]. This observation agrees with our results since the alumina samples were prepared at temperatures up to $1273 \mathrm{~K}$, and the overall deposition time varied between 60 and $85 \mathrm{~min}$.

The films deposited from MTS-AlCl${ }_{3}-\mathrm{CO}_{2}-\mathrm{H}_{2}$ mixtures were found to be smooth, dense, and uniform in thickness, having nodular structure (Figure 14a) similar to that of the alumina films. The size of the nodules in the codeposits tended to increase with increasing temperature; an average nodule size of about $20 \mu \mathrm{m}$ was observed at $1223 \mathrm{~K}$, 
while at $1273 \mathrm{~K}$ the deposit consisted of nodules of about $35 \mu \mathrm{m}$. In some cases, in which the supply of MTS to the reactor was stopped before that of $\mathrm{AlCl}_{3}$, small alumina crystals were found to exist on the external surface of the coating (see Figure 14c). This result lends further support to the conclusion that the presence of decomposition products of MTS in the gas phase suppresses the deposition of alumina. Formation of cracks, possibly induced by contact stresses, was observed in some of the samples. Figure 14b shows some cracks formed in a film prepared at $7 \mathrm{~cm}$ into the heating zone at $1273 \mathrm{~K}$ and 100 Torr. Alumina flakes are also seen to exist on the surface of this film as well.

Several codeposited films were analyzed by XRD, but in all cases they were found to be amorphous (no crystalline phase was detected). The elemental composition of the deposits was determined by EDXA. Silicon, aluminum, and oxygen were the only elements detected within the sensitivity limits of the analysis, and their relative amounts were consistent with those corresponding to the stoichiometry of mixtures of $\mathrm{SiO}_{2}$ and $\mathrm{Al}_{2} \mathrm{O}_{3}$. As we have already pointed out in the discussion of the reactivity data, the film composition data showed that the enhancement in the rate of deposition of the codeposition process was due to a dramatic rise in the rate of the deposition of $\mathrm{SiO}_{2}$, accompanied by a reduction in the rate of $\mathrm{Al}_{2} \mathrm{O}_{3}$ deposition (Table 2). The results of Table 2 clearly show that the results of the kinetic investigation of the individual deposition processes of silica and alumina cannot be used for the derivation of conclusions about the behavior of the codeposition process.

\section{Conclusions}

A comprehensive investigation of the deposition of silica, alumina, and aluminosilicate species from $\mathrm{CH}_{3} \mathrm{SiCl}_{3}-\mathrm{AlCl}_{3}-\mathrm{H}_{2}-\mathrm{CO}_{2}$ mixtures was carried out in this study. Chemical vapor deposition experiments were carried out in a tubular, hot-wall CVD reactor, equipped with a microbalance, and the deposits were analyzed using a variety of methods. In order to elucidate the origins of the effects of the operating conditions on the single species deposition processes (with one chloride present in the feed) and on the codeposition process, computations were done on thermodynamic equilibrium in $\mathrm{Al} / \mathrm{Cl} / \mathrm{C} / \mathrm{H} / \mathrm{O}, \mathrm{Si} / \mathrm{Cl} / \mathrm{C} / \mathrm{H} / \mathrm{O}$, and $\mathrm{Al} / \mathrm{Si} / \mathrm{Cl} / \mathrm{C} / \mathrm{H} / \mathrm{O}$ systems. 
The experimental results revealed strong effects of temperature on the deposition rate both in the single oxide deposition and in the codeposition experiments. Two temperature regions were identified from the deposition rate vs. temperature data. At temperatures below $1223 \mathrm{~K}\left(950{ }^{\circ} \mathrm{C}\right)$, the deposition of silica (from $\mathrm{CH}_{3} \mathrm{SiCl}_{3}$ mixtures) took place at very low rates, much lower than those of alumina from $\mathrm{AlCl}_{3}$ mixtures, for similar chloride concentrations. At higher temperatures, the rate of alumina deposition was smaller than that of silica, but not by a large margin. The apparent activation energy values extracted from the deposition rate vs. temperature curves in the high temperature region were similar for the three deposition processes (silica deposition, alumina deposition, and codeposition), ranging from 20 to $25 \mathrm{kcal} / \mathrm{mol}$.

The codeposition rates were higher, by a more than a factor of 2 in some cases, than the sum of the deposition rates of the two oxides in the independent experiments at the same operating conditions, and this result led to the conclusion that there should exist additional surface reaction steps in the codeposition process, leading to solid formation, that involve both silicon-containing and aluminum-containing species. The silicon oxide films and the codeposited films were found to be amorphous, while $\alpha-\mathrm{Al}_{2} \mathrm{O}_{3}$ was the main deposition product in the aluminum oxide coatings. The elemental analysis of the films showed that the codeposited films contained more than $90 \% \mathrm{SiO}_{2}$ even at reaction condition where the deposition rate of alumina was much higher than that of silica. The comparison of the deposition rates of $\mathrm{SiO}_{2}$ and $\mathrm{Al}_{2} \mathrm{O}_{3}$ during codeposition with those seen in single species deposition experiments at the same conditions revealed that the codeposition process was characterized by a dramatic enhancement of the deposition of $\mathrm{SiO}_{2}$ and an equally dramatic reduction in the rate of $\mathrm{Al}_{2} \mathrm{O}_{3}$ deposition. It was thus concluded that the main deposition product of the additional surface reactions in the codeposition process must be silicon oxide.

The deposition rate and the deposit stoichiometry were influenced strongly by the substrate position in the reactor, and the deposition rate could increase or decrease with increasing distance from the entrance of the reactor depending on the reaction temperature. The feed composition affected strongly the deposition rates. In general, the deposition rate increased with increasing reactant $\left(\mathrm{CO}_{2}\right.$ or chloride) concentration in the 
feed, reaching a plateau at relatively high concentration values. The only exception was the deposition of silica where the deposition rate tended to decrease with increasing $\mathrm{CO}_{2}$ concentration. This result was not inconsistent with the results of the thermodynamic analysis since it was found that even though an increase in the concentration of $\mathrm{CO}_{2}$ in the feed leads to higher equilibrium concentration of $\mathrm{H}_{2} \mathrm{O}$, it decreases the equilibrium concentrations of silicon chlorides. Some other effects could also be explained on the basis of the thermodynamic results. For instance, the suppression of alumina deposition in the codeposition process could be the combined effect of decreased concentrations aluminum-containing radical species $\left(\mathrm{AlCl}\right.$ and $\left.\mathrm{AlCl}_{2}\right)$ and increased concentration of $\mathrm{HCl}$ in the equilibrated gas phase, in comparison to the values when $\mathrm{AlCl}_{3}$ is the only chloride present in the feed. However, the thermodynamic equilibrium results could not explain the dramatic increase in the rate of deposition of silica in the codeposition process.

\section{Experimental}

The deposition source gases are MTS, $\mathrm{CO}_{2}$, and $\mathrm{H}_{2}$ for the case of silica deposition, $\mathrm{AlCl}_{3}, \mathrm{CO}_{2}$, and $\mathrm{H}_{2}$ for alumina deposition, and $\mathrm{MTS}, \mathrm{AlCl}_{3}, \mathrm{CO}_{2}$, and $\mathrm{H}_{2}$ for codeposition. Aluminum trichloride is formed in situ in a packed-bed reactor (chlorinator), loaded with high purity aluminum granules (99.9\% purity). A hydrogenhydrogen chloride mixture is sent through the chlorinator, whose temperature is maintained above $250^{\circ} \mathrm{C}$ since it has been reported that at such temperatures the conversion of $\mathrm{HCl}$ to $\mathrm{AlCl}_{3}$ is complete [41]. The deposition experiments were carried out in a vertical hot-wall reactor, made out of a quartz tube having $15 \mathrm{~mm}$ internal diameter. A stream of hydrogen (purge gas) is sent continuously to the reactor through the housing of the microbalance (Figure 6) to prevent corrosive gases from entering the housing and destroying the weighing mechanism. The purge gas is mixed with the $\mathrm{AlCl}_{3}-\mathrm{H}_{2}$ stream, which enters the reactor tube through a small side tube at about $18 \mathrm{~cm}$ from the top of the heating zone of the furnace. MTS ( $99.97 \%$ purity) is supplied to the reactor through a second side tube by sending through a bubbler containing liquid MTS a metered stream of carrier gas (hydrogen). A mass flow control system is used to monitor and control the 
MTS delivery rate. Carbon dioxide is sent to the reactor through the same side tube after it is mixed with MTS. Subambient pressures are generated using a mechanical vacuum pump, and the pressure in the deposition chamber is measured at the inlet of the CVD reactor using a capacitance manometer, and it is regulated by a throttling valve controlled by a pressure controller.

The deposition rate is monitored by employing an electronic microbalance (Cahn D-101) with $1 \mu \mathrm{g}$ sensitivity. The substrate used for deposition is hung from the sample arm of the microbalance with a thin molybdenum wire, and its weight is recorded continuously. The reactor tube and the substrate are heated with a high temperature, single-zone furnace, which provides $25 \mathrm{~cm}$ (10 inches) of heating zone. Two Pt/Pt-Rh (Stype) thermocouples are placed in proximity to the reactor at the center of the heating zone to record the chamber temperature. The side tube through which MTS and $\mathrm{CO}_{2}$ are introduced in the reactor is located at $36 \mathrm{~cm}$ from the top of the heating zone of the furnace, and this provides sufficient time for the mixing of the source gases with the $\mathrm{H}_{2}$ purge stream. Temperature measurements in the reactor showed that the part of the reactor tube that lies in the heating zone is almost isothermal, the temperature being within $\pm 5 \mathrm{oC}$ of the set point temperature $[43,44]$.

Deposition of silica, alumina, and aluminosilicates took place on $\mathrm{SiC}$ substrates suspended with very thin molybdenum wire in the reactor tube within the isothermal zone. The substrates had $1.35 \mathrm{~cm}$ length, $0.75 \mathrm{~cm}$ width, and $0.20 \mathrm{~mm}$ thickness, and they were obtained by depositing $\mathrm{SiC}$ from mixtures of methyltrichlorosilane and hydrogen on substrates made out of high density graphite. Silicon carbide was deposited at a high temperature $(1273 \mathrm{~K})$ until a constant rate of weight variation with time was obtained. This was done in order to plug the pores of the graphite and thus prevent the deposition measurements from being corrupted by deposition occurring within the pores. The deposition rate at each set of deposition conditions was determined from the slope of the weight vs. time curve. At the end of each experiment the wire and the substrate were weighed separately to determine whether significant deposition occurred on the wire. In almost all cases the weight placed on the substrate was more than $95 \%$ of the total weight. The deposition rates were corrected for deposition on the wire by assuming that 
deposition on the wire occurred at the same extent relative to deposition on the substrate at each set of deposition conditions.

\section{ACKNOWLEDGMENTS}

This research was supported by a grant from the Department of Energy. The

authors also acknowledge the help of Brian McIntyre of the Institute of Optics, and Christine Pratt of the Mechanical Engineering Department of the University of Rochester with the characterization of the films.

\section{REFERENCES}

[1] Jacobson, N.S., J. Amer. Cer. Soc. 1993, 76, 3.

[2] Jacobson, N.S., Smialek, J.L., Fox, D.S., NASA TM-101346, NASA 1988.

[3] Van Roode, M., Price, J.R., Stala, C., J. Eng. Gas Turb. Power 1993, 115, 139.

[4] Lee, K.N., and Miller, R.A., J. Am. Ceram. Soc. 1996, 79, 620.

[5] Federer, J.I., J. Mat. Eng. 1990, 12, 141.

[6] Lawson, MG., Pettit, F.S., and Blachere, J.R., J. Mater. Res. 1993, 8, 1964.

[7] Federer, J.I., van Roode, M., Price, J.R., Surf. Coat. Technol. 1989, 39/41, 71.

[8] Fredriksson, E., and Carlsson, J.-O., Surf. Coat. Technol. 1993, 56, 165.

[9] Tsapatsis, M., and Gavalas, G.R., AIChE J. 1992, 38, 847.

[10] Kim, S., and Gavalas, G.R., Ind. Eng. Chem. Res. 1995, 34, 168.

[11] De Vos, R.M., and Verweij, H., J. Membrane Sci. 1998, 143, 37.

[12] Kameyama, T., Dokiya, M., Fujushige, M., Yokokowa, H., and Fukuda, K., Ind. Eng. Chem. Fundam. 1981, 20, 97.

[13] Funk, R., Schachner, H., Triquet, C., Kornmann, M., and Lux, B., J. Electrochem. Soc. 1976, 123, 285.

[14] Colmet, R., Naslain, R., Hagenmuller, P., and Bernard, C., J. Electrochem. Soc. 1982, 129, 1367.

[15] Park, C.S., Kim, J.G., and Chun, J.S., J. Vac. Sci. Technol. A 1983, 1, 1820.

[16] Choi, S.W., Kim, C., Kim, J.G., and Chun, J.S., J. Mat. Sci. 1987, 22, 1051.

[17] Iida, K., and Tsujide, T., Jap. J. App. Phys. 1972, 11, 840. 
[18] Silvestri, V.J., Osburn, C.M., and Ormond, D.W., J. Electrochem. Soc. 1978, 125, 902.

[19] Kim, J.G, Park, C.S., and Chun, J.S., Thin Solid Films 1982, 97, 97.

[20] Colmet, R., and Naslain, R., Wear 1982, 80, 221.

[21] Bae, Y.W., Lee, W.Y., Besmann, T.M., Cavin, O.B., and Watkins, T.R., J. Am. Ceram. Soc. 1998, 81, 1945.

[22] Wong, P., and Robinson, McD., J. Am.. Ceram. Soc. 1970, 53, 617.

[23] Sneh, O., Wise, M.L., Ott, A.W., Okada, L.A., and George, S.M, Surf. Sci. 1995, 334, 135.

[24] Klaus, J.W., Ott, A.W., Johnson, J.M., and George, S.M., Appl. Phys. Lett. 1997, 70, 1092.

[25] Doppalapudi, D., Mulpuri, R., Basu, S.N., and Sarin, V.K., Mat. Res. Soc. Symp. Proc. 1995, 363, 95.

[26] Mulpuri, R., Ph.D. Dissertation, Boston University 1996.

[27] Itatani, K., Kubozono, T., Howell, F.S., Kishioka, A., and Kinoshita, M, J. Mater. Sci., 1995, 30, 1158.

[28] Reynolds, W.C., Internal Report, Dept. of Mech. Eng., Stanford University 1986.

[29] JANAF Thermochemical Tables (Eds.: Chase, M.W., Jr., Davies, C.A., Downey, J.R., Jr., Frurip, D.J, McDonald, R.A., and Syverud, A.N.), Journal of Physical and Chemical Reference Data, Vol. 14, Suppl. 1, 3rd ed. 1985.

[30] Thermochemical Data for Pure Substances (Ed.: Barin, I.), VCH Publishers, Weinheim 1989.

[31] Thermodynamic Properties of Individual Substances (Eds.: Gurvich, L.V., Veyts, I.V., and Alcock, C.B.), 4th ed., Hemisphere Publishing, New York 1990.

[32] Allendorf, M.D., and Melius, C.F., J. Phys. Chem. 1991, 96, 428.

[33] Gupta, P., Coon, P.A., Koehler, B.G., and George, S.M., Mat. Res. Soc. Symp. Proc. 1989, 131, 197.

[34] Aoyama, T., Inoue, Y., and Suzuki T., J. Electrochem. Soc. 1983, 130, 203.

[35] Papasouliotis, G. D., and Sotirchos, S. V., J. Electrochem. Soc. 1994, 141, 1599.

[36] Walkup, R.E., and Raider, S. I., Appl. Phys. Lett. 1988, 53, 888. 
[37] Buss, R. J., Ho, P., and Weber, M.E., Plasma Chem. Plasma P. 1993, 13, 61.

[38] Allendorf, M.D., Melius, C.F., Ho, P, and Zachariah, M.R., J. Phys. Chem. 1995, 99, 15285.

[39] Ho, P, and Melius, C.F., J. Phys. Chem. 1995, 99, 2166.

[40] Davis, R. F., and Pask, J. A., in High Temperature Oxides. Part IV, (Ed.: Alper, A.M.), Academic Press, New York 1971, pp. 37-76.

[41] Fredriksson, E., and Carlsson, J.-O., J. Chem. Vap. Dep. 1993, 1, 333.

[42] Fredriksson, E., and Carlsson, J. -O., Journal de Physique 1989, 50(C-5), 391.

[43] Papasouliotis, G.D., and Sotirchos, S.V., J. Electrochem. Soc. 1995, 142, 3834.

[44] Papasouliotis, G.D., and Sotirchos, S.V., J. Electrochem. Soc. 1998, 145, 3908. 


\section{LIST OF FIGURES}

Figure 1. Variation of the equilibrium mole fractions with the temperature for silica deposition at $13.3 \mathrm{kPa}$ (100 Torr). Solid phases were not allowed to form. $\mathrm{CO}_{2} / \mathrm{MTS}=3.3$, $x_{\mathrm{MTS}}=0.011$.

Figure 2. Variation of the equilibrium mole fractions with the temperature for alumina deposition at $13.3 \mathrm{kPa}$. Solid phases were not allowed to form. $\mathrm{CO}_{2} / \mathrm{AlCl}_{3}=4, x_{\mathrm{AlCl} 3}=$ 0.009 .

Figure 3. Variation of the equilibrium mole fractions with the temperature for codeposition at $13.3 \mathrm{kPa}$. Solid phases were not allowed to form.

$\mathrm{CO}_{2} / \mathrm{AlCl}_{3} / \mathrm{MTS}=3.3 / 0.8 / 1, x_{\mathrm{MTS}}=0.011$.

Figure 4. Variation of the equilibrium mole fractions with the temperature for codeposition at $13.3 \mathrm{kPa}$. Solid phases were not allowed to form.

$\mathrm{CO}_{2} / \mathrm{AlCl}_{3} / \mathrm{MTS}=6.6 / 2.5 / 1, x_{\mathrm{MTS}}=0.011$.

Figure 5. Variation of the equilibrium constants of solid phase reactions with the temperature. (A) : $\mathrm{Al}_{2} \mathrm{O}_{3}+\mathrm{SiO}_{2} \rightarrow \mathrm{Al}_{2} \mathrm{SiO}_{5} ;(\mathrm{B}): 3 \mathrm{Al}_{2} \mathrm{O}_{3}+2 \mathrm{SiO}_{2} \rightarrow \mathrm{Al}_{6} \mathrm{Si}_{2} \mathrm{O}_{13}$;

(C) $: 2 \mathrm{Al}_{2} \mathrm{SiO}_{5}+\mathrm{Al}_{2} \mathrm{O}_{3} \rightarrow \mathrm{Al}_{6} \mathrm{Si}_{2} \mathrm{O}_{13} ;(\mathrm{D}): 3 \mathrm{Al}_{2} \mathrm{SiO}_{5} \rightarrow \mathrm{Al}_{6} \mathrm{Si}_{2} \mathrm{O}_{13}+\mathrm{SiO}_{2}(\mathrm{xbt})$

$(\mathrm{E}): \mathrm{SiO}_{2}(\mathrm{qrtz}) \rightarrow \mathrm{SiO}_{2}(\mathrm{xbt})$.

Figure 6. Variation of the rate of deposition with the temperature for the deposition and codeposition processes.

Figure 7. Variation of the weight of the substrate with time in three sequential experiments (single oxide and codeposition) at $1273 \mathrm{~K}$. 
Figure 8. Variation of the weight of the substrate with time in the codeposition process at $1223 \mathrm{~K}$.

Figure 9. Effect of $\mathrm{CO}_{2}$ mole fraction on the deposition and codeposition rate at $1223 \mathrm{~K}$. Codeposition results are shown for two experimental runs.

Figure 10. Effect of $\mathrm{CO}_{2}$ mole fraction on the deposition and codeposition rate at $1273 \mathrm{~K}$.

Figure 11. Effect of $\mathrm{AlCl}_{3}$ mole fraction on the deposition rate in the presence or absence of MTS at 1223 and 1273 K. Solid lines: codeposition. Dashed lines: deposition from $\mathrm{AlCl}_{3}$.

Figure 12. Effect of MTS mole fraction on the rate of $\mathrm{SiO}_{2}$ deposition at $1223 \mathrm{~K}$.

Figure 13. SEM micrographs of CVD films prepared at $1273 \mathrm{~K}, 13.3 \mathrm{kPa}, 250 \mathrm{~cm}^{3} / \mathrm{min}$ total flow rate, and $4 \mathrm{~cm}$ location with $x_{\mathrm{CO} 2}=0.036$. a) silica with $\left.x_{\mathrm{MTS}}=0.011 ; \mathrm{b}\right)$ alumina with $x_{\mathrm{AlCl} 3}=0.009$.

Figure 14. SEM micrographs of codeposited CVD films at $13.3 \mathrm{kPa}$ and $250 \mathrm{~cm}^{3} / \mathrm{min}$ flow rate with $x_{\mathrm{CO} 2}=0.036, x_{\mathrm{MTS}}=0.011$, and $x_{\mathrm{AlCl} 3}=0.009$. Deposition temperature and location: a) $1273 \mathrm{~K}$ at $4 \mathrm{~cm}$; b) $1273 \mathrm{~K}$ at $7 \mathrm{~cm}$; ) $1323 \mathrm{~K}$ at $7 \mathrm{~cm}$. 
Table 1. Major gas phase species of the thermodynamic analysis

\begin{tabular}{lll}
\hline $\mathrm{CH}_{4}$ & $\mathrm{AlCl}$ & $\mathrm{SiCl}_{2}$ \\
$\mathrm{CO}$ & $\mathrm{AlCl}_{2}$ & $\mathrm{SiCl}_{3}$ \\
$\mathrm{CO}_{2}$ & $\mathrm{AlCl}_{3}$ & $\mathrm{SiCl}_{4}$ \\
$\mathrm{H}_{2}$ & $\mathrm{Al}_{2} \mathrm{Cl}_{6}$ & $\mathrm{SiO}$ \\
$\mathrm{HCl}$ & $\mathrm{AlOH}$ & $\mathrm{SiHCl}_{3}$ \\
$\mathrm{H}_{2} \mathrm{O}$ & $\mathrm{AlHO}_{2}$ & $\mathrm{SiH}_{2} \mathrm{Cl}_{2}$ \\
$\mathrm{H}$ & &
\end{tabular}


Table 2. Deposition rates (in $\left.\mathrm{mg} /\left(\mathrm{cm}^{2} \cdot \mathrm{min}\right)\right)$ of codeposited films and films of silica and alumina and composition of codeposited films. $13.3 \mathrm{kPa}, 250 \mathrm{~cm}^{3} / \mathrm{min}$ total flow rate, and $x_{\mathrm{MTS}}=0.011$.

\begin{tabular}{|c|c|c|c|c|c|c|c|c|c|c|}
\hline $\begin{array}{l}\text { Position } \\
(\mathrm{cm})\end{array}$ & $T(K)$ & ${ }^{x} \mathrm{CO}_{2}$ & $\begin{array}{l}\text { Al/Si } \\
\text { (feed) }\end{array}$ & $\begin{array}{c}A l / S i \\
\text { (deposit) }\end{array}$ & $\left(w t \% \mathrm{SiO}_{2}\right)^{c o d}$ & $\left(R_{d}\right)^{c o d}$ & $\left(R_{d}\right)_{\mathrm{SiO}_{2}}^{\text {ind }}$ & $\left(R_{d}\right)_{\mathrm{SiO}_{2}}^{\mathrm{cod}}$ & $\left(R_{d}\right)_{\mathrm{Al}_{2} \mathrm{O}_{3}}^{\text {ind }}$ & $\left(R_{d}\right)_{\mathrm{Al}_{2} \mathrm{O}_{3}}^{\mathrm{cod}}$ \\
\hline 4 & 1273 & 0.036 & 0.8 & 0.036 & 97.04 & 0.050 & 0.0137 & 0.0485 & 0.0135 & 0.0015 \\
\hline 4 & 1273 & 0.072 & 2.5 & 0.16 & 88.27 & 0.165 & 0.01 & 0.1456 & 0.0245 & 0.0194 \\
\hline 7 & 1273 & 0.036 & 0.8 & 0.085 & 94.42 & 0.065 & 0.0157 & 0.0614 & 0.0160 & 0.0036 \\
\hline 7 & 1223 & 0.036 & 0.8 & 0.032 & 97.41 & 0.026 & 0.0047 & 0.0253 & 0.0057 & 0.0007 \\
\hline
\end{tabular}




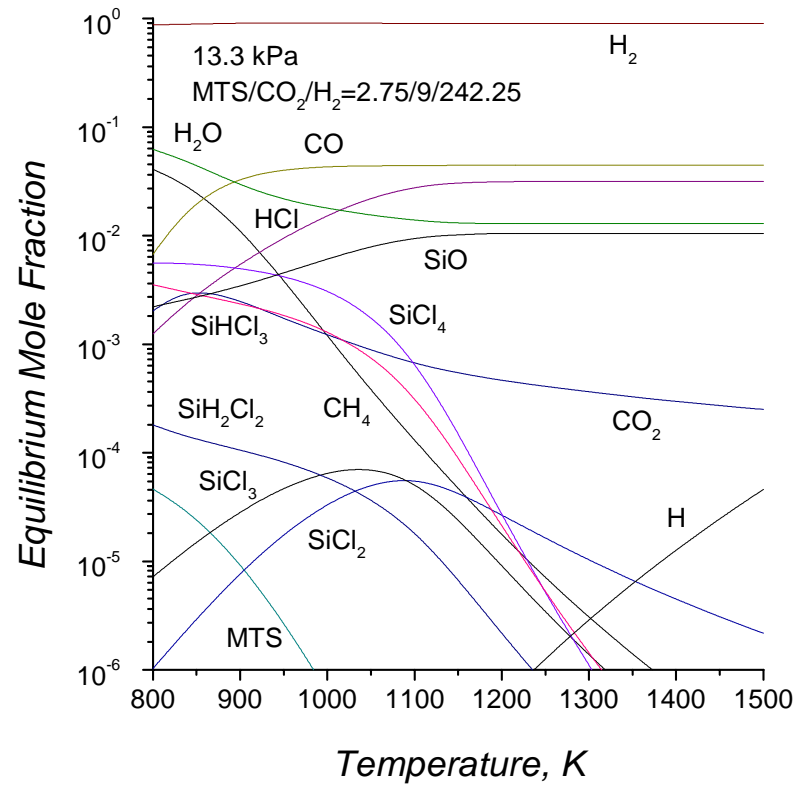

FIGURE 1 


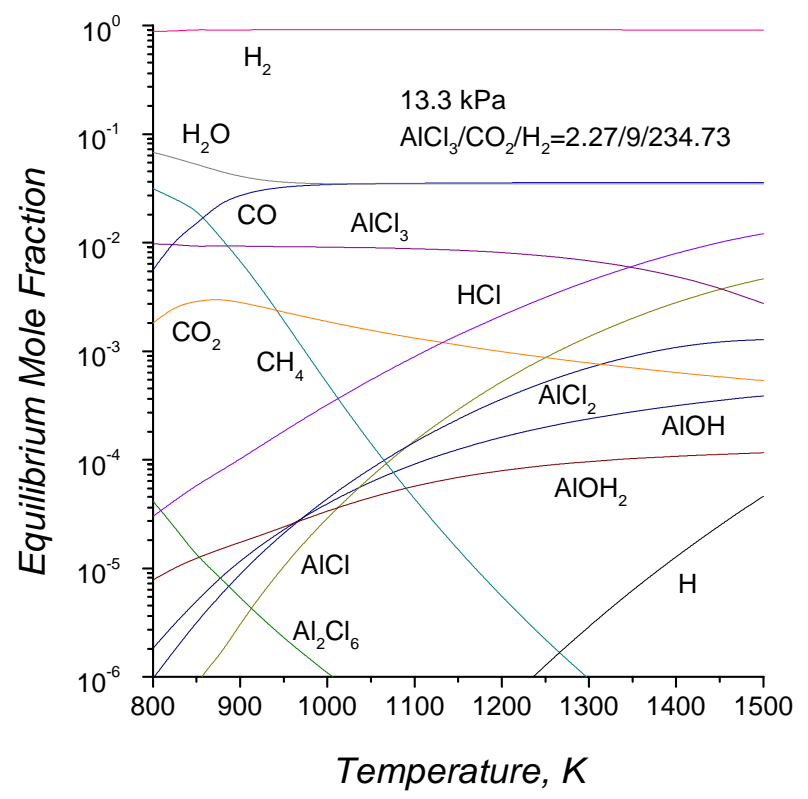

FIGURE 2 


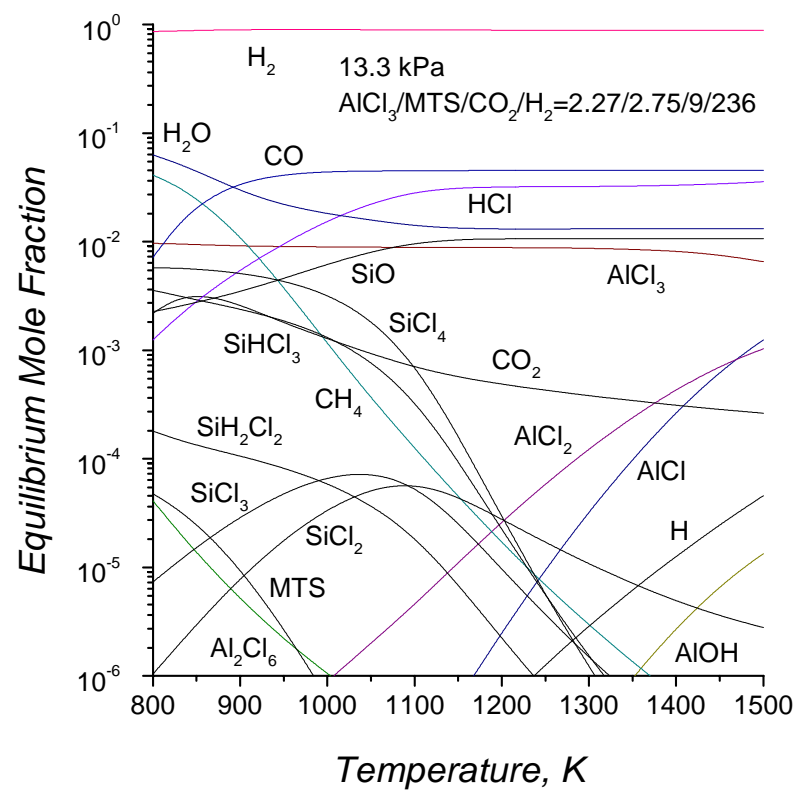

FIGURE 3 


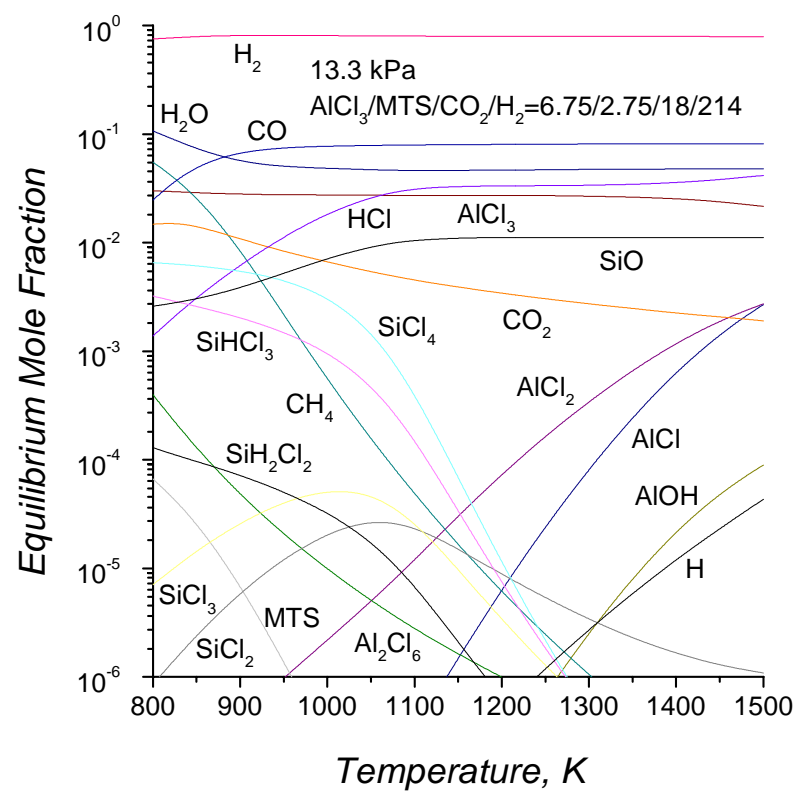

FIGURE 4 


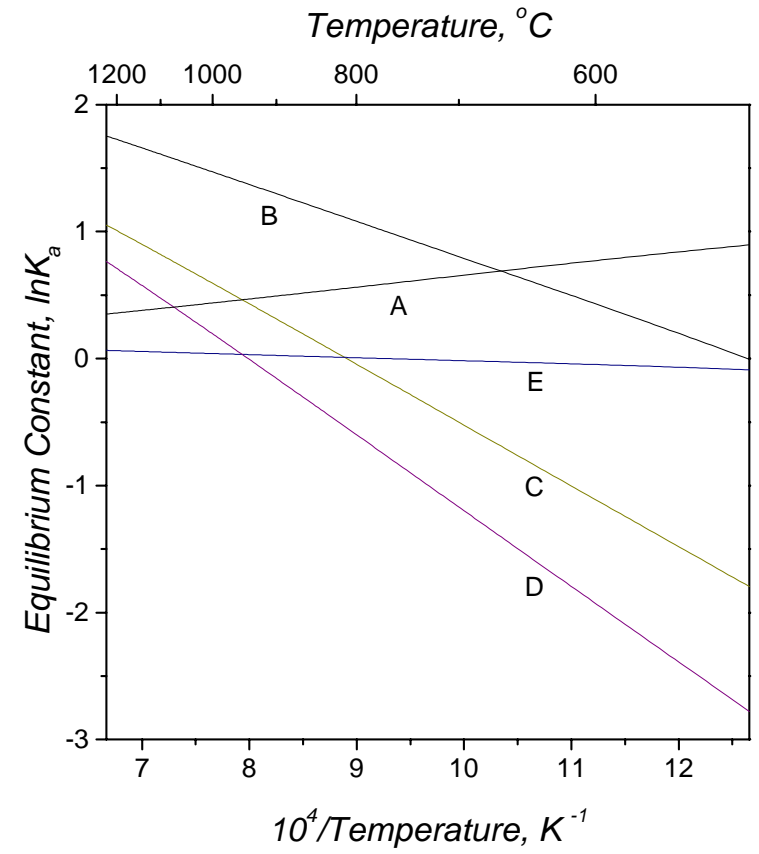

FIGURE 5 


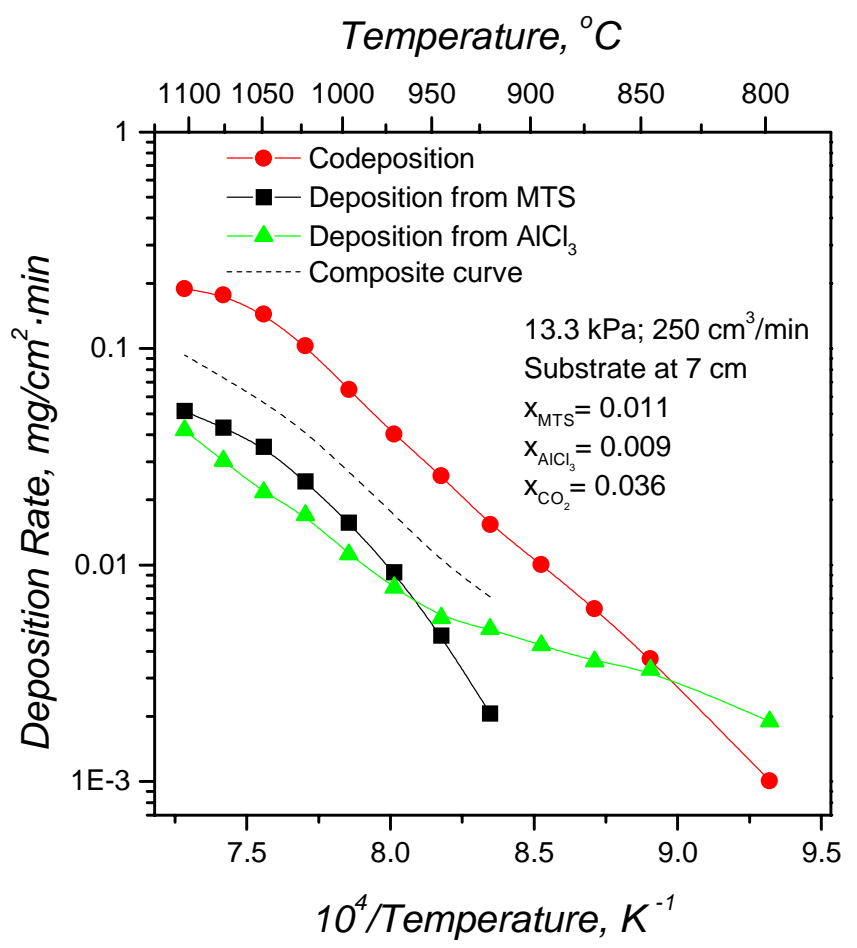

FIGURE 6 


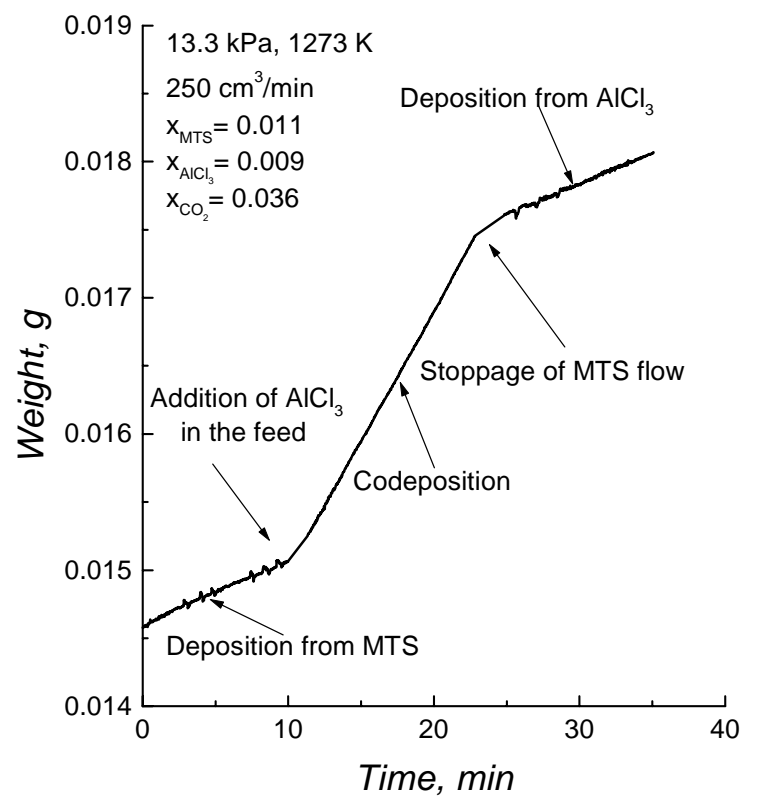

FIGURE 7 


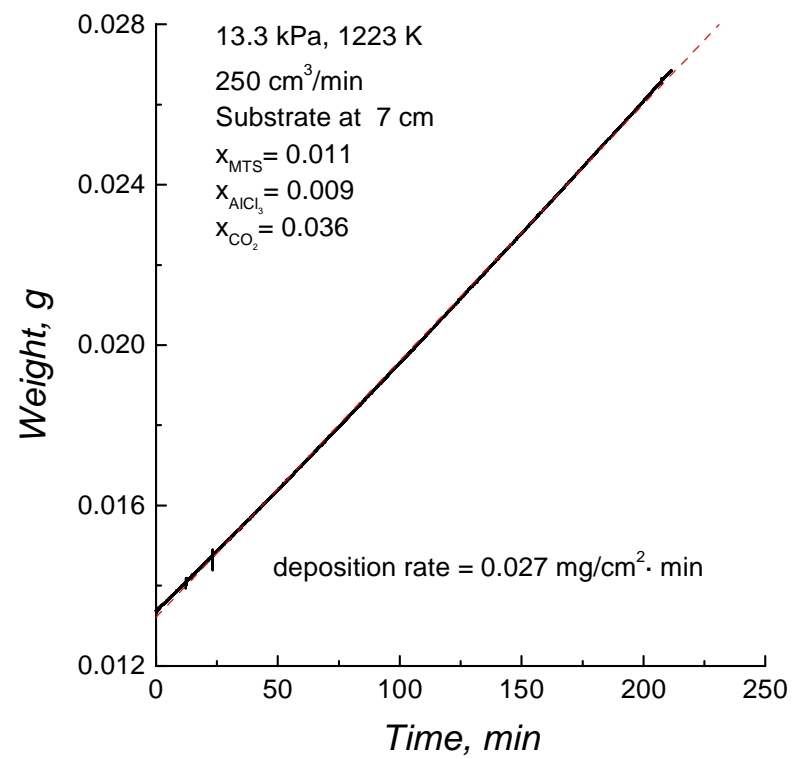

FIGURE 8 


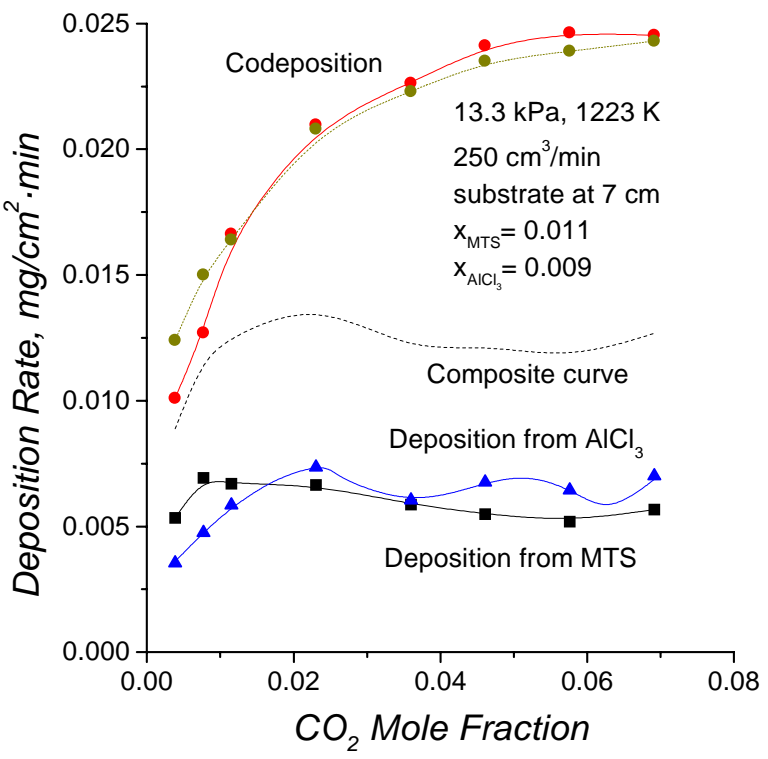

FIGURE 9 


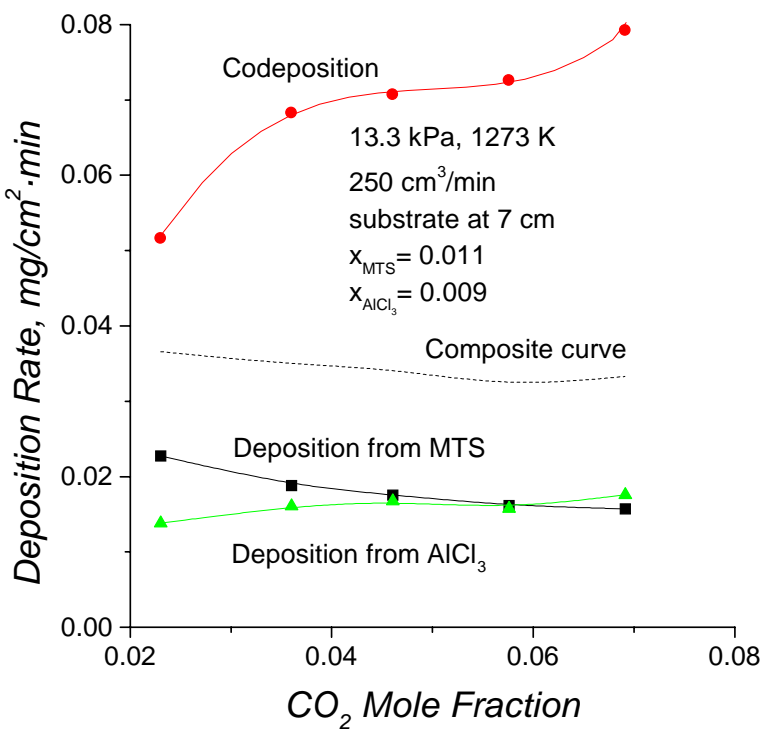

FIGURE 10 


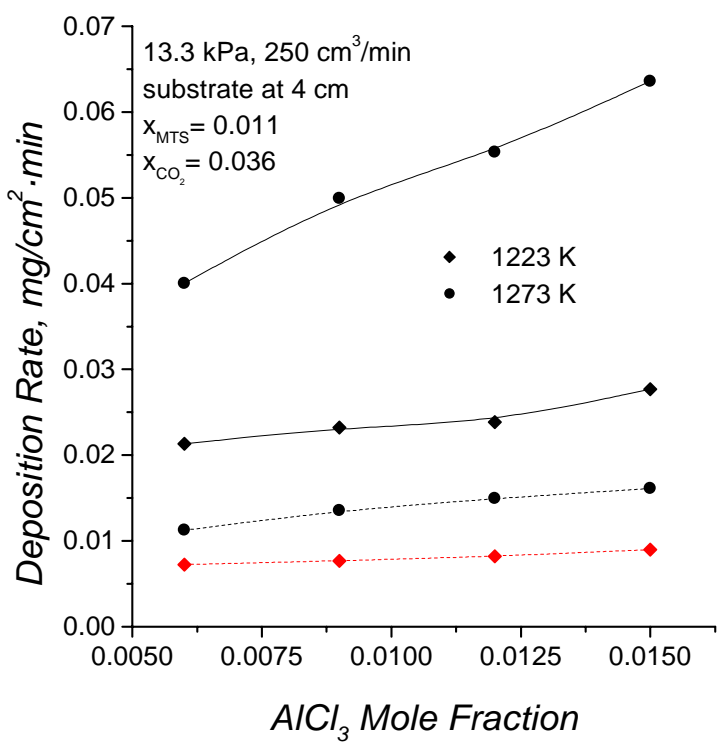

FIGURE 11 


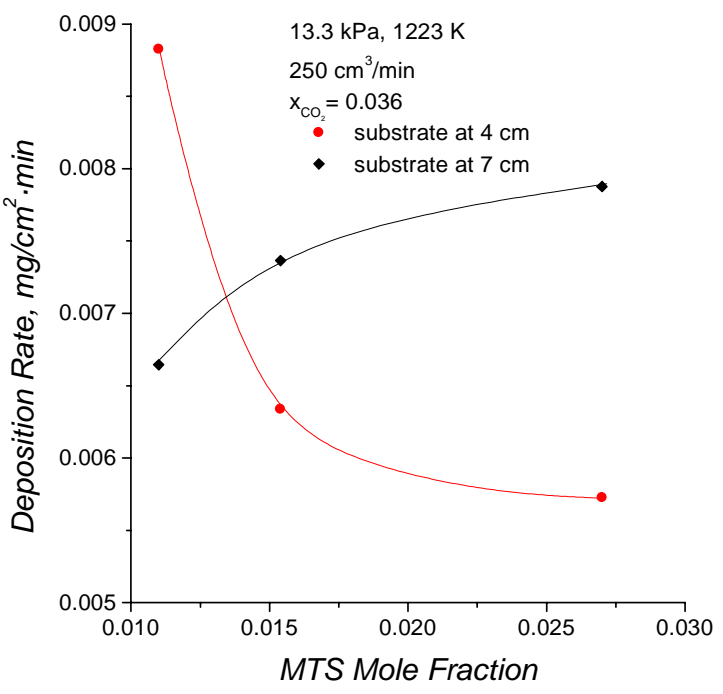

FIGURE 12 


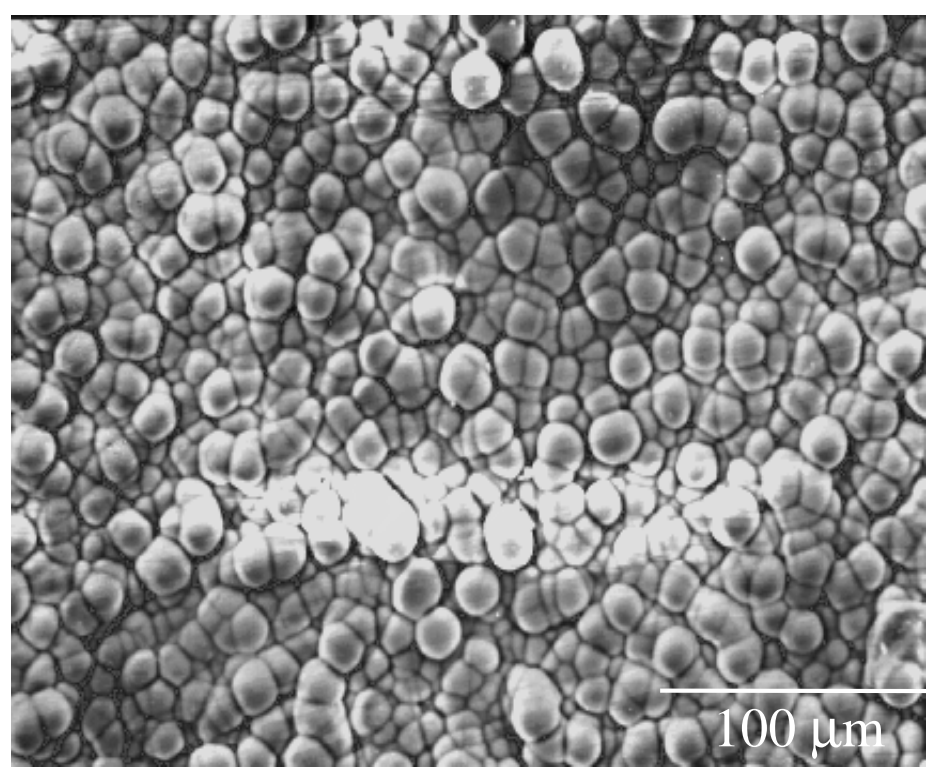

(a)

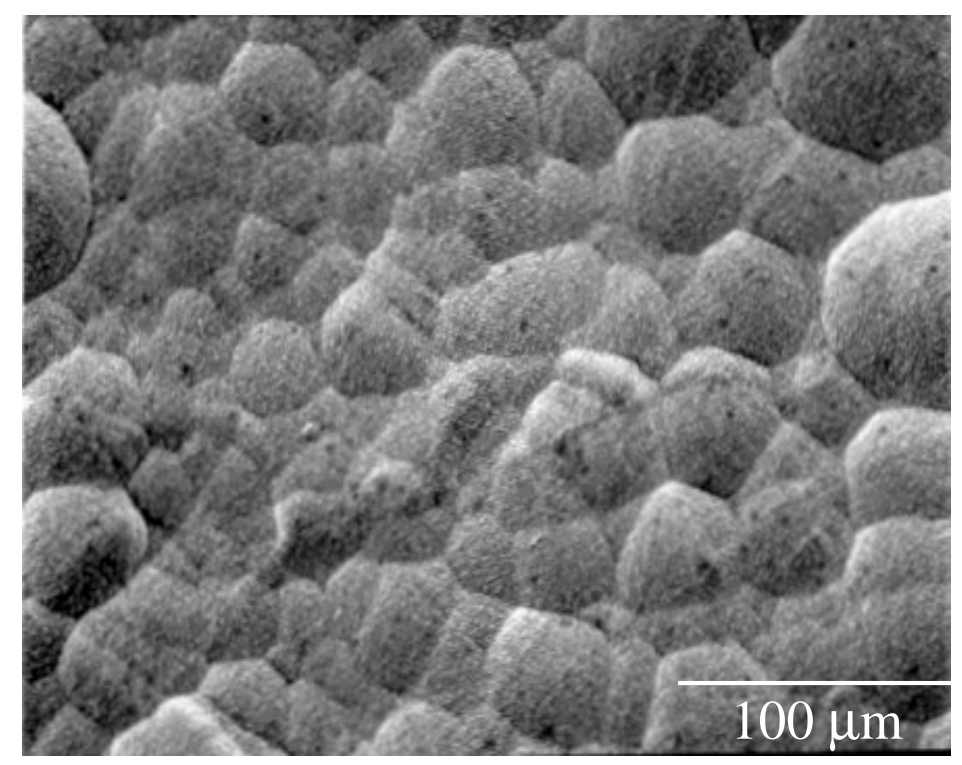

(b)

FIGURE 13 


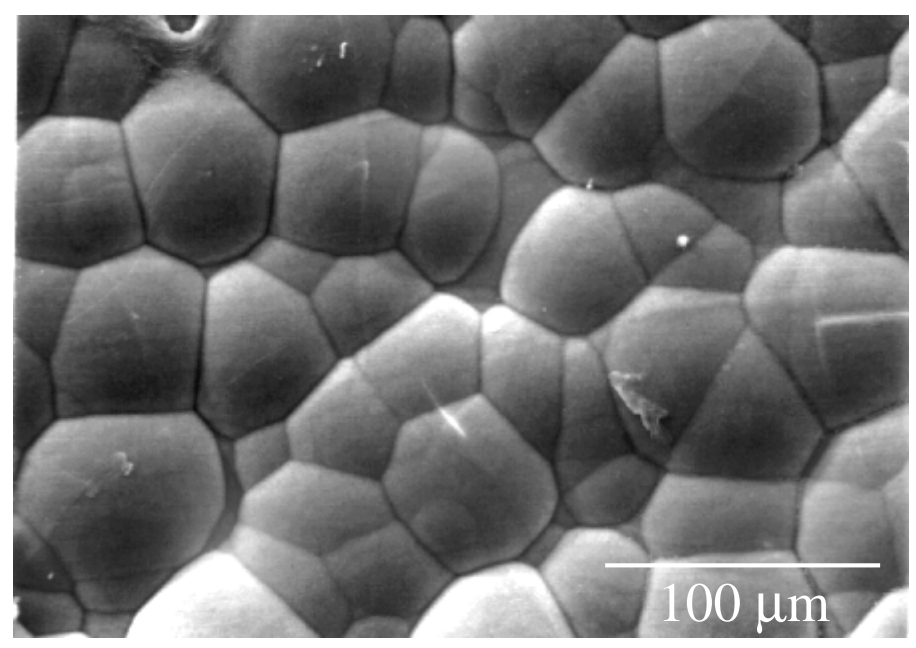

(a)
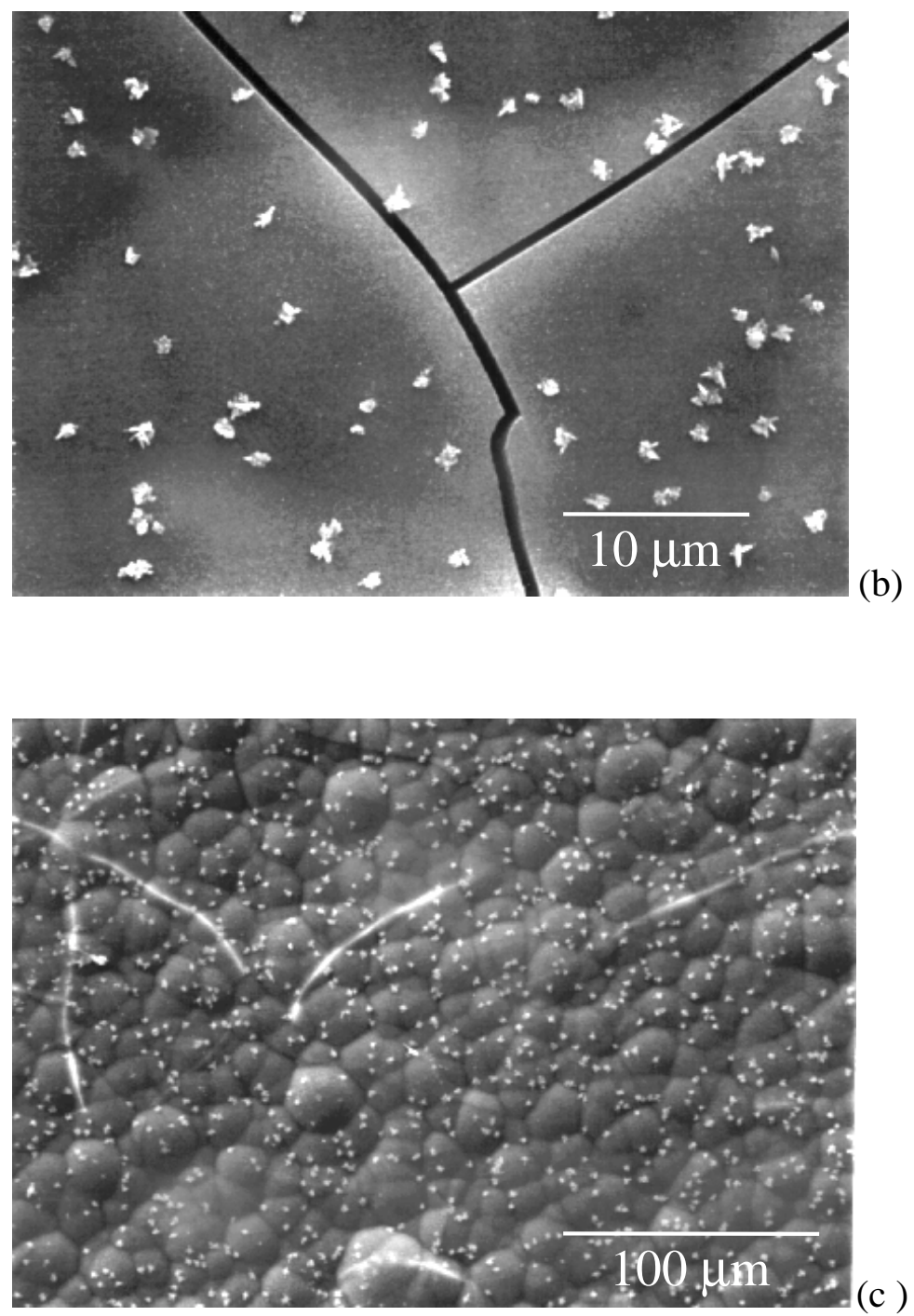

FIGURE 14 


\title{
Chemical Vapor Deposition of Aluminosilicates from Mixtures of $\mathrm{SiCl}_{4}, \mathrm{AlCl}_{3}, \mathrm{CO}_{2}$, and $\mathrm{H}_{2}$
}

\author{
Stephanos F. Nitodas and Stratis V. Sotirchos** \\ Department of Chemical Engineering \\ University of Rochester \\ Rochester, NY 14627
}

* to whom correspondence should be addressed (E-mail: svs2@ che.rochester.edu) 


\begin{abstract}
A comprehensive study of the chemical vapor codeposition of silica, alumina, and aluminosilicates from $\mathrm{SiCl}_{4}-\mathrm{AlCl}_{3}-\mathrm{H}_{2}-\mathrm{CO}_{2}$ mixtures is presented. A hot-wall reactor, coupled to an electronic microbalance, is used to investigate the dependence of the deposition rate on temperature, pressure, composition, and total flow rate over a broad range of operating conditions. The experimental observations are discussed in the context of the results obtained in independent deposition experiments of silica and alumina from mixtures of $\mathrm{SiCl}_{4}-\mathrm{H}_{2}-\mathrm{CO}_{2}$ and $\mathrm{AlCl}_{3}-\mathrm{H}_{2}-\mathrm{CO}_{2}$, respectively, in the same apparatus. The results show that the deposition of silica proceeds at very low rates that are by more than an order of magnitude lower than those of alumina deposition at the same temperature, pressure, total flow rate, and carbon dioxide and chloride mole fractions in the feed. When both chlorides $\left(\mathrm{SiCl}_{4}\right.$ and $\left.\mathrm{AlCl}_{3}\right)$ are fed to the reactor, that is, in the codeposition process, the rate of $\mathrm{SiO}_{2}$ deposition is much higher than that seen in the single species deposition experiments, while the opposite behavior is observed for the rate of deposition of $\mathrm{Al}_{2} \mathrm{O}_{3}$. The results of deposition experiments conducted on refractory wires - in order to obtain information on the effect of the substrate position in the reactor - show that manipulation of residence time offers a way to control the composition of the codeposited films in alumina and silica. The experimental results are compared with those obtained in a past study using methyltrichlorosilane as silicon source.
\end{abstract}

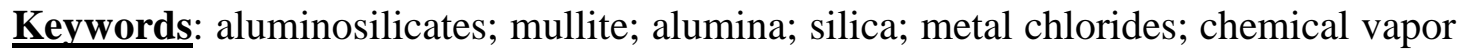
deposition 


\section{Introduction}

The preparation of films of metal oxides is of interest for a number of applications, such as high temperature gas separations, protection of metals and other materials from corrosion and oxidation, heterogeneous catalysis, and microelectronics [1-4]. An important application of inorganic oxides is in the field of structural applications, where they find use as coatings for the protection of metals and other materials from high temperature corrosion caused by combustion gases and trace contaminants. Because of their high hardness and excellent corrosion resistance, alumina and zirconia are very attractive for use as coatings for wear and corrosion protection [3-6]. Mullite $\left(3 \mathrm{Al}_{2} \mathrm{O}_{3} \cdot 2 \mathrm{SiO}_{2}\right)$ also possesses very attractive properties for structural applications [7]. Its thermal expansion coefficient is lower than those of alumina and zirconia and similar to that of Si-based ceramics (e.g., silicon carbide). As a result, it is suitable for application on $\mathrm{SiC}$ components that are subjected to thermal cycling in the course of their usage.

Several methods can be used for the preparation of inorganic oxides, such as thermal oxidation, sol-gel processing, and chemical vapor deposition. Because of their low cost, metal chlorides are the most frequently used metal sources for the chemical vapor deposition of metal oxides. An extensive amount of work has been done on the chemical vapor deposition of $\mathrm{Al}_{2} \mathrm{O}_{3}$ through the oxidation or hydrolysis of $\mathrm{AlCl}_{3}$ [4-6, 8-16], but only a few groups have dealt with the deposition of silica [17, 18], and fewer studies have examined the deposition of mullite [19-21]. $\mathrm{SiCl}_{4}$ is typically employed as silicon source in the chemical vapor deposition of silica and mullite.

In a previous study [22], we investigated the chemical vapor codeposition of $\mathrm{SiO}_{2}, \mathrm{Al}_{2} \mathrm{O}_{3}$, and aluminosilicates from mixtures of $\mathrm{CH}_{3} \mathrm{SiCl}_{3}$ (methyltrichlorosilane, MTS), $\mathrm{AlCl}_{3}, \mathrm{CO}_{2}$, and $\mathrm{H}_{2}$. MTS was used as silicon source because preliminary experiments showed that the rates of deposition of silica and alumina from $\mathrm{H}_{2}-\mathrm{CO}_{2}$ mixtures containing MTS and $\mathrm{AlCl}_{3}$, respectively, were of comparable magnitude for similar chloride concentrations, whereas mixtures of $\mathrm{SiCl}_{4}, \mathrm{CO}_{2}$, and $\mathrm{H}_{2}$ gave much lower rates of deposition of silica. The experiments revealed that the codeposition process exhibited deposition rates that were not only larger than those of the simple oxides $\left(\mathrm{Al}_{2} \mathrm{O}_{3}\right.$ and $\left.\mathrm{SiO}_{2}\right)$ from MTS and aluminum trichloride, respectively, at the same operating conditions, but also larger than their sum by a factor of 2-3. The analysis of the composition of the deposits showed that the increase in the 
codeposition rate was accompanied by a dramatic enhancement of the deposition of $\mathrm{SiO}_{2}$ and a reduction in the rate of $\mathrm{Al}_{2} \mathrm{O}_{3}$ deposition, the combination of which led to very low $\mathrm{Al} / \mathrm{Si}$ ratios in the deposits.

In order to obtain higher $\mathrm{Al} / \mathrm{Si}$ ratios in the codeposited films (corresponding to stoichiometric mullite or alumina rich-mullite), it is necessary to suppress the enhancement of $\mathrm{SiO}_{2}$ deposition and maintain the rate of $\mathrm{Al}_{2} \mathrm{O}_{3}$ deposition at least at the levels seen in the absence of silicon precursors from the feed. Since the rate of $\mathrm{SiO}_{2}$ deposition in the codeposition process is much higher than the rate of silicon deposition in the absence of $\mathrm{AlCl}_{3}$, it is evident that it is the interaction of aluminum and silicon precursors that is responsible for the enhanced deposition rate of silica and, hence, the enhanced codeposition rate. If the silicon surface species involved in the fast deposition steps are the same as those that lead to silicon deposition in the single species deposition process, it is possible to lower the rate of silica deposition in the codeposition process by employing a silicon precursor that exhibits much lower rate of $\mathrm{SiO}_{2}$ deposition than MTS, such as $\mathrm{SiCl}_{4}$.

The preparation of alumina, silica, and aluminosilicate (e.g., mullite) coatings through chemical vapor deposition from mixtures of $\mathrm{AlCl}_{3}, \mathrm{SiCl}_{4}, \mathrm{CO}_{2}$, and $\mathrm{H}_{2}$ is the subject of the present study. Deposition experiments are carried out in a gravimetric, hot-wall CVD reactor over a wide range of operational conditions in order to determine the dependence of the codeposition and single species deposition rates on temperature, pressure, flow rate, and feed composition. The effect of the substrate position in the reactor on the deposition rate and deposit composition is also studied by conducting experiments on thin refractory wires placed along the centerline of the reactor. The results are compared with those obtained with MTS as silicon source and discussed in the context of past studies on silica, alumina, and aluminosilicate deposition and on the basis of the results of thermodynamic equilibrium computations.

\section{Experimental}

Chemical vapor deposition experiments were carried out in a vertical hot-wall reactor, made of quartz, with $15 \mathrm{~mm}$ internal diameter. The reactor is coupled to an electronic microbalance ( $1 \mu \mathrm{g}$ sensitivity) for continuous monitoring of the weight of the deposit. Aluminum trichloride is formed in situ in a packed-bed reactor (chlorinator), loaded with high purity aluminum granules and kept at a temperature 
above $250{ }^{\circ} \mathrm{C}$ in order to achieve complete conversion of $\mathrm{HCl}$ to $\mathrm{AlCl}_{3}$ [4]. The pressure in the deposition chamber is measured at the inlet of the reactor using a capacitance manometer, and it is regulated by a throttling valve controlled by a pressure controller. Subambient pressures are generated using a mechanical vacuum pump. The pump and the control valve are protected by using a liquid nitrogen trap, a soda lime trap, and a particulate filter. The reactor tube and the substrate are heated with a high temperature single-zone resistance furnace, which provides about $25 \mathrm{~cm}$ (10 inches) of heating zone. Temperature measurements in the reactor showed that the part of the reactor tube that lies in the heating zone is almost isothermal [23], with the temperature being within $\pm 5{ }^{\circ} \mathrm{C}$ of the set point value.

Local deposition rates were measured using small silicon substrates (typically, $1.35 \mathrm{~cm}$ length, $0.75 \mathrm{~cm}$ width, and $0.20 \mathrm{~mm}$ thickness) obtained by depositing silicon from mixtures of silicon tetrachloride and hydrogen on substrates made out of high density graphite blocks. The substrates were hung from the sample arm of the microbalance and placed within the heating zone, with the deposition surface parallel to the flow of the reactive mixture, which enters the chemical reactor from the top. Experiments were also carried out on thin molybdenum wires placed along the centerline of the tubular reactor in order to obtain information on the profiles of deposition rate and deposit composition along the reactor. At each set of experimental conditions, the deposition process was allowed to occur for a period of time that was sufficient to extract a reliable deposition rate from the slope of the weight vs. time curve.

\section{Results and Discussion}

The overall reactions that describe the deposition of silica, alumina, and aluminosilicates (e.g., $\mathrm{Al}_{6} \mathrm{Si}_{2} \mathrm{O}_{13}$ and $\mathrm{Al}_{2} \mathrm{SiO}_{5}$ ) are:

$$
\begin{aligned}
\mathrm{SiCl}_{4}+2 \mathrm{H}_{2} \mathrm{O} & \rightarrow \mathrm{SiO}_{2}+4 \mathrm{HCl} \\
2 \mathrm{AlCl}_{3}+3 \mathrm{H}_{2} \mathrm{O} & \rightarrow \mathrm{Al}_{2} \mathrm{O}_{3}+6 \mathrm{HCl} \\
2 \mathrm{SiCl}_{4}+6 \mathrm{AlCl}_{3}+13 \mathrm{H}_{2} \mathrm{O} & \rightarrow \mathrm{Al}_{6} \mathrm{Si}_{2} \mathrm{O}_{13}+26 \mathrm{HCl} \\
\mathrm{SiCl}_{4}+2 \mathrm{AlCl}_{3}+5 \mathrm{H}_{2} \mathrm{O} & \rightarrow \mathrm{Al}_{2} \mathrm{SiO}_{5}+10 \mathrm{HCl}
\end{aligned}
$$

The overall reaction for the formation of water vapor is the water gas-shift reaction

$$
\mathrm{H}_{2}+\mathrm{CO}_{2} \rightarrow \mathrm{H}_{2} \mathrm{O}+\mathrm{CO}
$$


The above reactions do not represent what actually occurs in the CVD reactor. The deposition process involves a large number of homogeneous and heterogeneous reactions in which many gas phase species and species adsorbed on the deposition surface participate. The deposition rate at a certain location in the chemical reactor is determined by the concentrations of the various species that take part in the heterogeneous reactions that lead to solid deposition. These concentrations are in turn determined not only by the composition of the feed but also by the flow field in the chemical reactor and the rates of the other chemical reactions that take place in the reactor. The chemical reactor we use in this study has length much larger than its diameter, and thus, it is characterized by a simple flow field, which permits its operation to be described by a simple plug flow model. However, the interpretation of the various effects that are revealed by the experimental data still requires consideration of what the reactive mixture experiences before it reaches the deposition surface.

Most of the results that we present in this study were obtained using mixtures of $\mathrm{AlCl}_{3}$ and (or) $\mathrm{SiCl}_{4}$ in $\mathrm{H}_{2}$ and $\mathrm{CO}_{2}$ with $300 \mathrm{~cm}^{3} / \mathrm{min}$ total flow rate at 100 Torr total pressure. The substrates were placed with their midpoint at a distance of $4 \mathrm{~cm}$ from the top of the heating zone of the reactor $(0 \mathrm{~cm}$ position $)$. The top of the heating zone almost coincided with the beginning of the isothermal zone of the chemical reactor. The values of the operating parameters are reported in the figures for each curve of experimental results shown there.

\section{Temperature effects}

Figure 1 presents typical results on the variation of the deposition rate of the single oxides and of the codeposition rate with the temperature in Arrhenius coordinates, that is, as $\operatorname{lnR}_{d}$ vs. $1 / T$, with $R_{d}$ being the deposition rate and $T$ the absolute temperature in the reactor. To obtain these results, the temperature was varied between 850 and $1100{ }^{\circ} \mathrm{C}$ at $50{ }^{\circ} \mathrm{C}$ increments. The mole fractions of the source gases were $0.006 \mathrm{SiCl}_{4}\left(\mathrm{x}_{\mathrm{SiCl} 4}\right), 0.012 \mathrm{AlCl}_{3}\left(\mathrm{x}_{\mathrm{AlCl} 3}\right)$, and $0.035 \mathrm{CO}_{2}\left(\mathrm{x}_{\mathrm{CO} 2}\right)$. It is seen that the temperature has a positive effect on the deposition rates of all three processes. This effect is stronger in the case of $\mathrm{SiO}_{2}$ deposition, where the rate varies by more than three orders of magnitude between the lower and the upper temperature limit. When the CVD system operates at $1000{ }^{\circ} \mathrm{C}$ or above, the deposition of silica proceeds at 
significant rates. The decrease of the temperature from 1000 to $950{ }^{\circ} \mathrm{C}$ is followed by a dramatic reduction in the deposition rate. The resulting low values, of the order of $10^{-6} \mathrm{mg} / \mathrm{cm}^{2} \cdot \mathrm{min}$, lies within the limitations of our microbalance for small surface area (nonporous) substrates.

The apparent activation energy $\left(E_{\text {app }}\right)$, the slope of the $\ln R_{d}$ vs. $1 / T$ curve, decreases with increasing temperature for the case of silica deposition. Linear regression over the entire temperature range in which data are shown in Figure 1 gives an activation energy value of $71.5 \mathrm{kcal} / \mathrm{mol}$, while a much lower value of 28.5 $\mathrm{kcal} / \mathrm{mol}$ is obtained when the data at low temperatures $\left(<1000{ }^{\circ} \mathrm{C}\right)$ are not included in the calculations. The Arrhenius plot of the alumina deposition process gives an apparent activation energy of $14 \mathrm{kcal} / \mathrm{mol}$. This value is lower than the value $(19.6$ $\mathrm{kcal} / \mathrm{mol}$ ) that was determined in a past study [22] in the same experimental arrangement using different concentration of aluminum trichloride in the feed $\left(\mathrm{x}_{\mathrm{AlCl} 3}=0.009\right)$.

The overall deposition rate in the codeposition process changes with the temperature in a similar way as the rate of $\mathrm{Al}_{2} \mathrm{O}_{3}$ deposition. The Arrhenius plot of the codeposition process (Figure 1) yields an activation energy of $22.1 \mathrm{kcal} / \mathrm{mol}$. This value is by a factor of 3 bigger than the activation energy reported in [19] (7.4 $\mathrm{kcal} / \mathrm{mol}$ ), where the chemical vapor deposition of mullite from mixtures of $\mathrm{SiCl}_{4}$, $\mathrm{AlCl}_{3}, \mathrm{CO}_{2}$, and $\mathrm{H}_{2}$ was investigated. The deposition rates that are reported in that study are of the same order of magnitude as those found here. The difference in the apparent activation energies is most probably a reflection of the different reactor configuration and the different operating conditions.

The codeposition rate and the deposition rate of alumina have, in general, comparable values. At temperatures greater than $950{ }^{\circ} \mathrm{C}$, the codeposition rate is higher than the deposition rate of alumina and - since the latter is much larger than the deposition rate of silica - higher than the sum of the deposition rates that are measured when only one of the two chlorides $\left(\mathrm{AlCl}_{3}\right.$ or $\left.\mathrm{SiCl}_{4}\right)$ is contained in the feed at the same concentration as in the mixture (composite curve in Figure 1). This is an indication that in the codeposition process aluminum-containing species and siliconcontaining species participate in surface reaction steps that lead to solid product 
deposition at rates that are greater than those of the steps that lead to the deposition of $\mathrm{SiO}_{2}$ and $\mathrm{Al}_{2} \mathrm{O}_{3}$ in the independent deposition experiments.

\section{Pressure effects}

The effect of pressure on the reaction rate of the three deposition processes is shown in Figure 2 at $1000{ }^{\circ} \mathrm{C}$ and a $\mathrm{CO}_{2} /\left(\mathrm{SiCl}_{4}+\mathrm{AlCl}_{3}\right)$ feed ratio of 2 . An increase of the total system pressure is accompanied by an increase in the rate of $\mathrm{SiO}_{2}$ deposition, with the deposition rate changing by a factor of 3 between the two limits of the pressure range. The deposition rate of alumina also increases with increasing pressure over the whole pressure range covered in Figure 2. In contrast to the deposition rates in the single oxide deposition systems, the deposition rate of the codeposition process displays a complex dependence on pressure. The codeposition rate increases as the pressure moves from 75 to 150 Torr, but then it starts to decrease reaching a minimum value at 250 Torr. Subsequently, it starts to increase again with the rate at 300 Torr being higher by more than a factor of 2 than the local minimum rate at 250 Torr.

The negative effect of pressure on the codeposition rate at the range 150-250 Torr is not surprising considering that a rise in the pressure of operation affects various factors which may have qualitatively different effects on the deposition rate. With the feed composition and the temperature kept constant, an increase in the operating pressure increases both the concentrations of the reactants and the residence time in the reactor. Larger concentrations tend to lead, in general, to higher deposition rates, but this effect may be offset by the greater consumption of reactive species and the greater production of product species upstream of the deposition site - because of the increased residence time.

It must be noted that the deposition rate may be negatively influenced by the formation of powder in the reactor since when this happens, the consumption rates of the gaseous reactants are increased. Insignificant powder formation was observed in our experiments, even at 300 Torr. This observation is consistent with the results of Figure 2 which show increasing deposition rate with increasing pressure in the upper part of the pressure range where powder formation - if it occurred - should proceed with higher rate. A reduction in the rate of mullite deposition at pressures higher than 150 Torr was observed in [19], and it was attributed to powder production. Positive influence of pressure on $\mathrm{Al}_{2} \mathrm{O}_{3}$ deposition was reported by Colmet and Naslain [6], 
who conducted experiments at low aluminum trichloride concentrations $\left(\mathrm{x}_{\mathrm{AlCl} 3}=0.008\right)$ without detecting occurrence of powder formation even at ambient pressures. Funk et al. [5] noticed a dramatic drop in the deposition rate of $\mathrm{Al}_{2} \mathrm{O}_{3}$ at pressures above 200 Torr. They attributed it to powder formation even though they used mixtures with low $\mathrm{AlCl}_{3}$ content $\left(\mathrm{x}_{\mathrm{AlCl} 3}=0.004\right)$.

\section{Feed composition effects}

Results on the influence of the feed composition on the deposition rate are shown in Figures 3-6, which present deposition rate vs. reactant mole fraction data for various temperatures. The results of Figure 3 refer to the effects of $\mathrm{SiCl}_{4}$ on the deposition rate of silica. It is seen that the operating temperature may affect the dependence of the deposition rate of silica on the mole fraction of $\mathrm{SiCl}_{4}$ both qualitatively and quantitatively. The effect of the mole fraction of $\mathrm{SiCl}_{4}$ on the deposition rate of silica changes from negative at $1000{ }^{\circ} \mathrm{C}$ to positive at $1050{ }^{\circ} \mathrm{C}$. At $1100{ }^{\circ} \mathrm{C}$, the deposition rate depends weakly on $\mathrm{x}_{\mathrm{SiCl} 4}$, presenting a shallow minimum in the lower part of the 0.005-0.04 mole fraction range that is covered in the figure. As in the case of the data reported in Figure 2, very small amounts of powder were observed at the exit of the reactor. It should be noted that powder formation cannot be the cause of the negative dependence of the deposition rate on the $\mathrm{SiCl}_{4}$ mole fraction at $1000{ }^{\circ} \mathrm{C}$ because this phenomenon, whenever it occurs, tends to intensify with increasing temperature. The complex dependence of the deposition rate of silica on the mole fraction of $\mathrm{SiCl}_{4}$ most probably reflects the effects of the reaction byproducts and, in particular, of $\mathrm{HCl}$. An increase in the $\mathrm{SiCl}_{4}$ mole fraction in the feed leads not only to higher concentrations of $\mathrm{SiCl}_{4}$ in the reactor but also to higher concentrations of $\mathrm{HCl}$ and of the other byproducts of the gas phase decomposition reactions.

Figure 4 presents results on the dependence of the codeposition rate and the deposition rate of $\mathrm{Al}_{2} \mathrm{O}_{3}$ in single oxide deposition experiments on the $\mathrm{AlCl}_{3}$ mole fraction in the feed at three temperatures $\left(1000,1050\right.$, and $\left.1100{ }^{\circ} \mathrm{C}\right)$. The mole fractions of $\mathrm{SiCl}_{4}$ and $\mathrm{CO}_{2}$ are 0.006 and 0.035 , respectively, but similar results were obtained for other values of these two operating parameters. It is seen that the introduction of small quantities of $\mathrm{AlCl}_{3}$ in the $\mathrm{SiCl}_{4}-\mathrm{CO}_{2}-\mathrm{H}_{2}$ mixture leads to a steep rise of the deposition rate. A similar observation was made by Auger and Sarin [20], but Mulpuri [19] noticed a precipitous drop in the deposition rate as the Al/Si feed 
ratio changed from zero to 0.5 . As the $\mathrm{AlCl}_{3}$ feed mole fraction in the feed is increased, both the codeposition rate and the deposition rate of $\mathrm{Al}_{2} \mathrm{O}_{3}$ from $\mathrm{AlCl}_{3}-\mathrm{H}_{2}-$ $\mathrm{CO}_{2}$ mixtures increase. Enhancement of the codeposition rate with further increase of the $\mathrm{Al} / \mathrm{Si}$ feed ratio was observed in [19] after the initial drop, but the opposite behavior was reported in [20] for experiments conducted in a similar chemical vapor deposition apparatus.

In the lower part of the $\mathrm{AlCl}_{3}$ mole fraction range covered in Figure 4, the codeposition process proceeds with lower rate than the deposition of alumina. The $\mathrm{AlCl}_{3}$ mole fraction value at which the codeposition rate becomes larger than the rate of deposition of alumina decreases with increasing reaction temperature. Experiments at other conditions showed that this value also depends on the feed mole fractions of $\mathrm{SiCl}_{4}$ and $\mathrm{CO}_{2}$. Using the results of Figure 1 for the deposition rate of silica, one finds that in the upper part of the $\mathrm{AlCl}_{3}$ mole fraction range of Figure 4, the codeposition rate is much higher than the sum of the deposition rates of $\mathrm{Al}_{2} \mathrm{O}_{3}$ and $\mathrm{SiO}_{2}$ in independent deposition experiments. This was also observed to be the case in Figure 1 at high temperatures. These results reinforce the conclusion that the surface chemistry of the codeposition process must involve reaction steps that include both silicon species and aluminum species.

Data on the effect of the feed mole fraction of carbon dioxide on the deposition rate of the single oxides and on the codeposition rate are presented in Figures 5 and 6 at $1000{ }^{\circ} \mathrm{C}$ for several combinations of mole fractions of chlorides. For the codeposition process, data are also given at $1050{ }^{\circ} \mathrm{C}$ for $0.6 \% \mathrm{SiCl}_{4}$ and $1.2 \%$ $\mathrm{AlCl}_{3}$ in the feed (Figure 6). The results show that the feed mole fraction of $\mathrm{CO}_{2}$ influences the deposition rates of the three processes in a complex way. Depending on the values of the other operating parameters, an increase in the $\mathrm{CO}_{2}$ mole fraction may increase, decrease, or have no effect on the deposition rate. For the codeposition rate and the deposition rate of alumina, the most common behavior pattern is an initial increase as the $\mathrm{CO}_{2}$ mole fraction is raised from the lowest value used in experiments (i.e., 0.035), followed by a region on small change or a maximum. For deposition of silica with $0.6 \% \mathrm{SiCl}_{4}$ in the feed, the deposition rate undergoes a small drop as the $\mathrm{CO}_{2}$ in the feed is changed from $3.5 \%$ to $7 \%$ and shows little change after that. On the other hand, for $0.011 \mathrm{SiCl}_{4}$ mole fraction, it increases continuously, but slowly, as the $\mathrm{CO}_{2}$ mole fraction is increased. 
All codeposition rate vs. $\mathrm{CO}_{2}$ mole fraction curves in Figures 5 and 6 present a maximum, which is more pronounced for reaction conditions that give high rates of deposition. The $\mathrm{CO}_{2}$ mole fraction value at which the maximum occurs lies in the 0.07-0.013 range, and it tends to move toward lower values as the temperature is reduced or as the mole fraction of $\mathrm{SiCl}_{4}$ is increased. Since these changes lead to lower deposition rates, this behavior suggests that the location of maximum is moved to larger $\mathrm{CO}_{2}$ mole fractions as the codeposition rate is increased. The appearance of a maximum in the variation of the deposition rate with the $\mathrm{CO}_{2}$ mole fraction has been observed in many experimental studies on the chemical vapor deposition of alumina from mixtures of $\mathrm{AlCl}_{3}, \mathrm{CO}_{2}$, and $\mathrm{H}_{2}[13,16,24]$.

The increase in the deposition rate with an increase in the $\mathrm{CO}_{2}$ mole fraction is most probably caused by the increase in the concentration of $\mathrm{H}_{2} \mathrm{O}$ or of other oxygendonor species with high surface reactivity, such as $\mathrm{OH}$. The appearance of a maximum suggests that the formation of oxygen-donor species ceases to be the rate-limiting step of the overall process above some value of $\mathrm{CO}_{2}$ concentration. As the mole fraction of $\mathrm{CO}_{2}$ in the feed is increased, the concentrations of species that contain metal ( $\mathrm{Si}$ or Al) and oxygen should also increase at the expense of silicon or aluminum species that contain chlorine or hydrogen. For deposition of silicon from $\mathrm{SiCl}_{4}$, past studies $[25,26]$ have shown that $\mathrm{SiCl}_{\mathrm{x}}$ are the species that are mainly responsible for $\mathrm{Si}$ incorporation in the deposit. If an analogous situation exists in the case of metal incorporation in the deposit during deposition of oxides - that is, $\mathrm{SiCl}_{\mathrm{X}}$ and $\mathrm{AlCl}_{\mathrm{X}}$ are the main surface reactive species -the reduction in the concentration of metal-chlorine with the increase of the concentration of $\mathrm{CO}_{2}$ should eventually offset the positive effect of the increase in the concentrations of the oxygen-donor species on the reaction rate. $\mathrm{CO}_{2}$ appears to affect differently the deposition rate of silica from the deposition rate of alumina and the codeposition rate because the former is considerably lower at similar reaction conditions; therefore, the formation of water and of other oxygendonor species stops being the controlling step of the deposition process at much lower values of $\mathrm{CO}_{2}$ concentration.

The results of Figure 3 showed that the increase of the $\mathrm{SiCl}_{4}$ mole fraction in the feed has a negative effect on the silica deposition rate at $1000{ }^{\circ} \mathrm{C}$. Figure 5 shows that this is also the case for the codeposition rate at this temperature. The aluminum chloride mole fraction is larger in the case with the higher value of $\mathrm{SiCl}_{4}$ mole 
fraction, but this parameter does not affect significantly the deposition rate of alumina and the codeposition rate at $1000{ }^{\circ} \mathrm{C}$ when its value is above 0.01 (see Figure 4). Because of the decrease that the codeposition rate undergoes as the $\mathrm{SiCl}_{4}$ mole fraction is changed from 0.006 to 0.011 , the codeposition rate and the deposition rate of alumina have comparable values for $1.1 \% \mathrm{SiCl}_{4}$ in the feed, whereas they differ by almost a factor of two at the lower value. It was argued in the presentation of the results of Figure 3 that the negative effect of the increase of the concentration of $\mathrm{SiCl}_{4}$ on the deposition rate of silica is most probably a consequence of the increase in the concentration of gas phase reaction products (such as $\mathrm{HCl}$ ), which have an inhibitory effect on the solid formation reactions. The results of Figure 5 suggest that this must also be the case in the codeposition process.

\section{Effects of residence time}

The total flow rate and position in the reactor are the two variables that have the most influence on the residence time of the reactant molecules in the hot zone of the reactor upstream of the substrate. The effect of the total flow rate on the codeposition and the single species deposition rates is shown in Figure 7 for two temperatures (1000 and $\left.1050{ }^{\circ} \mathrm{C}\right), 100$ Torr total pressure, and an Al/Si feed ratio of 2. As the flow rate changes from 200 to $500 \mathrm{~cm}^{3} / \mathrm{min}$, a dramatic reduction in the rate of silica deposition takes place. Above $500 \mathrm{~cm}^{3} / \mathrm{min}$, the rate decreases only slightly with an increase in the flow rate. Since the mass transport coefficient increases with increasing velocity of flow of the gaseous mixture over the deposition surface, the negative effect of flow rate on the deposition rate indicates that there are insignificant mass transport limitations from the bulk of the gas phase to the deposition surface. The increase in the total flow rate also has a negative effect on the codeposition rate. However, there are regions of flow rate values where the deposition rate tends to increase with increasing flow rate, and this leads to appearance of local maxima in the deposition rate vs. flow rate curve. The negative effect of the flow rate on the codeposition rate becomes stronger as the temperature decreases. A maximum also appears in the variation of the alumina deposition rate with the total flow rate.

Decrease in the deposition rate with increasing total flow rate was observed in the study of $\mathrm{SiO}_{2}$ particle generation from oxidation of $\mathrm{SiCl}_{4}$ [27]. A similar observation was also made by Klaus et al. [28] and Wise et al. [29], who reported that 
the growth rate of $\mathrm{SiO}_{2}$ films formed on silicon surfaces through atomic layer control from $\mathrm{SiCl}_{4}$ and $\mathrm{H}_{2} \mathrm{O}$ using binary reaction sequence chemistry, increased significantly with increasing exposure time. For alumina deposition, the decrease of the deposition rate at flow rates higher than $400-500 \mathrm{~cm}^{3} / \mathrm{min}$ in Figure 7 is at variance with the behavior seen in [30], where a square root dependence on the total flow rate was observed. This was construed as an indication of the existence of mass transport limitations on the deposition process. Park et al. [11] reported linear decrease of deposition rate of $\mathrm{Al}_{2} \mathrm{O}_{3}$ with decreasing flow rate from 800 to $300 \mathrm{~cm}^{3} / \mathrm{min}$ at 1050 ${ }^{\circ} \mathrm{C}$. The presence of mass transport limitations was proposed as an explanation for this behavior. Other observations made in [11] were insignificant change of the deposition rate for flow rates greater than $800 \mathrm{~cm}^{3} /$ min and no deposition below $300 \mathrm{~cm}^{3} / \mathrm{min}$. These results are in disagreement with the behavior seen in Figure 7. The differences are most probably due to the use of a different reactor arrangement from that used in the present study, namely, a vertical cold-wall reactor.

To obtain results on the effects of the position of the substrate on the deposition rate from a single experiment, experiments were carried out on thin molybdenum wires, placed along the centerline of the reactor. Results on the variation of the codeposition rate with the distance from the entrance of the reactor at $1000{ }^{\circ} \mathrm{C}$ are given in Figure 8. Kinetic data are shown in the figure for positions lying within the isothermal zone of the reactor, that is $0-23 \mathrm{~cm}$, and therefore, the changes in the deposition rate reflect changes in the composition of the gaseous mixture and not in the temperature of reaction. The variation of the codeposition rate with the distance in the reactor presents a maximum at about the middle of the isothermal zone of the reactor. This behavior is in agreement with that seen in Figure 7 for the effects of flow rate. (It must be noted that deposition rate measurements conducted at the same distance from the entrance of the reactor on different substrates (walls of the reactor, plates, and wires) showed small differences among the various substrates. This is a further indication of the absence of significant mass transport limitations at the conditions of our experiments.) The appearance of the maximum in the variation of the deposition rate of alumina and in the codeposition rate with the residence time is most probably the result of the interaction of the formation of surface reactive species, the depletion of the species in the deposition reactions, and the formation of reaction byproducts that have an inhibitory effects on solid formation reactions (e.g., 
$\mathrm{HCl}$ ). This interaction must also be taking place in the case of silica deposition, but because of the much lower values of deposition rate, the maximum deposition rate probably occurs at flow rates below the lower limit of the range covered in Figure 7.

\section{Deposit composition and morphology}

The composition and morphology of the deposits were examined employing energy dispersive X-ray analysis (EDXA) and scanning electron microscopy (SEM), respectively. X-ray diffraction (XRD) analysis revealed that the films of pure alumina consisted of polycrystalline $\kappa-$ and $\theta-\mathrm{Al}_{2} \mathrm{O}_{3}$ [22], whereas the silica films were amorphous. Films deposited from $\mathrm{SiCl}_{4}-\mathrm{AlCl}_{3}-\mathrm{CO}_{2}-\mathrm{H}_{2}$ mixtures were dense and uniform in thickness. Several codeposited films were analyzed with XRD, and for deposition temperatures above $1000^{\circ} \mathrm{C}$, they were found to be a mixture of an amorphous component and $\kappa$ - and $\theta-\mathrm{Al}_{2} \mathrm{O}_{3}$. The alumina peaks in the codeposits were rather weak in comparison to the peaks seen in pure alumina deposits, suggesting that the amounts of crystalline $\mathrm{Al}_{2} \mathrm{O}_{3}$ were small and that significant amounts of $\mathrm{Al}_{2} \mathrm{O}_{3}$ were incorporated into amorphous aluminosilicates. No crystalline phase was detected in deposits obtained at temperatures lower than $1000^{\circ} \mathrm{C}$.

Figure 9 shows SEM micrographs of codeposited films formed at $4 \mathrm{~cm}$ location, 100 Torr, $300 \mathrm{~cm}^{3} / \mathrm{min}$ total flow rate, $0.006 \mathrm{SiCl}_{4}$ mole fraction, 0.012 $\mathrm{AlCl}_{3}$ mole fraction, $0.035 \mathrm{CO}_{2}$ mole fraction, and two deposition temperatures (1000 and $\left.1100^{\circ} \mathrm{C}\right)$. It is seen that the macroscopic morphology of the surface of the deposits is of nodular structure. The average nodule size decreased slightly as the temperature was changed from 1000 to $1100{ }^{\circ} \mathrm{C}$ (compare Figures $9 \mathrm{a}$ and $9 \mathrm{~b}$ ), and the surface of the deposit became rougher and similar to that of pure alumina deposits. The analysis of the composition of the deposits (see below) revealed that this change was accompanied by an increase in the aluminum content of the deposit.

The composition of the deposits was analyzed by EDXA. Since the deposition of alumina proceeds at much higher rates than the deposition of silica (Figure 1), one would expect that, if the two oxides $\left(\mathrm{SiO}_{2}\right.$ and $\left.\mathrm{Al}_{2} \mathrm{O}_{3}\right)$ were deposited in the codeposition process at rates proportional to those seen in the independent deposition experiments at the same operating conditions, $\mathrm{Al}_{2} \mathrm{O}_{3}$ would be the main component of the codeposited films, especially at low temperatures $\left(<1000{ }^{\circ} \mathrm{C}\right)$, where the 
codeposition rate is comparable to that of alumina. However, the results showed that $\mathrm{SiO}_{2}$ was the main constituent of the deposit in the whole temperature range, suggesting that the incorporation of silica in the codeposit is more favored than that of alumina. From the values of the codeposition rate and the film composition in $\mathrm{SiO}_{2}$ and $\mathrm{Al}_{2} \mathrm{O}_{3}$, the rates of incorporation of the oxides in the codeposited films were computed as functions of temperature, and the results are shown in Figure 10. The comparison of the alumina and silica deposition rates in the codeposition process (solid curves) and in the single oxide deposition experiments (dashed curves) shows that the codeposition process is followed by a dramatic enhancement of the deposition of silica and an equally dramatic reduction of alumina deposition. As a result, the $\mathrm{Al} / \mathrm{Si}$ ratio in the deposit is by a few orders of magnitude lower than the ratio expected on the basis of the deposition rates of silica and alumina in single oxide experiments at the same conditions (compare dashed and solid curves in Figure 10).

An increase in the reaction temperature has a positive effect on the content of the codeposited films in Al in Figure 10, but the opposite effect is observed for the $\mathrm{Al} / \mathrm{Si}$ ratio that is predicted on the basis of the single oxide deposition experiments. Increasing $\mathrm{Al} / \mathrm{Si}$ ratio of the deposit with increasing temperature was also reported in [19], where it was also observed that the deposition rate and the aluminum content of the deposit increased with increasing deposition time. Insignificant variation of the composition of the deposit and of the deposition tae with time was observed in the present study, and a similar observation was made in our past study of aluminosilicate deposition using MTS as silicon source [22].

Figure 11 presents the variation of the $\mathrm{Al} / \mathrm{Si}$ ratio along the length of the reactor for the film formed on a refractory wire at the conditions of Figure 8. It is seen that the $\mathrm{Al} / \mathrm{Si}$ deposit ratio increases with increasing distance from the entrance of the reactor, reaching a maximum close to the center of the hot zone. Since the maximum in the deposition rate and the maximum in the Al/Si ratio in the deposit occur at the about same position in the reactor (compare Figures 8 and 11), one is led conclude that high deposition rates promote the incorporation of $\mathrm{Al}$ in the deposit. The results of Figure 11 suggest that it may be possible to circumvent the effects of the enhancement of the deposition rate of $\mathrm{SiO}_{2}$ in the presence of $\mathrm{AlCl}_{3}$ in the feed and obtain deposits with significant alumina and aluminosilicate (e.g., mullite) content by manipulating the residence time of the reactive mixture in the reactor. 
Silicon tetrachloride vs. MTS as silicon source gas

It was mentioned in the introduction that in a past study [22] we carried out a comprehensive study of the deposition of silica, alumina, and aluminosilicates from mixtures of $\mathrm{CH}_{3} \mathrm{SiCl}_{3}$ (MTS), $\mathrm{AlCl}_{3}, \mathrm{CO}_{2}$, and $\mathrm{H}_{2}$. Results from that study on the variation with the temperature of the codeposition rate and the deposition rates of silica and alumina in independent experiments are compared in Figure 12 with deposition rate results measured when $\mathrm{SiCl}_{4}$ is used as silicon source (Figure 1). The comparison of the two sets of data reveals that when MTS is used as silicon source, both the deposition rate of silica and the deposition rate in the codeposition process are much higher (by almost an order of magnitude) than the corresponding values for $\mathrm{SiCl}_{4}$ at all temperatures. It should be noted that with the exception of the mole fraction of $\mathrm{CO}_{2}$ and the total pressure, the other operating parameters (chloride mole fractions, flow rate, and measurement location) do not have the same values in the two sets of data. However, as the results of Figures 3-8 on the effects of these parameters on the codeposition rate and the deposition of silica show, the differences in Figure 12 are much larger (by more than an order of magnitude in some cases) than the differences that would be expected from the different operating conditions and, in several cases, of the opposite sign. For example, as the results of Figures 3 and 5 show, changing the $\mathrm{SiCl}_{4}$ mole fraction from 0.006 to 0.011 (the MTS mole fraction in Figure 12) would decrease both the codeposition rate and the deposition rate of silica at $1000{ }^{\circ} \mathrm{C}$ and thus lead to larger differences between $\mathrm{SiCl}_{4}$ and MTS as silicon source.

The apparent activation energies that are extracted for deposition of silica and aluminosilicate deposition (codeposition) from the results of Figure 12 with MTS as silicon source (25.9 and $22.9 \mathrm{kcal} / \mathrm{mol}$, respectively) are very close to the values found in this study for deposition from mixtures containing $\mathrm{SiCl}_{4}$ (26.5 (excluding data below $925^{\circ} \mathrm{C}$ ) and $22.1 \mathrm{kcal} / \mathrm{mol}$, respectively (see Figure 1)). Even though apparent activation energies are influenced by several other factors in addition to the intrinsic kinetics of processes, the small differences in the activation energies for the two silicon sources offer a strong indication that the same controlling steps are probably involved in the deposition mechanisms of aluminosilicates and silica in the two cases. 
It is possible to explain some of the differences that are observed in Figure 12 between MTS and $\mathrm{SiCl}_{4}$ using thermochemical equilibrium analysis. Figure 13 presents results on thermochemical equilibrium in the $\mathrm{Si} / \mathrm{C} / \mathrm{Cl} / \mathrm{H} / \mathrm{O}$ system for elemental loadings corresponding to $\mathrm{MTS}-\mathrm{CO}_{2}-\mathrm{H}_{2}$ (Figure 13a) and $\mathrm{SiCl}_{4}-\mathrm{CO}_{2}-\mathrm{H}_{2}$ (Figure 13b) mixtures having the compositions used for deposition of silica in Figure 12. Figure 14, on the other hand, presents results for thermochemical equilibrium in the $\mathrm{Al} / \mathrm{Si} / \mathrm{C} / \mathrm{Cl} / \mathrm{H} / \mathrm{O}$ system for elemental loadings corresponding to the $\mathrm{AlCl}_{3}-\mathrm{MTS}$ $\mathrm{CO}_{2}-\mathrm{H}_{2}$ and $\mathrm{AlCl}_{3}-\mathrm{SiCl}_{4}-\mathrm{CO}_{2}-\mathrm{H}_{2}$ mixtures used for codeposition in Figure 12 (Figures $14 \mathrm{a}$ and $14 \mathrm{~b}$, respectively). More results on thermochemical equilibrium in silica, alumina, and aluminosilicate deposition with MTS as silicon source have been presented in [22]. Only species having mole fractions larger than $10^{-6}$ are shown in Figures 13 and 14, and the presented results refer to thermodynamic equilibrium with only gas phase species allowed to form. This was done because the quantities of material that must be transferred from the gas phase to the solid phase (i.e., to the walls of the reactor) in order to establish complete gas-solid equilibrium are very large, requiring residence times that are by several orders of magnitude larger than those prevailing in the experiments or in typical CVD reactors. A large database of gas phase species with thermodynamic data compiled from various sources (see [22] and references therein) was used for the thermodynamic computations, which were carried out using a free energy minimization method.

The comparison of Figures $13 \mathrm{a}$ and $14 \mathrm{a}$ with Figures $13 \mathrm{~b}$ and $14 \mathrm{~b}$, respectively, shows that even though the MTS mole fraction is by about a factor of 2 larger than the mole fraction of $\mathrm{SiCl}_{4}$, the mole fractions of $\mathrm{SiCl}_{2}$ and $\mathrm{SiCl}_{3}$ are by almost an order of magnitude larger in Figures 13a and 14a. These two radicals are the main products of silicon tetrachloride and MTS pyrolysis [25, 26], and their high surface reactivity renders them the principal precursors for silica incorporation in the deposit. The thermodynamic equilibrium results of Figures 13 and 14 are therefore consistent with the much higher deposition rates of silica and aluminosilicates when MTS is used as silicon source.

The introduction of $\mathrm{AlCl}_{3}$ in the reactive mixture appears to affect insignificantly the fraction of $\mathrm{HCl}$ both for $\mathrm{MTS}$ and for $\mathrm{SiCl}_{4}$ in the feed. The computation of thermodynamic equilibrium in the $\mathrm{Al} / \mathrm{C} / \mathrm{Cl} / \mathrm{H} / \mathrm{O}$ system (see results reported in [22]) gave much lower mole fractions of hydrogen chloride at the 
conditions of Figures 13 and 14. Since $\mathrm{HCl}$ is the main byproduct of reactions forming alumina from $\mathrm{AlCl}_{\mathrm{x}}$ and $\mathrm{H}_{\mathrm{y}} \mathrm{O}_{\mathrm{z}}$ species, this result can explain the suppression of the deposition of alumina when silicon chloride (MTS or $\mathrm{SiCl}_{4}$ ) is added to the $\mathrm{AlCl}_{3}-\mathrm{CO}_{2}-\mathrm{H}_{2}$ mixture. Figures 13 and 14 show that the introduction of $\mathrm{AlCl}_{3}$ in the reactive mixture also has rather insignificant effects on the concentration of the various $\mathrm{Si}$-containing species, such as $\mathrm{SiCl}_{\mathrm{x}}$. Therefore, the dramatic enhancement of the deposition of silica with the addition of $\mathrm{AlCl}_{3}$ in the feed cannot be justified on the basis of thermochemical equilibrium analysis alone. It is believed that the increased rate of silica deposition is due to surface reaction steps involving aluminum and silicon species, adsorbed on the surface, whose main reaction product is silicon oxide. It is interesting to point out that studies on the codeposition of $\mathrm{C}$ and $\mathrm{SiC}$ from MTS and ethylene mixtures [31] indicated that a similar interaction of silicon-containing species and carbon-containing species adsorbed on the deposition surfaces might be responsible for a dramatic enhancement of the deposition rate of carbon.

\section{Conclusions}

The chemical vapor codeposition of silica, alumina, and aluminosilicates from $\mathrm{SiCl}_{4}-\mathrm{AlCl}_{3}-\mathrm{CO}_{2}-\mathrm{H}_{2}$ mixtures was investigated in a subambient pressure hot-wall reactor, by monitoring gravimetrically the deposition rate on small substrates. To determine the variation of the deposition rate and deposit composition with the location in the CVD reactor, deposition experiments were carried out on refractory wires placed along the centerline of the reactor.

The results showed that both the codeposition rate and the single oxide deposition rates were positively influenced by temperature. Similar values of apparent activation energy (around $20 \mathrm{kcal} / \mathrm{mol}$ ) were determined for the three deposition processes for temperatures above $1000{ }^{\circ} \mathrm{C}$. The deposition rate of alumina and silica in independent experiments increased with increasing pressure for pressures between 75 and 300 Torr, but the codeposition rate exhibited local minima and maxima in the intermediate pressure range. The aluminum trichloride mole fraction had a positive effect on the rate of codeposition and the rate of alumina deposition. The effect of carbon dioxide mole fraction on the deposition rate was also investigated. The deposition rate vs. $\mathrm{CO}_{2}$ mole fraction curves exhibited a maximum for all three 
deposition processes. The flow rate had a strong influence on the codeposition rate and the deposition rates of silica and alumina. The codeposition rate and the $\mathrm{SiO}_{2}$ deposition rate were negatively affected by an increase in the flow rate, whereas the deposition rate of $\mathrm{Al}_{2} \mathrm{O}_{3}$ exhibited a maximum in its variation, the location of which was shifted to higher flow rates with increasing temperature. A maximum in the codeposition rate was also present at about the middle of the isothermal region of the CVD reactor.

The deposition of $\mathrm{Al}_{2} \mathrm{O}_{3}$ from mixtures containing $\mathrm{AlCl}_{3}$ proceeded much faster than the deposition of $\mathrm{SiO}_{2}$ from $\mathrm{SiCl}_{4}-\mathrm{CO}_{2}-\mathrm{H}_{2}$ mixtures of comparable chloride concentration. When both chlorides were fed into the chemical reactor, the overall deposition rate (i.e., the codeposition rate) was higher than the sum of the deposition rates of the simple oxides in the single species deposition experiments at the same conditions for temperature above $950{ }^{\circ} \mathrm{C}$. The difference between the codeposition rate and the alumina deposition rate increased with increasing temperature and aluminum trichloride concentration. The elemental analysis of the codeposited films revealed that in comparison to the rates seen in single species deposition experiments, the codeposition process was characterized by a dramatic enhancement of the deposition of $\mathrm{SiO}_{2}$ and a reduction in the deposition of $\mathrm{Al}_{2} \mathrm{O}_{3}$. This result was in agreement with what was seen in a past study where methyltrichlorosilane was used as silicon source. However, in that case, the rate of silica deposition in single species deposition experiment was much larger (by more than an order of magnitude), and the codeposition rate was by more than a factor of 3 higher than the sum of the deposition rates of the two oxides in independent experiments.

The morphology and the composition of the films were determined using SEM, XRD, and EDXA. The silica films were amorphous, and the alumina films consisted of $\kappa-\mathrm{Al}_{2} \mathrm{O}_{3}$ and $\theta-\mathrm{Al}_{2} \mathrm{O}_{3}$. These two alumina forms were also found to exist in codeposited films, along with amorphous components. The analysis of the composition of composite films deposited on wires showed that the $\mathrm{Al} / \mathrm{Si}$ ratio increased with increasing distance from the entrance of the reactor, reaching a maximum in the middle of the hot zone. The aluminum content of the codeposition product also increased with increasing temperature. These results indicate that it may be possible to obtain $\mathrm{Al} / \mathrm{Si}$ deposit ratios that are close to that of stoichiometric 
mullite and alumina rich-mullite by manipulating the temperature of the reaction and the residence time of the mixture in the reactor.

\section{Acknowledgment}

This research was supported by a grant from the Department of Energy. The authors also acknowledge the help of Brian McIntyre of the Institute of Optics of the University of Rochester with the characterization of the films.

\section{REFERENCES}

1. Shelby, J. E., in Treatise on Materials Science and Technology, Tomozawa, M., and Doremus, R. H., Eds., Vol. 17, p.1-35, Academic Press, New York (1979).

2. Gates, B. C., Katzer, J. R., Schuit, G. C. A., Chemistry of Catalytic Processes, McGraw-Hill, New York (1979).

3. Birkby, I., Stevens, R., Key Eng. Mat., 122, 527 (1996).

4. Fredriksson, E., and Carlsson, J.-O., J. Chem. Vap. Dep., 1, 333 (1993).

5. Funk, R., Schachner, H., Triquet, C., Kornmann, M., and Lux, B., J. Electrochem. Soc., 123, 285 (1976).

6. Colmet, R., and Naslain, R., Wear, 80, 221 (1982).

7. Lee, K. N., and Miller, R. A., J. Am. Ceram. Soc., 79, 620 (1996).

8. Messier, D. R., and Wong, P., J. Electrochem. Soc., 118, 772 (1971).

9. Altena, H., Colombier, C., and Lux, B., Proc. 4th. Eur. Conf. on Chem. Vap. Dep., Bloem., J., Verspui, G., and Wolf, L. R., Eds., Eidenhoven, The Netherlands, 435 (1983).

10. Taschner, C., Ljungberg, B., Alfredsson, V., Endler, I., and Leonhardt, A., Surf. Coat. Tech., 109, 257 (1998).

11. Park, C. S., Kim, J. G., and Chun, J.S., J. Vac. Sci. Technol. A, 1, 1820 (1983).

12. Bae, Y. W., Lee, W. Y., Besmann, T. M., Cavin, O. B., and Watkins, T. R., J. Am. Ceram. Soc., 81, 1945 (1998).

13. Choi, S. W., Kim, C., Kim, J. G., and Chun, J. S., J. Mat. Sci., 22, 1051 (1987).

14. Colmet, R., Naslain, R., Hagenmuller, P., and Bernard, C., J. Electrochem. Soc., 129, 1367 (1982). 
15. Ritala, M., and Leskela, M., Appl. Surf. Sci., 75, 333 (1994).

16. Sipp, E., Langlais, F., and Naslain, R., J. Alloy Compd., 186, 65 (1992).

17. Kim, S., and Gavalas, G. R., Ind. Eng. Chem. Res., 34, 168 (1995).

18. George, S. M., Sneh, O., Dillon, A. C., Wise, M. L., Ott, A. W., Okada, L. A., and Way, J. D., Appl. Surf. Sci., 82/83, 460 (1994).

19. Mulpuri, R., Ph.D. Dissertation, Boston Univ., Boston (1996).

20. Auger, M., and Sarin, V. K, Surf. Coat. Tech., 94-95, 46 (1997).

21. Itatani, K., Kubozono, T., Howell, F. S., Kishioka, A., and Kinoshita, M, J. Mater. Sci., 30, 1158 (1995).

22. Nitodas, S. F., and Sotirchos, S. V., to appear in Advanced Materials-CVD (1999).

23. Papasouliotis, G. D., and Sotirchos, S. V., J. Electrochem. Soc., 142, 3834 (1995).

24. Kim, J. G, Park, C. S., and Chun, J. S., Thin Solid Films, 97, 97 (1982).

25. Gupta, P., Coon, P. A., Koehler, B. G., and George, S. M., Surf. Sci., 249, 92 (1991).

26. Woiki, D., Catoire, L, and Roth, P., AIChE J., 43, 2670 (1997).

27. Kim, K. S., AIChE J., 43, 2679 (1997).

28. Klaus, J. W., Ott, A. W., Johnson, J. M., and George, S. M., Appl. Phys. Lett., 70, 1092 (1997).

29. Wise, M. L., Sneh, O., Okada, L. A., and George, S. M., Surf. Sci., 364, 367 (1996).

30. Silvestri, V. J., Osburn, C. M., and Ormond, D. W., J. Electrochem. Soc., 125, 902 (1978).

31. Sotirchos, S.V., and Kostjuhin, I., Ceramic Transactions, 79, 27 (1996). 


\section{FIGURE CAPTIONS}

Figure 1. Temperature dependence of deposition and codeposition rates at 100 Torr.

Figure 2. Pressure dependence of deposition and codeposition rates at $1000{ }^{\circ} \mathrm{C}$.

Figure 3. Effects of the $\mathrm{SiCl}_{4}$ mole fraction on the rate of $\mathrm{SiO}_{2}$ deposition at 100 Torr and various temperatures.

Figure 4. Effects of the $\mathrm{AlCl}_{3}$ mole fraction on the deposition rate in the presence or absence of $\mathrm{SiCl}_{4}$ at 100 Torr and various temperatures.

Figure 5. Effects of the $\mathrm{CO}_{2}$ mole fraction on the deposition and codeposition rates at 100 Torr and $1000{ }^{\circ} \mathrm{C}$ for two sets of chloride mole fractions.

Figure 6. Effects of the $\mathrm{CO}_{2}$ mole fraction on the deposition and codeposition rates at 100 Torr and $1000{ }^{\circ} \mathrm{C}$. Codeposition results are also shown at $1050{ }^{\circ} \mathrm{C}$.

Figure 7. Deposition rate vs. total flow rate for the deposition and codeposition processes at 100 Torr and 1000 and $1050{ }^{\circ} \mathrm{C}$.

Figure 8. Deposition rate vs. position in the CVD reactor for the codeposition process at 100 Torr and $1000{ }^{\circ} \mathrm{C}$.

Figure 9. SEM micrographs of CVD films at 100 Torr, $\mathrm{x}_{\mathrm{SiCl} 4}=0.006, \mathrm{x}_{\mathrm{AlCl} 3}=0.012$, substrate at $4 \mathrm{~cm}$, and $300 \mathrm{~cm}^{3} / \mathrm{min}$ total flow rate. Deposition temperature: a) $1000{ }^{\circ} \mathrm{C}$; b) $1100{ }^{\circ} \mathrm{C}$.

Figure 10. Effect of temperature on the rates of incorporation of $\mathrm{Al}_{2} \mathrm{O}_{3}$ and $\mathrm{SiO}_{2}$ in the deposit and the $\mathrm{Al} / \mathrm{Si}$ ratio at 100 Torr.

Figure 11. Al/Si deposit ratio vs. position in the reactor at the conditions of Figure 8.

Figure 12. Comparison of deposition rates using MTS (solid symbols) and $\mathrm{SiCl}_{4}$ (open symbols) as silicon source at 100 Torr and $3.5 \% \mathrm{CO}_{2}$. Other reaction conditions: Solid symbols: $1.1 \%$ MTS, $0.9 \% \mathrm{AlCl}_{3}, 250 \mathrm{~cm}^{3} / \mathrm{min}$ total flow rate, and substrate at 7 cm. Open symbols: $0.6 \% \mathrm{SiCl}_{4}, 1.2 \% \mathrm{AlCl}_{3}, 300 \mathrm{~cm}^{3} / \mathrm{min}$ total flow rate, and substrate at $4 \mathrm{~cm}$.

Figure 13. Equilibrium mole fraction vs. temperature for $\mathrm{SiO}_{2}$ deposition at 100 Torr. Solid phases are not allowed to form. (a) $\mathrm{CO}_{2} / \mathrm{MTS}=3.3, \mathrm{x}_{\mathrm{MTS}}=0.011$; (b) $\mathrm{CO}_{2} / \mathrm{SiCl}_{4}$ $=5, \mathrm{x}_{\mathrm{SiC} 14}=0.006$.

Figure 14. Equilibrium mole fraction vs. temperature for codeposition at 100 Torr. Solid phases were not allowed to form. (a) $\mathrm{CO}_{2} / \mathrm{AlCl}_{3} / \mathrm{MTS}=3.3 / 0.8 / 1$, $\mathrm{x}_{\mathrm{MTS}}=0.011$; (b) $\mathrm{CO}_{2} / \mathrm{AlCl}_{3} / \mathrm{SiCl}_{4}=5 / 2 / 1, \mathrm{x}_{\mathrm{SiCl} 4}=0.006$. 
Temperature, ${ }^{\circ} \mathrm{C}$

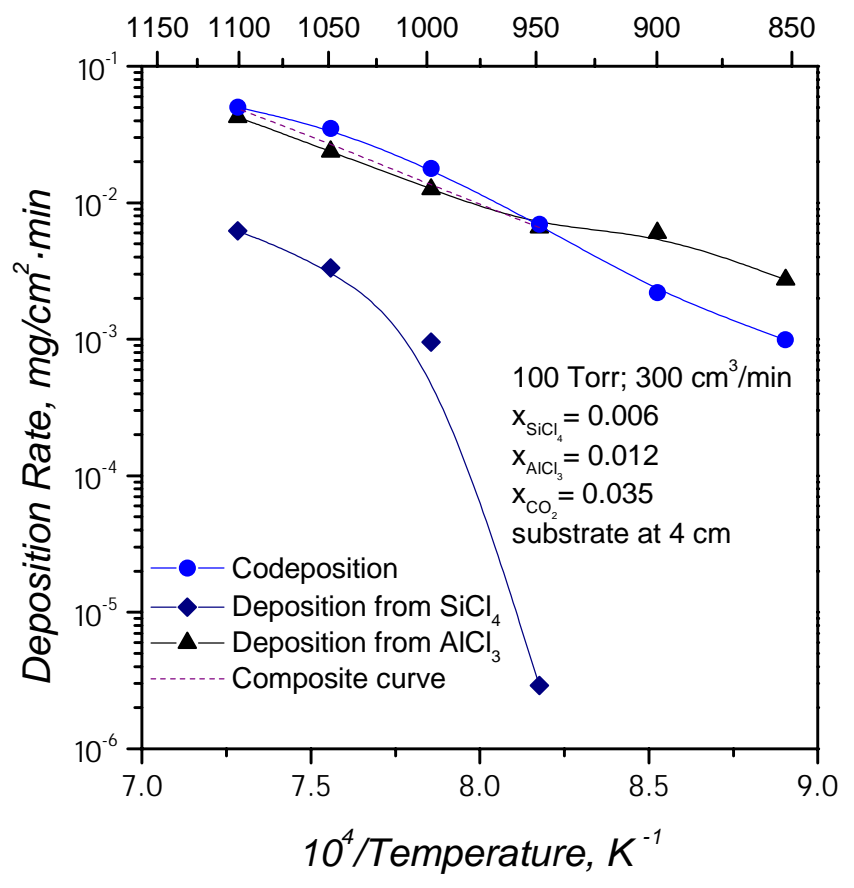

FIGURE 1 


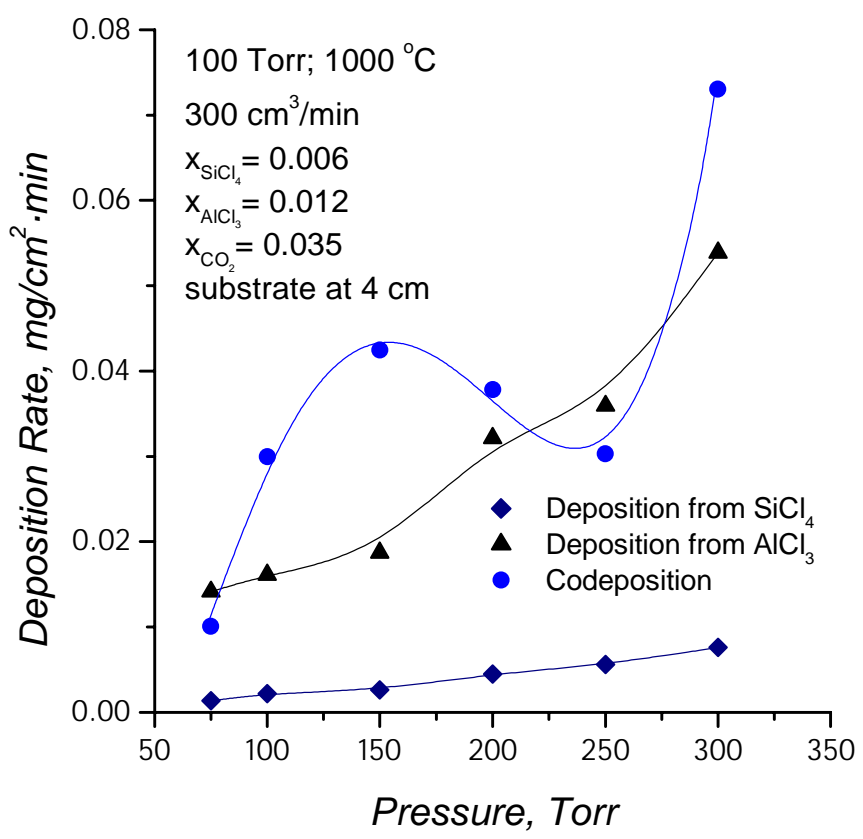

FIGURE 2 


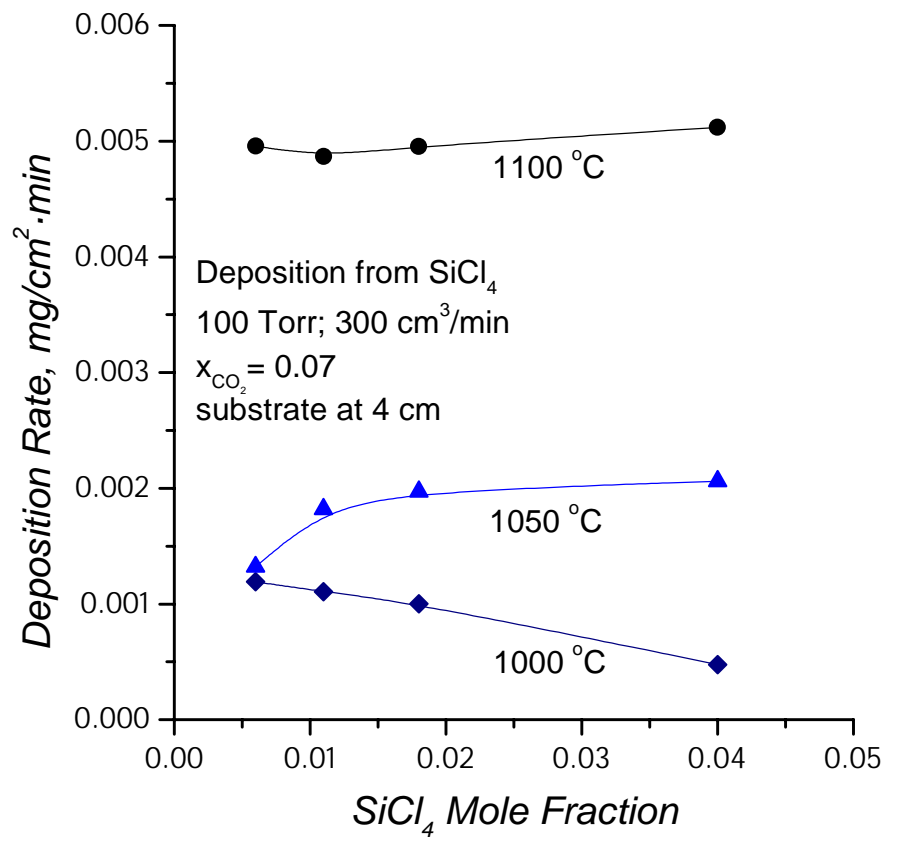

FIGURE 3 


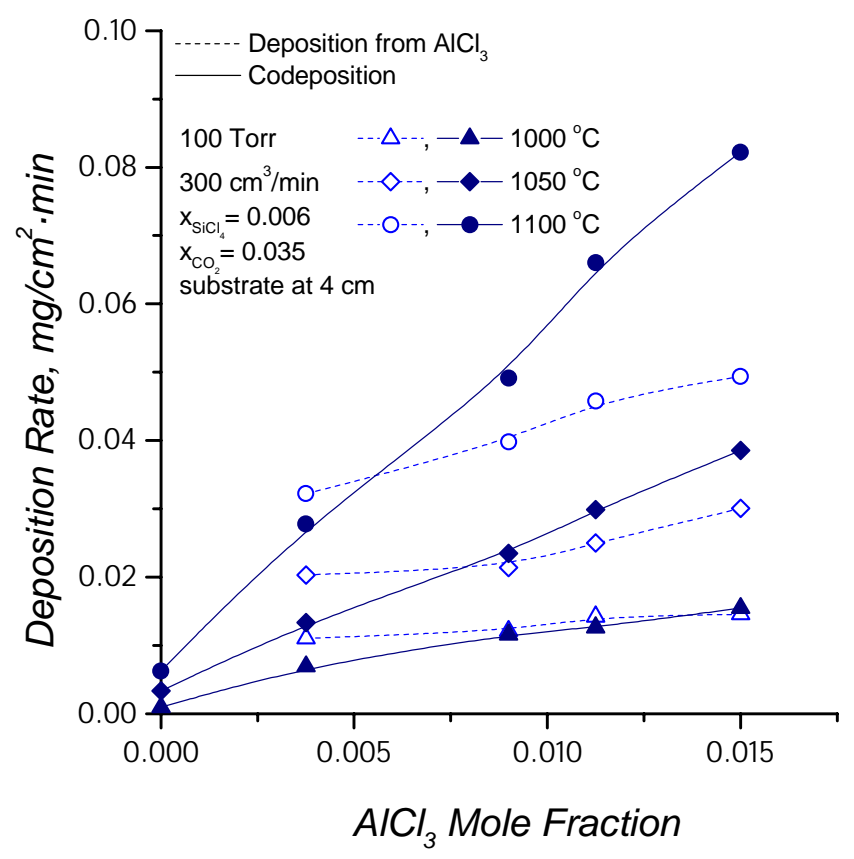

FIGURE 4 


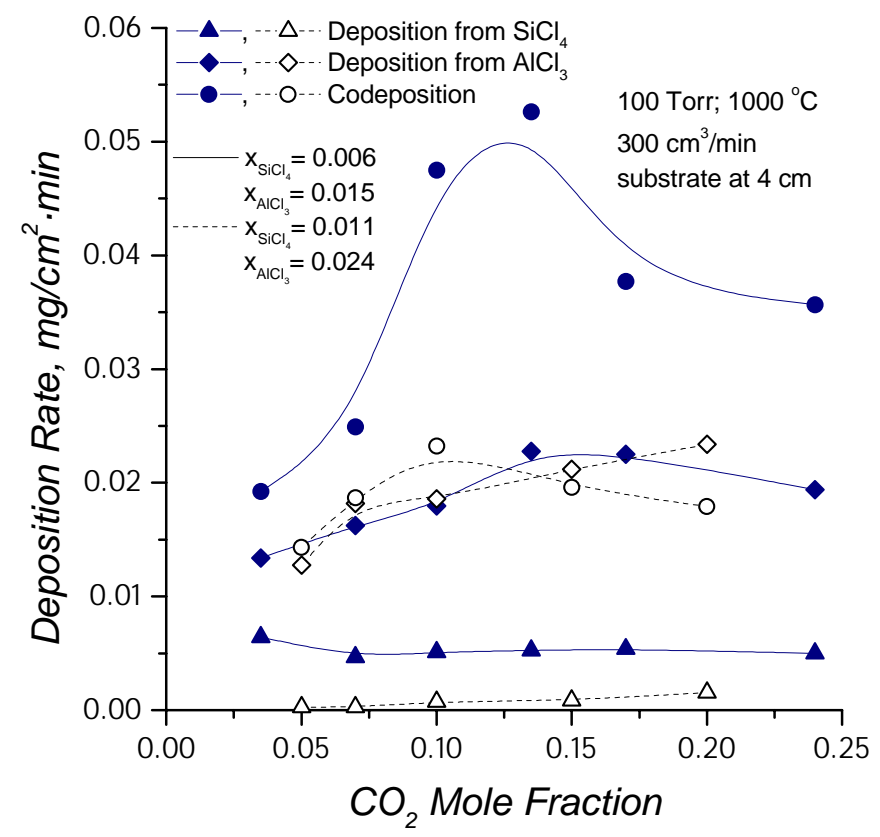

FIGURE 5 


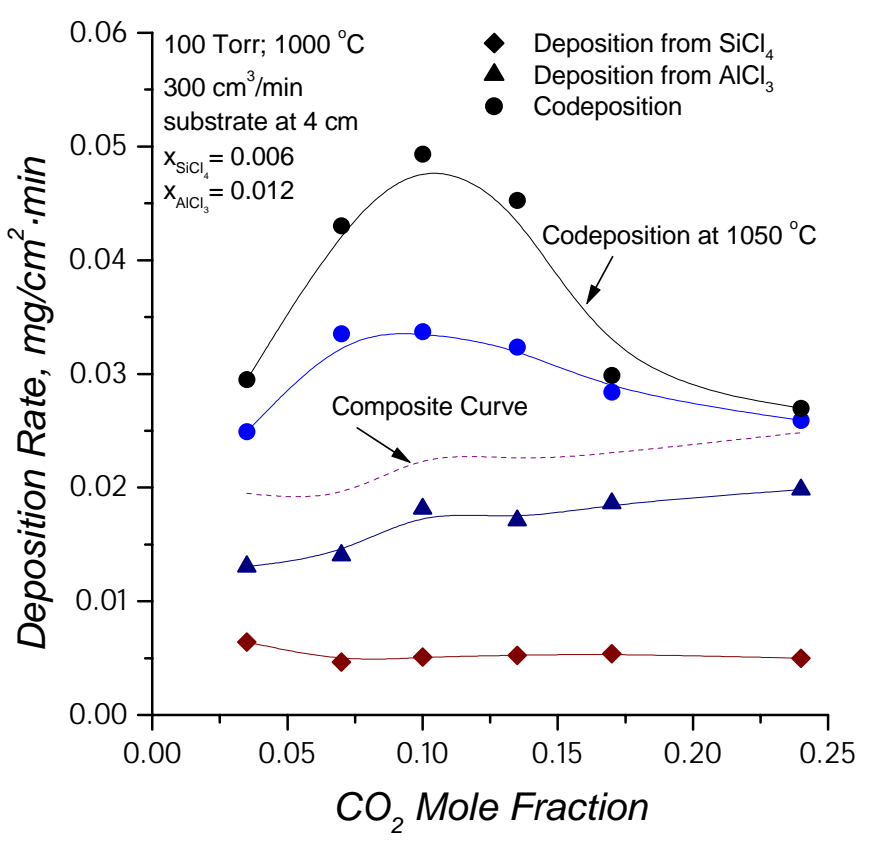

FIGURE 6 


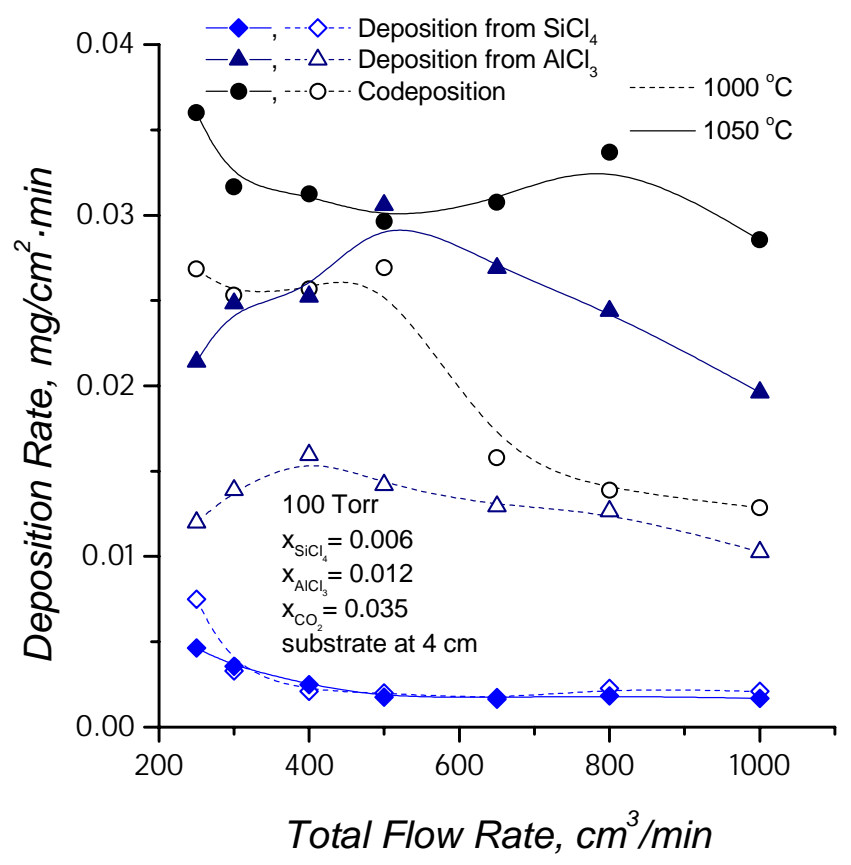

FIGURE 7 


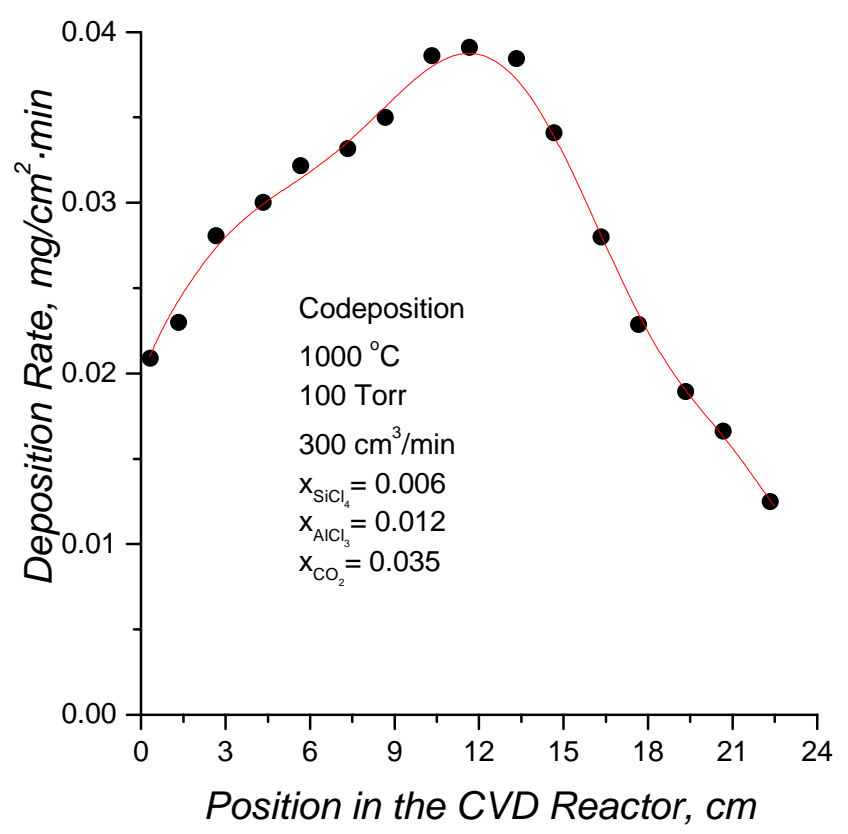

FIGURE 8 


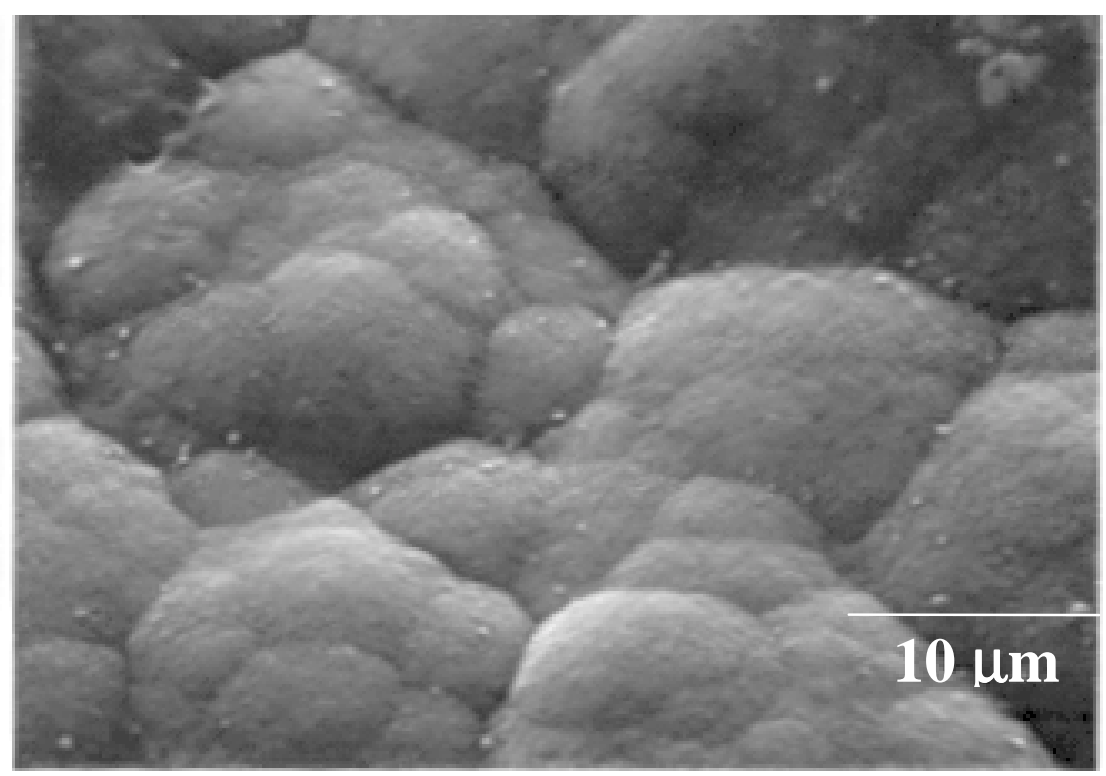

(a)

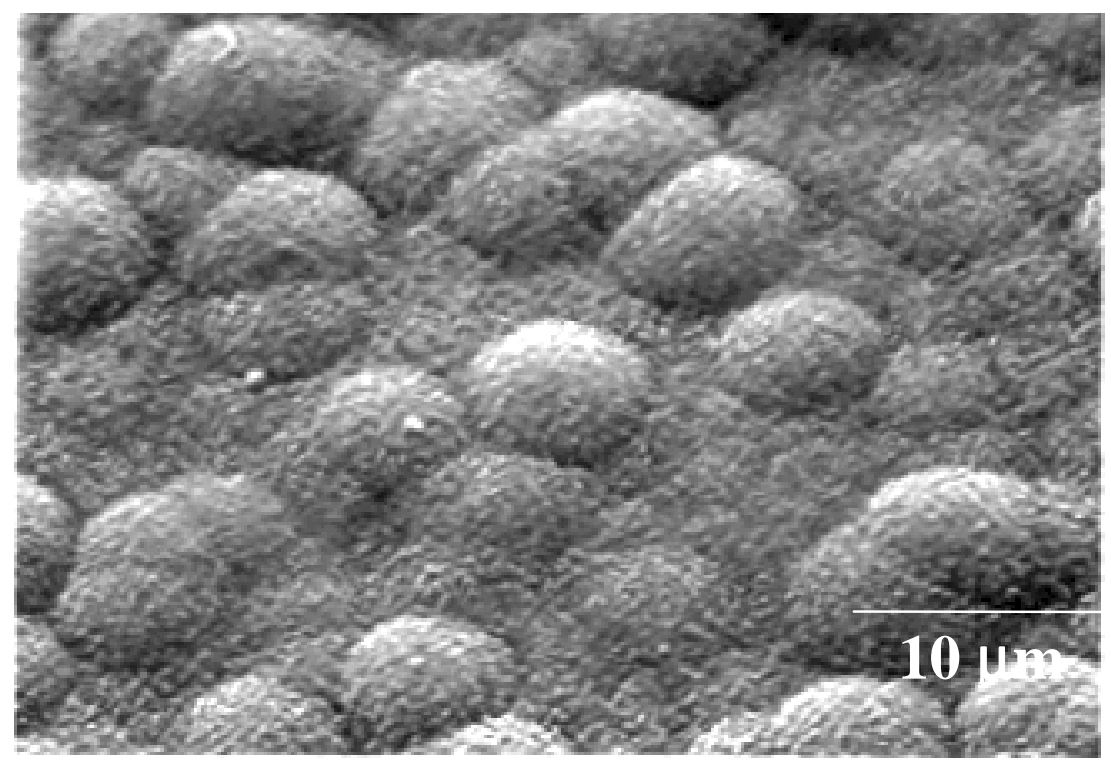

(b)

FIGURE 9 


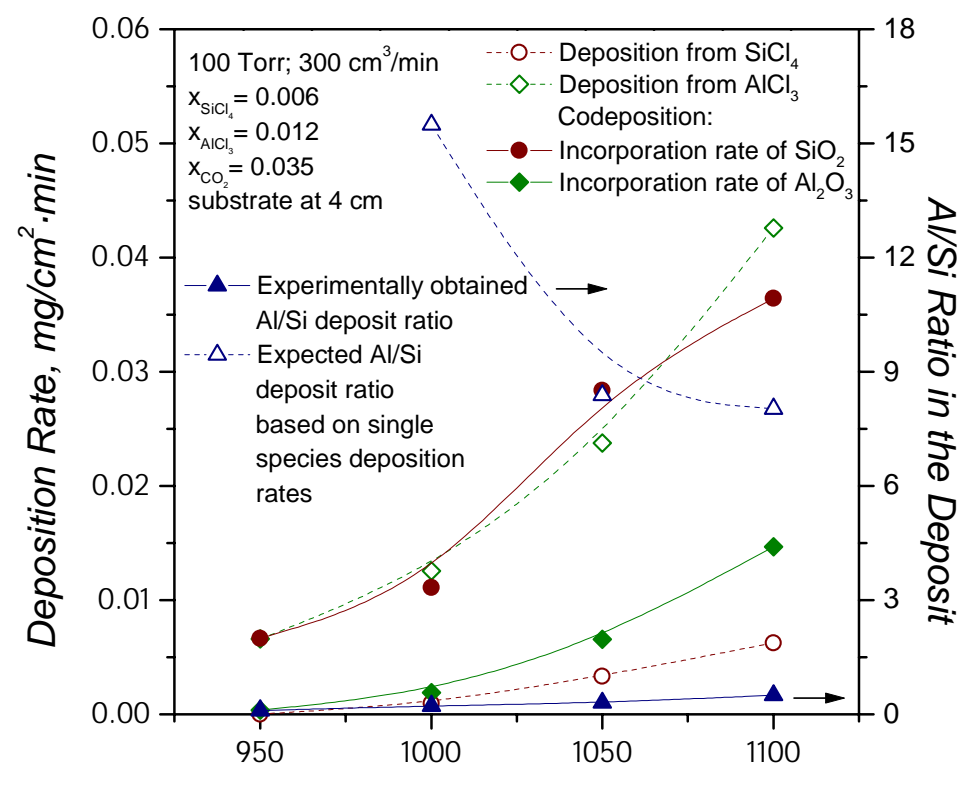

Temperature, ${ }^{\circ} \mathrm{C}$ 


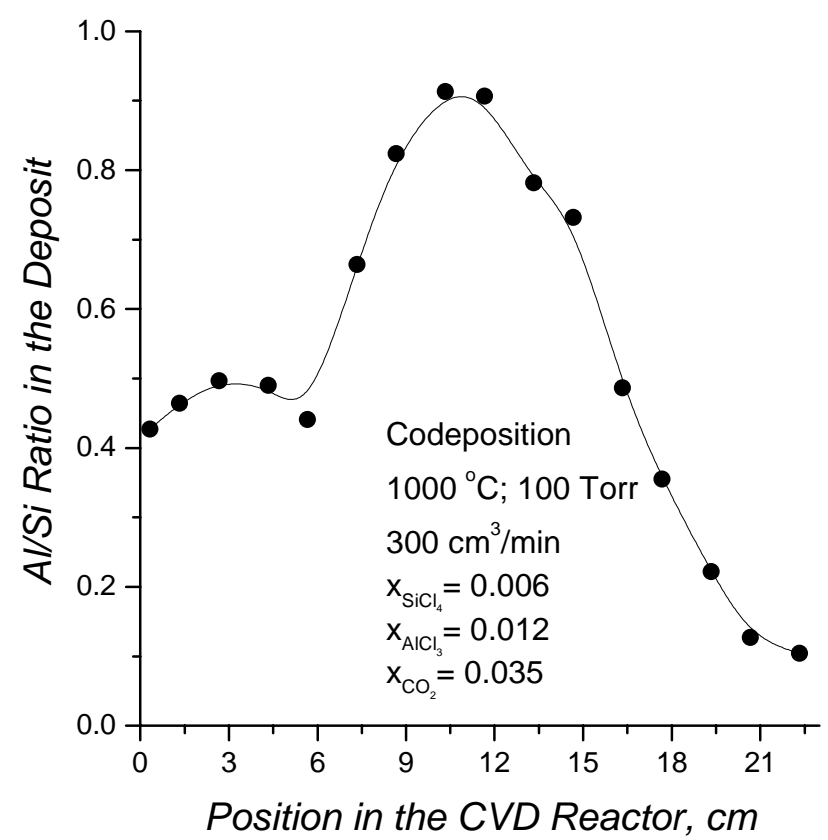

FIGURE 11 


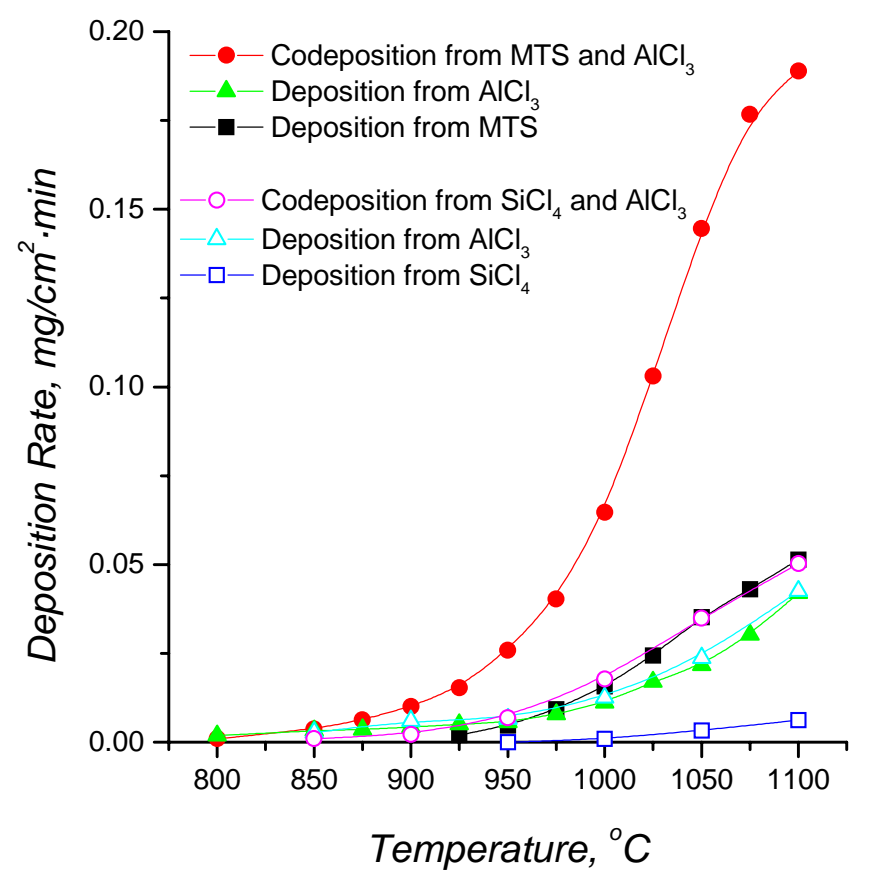

FIGURE 12 


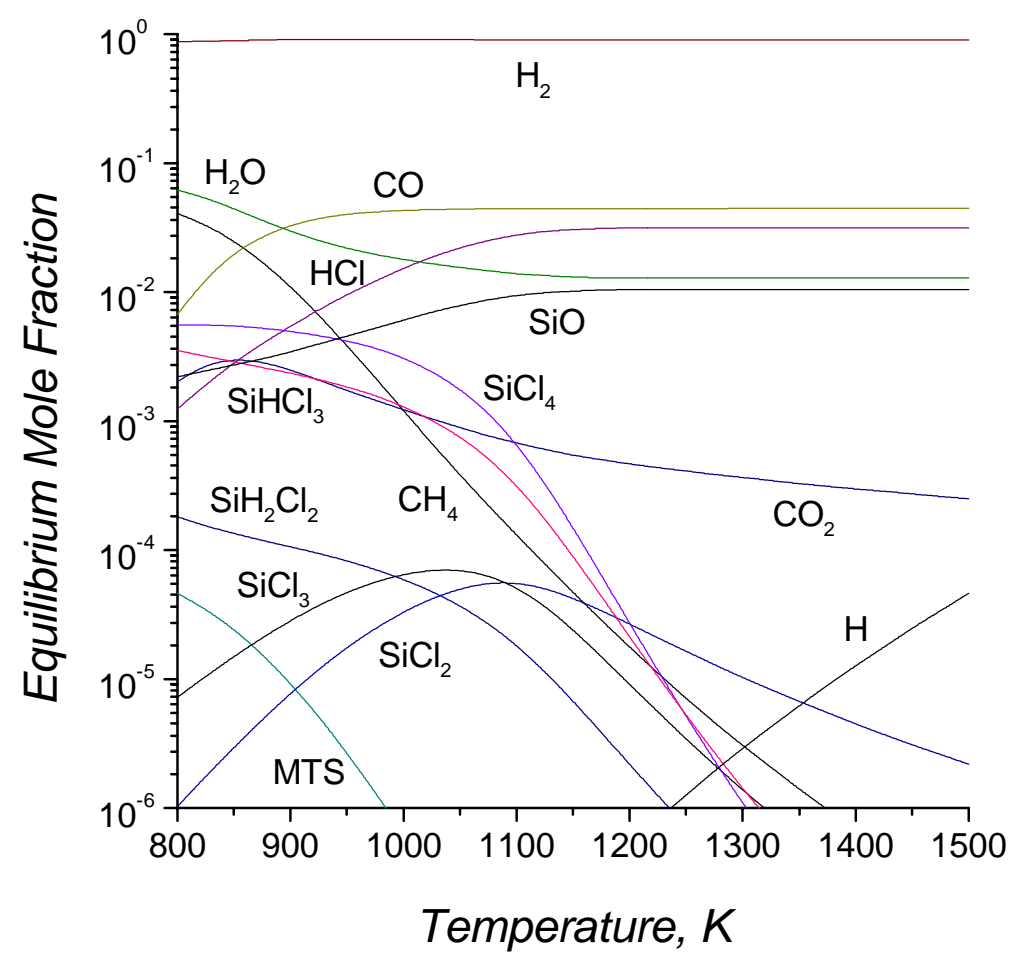

(a)

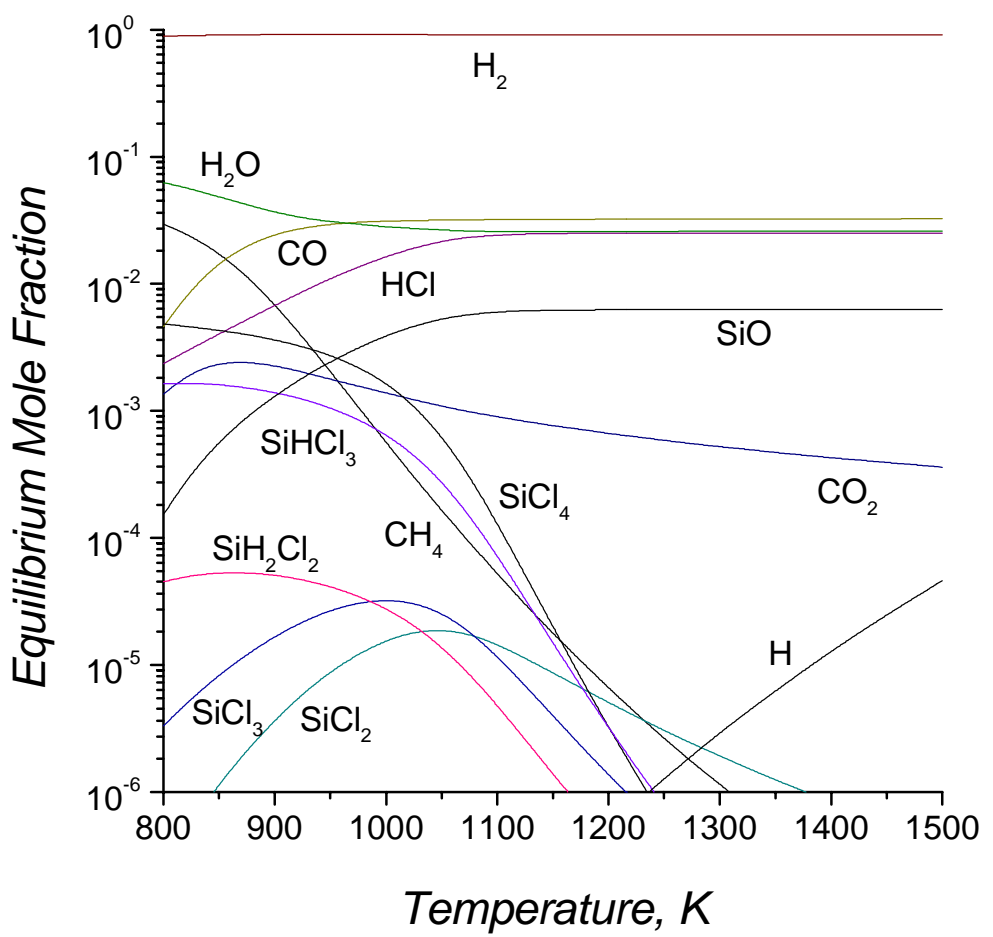

(b)

FIGURE 13 


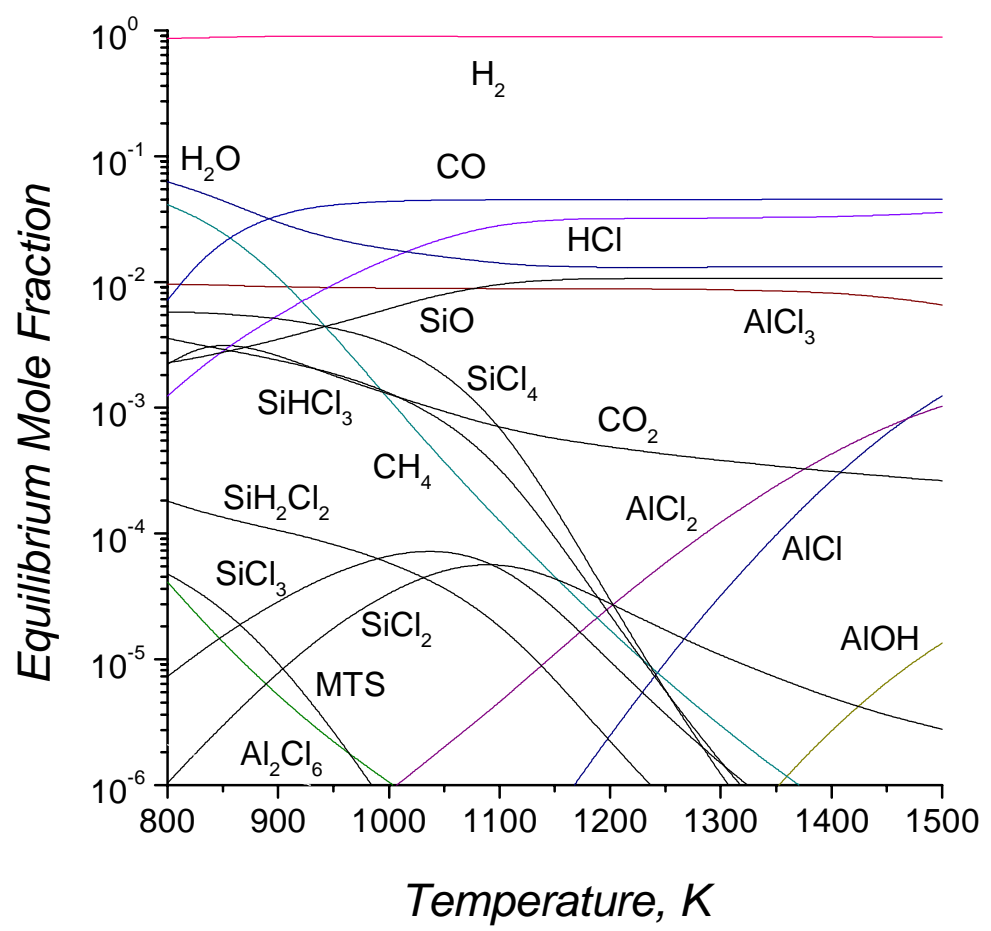

(a)

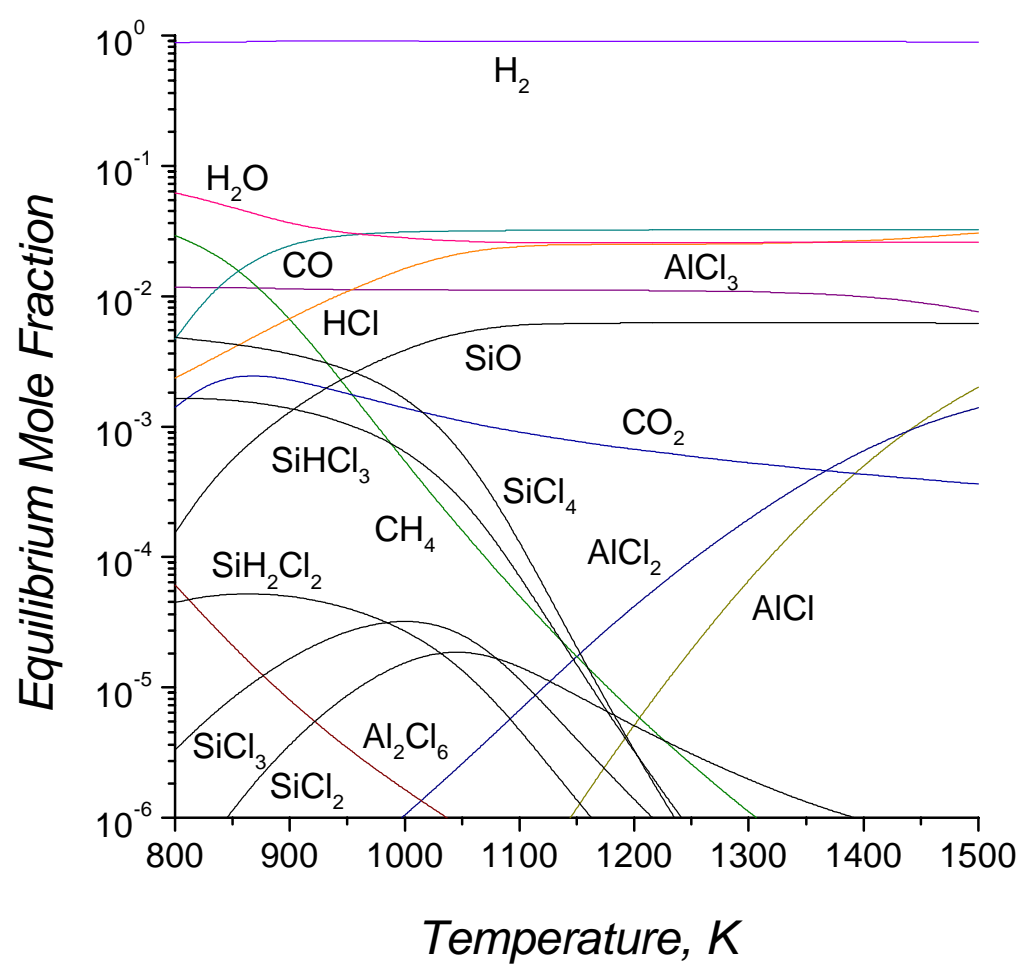

(b)

FIGURE 14 


\section{Effects of Residence Time and Reaction Conditions on the Deposition of Silica, Alumina, and Aluminosilicates from $\mathrm{CH}_{3} \mathrm{SiCl}_{3}, \mathrm{AlCl}_{3}, \mathrm{CO}_{2}$, and $\mathrm{H}_{2}$ Mixtures}

Stephanos F. Nitodas and Stratis V. Sotirchos *

Department of Chemical Engineering

University of Rochester

Rochester, NY 14627

* to whom correspondence should be addressed 


\begin{abstract}
Films of silicon oxide $\left(\mathrm{SiO}_{2}\right)$, aluminum oxide $\left(\mathrm{Al}_{2} \mathrm{O}_{3}\right)$, and aluminosilicates are prepared in this study by chemical vapor deposition (CVD) from mixtures of methyltrichlorosilane $\left(\mathrm{CH}_{3} \mathrm{SiCl}_{3}\right)$, aluminum trichloride $\left(\mathrm{AlCl}_{3}\right)$, carbon dioxide, and hydrogen. The dependence of the deposition rate of the oxides on the processing parameters, such as the pressure and the gas flow rate of the reactant mixture, is studied. The kinetic investigation of the oxides deposition is carried out in a hot-wall reactor of tubular configuration, coupled to a sensitive microbalance. In order to obtain information on the profiles of the deposition rate and deposit composition along the reactor, deposition experiments are conducted on refractory wires traversing the tubular reactor along its centerline. The results show that the enhancement of the incorporation rate of $\mathrm{SiO}_{2}$ in the deposit in the codeposition process and the attenuation of that of $\mathrm{Al}_{2} \mathrm{O}_{3}$, relative to the deposition rates seen in silica and alumina deposition experiments, are also encountered when relatively high $\mathrm{Al} / \mathrm{Si}$ ratios in the feed are employed. In all the deposition processes the deposition rate presents a maximum at about the middle of the isothermal zone of the reactor. The $\mathrm{Al} / \mathrm{Si}$ ratio of the deposit obtained in the codeposition process decreases fast with increasing the distance from the entrance of the CVD reactor, but in the vicinity of the entrance, it can reach values close to those corresponding to mullite. The $\mathrm{Al}_{2} \mathrm{O}_{3}$ content in the deposit can, in general, be increased by decreasing the residence time of the mixture in the reactor upstream of the location of deposition, such as by decreasing the pressure of operation or by increasing the flow rate.
\end{abstract}

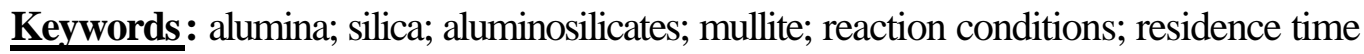

\title{
SUMMARY
}

The chemical vapor deposition of silica, alumina, and aluminosilicates from mixtures of $\mathrm{CH}_{3} \mathrm{SiCl}_{3}, \mathrm{AlCl}_{3}, \mathrm{CO}_{2}$, and $\mathrm{H}_{2}$ was studied in a hot-wall reactor of tubular configuration. The effects of reaction conditions, flow rate, and location of deposition on the deposition rate and stoichiometry of the obtained films were investigated. The results show that parameters that influence significantly the residence time of the mixture in the reactor upstream of the location of deposition have strong effects on the deposition rate and the composition of the deposit. The content of the deposit in $\mathrm{Al}_{2} \mathrm{O}_{3}$ tends to increase in the direction of decreasing residence time, that is, increasing flow rate, decreasing pressure, and decreasing distance from the entrance of the reactor. Deposit compositions close to those corresponding to mullite can be obtained close to the entrance of the CVD reactor. 


\section{Introduction}

Mullite has various properties ${ }^{[1,2]}$ that make it attractive for use in a broad spectrum of applications. ${ }^{[3-6]}$ Mullite and aluminosilicate materials can be prepared by methods, such as powder-based methods ${ }^{[1,7]}$, chemical vapor deposition $(\mathrm{CVD})^{[8-14]}$, and sol-gel synthesis ${ }^{[15,16]}$. The chemical vapor deposition of mullite and aluminosilicates from chloride mixtures has been examined by several investigators. The preparation of mullite powder by chemical vapor deposition from $\mathrm{SiCh} / \mathrm{AlCl}_{3} / \mathrm{O}_{2}$ mixtures was addressed in Refs. 10 and 11, and results on the effects of temperature, pressure, and feed concentration on the preparation of films of mullite and aluminosilicates though hydrolysis of chlorides have been presented in Refs. 12-15 and 17-19. Films and coatings of aluminum oxide are used in several applications ranging from protective coatings to films in microelectronics, and CVD from $\mathrm{AlCl}_{3}$, with $\mathrm{O}_{2}, \mathrm{H}_{2} \mathrm{O}$, or $\mathrm{CO}_{2} / \mathrm{H}_{2}$ as oxygen source, has been the most commonly used method for their preparation ${ }^{[20-26]}$. Silica is also of interest as a film or coating material in many applications, including separation of gaseous mixtures using permselective membranes and microelectronic components ${ }^{[27-29]}$. As in the case of alumina, CVD is a frequently used method for the preparation of silica films from a variety of precursors, such as tetraethoxysilane (TEOS) and $\mathrm{SiCh}_{4}$ with some oxygen-containing compound.

In a previous study ${ }^{[17]}$, we investigated the deposition of aluminosilicate species from $\mathrm{MTS} / \mathrm{AlCl}_{3} / \mathrm{CO}_{2} / \mathrm{H}_{2}$ mixtures. Methyltrichlorosilane was used as silicon source because it gave relatively high deposition rate as silicon source in silica deposition experiments. It was found that the codeposition rate could be much higher than the sum of the deposition rates of the two oxides in independent experiments at the same operating conditions. However, the elemental analysis of the films showed that this rise in the deposition rate was accompanied by a dramatic increase in the deposition rate of silica and a decrease in the deposition rate of alumina. Even at conditions where the deposition rate of pure alumina was much higher than that of pure silica, the codeposit consisted mainly of $\mathrm{SiO}_{2}$.

The chemical vapor codeposition of alumina, silica, mullite and other aluminosilicates from mixtures of methyltrichlorosilane (MTS), aluminum trichloride, 
carbon dioxide, and hydrogen is investigated further in this study. Particular emphasis is placed on the effects of the residence time of the mixture in the reactor since results of Ref. 17 indicated that the deposition rate and the deposit stoichiometry could vary significantly with the position in the reactor. In order to measure the deposition rate and the composition of the deposit at different locations, deposition experiments are carried out on SiC-coated refractory wires placed along the centerline of a tubular, hot-wall CVD reactor. Results are also presented on the deposition of single oxides, $\mathrm{SiO}_{2}$ and $\mathrm{Al}_{2} \mathrm{O}_{3}$, through hydrolysis of methyltrichlorosilane and aluminum trichloride, respectively. Comparable feed concentrations of the chlorides (MTS and $\mathrm{AlCl}_{3}$ ) were employed in the experiments of Ref. 17. In an effort to circumvent the enhancement of $\mathrm{SiO}_{2}$ deposition in the codeposition process and be able to obtain higher $\mathrm{Al} / \mathrm{Si}$ ratios in the deposits, larger feed concentrations of $\mathrm{AlCl}_{3}$ than those of MTS are used in the present study, and the effects of the various processing parameters (temperature, pressure, and feed composition) and residence time (total gas flow rate and substrate position in the reactor) on the deposition rate and the composition of the deposits are studied. The composition of the films is determined using energy dispersive X-ray analysis (EDXA). The observed

patterns of behavior are discussed on the basis of past experimental studies and thermochemical equilibrium results.

\section{Experimental Results}

\subsection{Effects of Reaction Conditions}

The reactor is a quartz tube with $15 \mathrm{~mm}$ internal diameter, heated in tubular furnace. The distance of deposition location that is reported in the figures is measured by taking the beginning of the heating zone as a reference point. This point almost coincides with the beginning of the isothermal zone of the reactor, which has a length of about 23 $\mathrm{cm}$. In the section that precedes the isothermal zone, the temperature rises almost linearly from about $50 \%$ of its set point value (in $\mathrm{K}$ ) to the set point within a distance of $7 \mathrm{~cm}$. The curve labeled composite in some figures gives the sum of the deposition rates of silica and alumina in independent deposition experiments from mixtures containing only one metal chloride at the same conditions as in the codeposition process. The points 
shown in the figures are those obtained in the experiments. The curves passing through them or around them are those produced by the plotting software as guides to the eye.

Results on the effect of temperature on the deposition rates of the three processes are presented in Figure 1 in Arrhenius-plot coordinates $\left(\ln R_{d}\right.$ vs. $1 / T$, with $R_{d}$ being the deposition rate and $\mathrm{T}$ the absolute temperature in the reactor). The temperature varied between 1123 and $1373 \mathrm{~K}\left(850\right.$ and $\left.1100^{\circ} \mathrm{C}\right)$ at $50 \mathrm{~K}$ steps. The mole fractions of the source gases were 0.011 MTS ( $\left.\mathrm{x}_{\mathrm{MTS}}\right), 0.027 \mathrm{AlCl}_{3}\left(\mathrm{x}_{\mathrm{AlCl} 13}\right)$, and $0.072 \mathrm{CO}_{2}\left(\mathrm{x}_{\mathrm{CO} 2}\right)$, the operating pressure $13.3 \mathrm{kPa}$ (100 Torr), and the total flow rate $250 \mathrm{~cm}^{3} / \mathrm{min}$. The effects revealed by the results of Figure 1 are qualitatively similar to those reported in Ref. 17 at other conditions. For all three cases, an increase in temperature leads to an increase in the deposition rate. The deposition of $\mathrm{SiO}_{2}$ proceeds at relatively low rates for temperatures below $1173 \mathrm{~K}$. An apparent activation energy, slope of the $\ln R_{d}$ vs. $1 / T$ curve $\left(E_{\text {app }}\right)$, of $28 \mathrm{kcal} / \mathrm{mol}$ is calculated by employing linear regression, a value that is by $7.8 \%$ higher than the $E_{a p p}$ calculated in Ref. 17 but at a larger distance from the entrance of the reactor $(7 \mathrm{~cm})$. The temperature of operation has a much stronger effect on the rate of alumina deposition above $1173 \mathrm{~K}$. This behavior may be related to the observation that the formation of water from $\mathrm{CO}_{2}$ and $\mathrm{H}_{2}$ proceeds at significant rates only at temperatures greater than $1173 \mathrm{~K}^{[27]}$. It has been reported that the chemical vapor deposition of alumina does not depend only on water formation in the gas phase ${ }^{[20]}$. According to Choi et al. ${ }^{[31]}$, alumina CVD is a thermally activated process limited by surface reactions. The experimental data of Figure 1 yield an activation energy of 11.4 $\mathrm{kcal} / \mathrm{mol}$, which is much smaller than the activation energy for the water gas-shift reaction $(78 \mathrm{kcal} / \mathrm{mol})^{[25]}$. For the codeposition process, the corresponding value of activation energy is $22.1 \mathrm{kcal} / \mathrm{mol}$. It must be pointed out that these values of activation energy should be viewed as being representative of the overall temperature effect on the process and on its intrinsic kinetics. Not only the deposition process proceeds through a large number of homogeneous and heterogeneous chemical reactions, but also the concentrations of the actual deposition precursors at a certain location depend on the history of the gaseous mixture in the upstream section of the reactor and, thus, vary with the temperature. 
The effect of pressure on the deposition rate of the single oxides and the codeposition rate is shown in Figure 2. These data were obtained by varying the system pressure between 10 and $39.9 \mathrm{kPa}$ (75 and 300 Torr) at $1273 \mathrm{~K}$ and $250 \mathrm{~cm}^{3} / \mathrm{min}$ total flow rate. The $\mathrm{Al} / \mathrm{Si}$ feed ratio of the source gases was 2.5 (0.027 $\mathrm{AlCl}_{3}$ mole fraction, 0.011 MTS mole fraction), and $\mathrm{CO}_{2}$ was introduced at 0.072 mole fraction. As the pressure in increased, the deposition rate of silica increases, eventually going through a maximum. In the variation of the deposition rate of alumina, the increase is followed by the attainment of a "plateau" value. The reported results on the variation of the deposition rate of alumina with the pressure vary among different studies, both qualitative and quantitatively. Colmet and Naslain ${ }^{[24]}$ found that the deposition rate of $\mathrm{Al}_{2} \mathrm{O}_{3}$ increases linearly as a function of the total pressure up to $101.3 \mathrm{kPa}$ (1 atm), while Funk et al. $^{[21]}$ reported a maximum in the deposition rate between 6.65 and $13.3 \mathrm{kPa}-$ depending on the operating conditions -- and a decrease down to zero at higher pressures (above $26.6 \mathrm{kPa}$ ). The formation of powder because of higher residence times of the reactive mixture in the reactor was proposed as the reason for this drop. Park et al. ${ }^{[32]}$ observed a behavior, which is similar to that seen here. It must be noted that powder formation was not observed at the exit of the reactor at the conditions used in our experiments. The deposition rate in the codeposition process increases monotonically with increasing pressure in the pressure range covered by our experiments. However, the positive effect of pressure on it becomes weaker at higher pressures, and thus, a maximum may be present at pressures above $40 \mathrm{kPa}$.

The positive effect of pressure on the deposition rate may be the result of higher concentrations of reactive species in the feed and higher concentrations of actual deposition precursors at the reactive sites because of larger residence time of the mixture in the upstream section of the reactor. Large residence time of the mixture in the reactor and high deposition rate can also lead to increased concentrations of reaction byproducts in the reactor and depletion of the gas phase of actual deposition precursors at locations away from the entrance of the reactor. Both of these occurrences may offset the aforementioned positive effects and cause decrease of the deposition rate and appearance of a maximum. Thermodynamic analysis shows that hydrogen chloride is the main byproduct in the three deposition processes, and this is in accordance with the results of 
several experimental studies. The effect of increasing hydrogen chloride concentration on the rate of silica deposition has been examined by adding hydrogen chloride to a MTS $/ \mathrm{CO}_{2} / \mathrm{H}_{2}$ mixture of constant flow rate and composition, thus simulating various levels of reactant depletion. Some results are presented in Figure 3, where it is seen that the deposition rate decreases as the partial pressure of hydrogen chloride in the reactor feed stream increases. The effect is stronger at the lower temperature $(1223 \mathrm{~K})$, where the deposition rate decreases by more than $90 \%$ at about $9 \% \mathrm{HCl}$ in the feed.

The effect of the $\mathrm{AlCl}_{3} / \mathrm{MTS}(\mathrm{Al} / \mathrm{Si})$ feed ratio on the reactivity of the codeposition process is examined in Figure 4. The variation in the $\mathrm{Al} / \mathrm{Si}$ feed ratio was accomplished by changing the $\mathrm{AlCl}_{3}$ mole fraction, while keeping the MTS mole fraction constant. Two $\mathrm{MTS} / \mathrm{CO}_{2}$ mole fraction ratios were employed in the experiments: 0.011/0.072 and 0.007/0.072. At the low value $\mathrm{MTS} / \mathrm{CO}_{2}$ mole fraction ratio, deposition rate data were obtained for both increasing and decreasing aluminum trichloride mole fraction. (The arrows denote direction of $\mathrm{Al} / \mathrm{Si}$ ratio change.) Figure 4 shows that when only MTS is present in the system $(\mathrm{Al} / \mathrm{Si}=0)$, the deposition proceeds at a relatively low rate. The introduction of a small amount of $\mathrm{AlCl}_{3}$ in the feed $(\mathrm{Al} / \mathrm{Si}=0.4)$ results in a significant increase of the codeposition rate, especially in the case of the high $\mathrm{MTS} / \mathrm{CO}_{2}$ mole fraction ratio. Further increase of the $\mathrm{AlCl}_{3} / \mathrm{MTS}$ ratio has, in general, a positive effect on the deposition rate. However, in some cases the deposition rate presented large and abrupt changes as the $\mathrm{Al} / \mathrm{Si}$ ratio was varied, especially for relatively high values of $\mathrm{Al} / \mathrm{Si}$ ratio. A case where such a situation was encountered in shown in Figure 4. The only difference between that case and the other case shown in the figure, in which smooth variation of the deposition rate is observed, is the concentration of MTS in the feed. Experiments at the conditions of Figure 4 and at other conditions showed that this phenomenon could be reproduced in different runs but the $\mathrm{Al} / \mathrm{Si}$ ratios at which the various jumps occurred varied among different experiments. Similar abrupt changes were observed in the case of $\mathrm{SiC}$ and $\mathrm{C}$ codeposition from chlorosilane (MTS or $\mathrm{SiCh}_{4}$ ) and hydrogen mixtures ${ }^{[33-35]}$, and there were found to be a manifestation of the existence of multiple steady states. The appearance of multiple steady states is not an uncommon occurrence in complex heterogeneous reaction systems and should be examined as a possible cause of the apparently aberrant behavior shown in Figure 4. It must be pointed 
out that at all other conditions we investigated in our study, the obtained experimental data exhibited excellent reproducibility and repeatability characteristics. This issue is addressed in some detail in Ref. 17.

The strong effect of the presence of $\mathrm{AlCl}_{3}$ in the gas phase on the codeposition rate indicates that reaction steps involving both aluminum and silicon species on the surface must be present in the heterogeneous chemistry mechanism of the process. These steps must proceed at rates much higher than the steps involved in the deposition of the single oxides $\left(\mathrm{SiO}_{2}\right.$ and $\left.\mathrm{Al}_{2} \mathrm{O}_{3}\right)$ since as it is seen in Figures 1 and 2, the codeposition rate is by a large factor (of more than 3 in some cases) larger than the sum of the deposition rates of $\mathrm{SiO}_{2}$ and $\mathrm{Al}_{2} \mathrm{O}_{3}$ in independent experiments (composite curve), in agreement with the observation made in Ref. 17. As it will be reported in the next section when we discuss the effects of flow rate and position in the reactor on the deposition process, the increase in the deposition rate upon the introduction of $\mathrm{AlCl}_{3}$ in the feed is solely due to an increase in the deposition rate of $\mathrm{SiO}_{2}$. The aluminum content of the codeposit is very low corresponding to deposition rates of $\mathrm{Al}_{2} \mathrm{O}_{3}$ much lower than those seen in pure alumina deposition experiments. As it was mentioned in the introductory section of this study, this observation was also made in our previous study ${ }^{[17]}$.

\subsection{Effects of Flow rate and Position in the Reactor}

Results on the effects of flow rate on the deposition rate are presented in Figures 5 and 6 for four temperatures $(1223,1273,1323$, and $1373 \mathrm{~K}), 13.3 \mathrm{kPa}$ system pressure, 0.011 MTS mole fraction, and $0.027 \mathrm{AlCl}_{3}$ mole fraction. The results show that the way in which the $\mathrm{SiO}_{2}$ deposition rate varies with the total flow rate depends strongly on temperature. At 1223 and $1273 \mathrm{~K}$, an increase of the flow rate leads to a decrease in the deposition rate of $\mathrm{SiO}_{2}$ over the whole flow range covered in our experiments, but at the other two temperatures, a pronounced maximum is present in its variation. A maximum is also present in the variation of the codeposition rate, whereas the rate of deposition of alumina increases continuously, in general, with the flow rate, with the increase being more pronounced at the low end of the flow rate range.

A change in the flow rate affects the residence time of the mixture in the reactor, but also the mass transfer coefficient of the actual deposition precursors (i.e., the species 
adsorbed on the surface of the substrate) from the gas phase to the deposition surface. Silvestri et al. ${ }^{[22]}$ observed increasing deposition rate of alumina with increasing flow rate, as in Figures 5 and 6, and they attributed it to the existence of mass transport limitations. In the present study, deposition rate measurements at the same axial distance of the reactor were carried out using both flat substrates and wires aligned along the axis of the reactor. The measured rates were similar, and since the mass transfer coefficient is influenced not only by the flow rate but also by the local geometry of the surface, this led us to conclude that mass transfer limitations did not play an important role in our experiments. It should be noted that if the mass transfer resistance controlled to a significant degree the overall reaction rate, then it would not be possible to obtain the high rates seen in the codeposition process. The main product of the codeposition reaction is $\mathrm{SiO}_{2}$, and therefore, the species involved must be the same as those in the pure silica deposition experiments, where the reaction rate is much lower.

The position of the substrate in the CVD reactor is another parameter that has a strong effect on the residence time of the reactants. The effect of substrate location on the deposition rate is shown in Figures 7 and 8. The zero position corresponds to the beginning of the heating zone of the reactor, and hence, negative position values refer to the part of the reactor tube that is located before the heating zone. To obtain these data, deposition experiments were conducted on molybdenum wires placed along the centerline of the reactor. A total flow rate of $400 \mathrm{~cm}^{3} / \mathrm{min}$ was employed in most of the experiments, which were carried out at $13.3 \mathrm{kPa}$ and four temperatures (1223, 1248, 1273 , and $1300 \mathrm{~K})$. As explained in the experimental section, the reactor temperature is practically uniform (within $\pm 5 \mathrm{~K}$ of the set point temperature) within the heating zone of the reactor (between 0 and $23 \mathrm{~cm}$ ), and therefore, variations in the deposition rate within this range are not caused by temperature variations.

It is seen in Figure 7 that the deposition rate profiles of all three deposition processes present a maximum close to the middle of the isothermal zone. In the case of alumina deposition, this maximum is less pronounced, and it is flanked by two smaller maxima. The first of these maxima must be due to the rise of the temperature to its set point in the entry section of the reactor. The deposition rate of alumina does not vary significantly over the isothermal section of the reactor, and this is in agreement with the 
rather weak effect of flow rate on it that was seen in Figures 5 and 6 . The presence of a minimum in the variation of the rate of alumina deposition with the distance in the reactor indicates that it is possible to have a situation where the alumina deposition rate does not vary monotonically with parameters leading to decrease of the residence time.

Within the first $3.5 \mathrm{~cm}$ of the hot zone, an increase in the distance from the entrance of the reactor does not affect significantly the rate of $\mathrm{SiO}_{2}$ deposition. Further increase in the distance has a positive effect on the rate, which attains a maximum at about $9 \mathrm{~cm}$. After the maximum, the rate drops relatively fast with the distance, attaining values lower than those at the inlet of the reactor before the end of the isothermal zone. The deposition rate at the maximum is by about a factor of 5 greater than the average rate of deposition in the beginning of the reactor (between 0 and $5 \mathrm{~cm}$ ). This clearly indicates that there is strong influence of residence time on the deposition rate of silica. The deposition rate of $\mathrm{SiO}_{2}$ at $4 \mathrm{~cm}$ agrees well with that measured under the same conditions in deposition experiments on flat substrates ${ }^{[17]}$, and his leads to the conclusion that the geometry of the substrate does not have a strong effect on the deposition rate.

As in Figures 1 and 2, the sum of the rates of the single oxides along the reactor (composite curve in Figure 7) is significantly lower than the respective codeposition rates. The codeposition rate increases sharply with increasing the distance from the entrance of the reactor, and it exhibits a maximum at around $11 \mathrm{~cm}$. Figure 8 shows that similar codeposition rate profiles were obtained at other deposition temperatures. The maximum in the deposition rate is shifted towards lower locations in the reactor as the operating temperature is increased. The values of deposition rate at positions before the beginning of the heating zone (corresponding to negative locations in the figure) are relatively low at the temperature range 1223-1273 K. However, even in those cases, these deposition rates cannot be considered negligible in comparison to the rates measured at locations within the isothermal zone. Since it is the products of the gas phase reactions that serve as actual deposition precursors and not the species fed into the chemical reactor, this observation suggests that the occurrence of any chemical reactions in the entry section of the reactor before the isothermal hot zone may have significant effects on the deposition rate profile in the isothermal zone. 
Figure 8 also presents results on the effect of the feed mole fraction of $\mathrm{AlCl}_{3}$ and of the flow rate on the deposition rate profile in the codeposition process. Increasing the flow rate from 400 to $500 \mathrm{~cm}^{3} /$ min decreases markedly the deposition rate over the whole length of the chemical reactor. This behavior is in agreement with the observation made earlier during discussion of the total flow rate effects at a fixed location (Figures 5 and 6) that the codeposition rate decreases with increasing flow rate beyond $400 \mathrm{~cm}^{3} / \mathrm{min}$. It was seen in Figure 4 that the codeposition rate decreases with decreasing $\mathrm{AlCl}_{3}$ mole fraction in the feed. The two codeposition curves of Figure 8 at $1223 \mathrm{~K}$ show that this happens up to a distance of about $15 \mathrm{~cm}$, beyond which the opposite trend is presented. This behavior could be caused by higher concentrations of $\mathrm{HCl}$ in the lower part of the reactor with increasing concentration of $\mathrm{AlCl}_{3}$ in the feed.

\subsection{Variation of Deposit Composition.}

The morphology and the structure of the deposits were analyzed using X-ray diffraction (XRD) and scanning electron microscopy (SEM). The obtained results were in agreement with those reported in Ref. 17. The alumina deposits were crystalline, consisting mainly of $\mathrm{Al}_{2} \mathrm{O}_{3}$, whereas the silica deposits and the codeposits were amorphous. The surface of the silica films and of the codeposited films was smooth and exhibited nodular structure, with average nodule size varying from 20 to $50 \mu \mathrm{m}$. Large nodules of about the same average size could also be distinguished on the surface of the alumina films, but these films they were not smooth and appeared to consist of clearly distinguishable small grains.

The elemental composition of the codeposited films was determined using energy dispersive $\mathrm{X}$-ray analysis (EDXA). $\mathrm{Si}, \mathrm{Al}$, and $\mathrm{O}$ were found to be the only elements present in appreciable quantities in the deposits, and their relative amounts were consistent with the stoichiometry of mixtures of $\mathrm{SiO}_{2}$ and $\mathrm{Al}_{2} \mathrm{O}_{3}$. In agreement with the results obtained in Ref. 17, the codeposits obtained at locations in the isothermal zone away from the entrance of the reactor consisted primarily of $\mathrm{SiO}_{2}$. The aluminum content of the deposit increased towards the entrance of the reactor, reaching in the vicinity of the beginning of the heating zone values close to that corresponding to mullite $(\mathrm{Al} / \mathrm{Si} \dot{(m u l l i t e}=3)$. This behavior may be seen in Figure 9 , which shows the variation of the 
$\mathrm{Al} / \mathrm{Si}$ deposit ratio with the distance in the reactor for four temperatures $(1223,1248$, 1273 , and $1300 \mathrm{~K}$ ) at $13.3 \mathrm{kPa}$ and $400 \mathrm{~cm}^{3} / \mathrm{min}$ total flow rate. Lower deposition temperatures result in higher $\mathrm{Al} / \mathrm{Si}$ deposit ratios along the reactor, especially at the beginning of the isothermal heating zone. The $\mathrm{Al} / \mathrm{Si}$ ratio decreases fast with increasing distance from the entrance of the reactor. For example, at $1223 \mathrm{~K}$, the $\mathrm{Al} / \mathrm{Si}$ deposit ratio decreases from 1.5 at the top of the heating zone to 0.1 at the bottom of the zone $(23 \mathrm{~cm})$.

The strong effect of distance on the stoichiometry of $\mathrm{SiO}_{2}$ and $\mathrm{Al}_{2} \mathrm{O}_{3}$ in the deposit suggests that it may be possible to modify the composition of the deposit by manipulating the residence time of the mixture in the reactor. According to the results of Figure 9, if the objective is the preparation of films with $\mathrm{Al}$ content comparable to or higher than that of mullite, the CVD reactor should be operated at relatively low residence times or the reaction temperature should be reduced. The same conclusions were reached from experiments conducted at other flow rates. Figure 10 presents $\mathrm{Al} / \mathrm{Si}$ ratio in the deposit vs. position results within the isothermal zone of the reactor at the same conditions as in Figure 9 but with $500 \mathrm{~cm}^{3} / \mathrm{min}$ total flow rate. A relatively large decrease of the $\mathrm{Al}$ content of the deposit occurs at all locations as the temperature changes from 1148 to $1300 \mathrm{~K}$, but at the two lower temperatures (1123 and $1148 \mathrm{~K})$, the Al content of the deposit decreases with the temperature only at locations away from the entrance of the reactor. The comparison of the results of Figures 9 and 10 shows that at the same reaction temperature and at the same location in the reactor, the $\mathrm{Al} / \mathrm{Si}$ ratio in the deposit is larger for $500 \mathrm{~cm}^{3} / \mathrm{min}$ flow rate. This result is in agreement with the decrease of the $\mathrm{Al}$ content of the deposit with the distance in the reactor since an increase in the total flow rate brings about a decrease in the residence time of the mixture upstream of the deposition location.

The deposition rate data of Figure 8 and the composition data of Figure 9 were used to determine the rates of $\mathrm{SiO}_{2}$ and $\mathrm{Al}_{2} \mathrm{O}_{3}$ incorporation in the deposit in the codeposition process as functions of the distance from the entrance of the reactor. The obtained results are presented in Figure 11. Because of the relatively steep drop of the Al content of the deposit in the entry section of the reactor, the primary content of the deposit in the most part of the isothermal zone is $\mathrm{SiO}_{2}$, especially at the highest temperature used in our experiments, viz., $1300 \mathrm{~K}$. The results of Figure 7 show that in 
single species deposition experiments at the same reaction conditions as in the codeposition process, the deposition rate of alumina at $1300 \mathrm{~K}$ in an independent deposition experiment is much higher than that of $\mathrm{SiO}_{2}$ over the whole length of the reactor except at a very small section close to its middle. One would therefore expect the codeposit to consist primarily of $\mathrm{Al}_{2} \mathrm{O}_{3}$ if $\mathrm{Al}$ and $\mathrm{Si}$ were incorporated in the deposit at rates proportional to those measured in independent silica and alumina deposition experiments. As it was seen in Figures 1, 2, and 7, the codeposition process is characterized by a dramatic rise of the deposition rate relative to the sum of the deposition rates of silica and alumina in independent deposition experiments at the same conditions. The results of Figures 9 and 11 clearly show that this increase in the deposition rate is due to a dramatic increase in the rate of $\mathrm{SiO}_{2}$ incorporation of the deposit. The rate of incorporation of $\mathrm{Al}$ in the deposit in the codeposition process is comparable to, and in some cases lower than (see Figures 7 and 11), the corresponding rate in alumina deposition under the same conditions. Similar observations were also made in Ref. 17, where, because of the use of comparable concentrations of MTS and $\mathrm{AlCl}_{3}$ in the feed, the codeposit contained more than $95 \% \mathrm{SiO}_{2}$ (on a weight basis) even in cases where the independent deposition rates of $\mathrm{SiO}_{2}$ and $\mathrm{Al}_{2} \mathrm{O}_{3}$ were comparable.

\section{Discussion of the Results}

Several factors can influence the variation of the deposit composition and of the deposition rate in the codeposition process with the distance in the reactor. The actual precursors for $\mathrm{Si}, \mathrm{Al}$, and $\mathrm{O}$ incorporation in the deposit are not the species fed into the chemical reactor, i.e., metal chlorides and $\mathrm{CO}_{2}$, but several species formed in a large set of chemical reactions that take place in the gas phase of the reactor. In addition to species that adsorb on the surface of the substrate and thus serve as vehicles for $\mathrm{Si}, \mathrm{Al}$, and $\mathrm{O}$ incorporation in the deposit, the gas phase reactions also form species that are products of the heterogeneous reactions that produce $\mathrm{SiO}_{2}$ and $\mathrm{Al}_{2} \mathrm{O}_{3}$ on the surface, such as $\mathrm{HCl}$. Because of their effects on the reverse rates of the solid product formation reactor, these species have an inhibitory effect on the rates of solid deposition, which should intensify as their concentrations increase, that is, with increasing distance from the entrance of the reactor. 
The production of $\mathrm{HCl}$ and of other product species in the gas phase and the increase of their concentrations with the residence time of the mixture in the reactor must be one of the main reasons for the decrease of the deposition rate close to the exit of the reactor inside the isothermal region. On the other hand, the initial increase with the distance of the deposition rate in the entry section of the reactor should chiefly be due to the combined effect of the increase of the temperature (outside the isothermal zone) and of the concentrations of the actual precursors of deposition (gas phase species). As deposition takes place, $\mathrm{Si}, \mathrm{Al}$, and $\mathrm{O}$ are transferred from the gas phase to the walls of the reactor, and thus, the concentrations of the actual deposition precursors should eventually start to decrease with the distance from the entrance of the reactor. Therefore, the decrease of the deposition rate with the distance at the lower part of the reactor could also be caused by lower concentrations of deposition precursors.

Figure 12 shows results for the amount of $\mathrm{Si}$ and $\mathrm{Al}$ left in the reactor as a function of distance from its entrance for the codeposition experiments of Figure 8 at 1223,1273 , and $1300 \mathrm{~K}$. These curves were constructed using the deposition rate data of Figure 8 and the deposit composition data of Figure 9 under the assumption that at a given distance from the entrance of the reactor, deposition occurred on the reactor walls at the same rate and with the same deposit composition as on the refractory wire. (This assumption was verified by measuring the deposition rate and analyzing the deposit at the wall at a few locations in some deposition experiments.) The results of Figure 12 indicate that there is significant reduction of $\mathrm{Si}$ in the reactive mixture between the upper and the lower part of the isothermal heating zone, and this phenomenon intensifies with increasing temperature. At $1300 \mathrm{~K}$ the depletion of $\mathrm{Si}$ from the gas phase at $23 \mathrm{~cm}$ is approximately 95\%. On the other hand, the $\mathrm{Al}$ content of the gas phase is reduced by less than $15 \%$ over the entire length of the reactor, even at high temperatures. Since much smaller deposition rates are encountered in the single oxide deposition experiments (see Figures 1,2, and 7), the $\mathrm{Al}$ and $\mathrm{Si}$ depletion levels in those cases are much lower.

Since the $\mathrm{Al} / \mathrm{Si}$ ratio of the deposit is lower than that of the feed mixture, the $\mathrm{Al} / \mathrm{Si}$ ratio in the gaseous mixture increases towards the exit of the reactor. However, despite this increase, the $\mathrm{Al} / \mathrm{Si}$ ratio in the deposit decreases monotonically with the axial distance even at $1300 \mathrm{~K}$ where, because of the very high depletion levels of $\mathrm{Si}$, the $\mathrm{Al} / \mathrm{Si}$ 
ratio in the gas phase attains very high values. Using a computational scheme based on free energy minimization and a large database of thermodynamic properties of gaseous stable species, computations of thermochemical equilibrium in the $\mathrm{Al} / \mathrm{Si} / \mathrm{C} / \mathrm{O} / \mathrm{H} / \mathrm{Cl}$ system were carried out in Ref. 17, and the results were employed to elucidate the origins of some of the effects of the operating conditions on the behavior of the process. The same procedure was also used in the same study to investigate how the removal of $\mathrm{Al}, \mathrm{Si}$, and $\mathrm{O}$ from the gas phase, through deposition of solid material, influences the concentration of the species present in the gas phase at equilibrium. Results are presented in Figure 13 for the variation of the concentrations of the main components of the equilibrated gas phase with the fraction of $\mathrm{Al}$ left in it in the codeposition process at the conditions of Figure 7. To obtain the results shown in the figure, it was assumed that the removal of $\mathrm{Al}$ from the gas phase was accompanied by those of $\mathrm{Si}$ and $\mathrm{O}$ at the proportion that corresponds to deposition of mullite $\left(\mathrm{Al}_{6} \mathrm{Si}_{2} \mathrm{O}_{13}\right)$. However, similar results, in a qualitative sense, were obtained assuming other ratios of $\mathrm{SiO}_{2}$ and $\mathrm{Al}_{2} \mathrm{O}_{3}$ in the deposit. It is seen in Figure 13 that as more mullite is deposited on the wall, the concentrations of aluminum gas phase species decreases, whereas those of silicon species rise. This behavior is obviously consistent with the influence of the distance from the entrance of the reactor on the composition of the deposit.

The thermochemical equilibrium computations in Ref. 17 revealed that when both $\mathrm{AlCl}_{3}$ and $\mathrm{SiCl}_{4}$ are sent through the chemical reactor, the equilibrium concentration of $\mathrm{HCl}$ is for comparable mole fractions of chlorides in the feed similar to that in the $\mathrm{MTS} / \mathrm{H}_{2} / \mathrm{CO}_{2}$ system and much higher than that in the $\mathrm{AlCl} / \mathrm{H}_{2} / \mathrm{CO}_{2}$ system. This observation led us to conclude that the suppression of the deposition of $\mathrm{Al}_{2} \mathrm{O}_{3}$ in the codeposition process relative to the rates measured in independent alumina deposition experiments could also be caused by the increased concentration of $\mathrm{HCl}$. The inhibition of the incorporation of $\mathrm{Al}$ in the deposit by the presence of $\mathrm{HCl}$ could also be the reason for the decreasing $\mathrm{Al} / \mathrm{Si}$ ratio in the deposit along the length of the reactor. As Figure 13 shows, the equilibrium concentration of $\mathrm{HCl}$ increases significantly as $\mathrm{Al}, \mathrm{Si}$, and $\mathrm{O}$ are removed from the gas phase. It should be noted that the concentration of $\mathrm{HCl}$ would increase continuously away from the entrance of the reactor even if gas phase equilibrium is not attained in the gas phase. $\mathrm{HCl}$ is the product of several gas phase reactions and of 
the reaction steps that lead to solid deposition, and therefore, it accumulates in the gas phase as the reactive mixture moves away from the entrance of the reactor.

At a given temperature of operation, the pressure in the reactor is another parameter that affects strongly the residence time of the mixture in the high temperature environment upstream of the location of deposition. The residence time decreases with decreasing pressure, and therefore, based on the deposit composition results of Figures 9 and 10, it is expected the content of the deposit in $\mathrm{Al}$ to increase with decreasing pressure of operation. Figure 14 shows the codeposition rate profile and the profiles for the rates of incorporation of $\mathrm{SiO}_{2}$ and $\mathrm{Al}_{2} \mathrm{O}_{3}$ in the deposit at $10 \mathrm{kPa}$ (75 Torr) pressure at the same conditions as the profiles given by solid curves in Figure 11. The comparison of the results of the two figures shows that operation at a lower pressure yields lower codeposition rate at all locations. However, in agreement to what is expected on the basis of the effects of location of deposition and flow rate, the profiles of the rates of incorporation of $\mathrm{Al}_{2} \mathrm{O}_{3}$ and $\mathrm{SiO}_{2}$ in the deposit indicate that a dramatic rise takes place in the $\mathrm{Al} / \mathrm{Si}$ ratio of the deposit at all locations in the reactor at the lower pressure. This observation offers further support to the conclusion that in order to obtain deposits rich in $\mathrm{Al}_{2} \mathrm{O}_{3}$, it would be necessary to carry out the deposition process at conditions that yield relatively low values of residence time.

\section{Summary and Conclusions}

The effects of reaction conditions and residence time on the deposition of alumina, silica, and aluminosilicates from mixtures of $\mathrm{MTS}, \mathrm{AlC}_{3}, \mathrm{CO}_{2}$, and $\mathrm{H}_{2}$ were investigated using a hot-wall reactor of tubular configuration coupled to an electronic microbalance. Local deposition rates were measured using small SiC substrates hung from the sample arm of the microbalance. Deposition experiments were also carried out on thin refractory wires placed along the centerline of the reactor in order to obtain information on the profiles of the deposition rate and deposit composition along the reactor in a single experiment.

The experimental results showed that an increase in temperature had a positive effect on the rate of codeposition and the rates of deposition of the two oxides in independent experiments. The deposition rate of the three CVD processes generally 
increased with increasing pressure, and this effect was stronger at low pressures. The codeposition rate also increased with increasing $\mathrm{Al} / \mathrm{Si}$ ratio in the feed at constant $\mathrm{SiCl}_{4}$ and $\mathrm{CO}_{2}$ mole fractions. However, in some cases, the codeposition rate was observed to go through large and abrupt changes (increase or decrease) as the $\mathrm{Al} / \mathrm{Si}$ ratio was varied. While this phenomenon could be qualitatively reproduced in the range of conditions it was observed, the quantitative reproducibility of the observed increases or decreases of the deposition rate was rather poor. Similar abrupt changes were observed in the case of $\mathrm{SiC}$ and $\mathrm{C}$ codeposition from chlorosilane (MTS or $\mathrm{SiCh}_{4}$ ) and hydrogen mixtures ${ }^{[33-35]}$, and there were found to be a manifestation of the existence of multiple steady states. The possibility of having the occurrence of this phenomenon in the present system deserves investigation.

The distance in the CVD reactor and the flow rate had a strong influence on the reactivity. The variation of silica deposition with the total flow rate showed a maximum at temperatures above $1300 \mathrm{~K}$ but decreased monotonically with it at lower temperatures. The alumina deposition rate was positively affected by the total flow rate, whereas the codeposition rate exhibited a maximum at the range between 300 and $400 \mathrm{~cm}^{3} / \mathrm{min}$. The profile of the deposition rate along the reactor in all three deposition processes exhibited a pronounced maximum, located around the middle of the isothermal zone. The rate of incorporation of $\mathrm{SiO}_{2}$ in the codeposited films was typically much higher than the rate of silica deposition in an independent deposition experiment at the same conditions, whereas the incorporation rate of $\mathrm{Al}_{2} \mathrm{O}_{3}$ was comparable to or lower than the rate of alumina deposition at the same conditions.

The analysis of the composition of the codeposits showed that the content in $\mathrm{Al}_{2} \mathrm{O}_{3}$ increased towards the entrance of the reactor, and it could reach in the beginning of the isothermal zone of the reactor levels close to those corresponding to mullite. Even though relatively high $\mathrm{Al} / \mathrm{Si}$ ratios were used in the feed, the $\mathrm{Al}_{2} \mathrm{O}_{3}$ content of the deposit dropped fast with increasing distance from the entrance of the reactor. Lowering the deposition temperature was found to have a positive effect on the $\mathrm{Al} / \mathrm{Si}$ ratio in the deposit. However, the $\mathrm{Al}_{2} \mathrm{O}_{3}$ content of the deposit was more strongly affected by factors influencing the residence time of the mixture of the reactor, such as the pressure, the flow rate, and the distance from the entrance of the reactor; in general, it increased in the 
direction of decreasing residence time. Therefore, it may be possible to circumvent the effects of the enhancement of the deposition rate of Si-containing phases in the presence of $\mathrm{AlCl}_{3}$ in the feed and direct the composition of the deposit towards mullite and alumina-rich mullite by decreasing the residence time of the reactive mixture in the heating zone. Another possibility would be to employ relatively low deposition temperatures.

\section{Experimental}

Deposition experiments were carried out in a vertical hot-wall reactor coupled with a sensitive microbalance ( $1 \mu \mathrm{g}$ sensitivity), used for continuous monitoring of the weight of the deposit. Some information on the CVD system for deposition from $\mathrm{MTS} / \mathrm{AlCl}_{3} / \mathrm{CO}_{2} / \mathrm{H}_{2}$ mixtures is given in Ref. 17. A bubbler with flow rates of vapor and carrier gas controlled by mass flow controllers was used for the supply of methyltrichlorosilane in the reactor, and aluminum trichloride was formed in situ in a packed-bed reactor (chlorinator) through the reaction of hydrogen chloride with high purity aluminum granules. The flow rates of all gaseous streams were controlled by mass flow controllers.

The pressure in the deposition chamber was measured at the inlet of the CVD reactor using a capacitance manometer, and it was regulated by a throttling valve controlled by a pressure controller. Subambient pressures were generated using a mechanical vacuum pump, and the pump and the valve were protected by using a liquid nitrogen trap, a soda lime trap, and a particulate filter in sequence. The reactor tube and the substrate were heated with a high temperature single-zone resistance furnace, which provided 10 inches of heating zone.

Local deposition rates were measured using small silicon carbide substrates (typically, $1.35 \mathrm{~cm}$ length, $0.75 \mathrm{~cm}$ width, and $0.20 \mathrm{~mm}$ thickness) hung from the sample arm of the microbalance with the deposition surface parallel to the flow of the reactive mixture, which entered the chemical reactor from the top. The position of the substrate that is reported in the figures is taken from the beginning of the heating zone of the furnace, which practically coincided with the beginning of an isothermal region in the reactor of about $23 \mathrm{~cm}$ in length. The temperature in the section of the reactor that 
preceded the isothermal zone was such that the temperature rose from about $50 \%$ of the set point value (in $\mathrm{K}$ ) to the set point almost linearly within a distance of about $7 \mathrm{~cm}$. Experimental temperature profiles in the reactor are presented in Ref. 36 for various set point temperatures. The deposition rate was corrected for the weight of the material deposited on the suspension wire by measuring the total weights of the substrate and of the wire before and after the end of each series of experiments. Because of the small thickness of the wire, the correction was rather small (typically less than 5\%).

In order to obtain information on the profiles of deposition rate and deposit composition along the reactor from a single experimental run, deposition experiments were carried out on molybdenum wires placed along the centerline of the tubular reactor At each set of experimental conditions, the deposition process was allowed to occur for a period of time that was sufficient to extract a reliable deposition rate from the slope of the weight vs. time curve. When deposition was carried out on refractory wires, the deposition rate at a certain location was determined by measuring the thickness of the wire at that location using scanning electron microscopy.

\section{ACKNOWLEDGEMENTS}

This research was supported by a grant from the Department of Energy. The authors also acknowledge the help of Brian McIntyre of the Institute of Optics of the University of Rochester with the characterization of the films.

\section{REFERENCES}

[1] Aksay, I. A., Dabbs, D. M., and Sarikaya, M., J. Am. Ceram. Soc. 1991, 74, 2343.

[2] Somiya, S., and Hirata, Y., Am. Ceram. Soc. Bull. 1991, 70, 1624.

3] Musikant, S., Proc. SPIE-Int. Soc. Opt. Eng. 1981, 297, 2.

[4] Gentilman, R. L., Proc. SPIE-Int. Soc. Opt. Eng. 1986, 683, 2.

[5] Kanzaki, S., Ohashi, M., Tabana, H., Kurihara, T, Iwai, S. -I., and Wakabayashi, S. -I., in Ceramics Transactions, Somiya, S., Davis, R. F., and Pask, J. A., Eds., American Ceramic Society, Westerville, OH 1990, 6, 389.

[6] Giess, E. A., Roldan, J. M., Bailey, P. J., and Goo, E., in Ceramics Transactions, 
Nair, K. M., Pohanka, R. C., and Buchanan, R. C., Eds., American Ceramic Society, Westerville, OH 1990, 15, 167.

[7] Kara, F., and Little, J. A., J. Mater. Sci. 1993, 28, 1323.

[8] Hori, S., and Kurita., R., in Ceramic Transactions, Somiya, S., Davis, R. F., and Pask, J. A., Eds., The American Ceramic Society, Westerville, OH 1990, 6, 311.

[9] Chung, S. L., Shu, Y. C., and Tsai, M. S., in Ceramic Transactions, Messing, G. L., Hirano, S., and Hauser, H., Eds., The American Ceramic Society, Westerville, $\mathrm{OH}$ 1990, 12, 275.

[10] Itatani, K., Kubozono, T., Howell, F.S., Kishioka, A., and Kinoshita, M., J. Mater. Sci. 1995, 30, 1158.

[11] Itatani, K., Kubozono, T., Howell, F.S., Kishioka, A., and Kinoshita, M., J. Mater. Sci. 1995, 30, 1196.

[12] Auger, M.L., and Sarin, V.K., Surf. Coat. Technol. 1997, 94-95, 46.

[13] Haynes, J.A., Lance, M.J., Ferber, M.K., Cooley, K.M., Lowden, R.A., and Stinton, D.P., J. Am. Ceram. Soc. 2000, 83, 657.

[14] Haynes, J.A., Cooley, K.M., Stinton, D.P., Lowden, R.A., and W.Y. Lee, Ceram. Eng. Sci. Proc. 1999, 20, 355.

[15] Conde, A. R. D. G., Puerta., M., Ruiz, H., and Olivares, J. L., J. Non-Cryst. Solids 1992, 147, 467.

[16] Colomban, P., and Vendange, V., J. Non-Cryst. Solids 1992, 147, 245.

[17] Nitodas, S. F., and Sotirchos, S. V., Chem. Vapor Deposition 1999, 5, 219.

[18] Mulpuri, R. P., and Sarin, V. K., J. Mater. Res. 1996, 11, 1315.

[19] Nitodas, S. F., and Sotirchos, S. V., J. Electrochem. Soc. 2000, 147, 1050.

[20] Fredriksson, E., and Carlsson, J.-O., J. Chem. Vap. Dep. 1993, 1, 333.

[21] Funk, R., Schachner, H., Triquet, C., Kornmann, M., and Lux, B., J. Electrochem. Soc. 1976, 123, 285.

[22] Silvestri, V. J., Osburn, C. M., and Ormond, D. W., J. Electrochem. Soc. 1978, 125, 902.

[23] Kim, J. G, Park, C. S., and Chun, J. S., Thin Solid Films 1982, 97, 97.

[24] Colmet, R., and Naslain, R., Wear 1982, 80, 221.

[25] Bae, Y. W., Lee, W. Y., Besmann, T. M., Cavin, O. B., and Watkins, T. R., 
J. Am. Ceram. Soc. 1998, 81, 1945.

[26] Wong, P., and Robinson, McD., J. Am.. Ceram. Soc. 1970, 53, 617.

[27] Tsapatsis, M., and Gavalas, G.R., AIChE J. 1992, 38, 847.

[28] Kim, S., and Gavalas, G. R., Ind. Eng. Chem. Res. 1995, 34, 168.

[29] George, S. M., Sneh, O., Dillon, A. C., Wise, M. L., Ott, A. W., Okada, L. A., and Way, J. D., Appl. Surf. Sci. 1994, 82/83, 460.

[30] Tingey, G. L., J. Phys. Chem. 1966, 70, 1406.

[31] Choi, S. W., Kim, C., Kim, J. G., and Chun, J. S., J. Mat. Sci. 1987, 22, 1051.

[32] Park, C. S., Kim, J. G., and Chun, J.S., J. Vac. Sci. Technol.A 1983, 1, 1820.

[33] Sotirchos, S. V., and Kostjuhin, I. M., in Ceramic Transactions, The American Ceramic Society, Westerville, OH 1996, 79, 27.

[34] Sotirchos, S. V., and Kostjuhin, I. M, in the Chemical Vapor Deposition Proceedings of the $14^{\text {th }}$ International Conference and EUROCVD-11, Allendorf, M. D., and Bernard, C., Eds., Paris, France 1997, 512.

[35] Papasouliotis, G. D., and Sotirchos, S. V., J. Electrochem. Soc. 1998, 145, 3908.

[36] Papasouliotis, G. D., and Sotirchos, S. V., J. Mater. Res., 1999, 14, 3397. 


\section{LIST OF FIGURES}

Figure 1. Variation of the deposition rate with the temperature for the single oxides deposition and codeposition processes.

Figure 2. Variation of the deposition rate with the pressure for the single oxides deposition and codeposition processes.

Figure 3. Effect of hydrogen chloride on the silica deposition rate.

Figure 4. Effect of $\mathrm{Al} / \mathrm{Si}$ feed ratio on the codeposition rate.

Figure 5. Variation of the deposition rate with the total flow rate for he deposition and codeposition processes at 1223 and 1273 K. Solid lines: codeposition. Dashed lines: deposition from MTS. Dotted lines: deposition from $\mathrm{AlCl}_{3}$.

Figure 6. Variation of the deposition rate with the total flow rate for the deposition and codeposition processes at 1323 and 1373 K. Solid lines: codeposition. Dashed lines: deposition from MTS. Dotted lines: deposition from $\mathrm{AlCl}_{3}$.

Figure 7. Deposition rate profiles in the CVD reactor for silica deposition, alumina deposition, and codeposition.

Figure 8. Deposition rate profiles in the CVD reactor for the codeposition process at various operating conditions.

Figure 9. Profiles of $\mathrm{Al} / \mathrm{Si}$ ratio in the deposit in the reactor.

Figure 10. Profiles of $\mathrm{Al} / \mathrm{Si}$ ratio in the deposit. Same conditions as in Figure 9 but with $500 \mathrm{~cm}^{3} / \mathrm{min}$ flow rate.

Figure 11. Profiles of the codeposition rate and of the rates of incorporation of $\mathrm{SiO}_{2}$ and $\mathrm{Al}_{2} \mathrm{O}_{3}$ in the deposit at the conditions of Figure 8.

Figure 12. Variation of the depletion of $\mathrm{Al}$ and $\mathrm{Si}$ from the gas phase with the distance in the CVD reactor at the conditions of Figure 8.

Figure 13. Variation of the equilibrium mole fractions of the major species of the gas phase with the fraction of $\mathrm{Al}$ left in the reactive mixture at $1300 \mathrm{~K}$ and $13.3 \mathrm{kPa}$. $\mathrm{CO}_{2} / \mathrm{AlCl}_{3} / \mathrm{MTS}=28.8 / 4.8 / 1.6, x_{\mathrm{MTS}}=0.004$. The deposit is assumed to be mullite.

Figure 14. Profiles of the codeposition rate and of the rates of incorporation of $\mathrm{SiO}_{2}$ and $\mathrm{Al}_{2} \mathrm{O}_{3}$ in the deposit at $1300 \mathrm{~K}$ and $10 \mathrm{kPa}$. 


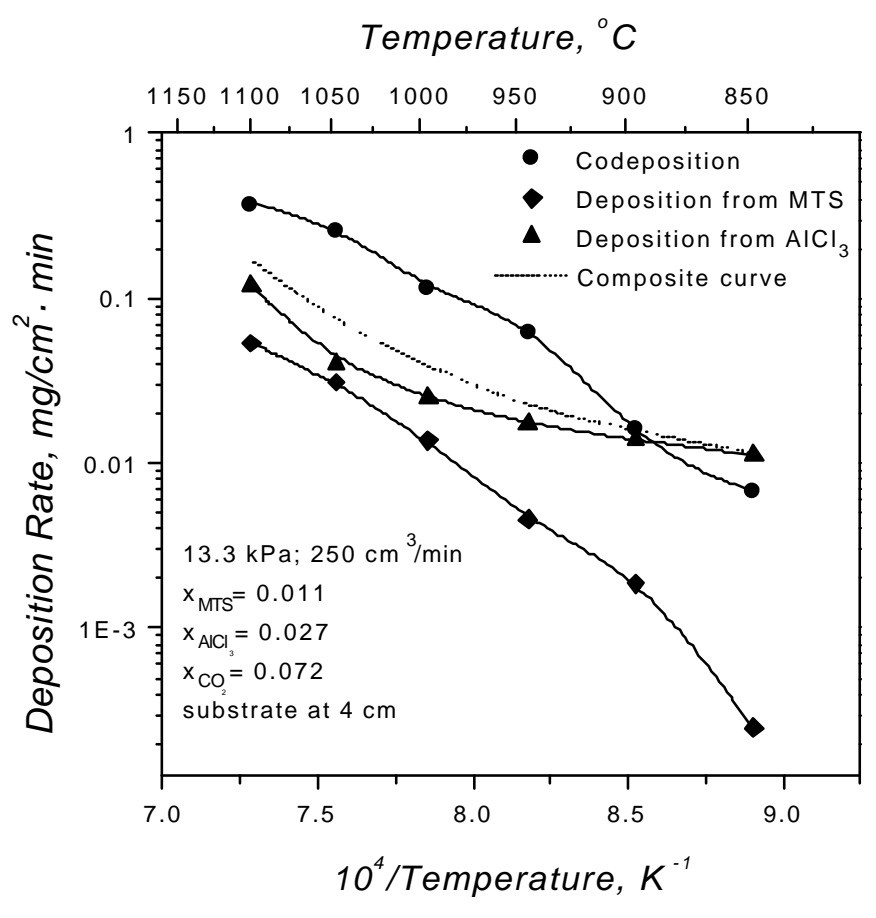

FIGURE 1 


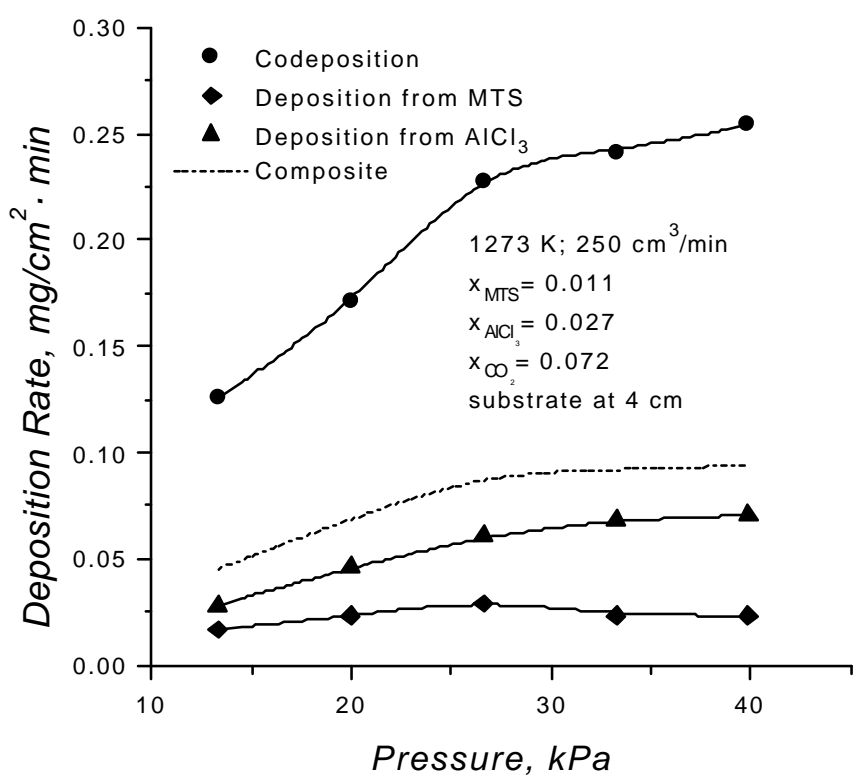

FIGURE 2 


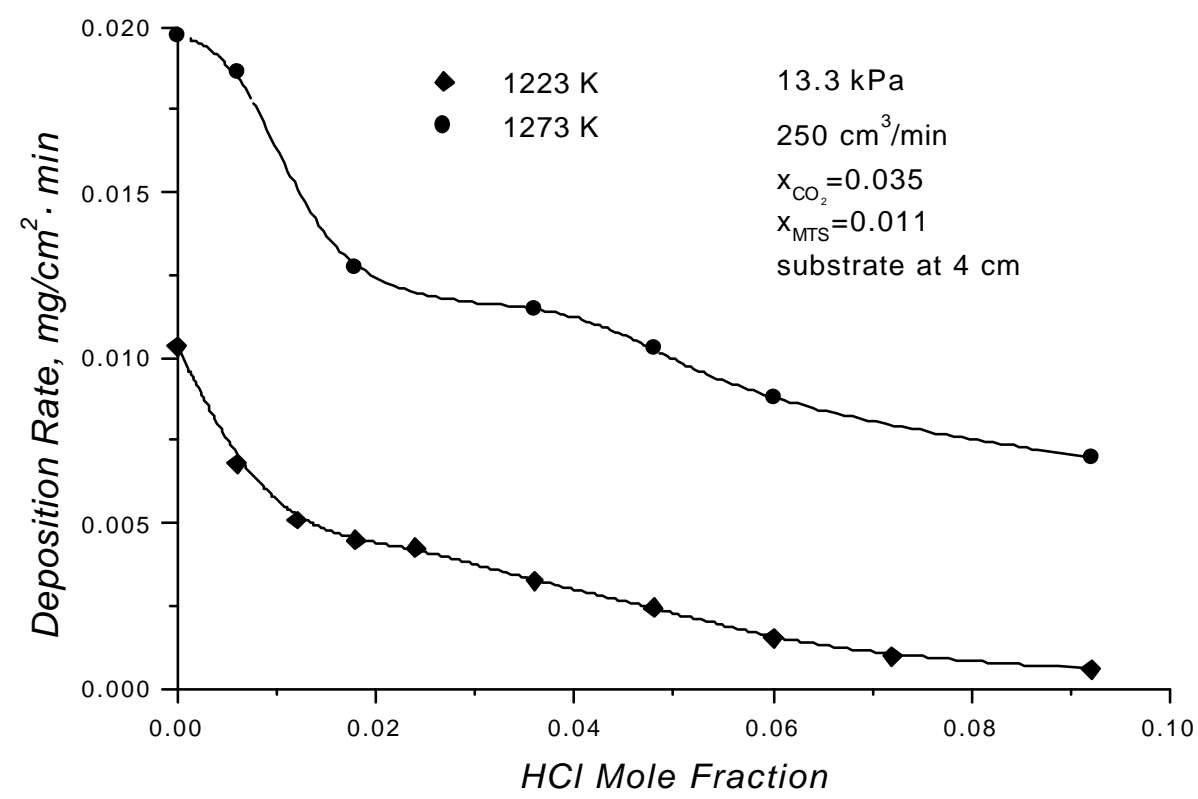

FIGURE 3 


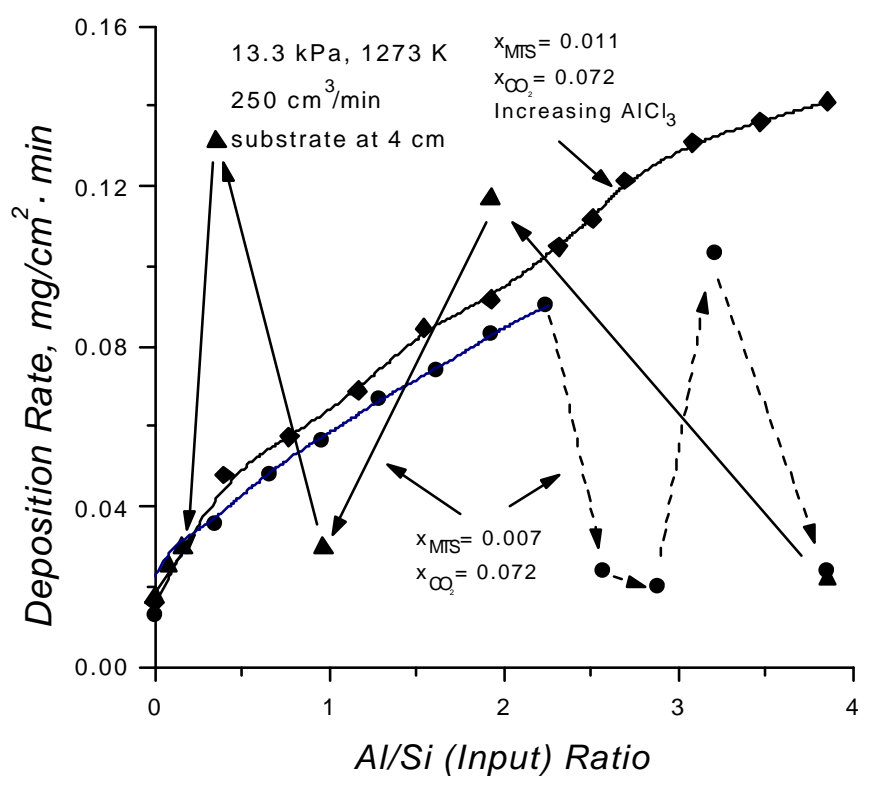

FIGURE 4 


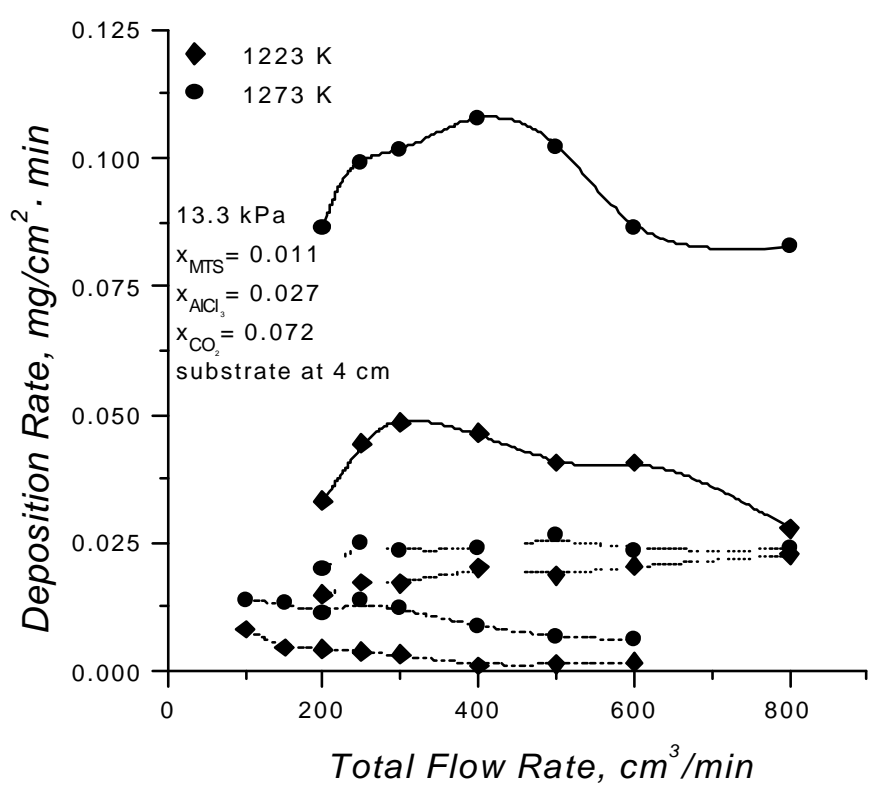

FIGURE 5 


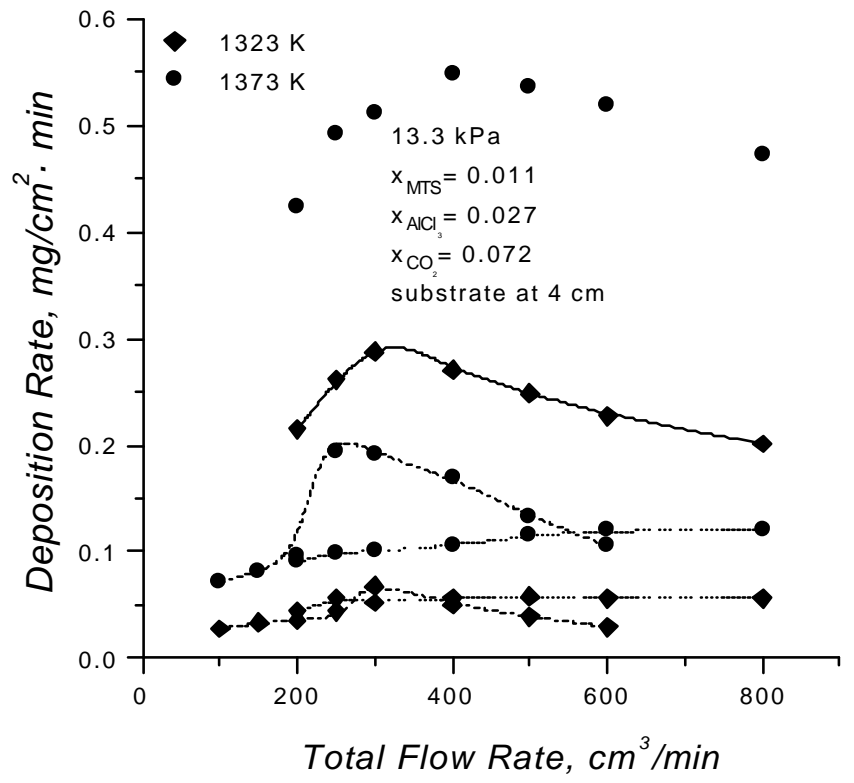

FIGURE 6 


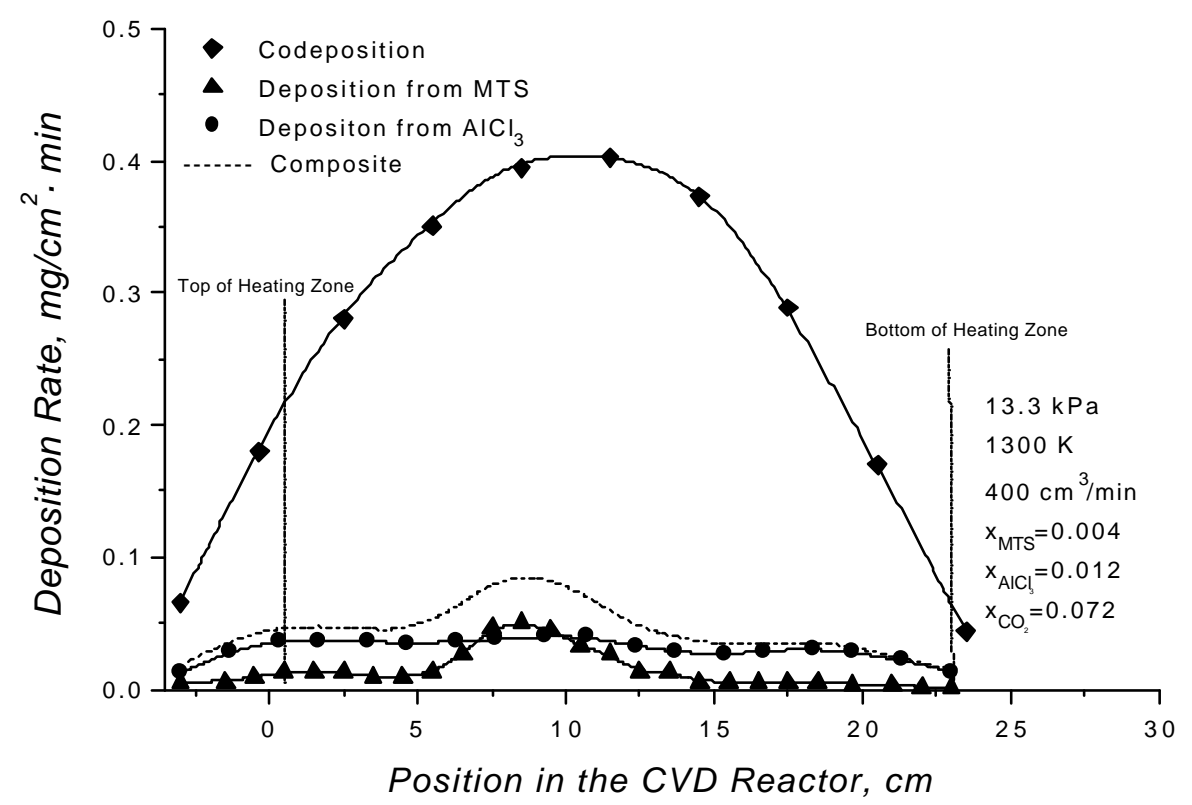

FIGURE 7 


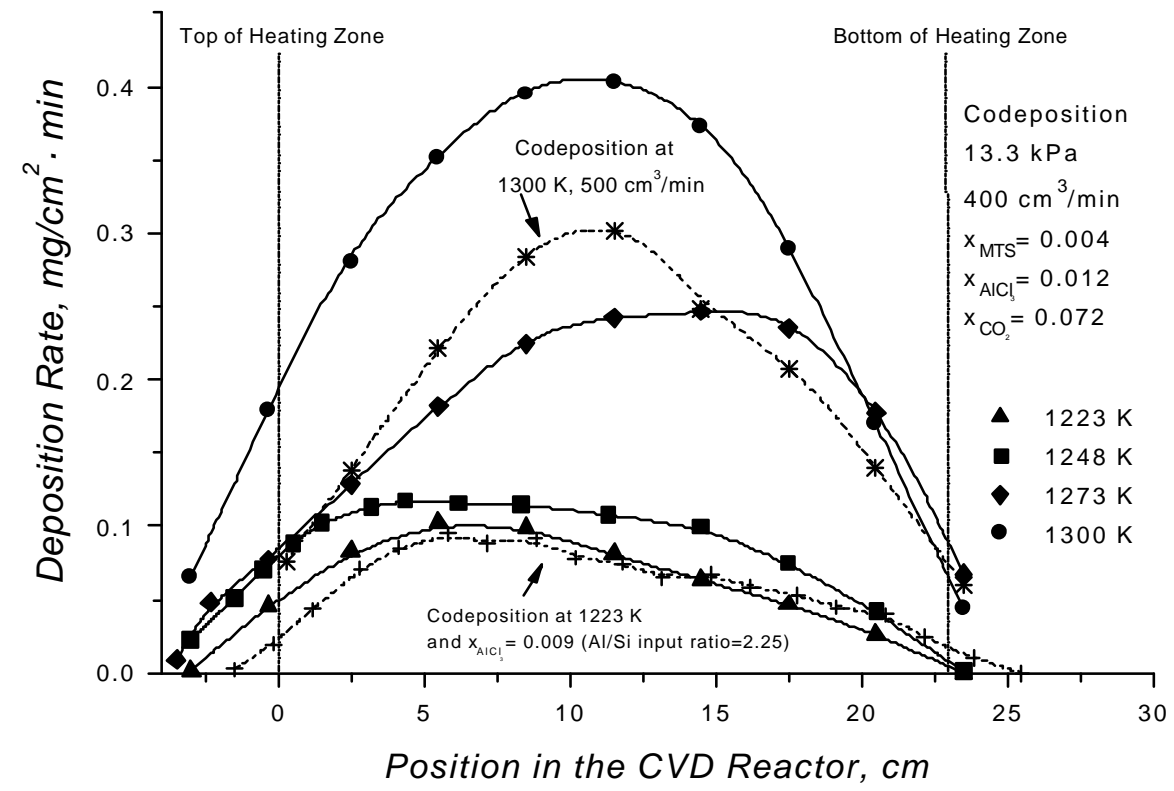

FIGURE 8 


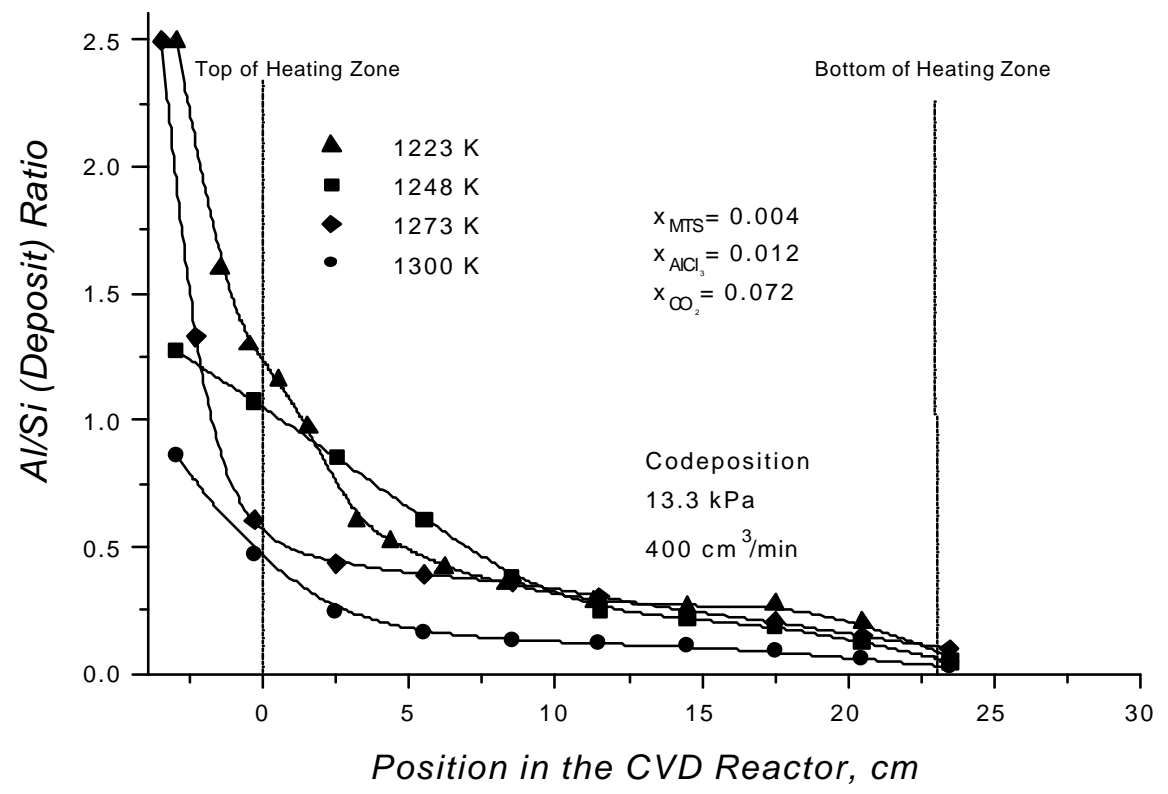

FIGURE 9 


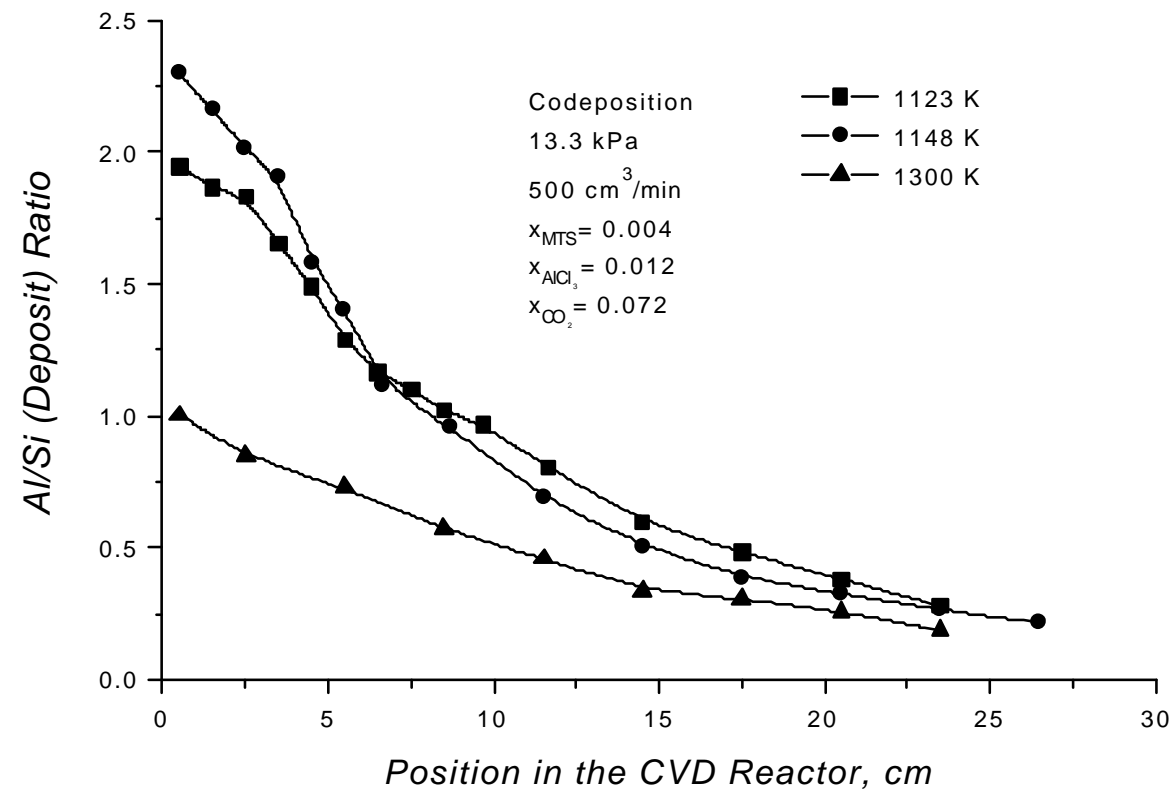

FIGURE 10 


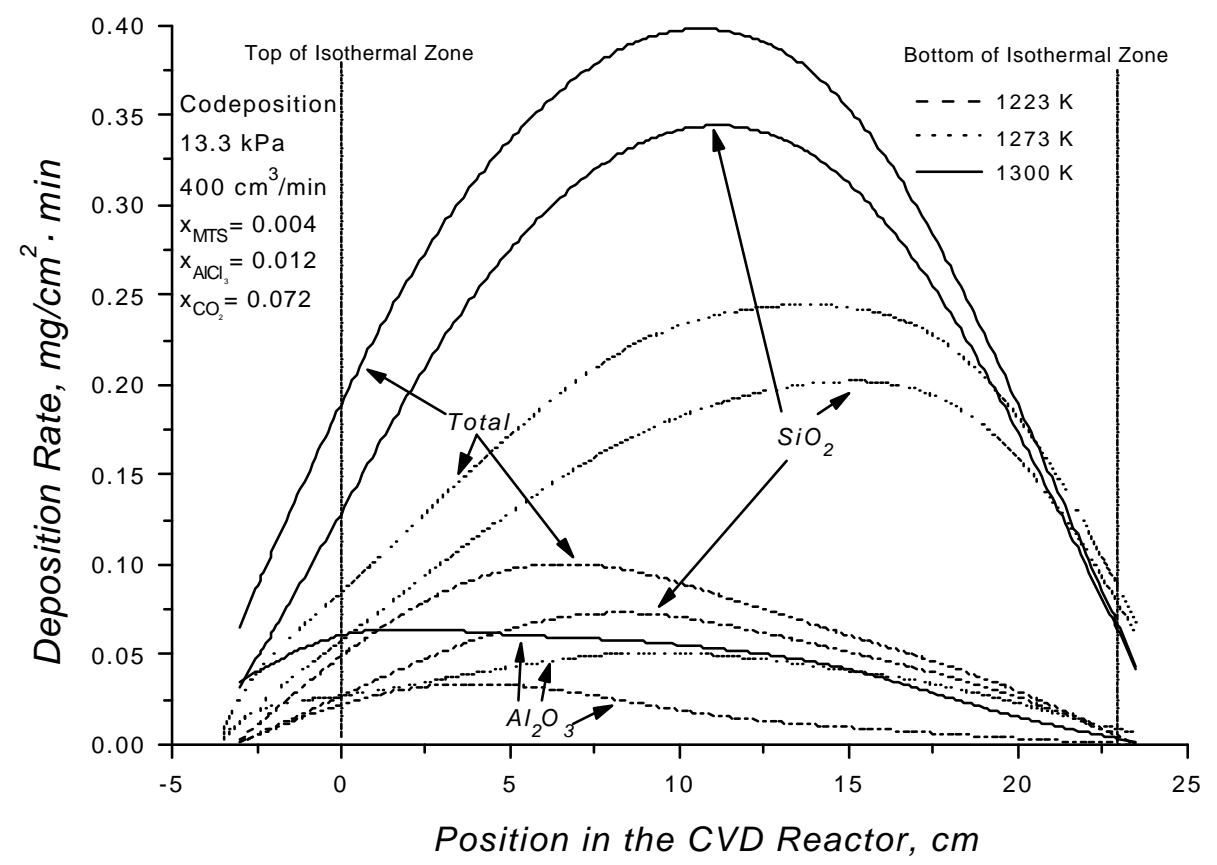

FIGURE 11 


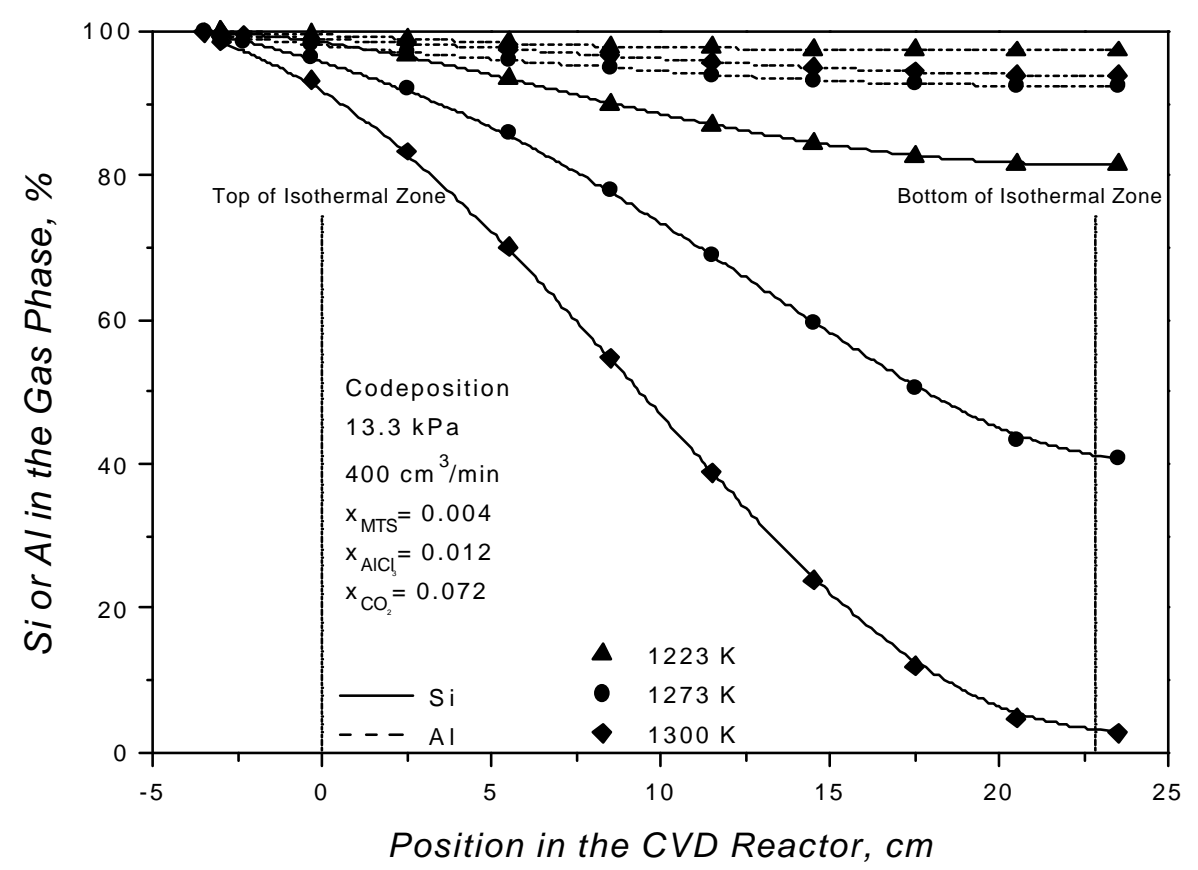

FIGURE 12 


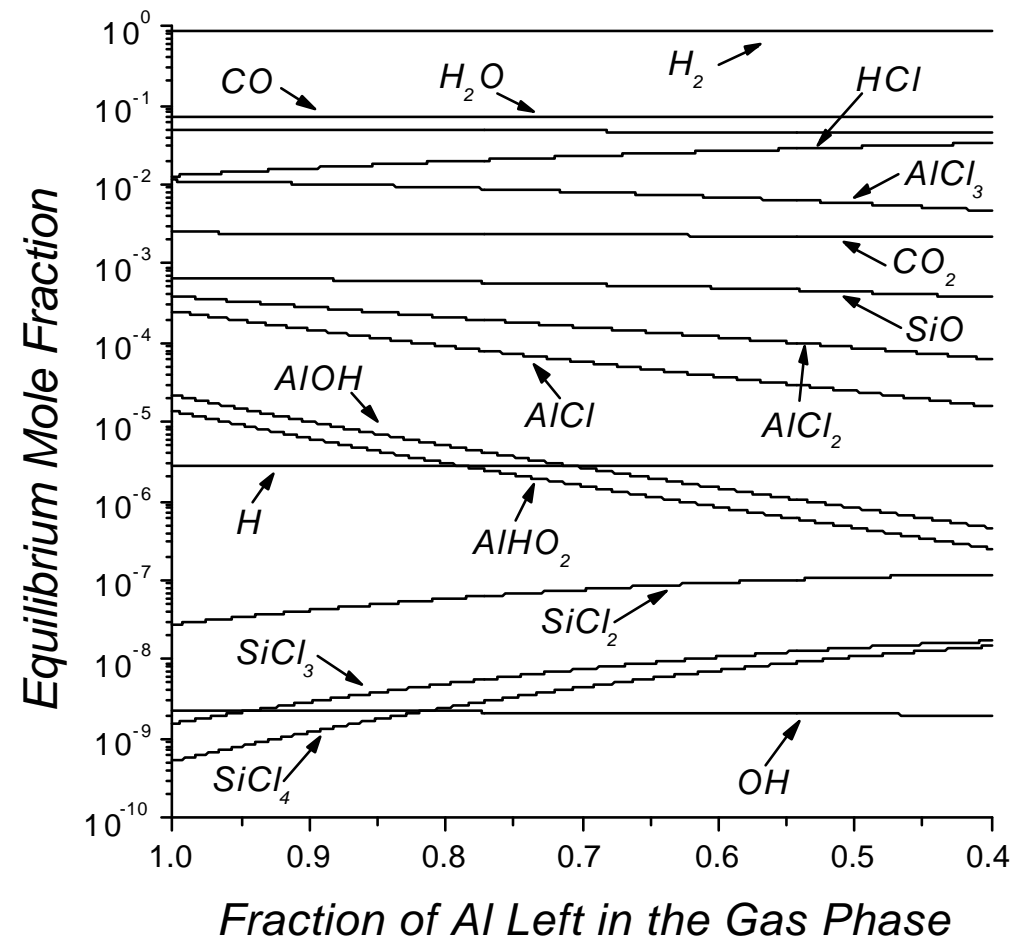

FIGURE 13 


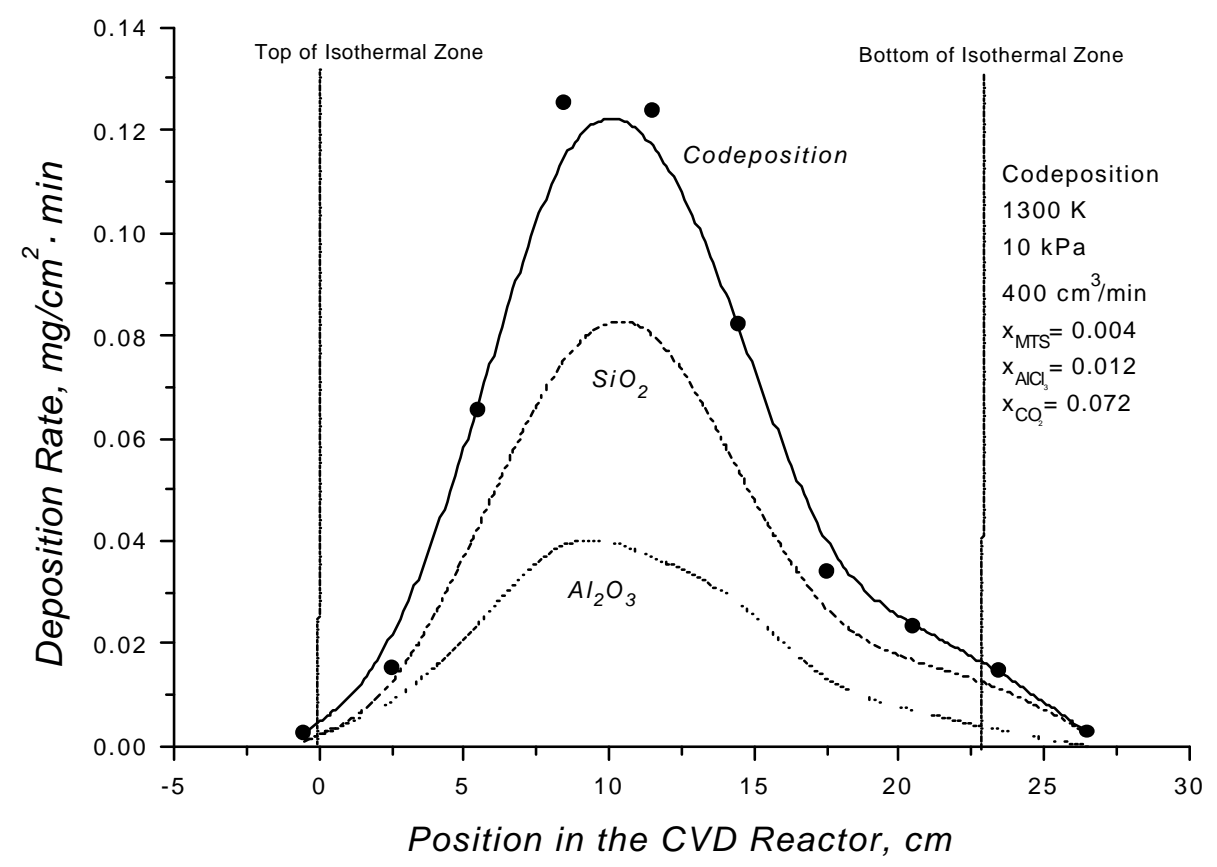

FIGURE 14 


\title{
Homogeneous and Heterogeneous Kinetics of the Chemical Vapor Deposition of Silica from Mixtures of Chlorosilanes, $\mathrm{CO}_{2}$, and $\mathrm{H}_{2}$. Model vs. Experiment
}

Stephanos F. Nitodas and Stratis V. Sotirchos*

\author{
Department of Chemical Engineering \\ University of Rochester \\ Rochester, NY 14627
}

* to whom correspondence should be addressed 


\begin{abstract}
A detailed homogeneous and heterogeneous kinetic model is formulated for the deposition of $\mathrm{SiO}_{2}$ from $\mathrm{SiCl} / \mathrm{CO}_{2} / \mathrm{H}_{2}$ and $\mathrm{MTS} / \mathrm{CO}_{2} / \mathrm{H}_{2}$ mixtures. A complete mechanistic model for the water gas-shift reaction is included as a subset in the overall decomposition and deposition mechanism. The kinetic model is introduced into the transport and reaction model of a plug-flow reactor, and the overall model is employed to investigate the sensitivity of the predicted deposition rates, surface coverages of adsorbed species, and gas phase composition on the operating conditions, the residence time in the reactor, and some key steps in the pathways of the homogeneous chemistry of the process. The results show that in the absence of deposition reactions, the gas phase approaches equilibrium at residence times that are much greater than those typically encountered in CVD reactors. The concentrations of the gas phase species (silicon species and oxygen species) that are responsible for silica deposition are strongly influenced by the occurrence of the heterogeneous reactions, and this in turn leads to strong dependence of the deposition rate profile on the reactor geometry (deposition surface to reactor volume ratio). The concentrations of the deposition precursors are much higher when methyltrichlorosilane is used as silicon source, for comparable silicon and oxygen loadings of the feed, and thus, the rate of silicon oxide deposition from MTS can be higher by a few orders of magnitude. Experiments on silica deposition conducted in our laboratory showed that this is indeed the case, and the overall transport and reaction model was found to be capable of reproducing, both qualitatively and quantitatively, all results obtained in those experiments.
\end{abstract}

Keywords: silica; kinetic modeling; chemical vapor deposition; water gas-shift reaction; chlorosilanes. 


\section{Introduction}

The preparation of silica films through chemical vapor deposition (CVD) is of interest in a number of applications, such as protective coatings for structural ceramics, separation of gaseous mixtures using permselective membranes, and microelectronic engineering [1-3]. The chemical vapor deposition of silica from mixtures of chlorosilanes, $\mathrm{H}_{2}$, and $\mathrm{CO}_{2}$ is addressed in this study. This is a very complex reaction system, involving large numbers of homogeneous and heterogeneous reactions. As in all CVD processes, radical species are believed to be the active precursors to film formation. The presence of many gas phase species makes the identification of species that play an active role in the film growth process difficult, and this makes the need for the development of a detailed gas phase and surface reaction mechanism imperative. Satisfactory knowledge of the homogeneous and heterogeneous chemistry of a deposition reaction is indispensable not only for the analysis of experimental data but also for the successful scale-up of a lab-scale process.

Despite the considerable amount of experimental work that has been done on the silica deposition process, no detailed model has been presented in the literature on its homogeneous and heterogeneous chemistry when chlorosilanes are used as silicon precursors. A simplified heterogeneous model for silica deposition from mixtures of $\mathrm{SiCh}_{4}$ and $\mathrm{H}_{2} \mathrm{O}$ was proposed by Armistead and Hockey [4] and Hair and Hertl [5]. This scheme assumes that $\mathrm{SiCh}_{4}$ and $\mathrm{H}_{2} \mathrm{O}$ are the actual deposition precursors and that deposition takes place through interaction of silicon tetrachloride with surface hydroxyl groups and water with surface chlorine groups and subsequent reaction of these surface groups with each other. Tsapatsis and Gavalas [2] employed this heterogeneous reaction scheme in a transport and reaction model in porous media to simulate silica deposition in porous glass.

Detailed homogeneous and heterogeneous chemistry models for the deposition of $\mathrm{SiO}_{2}$ are formulated in the present work for use with any chlorosilane compound in the feed. Since formation of the species that are required for the incorporation of oxygen atoms in the film (primarily $\mathrm{OH}$ and $\mathrm{H}_{2} \mathrm{O}$ ) takes place through the pathways of the watergas-shift reaction (WGSR), a complete kinetic model for this process is incorporated as a submodel in the homogeneous chemistry model. Information obtained from the analysis 
of thermodynamic equilibrium in the gas phase of the reacting mixture and from past experimental and theoretical studies is employed to determine which elementary reaction steps may play an important role in the overall deposition process. The kinetic parameters of the homogeneous reactions are estimated using information from the literature. The kinetic parameters of the heterogeneous reactions, on the other hand, are extracted using literature information on the adsorption parameters and sticking coefficients of the various gas phase species that participate in them, the equilibrium constants of overall reactions that involve gas phase and solid species, and experimental data for the deposition rate.

The kinetic model is introduced into the transport and reaction model of a tubular, hot-wall CVD reactor. Computations are carried out using only the homogeneous chemistry mechanism in order to study the spatial variation of the gas phase composition and the effects of the operating conditions on it under conditions typically encountered in silicon oxide CVD. The predictions of the overall (homogeneous and heterogeneous) model are compared with experimental data obtained in a hot-wall CVD reactor in our laboratory. Two sources of silicon were used in these experiments, namely silicon tetrachloride and methyltrichlorosilane (MTS), for which the overall reactions of $\mathrm{SiO} 2$ depositions are

$$
\begin{gathered}
\mathrm{SiCl}_{4}+2 \mathrm{H}_{2} \mathrm{O} \rightarrow \mathrm{SiO}_{2}+4 \mathrm{HCl} \\
\mathrm{CH}_{3} \mathrm{SiCl}_{3}+2 \mathrm{H}_{2} \mathrm{O} \rightarrow \mathrm{SiO}_{2}+3 \mathrm{HCl}+\mathrm{CH}_{4}
\end{gathered}
$$

The deposition rate was measured by using gravimetric monitoring of the deposition rate on small substrates or by measuring the thickness of the film on thin refractory wires traversing the axis of the tubular reactor. The model is found to be capable of predicting most of the behavior patterns observed in the experiments, including that of higher deposition rates of silica from MTS (by more than one order of magnitude). The model can also account for the inhibitory effect of reaction by-products on the deposition process. 


\section{Homogeneous Chemistry Mechanism}

The kinetic model of the gas phase reactions is formulated taking some guidance from the results of the thermochemical equilibrium analysis of the $\mathrm{Si} / \mathrm{C} / \mathrm{Cl} / \mathrm{H} / \mathrm{O}$ system. Some of these results have been presented and discussed in a past experimental study of the codeposition of silica, alumina, and aluminosilicates from $\mathrm{CH}_{3} \mathrm{SiCl}_{3}, \mathrm{AlCl}_{3}, \mathrm{CO}_{2}$, and $\mathrm{H}_{2}$ mixtures [1]. The species included in the homogeneous mechanism are those encountered in appreciable quantities in the equilibrium composition of the gas phase in the temperature range 800-1500 K. These species are shown in Table 1. (It must be noted that methyltrichlorosilane (MTS) exists in significant quantities only when it is employed as silicon source.) The fact that a species does not exist in significant quantities in the equilibrium composition of the gas phase does not necessarily imply that it may not play an important role in the deposition process. Table 2 lists the additional species that have been included in the kinetic mechanism because either they play an important role in MTS or $\mathrm{SiCh}_{4}$ homogeneous decomposition or they participate in important steps of kinetic pathways that lead to deposition of $\mathrm{SiO}_{2}$. The radical species included in the mechanism are gas phase decomposition products and intermediate species for the generation of stable compounds or deposition precursors. The hydrocarbon species shown in Table 2 were included because they may be present in significant quantities when MTS is used as silicon source. The reactions used to model the homogeneous chemistry of the $\mathrm{SiCh} / \mathrm{CO}_{2} / \mathrm{H}_{2}$ and $\mathrm{MTS} / \mathrm{CO}_{2} / \mathrm{H}_{2}$ systems are presented in Table 3. All reactions are treated as reversible. The rate constants, obtained from several kinetic studies, are summarized in Table 4. The reaction rate constant of the forward step is given for reactions R2-R16, R18, R20-R22, R26-R31, and R34-R41, while for reactions $\mathrm{R} 1, \mathrm{R} 17, \mathrm{R} 19, \mathrm{R} 23-\mathrm{R} 25, \mathrm{R} 32$, and R33, the values given in Table 4 refer to the reverse step. Thermodynamic data were used to calculate the equilibrium constants, and those in turn were used to compute the rate constant of the other step (reverse or forward).

When MTS is employed as the silicon source, the starting reaction for the formation of silicon-chlorine species in the gas phase is $\mathrm{R} 34$. In the case of $\mathrm{SiCh}$, on the other hand, this process starts with R18 or R20. The first twelve reactions represent the mechanism of the water-gas-shift reaction $\left(\mathrm{CO}_{2}+\mathrm{H}_{2} \rightarrow \mathrm{CO}+\mathrm{H}_{2} \mathrm{O}\right.$, WGSR). Wherever it appears, symbol M stands for any other component of the gas mixture apart from those 
participating in the reaction where $M$ appears. Suski and Wutke [6] have summarized the elementary reactions that have been proposed by several authors as the most important pathways of the WGSR. Reactions R1-R3 were proposed by Bradford [7], and their rate constants were obtained from the study of Warnatz [8] on the rate coefficients in the $\mathrm{C} / \mathrm{H} / \mathrm{O}$ system, except that of $\mathrm{R} 2$ which was taken from the kinetic study of Vandooren et al. [9]. The study of Warnatz [8], which was conducted at a temperature range between 1000 and $3000 \mathrm{~K}$, was also the source for the rate constants of R4 and R7. The recombination reaction of hydroxyl radicals (reaction R5), the reaction of molecular hydrogen with atomic oxygen (reaction R6), and that of hydrogen with molecular oxygen (reactions R10 and R11) were suggested by Miller and Kee [10]. Their rate constants were taken from the studies of Baulch et al. [11], Sutherland et al. [12], Davidson et al. [13], and Germann and Miller [14], respectively. The study of Azatyan et al. [15] was the source for the rate constant of reaction R8, and that of Koike [16] for R9, whereas the rate constant of R12 was obtained from Arustamyan et al. [17]. The kinetic pathway for the generation of methane, which was found to be present in significant quantities in the equilibrium composition of the gas phase [1], consists of reactions R13-R17. The R13R15 reaction sequence was proposed by Tsang and Hampson [18], while the R16-R17 by Westbrook and Pitz [19]. The rate constants of R14 and R15 were taken from Baulch [11], and those of R13, R16, and R17 from the studies of Warnatz [8], Berry et al. [20], and Forst [21], respectively.

Reaction R18 was proposed by Catoire et al. [22] as the initiation step of the thermal decomposition of $\mathrm{SiCl}_{4}$ at temperatures between 1550 and $2370 \mathrm{~K}$. The same authors proposed a simplified kinetic model for $\mathrm{SiCh}_{4}$ pyrolysis in the presence of $\mathrm{H}$ and Ar, consisting of reactions R1 and R18-R20. This reaction sequence was considered to be the main source for the $\mathrm{H}$ atoms that were observed in the experimental shock tube system of [22]. The rate constants of R18 and R20 were obtained from [22], and those of R19 from the study of Adusei and Fontijn [23]. The recombination of $\mathrm{SiCl}_{3}$ with $\mathrm{H}_{2}$ (reaction R21) was proposed in the chlorosilane reduction study of Ashen et al. [24], and the decomposition of $\mathrm{SiHCl}_{3}$ (reaction R22) by Sirtl et al. [25]. The rate constants of these two reactions were obtained from Arthur et al. [26] and Swihart and Carr [27], respectively. The $\mathrm{SiH}_{2} \mathrm{Cl}_{2}$ generation and decomposition reactions ( $\mathrm{R} 23$ and $\mathrm{R} 24$, 
respectively) were proposed by Wittbrodt and Schlegel [28], and their rate constants were obtained from the same source. The rate constant of R25 was taken from the study of Cagliostro and Riccitiello [29], in which a simple model for the deposition of silicon carbide from the pyrolysis of dichlorodimethylsilane in hydrogen was developed. Reaction R26 was proposed by Serdvuk et al. [30] in their study of formation kinetics of silane chlorination products, and reaction R27 by Kerr et al. [31]. The rate constants of R26 and R27 were obtained from [30] and [31], respectively, and they should be considered as approximate values since the first study was conducted at $298 \mathrm{~K}$ and the second one at 333-443 K.

An approximate value was also used for the rate constant of the $\mathrm{SiO}$ generating reaction (R28) on the basis of the study of Jasinski et al. [32] at $298 \mathrm{~K}$. Silicon monoxide was included in the gas phase chemistry of silica deposition since the thermochemical equilibrium analysis of the problem [1] showed that this compound exists in significant quantities in the equilibrium composition of the gas phase. However, there was not any information in the literature on kinetic data for reactions involving silicon chlorides and leading to production of $\mathrm{SiO}$. The rate constant used for reaction R28 is the one reported for the reaction of $\mathrm{SiO}$ generation from $\mathrm{SiH}_{2}$ and oxygen in [32]. Reaction $\mathrm{R} 29$ was suggested by Zachariah and Tsang [33], and its rate constant was obtained from the same study, whereas R30 was studied by several authors, and its rate constant was taken from the study of Singleton and Cvetanovic [34]. The rate constant used for reaction R31, which was proposed by Pritchard et al. [35], was obtained from Manion and Louw [36]. Reactions R32 and R33 were proposed in [37] and [27], respectively, and their kinetic constants were taken from these sources. The reaction rate constant for the decomposition of MTS (reaction R34) was obtained from the study of Osterheld et al. [38], which was conducted between 800 and $1500 \mathrm{~K}$. This reaction was proposed by Ashen et al. [24], among others. The rate constants of reactions R35-R41 were compiled by Papasouliotis [39] from various sources of the literature.

\section{Heterogeneous Chemistry Mechanism}

Our objective is to propose a detailed heterogeneous reaction mechanism which, when it is coupled with the proposed homogeneous mechanism and incorporated into the 
reaction and transport model of a hot-wall plug flow CVD reactor, would be capable of reproducing the general trends observed in our experiments. Experimental studies showed that the decomposition of methyltrichlorosilane takes place exclusively in the gas phase, even at low temperatures [40]. The decomposition of silicon tetrachloride is also a homogeneous reaction [22,41]. The tetrahedral molecular structure of $\mathrm{SiCh}_{4}$ leads to rather low probability of reacting on the substrate surface $[42,43]$. Thus, a key assumption in the development of the proposed heterogeneous reaction mechanism is that $\mathrm{SiCh}_{4}$ or MTS are not the actual precursors of $\mathrm{Si}$ incorporation in the deposit. This role is reserved for surface reactive species that exhibit relatively high surface reactivity with the deposition surface, and whose presence has been predicted in the equilibrium composition of the gas phase [1] and detected in the effluent of silica and silicon deposition reactors $[41,44-46]$. The reactions used to model the surface chemistry of the $\mathrm{SiCl} / \mathrm{CO}_{2} / \mathrm{H}_{2}$ and $\mathrm{MTS} / \mathrm{CO}_{2} / \mathrm{H}_{2}$ systems are presented in Table 5. All reactions are treated as reversible, and as a result, the overall model can account for the inhibitory effects of the reaction by-products on the deposition process. The adsorbed species are denoted by a bracket, [ ] with the subscript $s$, and $[S]$ is used to denote free active surface site.

The two silicon chlorides, $\mathrm{SiCl}_{2}$ and $\mathrm{SiCl}_{3}$, have a much higher tendency than $\mathrm{SiCl}_{4}$ and MTS to react with the substrate surface because of their asymmetrical structure. The role of $\mathrm{SiCl}_{2}$ as the major silicon deposition precursor has been established in experimental investigations of silicon deposition using silicon tetrachloride as source gas $[42,45]$. The immediate product of the homogeneous decomposition of methyltrichlorosilane and silicon tetrachloride, $\mathrm{SiCl}_{3}$, is also considered to participate in the surface chemistry because it has been suggested as a potential precursor for silicon and silicon carbide deposition [39] or has been detected in silicon surfaces during decomposition of $\mathrm{SiCh}_{4}$ [43]. The oxygen needed for the formation of $\mathrm{SiO}_{2}$ is provided by both $\mathrm{H}_{2} \mathrm{O}$ molecules and $\mathrm{OH}$ radicals. Bogart et al. [47], in a study of plasma deposition of silica, detected hydroxyl radicals in the plasma and measured a significant surface reactivity for $\mathrm{OH}$. This suggests that $\mathrm{OH}$ might play an important role in the deposition of $\mathrm{SiO}_{2}$. 
Preliminary computations were carried out assuming that silica generation proceeds through the reaction

$$
\left[\mathrm{SiCl}_{2}\right]_{\mathrm{s}}+2[\mathrm{OH}]_{\mathrm{s}} \rightarrow \mathrm{SiO}_{2}+3[\mathrm{~S}]+2 \mathrm{HCl}
$$

The results of these computations were in very good agreement with the experimental data, but since this reaction is too complex to be elementary, it was decided to separate it into two steps, one leading to formation of $[\mathrm{SiClO}]_{\mathrm{s}}$ with generation of one molecule of $\mathrm{HCl}$ (reaction RS6) and the other producing silicon oxide with simultaneous desorption of a second hydrogen chloride molecule (reaction RS7). The reverse step of reaction RS7 proceeds through the dissociative chemisorption of $\mathrm{HCl}$ molecules on the surface. The silica generation reaction is treated as reversible because the results of past studies [48] have shown that the presence of $\mathrm{HCl}$ in the feed has a strong inhibitory effect on the deposition rate.

Each of the surface-reactive gas phase species is assumed to adsorb on one surface site. Steric hindrance and electronic interactions between the adsorbates are considered negligible, and thus, the rate constants are assumed to be independent of the extent of surface coverage. The adsorbed species concentrations are expressed as fractional coverages (that is, in dimensionless form) in the formulation of the rate expressions of the heterogeneous reactions. The kinetic parameters of the various surface reactions are shown in Table 6. They were determined by using the experimental kinetic data for $\mathrm{SiO}_{2}$ deposition from the $\mathrm{SiCl} / \mathrm{CO}_{2} / \mathrm{H}_{2}$ and $\mathrm{MTS} / \mathrm{CO}_{2} / \mathrm{H}_{2}$ systems, literature information on the heats of reaction of some of the reactions, the collision frequencies of the gaseous species with the surface, and literature information and estimates of the sticking coefficients of the gas phase species involved in the adsorption step of the reactions and by requiring that the equilibrium constants of the surface reaction steps be consistent with the equilibrium constants of reactions involving gas phase species and bulk solid species (i.e., $\mathrm{SiO}_{2}$ ).

The rate constants of the steps involving adsorption of a radical species or reaction of a radical species with an adsorbed surface species were set equal to the collision frequency factor of that species. This is equivalent to using sticking coefficient equal to unity for the gas phase species involved in the reaction step. This procedure was 
followed for the forward steps of reactions RS2, RS3, RS4, and RS5, but not for the reverse step of RS1, since the latter is not an elementary reaction.

According to several literature studies [49-53], the dissociative adsorption of water proceeds through the elementary step

$$
\mathrm{H}_{2} \mathrm{O}+2[\mathrm{~S}] \rightarrow[\mathrm{H}]_{\mathrm{S}}+[\mathrm{OH}]_{\mathrm{S}}
$$

In writing the adsorption of water as reaction RS1, it was assumed that the desorption of $\mathrm{H}$ from the surface, written in the reverse direction as

$$
\mathrm{H}+[\mathrm{S}] \rightarrow[\mathrm{H}]_{\mathrm{S}}
$$

occurs very fast so that reactions (4) and (5) could be practically written as reaction RS1. This assumption is consistent with the results of a number of literature studies on the adsorption of $\mathrm{H}$ on surfaces $[54,55]$. The absence of adsorbed hydrogen atoms from the substrate surface led us to exclude their possible reactions with other adsorbed species from the kinetic mechanism. This assumption is supported by the study of Ohshita et al. [56], according to which adsorbed $\mathrm{SiCl}_{2}$ reacts with gas phase hydrogen to generate silicon.

Since RS1 is not an elementary reaction, the rate constant of its reverse step was not determined by setting the sticking coefficient equal to unity, but it was treated as a model parameter. Ezzehar et al. [53] computed using molecular simulation methods the heats of reactions (4), (5), and RS2 on silicon surfaces. Their results showed that all three reactions were highly exothermic (in the adsorption direction) having heats of reaction around $5 \mathrm{eV}$ per adsorbed molecule. Using these results, we found that the heat of reaction RS1 is rather low, and this is in agreement with the results of studies on the activation energy of the adsorption of water on surfaces [49,50]. These results indicate very low activation energy of the adsorption step, and in view of the low heat of reaction $\mathrm{RS} 1$, it was decided to set the activation energies of both the forward and the reverse steps of reaction RS1 equal to zero. The other parameters of the forward step (A and n) were determined using the collision frequency of water with the surface and an average sticking coefficient equal to 0.01 [57]. The parameters of the reverse step of reaction RS2 were determined by requiring that the equilibrium constants of reaction RS1 and RS2 be consistent with the equilibrium constant of the gas phase reaction

$$
\mathrm{H}_{2} \mathrm{O} \rightarrow \mathrm{H}+\mathrm{OH}
$$


Since $(\mathrm{A})=\mathrm{RS} 1-\mathrm{RS} 2$, we must have

$$
\left(\frac{k_{s 1, f}}{k_{s 1, r}}\right) /\left(\frac{k_{s 2, f}}{k_{s 2, r}}\right)=K_{c A}
$$

where $K_{c A}$ is the concentration-based equilibrium constant of reaction (A), and $k_{s i, f}$ and $k_{s i, r}$ the forward and reverse rate constant, respectively, of surface reaction RSi.

The preexponential factor and the activation energy of the reverse step of reaction RS3 were obtained from the study of Gupta et al. [42]. The same activation energy was assumed to hold for the desorption step of reaction RS4. Since the forward steps of reactions RS3 and RS4 have zero activation energy, this is equivalent to assuming that the heats of reactions RS3 and RS4 are equal. RS3, RS4, and RS5 may be combined as RS4-RS3+RS5 to yield the reaction

$$
\mathrm{SiCl}_{3}+\mathrm{H} \rightarrow \mathrm{SiCl}_{2}+\mathrm{HCl}
$$

If $K_{c B}$ is the concentration-based equilibrium constant of this reaction, thermodynamic consistency required that

$$
\left(\frac{k_{s 4, f}}{k_{s 4, r}}\right)\left(\frac{k_{s 5, f}}{k_{s 5, r}}\right) /\left(\frac{k_{s 3, f}}{k_{s 3, r}}\right)=K_{c B}
$$

Equation (B) yields that the activation energy of the reverse step of reaction RS5 is equal to the heat of reaction (B). Equation (7) can then used to determine the preexponential factors of the reverse steps of reactions RS4 and RS5 once the value of one of them has been obtained.

When equation (3) was employed as the $\mathrm{SiO}_{2}$ generation reaction, the activation energy of its forward step was set equal to the average value of the apparent activation energy that was determined from the analysis of the chemical vapor deposition data for $\mathrm{SiO}_{2}$ deposition from $\mathrm{SiCl} / \mathrm{CO}_{2} / \mathrm{H}_{2}$ and $\mathrm{MTS} / \mathrm{CO}_{2} / \mathrm{H}_{2}$ mixtures that were obtained in our laboratory. Reaction (3) can be written as a linear combination of reactions RS2 and RS3 and of the overall reaction

$$
\mathrm{SiCl}_{2}+2 \mathrm{OH} \rightarrow \mathrm{SiO}_{2}+2 \mathrm{HCl}
$$


as $(3)=(C)-R S 3-2 R S 2$. From this relationship, we can find the heat of reaction (3), and from that the activation energy of its reverse step. If $K_{c C}$ is the concentration-based equilibrium constant of reaction (C), the rate constants of reaction (3) must satisfy the relationship

$$
\left(\frac{k_{s(3), f}}{k_{s(3), r}}\right)=K_{c C}\left(\frac{k_{s 3, r}}{k_{s 3, f}}\right)\left(\frac{k_{s 2, r}}{k_{s 2, f}}\right)^{2}
$$

With the activation energies known, this relationship can be used to determine the preexponential factors of the forward and reverse step of (3) given either one of them.

To facilitate the estimation of the values of the parameters from the experimental data, the deposition rate data close to the entrance of our CVD reactor were employed to determine the value of the forward deposition rate constant by assuming that because of the low concentration of $\mathrm{HCl}$ there, the reverse rate of reaction (3) was relatively small. This kinetic constant was estimated together with the preexponential factor of the reverse step of reaction RS1 and the preexponential factor of the reverse step of reaction RS4. When the generation of silica was assumed to proceed in two steps through reaction RS6 and RS7 instead of through reaction (3), it was decided to set the activation energy of each of these steps equal to the apparent activation energy estimated from the experimental data. The reverse steps of reactions RS6 and RS7 involved dissociative adsorption of $\mathrm{HCl}$, and thus, it was assumed that they have the same activation energy, which was determined using the relationship

$$
\left(\frac{k_{s 6, f}}{k_{s 6, r}}\right)\left(\frac{k_{s 7, f}}{k_{s 7, r}}\right)=K_{c C}\left(\frac{k_{s 3, r}}{k_{s 3, f}}\right)\left(\frac{k_{s 2, r}}{k_{s 2, f}}\right)^{2}
$$

This relationship is a consequence of the fact that RS6+RS7 $=(3)=(C)-R S 3-2 R S 2$.

The equilibrium constants of reactions (A), (B), and (C) were assumed to be given by the formula $K_{c \mid 1300 K} \exp \left(\frac{-E}{R}\left(\frac{1}{T}-\frac{1}{1300 K}\right)\right)$. The values of exponent $n$ in the adsorption steps and in steps involving reaction of a gaseous species with an adsorbed species (0.5) esulted from the collision frequency. The value of $n$ in the reverse step of reaction RS7 (1.5) was dictated by the requirement of thermodynamic consistency 
(equation (9)). Of course, any values of $n$ in the reverse steps of reactions RS6 and RS7 having sum equal to 1.5 would conform to that requirement. Since the effect of temperature on the rate constants through the $T^{n}$ term is rather weak in comparison to that through the $\exp (-E / R T)$ term, results similar to those presented in this study are obtained using other values of $n$ for the reverse steps of reactions RS6 and RS7.

\section{Transport and Reaction Model}

A hot wall, tubular chemical vapor deposition reactor has been used in our laboratory to obtain the experimental data $[1,58]$ that we will use to validate the predictions of the kinetic model that we formulated in the preceding sections. The diameter of this reactor is much smaller than its length, and thus, a plug-flow reactor [59] will be used to model it. Starting from the steady state mass balance equations for the gaseous species of the mixture, it can be shown that the plug-flow reactor model for the gas phase species is described by the equations

$$
\begin{gathered}
\frac{d x_{i}}{d z}=\frac{A}{\hat{F}} \frac{P_{i}-x_{i} P_{T}}{f} \\
\frac{d f}{d z}=\frac{A}{\hat{F}} P_{T}
\end{gathered}
$$

$F$ is the molar flow rate of the gas mixture, $A$ the area of the cross section of the reactor, $z$ the axial distance in the reactor, $x_{i}$ the mole fraction of species $i, \hat{F}$ the molar flow rate of the mixture at the entrance of the reactor, and $f$ a dimensionless quantity equal to $F / \hat{F}$. $P_{i}$ and $P_{T}$ are the production rate of species $i$ and the overall (molar) production rate in the gas phase, and they are given by

$$
\begin{gathered}
P_{i}=\sum_{\rho} v_{i \rho} R_{\rho}+a_{R} \sum_{\rho^{\prime}} v_{i \rho^{\prime}}^{G} R_{s \rho^{\prime}} \\
P_{T}=\sum_{i}\left(\sum_{\rho} v_{i \rho} R_{\rho}+a_{R} \sum_{\rho^{\prime}} v_{i \rho^{\prime}}^{G} R_{s \rho^{\prime}}\right)
\end{gathered}
$$


$R_{\rho}$ is the rate of homogeneous reaction $\rho, R_{s \rho^{\prime}}$ is the rate of heterogeneous reaction $\rho^{\prime}$, $v_{i p}$ is the stoichiometric coefficient of gaseous species $i$ in the $\rho$ homogeneous reaction, and $v_{i \rho^{\prime}}^{G}$ the stoichiometric coefficient of gaseous species $i$ in the $\rho^{\prime}$ heterogeneous reaction, and $a_{R}$ is the area of the wall of the reactor per unit volume. The summation over $\rho$ in equations (12) and (13) involves summation over all homogeneous reactions and that over $\rho^{\prime}$ is taken over all heterogeneous reactions. The summation over $i$ in equation (13) involves all gas phase species.

The fractional surface coverages of the surface species are found from the mass balances for the surface species. Since each surface species exists only on the surface, and no surface diffusion is allowed, the mass balance for surface species $i$ is

$$
P_{s i}=\sum_{\rho^{\prime}} v_{i \rho^{\prime}}^{S} R_{s \rho^{\prime}}=0
$$

where $P_{s i}$ is the production rate of surface species $i, v_{i \rho^{\prime}}^{S}$ is the stoichiometric coefficient of surface species $i$ in surface reaction $\rho^{\prime}$. For a given set of gas phase concentrations, equation (14) is solved for the surface coverages of the surface species together with the

requirement that the total concentration of active sites remains constant, i.e., $\sum_{i} \theta_{i}=1$, where $\theta_{i}$ is the coverage of surface species $i$.

The model does not include an energy balance equation since heat effects associated with the reactions in the gas phase and on the surface are negligible. For example, the formation of $\mathrm{SiO}_{2}$ either from $\mathrm{SiCl}_{4}$ (equation (1)) or from MTS (equation (2)) is an exothermic reaction. $\Delta \mathrm{H}$ is $-123.26 \mathrm{~kJ} / \mathrm{mol}$ and $-199.6 \mathrm{~kJ} / \mathrm{mol}$ for $\mathrm{SiCh}_{4}$ and MTS, respectively, at $1300 \mathrm{~K}$. Assuming a deposition rate of $0.001 \mathrm{mg} /\left(\mathrm{cm}^{2} \cdot \mathrm{min}\right)$ for $\mathrm{SiCh}_{4}$, and $0.024 \mathrm{mg} /\left(\mathrm{cm}^{2} \cdot \mathrm{min}\right)$ for MTS at $1300 \mathrm{~K}$ (based on the experimental results), the overall enthalpy change is 0.0021 and $0.08 \mathrm{~J} /\left(\mathrm{cm}^{2} \cdot \mathrm{min}\right)$, respectively. These values are too low to cause significant temperature differences between the bulk of the gas phase and the deposition surface. This was also experimentally verified by placing a thermocouple in the vicinity of the substrate. It should be noted that even though an 
energy balance is not used, the model is not isothermal. When comparison is made with experimental data, the experimental temperature profile is used in the model to find the temperature at each value of distance $z$. This profile is determined only by the experimental arrangement and not the rates at which reactions occur.

\section{Numerical Aspects}

For $N^{G}$ gas phase species, the $N^{G}+1$ differential equations that result from equations (10) and (11) are integrated in distance to get the gas phase composition profile. Only $N^{G}$ equations are needed, but the form of the model remains simpler if all of them are included. The system of differential equations was solved using the solver LSODE [60,61]. When both homogeneous and surface reactions are considered, a system of differential-algebraic equations is obtained, and one must employ a differentialalgebraic equation solver. Several solvers were tried, but they, in general, appeared to face severe numerical difficulties in a large region of the operating parameters of the problem. For this reason, an alternative computational approach was employed. The surface coverages were treated as parameters in the set of differential equations (equations (10) and (11)), and their values were obtained by solving equations (14)

(along with $\sum_{i} \theta_{i}=1$ ) at each set of gas phase concentrations. The Newton-Raphson method was used to solve these algebraic equations, with the previous solution employed as first guess for each new set of gas phase concentrations.

\section{Results for Uniform Temperature in the Reactor}

Results are presented and discussed here are for uniform temperature in the reactor, 1273 or $1373 \mathrm{~K}\left(1000\right.$ or $\left.1100^{\circ} \mathrm{C}\right)$. However, in the comparison of the predictions of the model with experimental data for $\mathrm{SiO}_{2}$ deposition that is presented later the actual temperature profile in the reactor is employed in the mathematical model. The feed is assumed to contain $\mathrm{SiCl} / \mathrm{CO}_{2} / \mathrm{H}_{2}$ and $\mathrm{MTS} / \mathrm{CO}_{2} / \mathrm{H}_{2}$ at a ratio of $0.06 / 0.35 / 9.59$. These conditions were among those employed in silica deposition experiments in past studies $[1,66]$. 


\section{Homogeneous Chemistry Model}

The case in which only homogeneous reactions are allowed to take place is considered first. This permits us to study the gas phase chemistry independently of the heterogeneous reactions and, in this way, to obtain an estimate of the order of magnitude of the residence time needed for the system to reach thermodynamic equilibrium in the gas phase. Since the occurrence of the heterogeneous reactions is not taken into account, the only reactor parameter that enters in the mathematical model for a plug flow reactor is the space time of the reactor, that is the time required for the mixture to reach, at the inlet conditions, the location of measurement from the entrance of the reactor in the absence of chemical reactions. For isothermal operation and negligible change of the molar flow of the mixture because of the occurrence of chemical reactions, the space time is equal to the residence time of the mixture in the upstream section of the reactor. This is why it is referred to as such in the presentation of the results.

\section{$\underline{\mathrm{SiCl}}_{4} / \underline{C O}_{2} / \underline{H}_{2} \underline{\text { system }}$}

Figure 1 presents the variation with the residence time of the rates of some of the reactions in the homogeneous chemistry mechanism. It is seen that $\mathrm{H}_{2} \mathrm{O}$ is generated mainly through reaction R3. The other water-yielding reactions do not contribute significantly to the gas phase chemistry. Reaction $\mathrm{R} 3$ has been proposed as an $\mathrm{H}_{2} \mathrm{O}-$ yielding reaction by several investigators $[6,7,64,65]$. Reaction $\mathrm{R} 4$ occurs in the reverse direction (formation of $\mathrm{OH}$ radicals), but its ate takes values above the threshold used in the presentation of the results in the figures $\left(10^{-15} \mathrm{kmol} / \mathrm{m}^{3} \cdot \mathrm{s}\right)$ only for residence times greater than 2 s. Computations performed in the absence of reactions R4, R5 and R12 gave results almost identical to those seen in Figure 1. However, it was decided to include these reactions in the homogeneous mechanism because they play an important role in the $\mathrm{MTS} / \mathrm{CO}_{2} / \mathrm{H}_{2}$ system. The production of $\mathrm{H}_{2} \mathrm{O}$ from $\mathrm{R} 3$ depends strongly on $\mathrm{R} 2$, the starting reaction for the generation of $\mathrm{OH}$ radicals. The fact that reactions $\mathrm{R} 2$ and $\mathrm{R} 3$ proceed at the same rate (Figure 1) indicates that the rate of generation of $\mathrm{CO}$ from R2 (which is the only $\mathrm{CO}$ yielding reaction) equals the rate of $\mathrm{H}_{2} \mathrm{O}$ generation. This can be also seen in Figure 2 where he concentrations of these two species evolve in exactly the same way throughout the residence time horizon considered in our calculations. This observation, however, does not imply that the concentrations of $\mathrm{H}_{2} \mathrm{O}$ and $\mathrm{CO}$ in the 
reactor will be the same if reactions $\mathrm{R} 2$ and R3 occur under conditions of significant deposition of $\mathrm{SiO}_{2}$ since water participates in the heterogeneous reactions that lead to silica deposition.

The formation rates of water and carbon monoxide reach a maximum at a residence time of about $15 \mathrm{~s}$. Computations at pressures different from 100 Torr revealed that the pressure has a positive effect on the generation rate of $\mathrm{H}_{2} \mathrm{O}$ and $\mathrm{CO}$ and that the rate maximum tends to shift to lower residence times as the pressure increases. Because of the Arrhenius-type dependence of the rate constants on temperature, the temperature has a much stronger effect than the pressure on the behavior of the process. Results for the variation of the concentrations and of the reaction rates at $1373 \mathrm{~K}$ are presented in Figures 3 and 4 at the same values for the other conditions as in Figures 1 and 2. The comparison of the results of these figures reveals that the effects of temperature are mainly quantitative. The increase of the rates of the various reactions reduces considerably the residence time that is required for the concentrations of the various major species to reach almost constant values (from about $100 \mathrm{~s}$ at $1273 \mathrm{~K}$ to about $10 \mathrm{~s}$ at $1373 \mathrm{~K})$.

These constant values do not correspond to a situation of thermodynamic equilibrium in the system since, as Figures 1 and 4 show, the rates of various chemical reactions are far from being equal to zero. They represent a situation of partial equilibrium at which some of the major reactions in the homogeneous chemistry mechanism (e.g., reactions R2, R3, R20, and R23) have rates that are by a few orders of magnitudes smaller than at lower values of residence time. Figure 5 presents the variation of the mole fractions of some of the major species with the temperature at thermodynamic equilibrium at the conditions of Figures 1-4. These data were computed using the procedure described in [1]. Comparing the results of Figure 5 at 1273 and 1373 $\mathrm{K}$ with those of Figures 2 and 3 clearly shows that even at large residence times the system is not at a state of thermochemical equilibrium. The main reason for this is that the reaction that leads to $\mathrm{SiO}$ formation proceeds with very low rate. The thermodynamic analysis predicts (see Figure 5) that $\mathrm{SiO}$ is the main silicon-containing species and among the major oxygen-containing species in the temperature region of our interest both for $\mathrm{SiCh}_{4}$ and MTS in the feed. Since most of the silicon and a significant part of oxygen exist in the form of $\mathrm{SiO}$ under thermochemical equilibrium conditions, it is not surprising 
that in Figures 2 and 3, where the concentration of $\mathrm{SiO}$ is very low, the concentrations of most species that contain $\mathrm{Si}$ or $\mathrm{O}$ are higher than the corresponding equilibrium values of Figure 5. The equilibrium mole fractions in the gas phase at the conditions of Figure 5 when $\mathrm{SiO}$ is not included in the gas phase are shown in Figure 6. It is seen that the omission of $\mathrm{SiO}$ from the gas phase increases markedly the concentrations of all $\mathrm{Si}$ and $\mathrm{O}$ species.

Increasing the temperature by $100 \mathrm{~K}$ raises the concentration of $\mathrm{OH}$ in the region of partial equilibration of the system by about two orders of magnitude, but it affects insignificantly the concentration of $\mathrm{H}_{2} \mathrm{O}$. However, the concentration of $\mathrm{H}_{2} \mathrm{O}$ is by several orders of magnitude larger than the concentration of $\mathrm{OH}$ even at $1373 \mathrm{~K}$. Therefore, even though $\mathrm{OH}$ is expected to be much more reactive towards the surface of the substrate than $\mathrm{H}_{2} \mathrm{O}$, it may not play a very important role as $\mathrm{O}$ donor for $\mathrm{SiO}_{2}$ formation on the surface. It is interesting to point out that at $1373 \mathrm{~K}$, reaction $\mathrm{R} 4$ proceeds in the direction of $\mathrm{OH}$ production initially - as at $1273 \mathrm{~K}$ in Figure 1 - but its direction changes towards $\mathrm{H}_{2} \mathrm{O}$ production when the residence time exceeds $6 \mathrm{~s}$.

The decomposition of $\mathrm{SiCh}_{4}$ proceeds through reactions $\mathrm{R} 18$ and R20. The results of Figures 2 and 3 show that the concentration of $\mathrm{SiCh}_{4}$ starts to deviate significantly from the value at the inlet after $\mathrm{R} 20$ becomes the main path of $\mathrm{SiCh}_{4}$ consumption. The rate of $\mathrm{R} 20$ reaches a maximum just before $\mathrm{SiCh}_{4}$ and the other major components of the reacting mixture attain partial equilibrium. At very low residence times, the rate of R18 is by more than an order a magnitude higher than the rate of R20, mainly because of the low concentration of $\mathrm{H}$. Even though reaction R18 proceeds with higher rate than reaction R20 only at relatively low residence times, it is one of the most important reactions in the homogeneous mechanism. As the results of Figure 1 show, when R18 is not included in the kinetic mechanism, the rates of all of the reactions are reduced dramatically, by more than two orders of magnitude. This is also true for the reactions in the water gas-shift reaction even though they do not involve chlorosilane species. The main reason for this is that reactions R21 and R19 are important sources of H radicals, which are needed for several reactions (e.g., R2 and R20) to occur. R21 and R19 need the presence of $\mathrm{SiCl}_{3}$ and $\mathrm{Cl}$, respectively, to take place, but initially these species are produced only through R18. $\mathrm{H}$ radicals are also formed through reactions $\mathrm{R} 1$ and $\mathrm{R} 4$, but the contributions of these two reactions are very small. It should be noted that at the point where the 
concentration of $\mathrm{H}$ reaches partial equilibrium in Figure 3 - because of the equilibration of reactions R18, R20, and R19 - reactions R1 and R4 change direction and start proceeding towards $\mathrm{H}$ consumption.

Dichlorosilylene $\left(\mathrm{SiCl}_{2}\right)$ is the silicon-bearing compound with the largest concentration for high residence times, that is, in the region of partial equilibrium. It is formed through reactions R22 and R23 (in the reverse direction). Figures 1 and 4 show that at both temperatures, both of these reactions are favored to occur in the direction of $\mathrm{SiCl}_{2}$ formation. $\mathrm{R} 23$ is the main route of $\mathrm{SiCl}$ formation for low residence times, but it is surpassed by R22, just before it goes through a maximum and starts to approach equilibrium. The thermodynamic analysis showed that $\mathrm{SiHCl}_{3}$ and $\mathrm{SiH}_{2} \mathrm{Cl}_{2}$ exist in significant quantities in the equilibrium composition of the gas phase. The homogeneous model also predicts their generation in significant amounts. These species play a very important role in the deposition process since they are involved, through reactions R22 and $\mathrm{R} 23$, in the production of $\mathrm{SiCl}$, one of the main precursors for $\mathrm{Si}$ incorporation in the deposit.

Hydrogen chloride, the main byproduct of the silica deposition process, is consumed and produced in several pathways of the proposed homogeneous mechanism. Its mole fraction in Figures 2 and 3 is relatively high and comparable to that of $\mathrm{H}_{\mathrm{O}} \mathrm{O}$, and since $\mathrm{HCl}$ is a product of various important heterogeneous steps in the deposition of $\mathrm{SiO}_{2}$, its presence in the gas phase may have an inhibitory effect of the deposition process. Because of their high rates, R20 and R22 are the major routes of $\mathrm{HCl}$ formation, but reaction R19 also contributes significantly. The concentrations of most of the radical species were found to be much lower than their equilibrium values even at residence times where a situation of partial equilibrium exists. This was also found to be the case for the concentration of methane, which is the hydrocarbon with the highest equilibrium mole fraction (see Figure 5). Methane is primarily formed in reactions R16 and R17 (in the reverse drection), but the rates of both of these reactions are very low because of the very concentration of $\mathrm{CH}_{3}$.

\section{$\underline{\mathrm{MTS} / \mathrm{CO}} \underline{2} \underline{\mathrm{H}_{2}} \underline{\text { system }}$}

Figures 7 and 8 present results for the evolution of the mole fraction profiles of species with mole fraction above $10^{-10}$ and of the rates of some of the reactions of the 
homogeneous model, respectively, for the case in which the silicon source is MTS. The conditions are the same as those in Figures 1 and 2 for $\mathrm{SiCh}_{4}$ in the feed. A general observation from the comparison of Figures 2 and 7 is that when MTS is employed in the feed, the major components of the gas phase mixture reach a situation of partial equilibrium (that is, almost constant values) at much lower residence times. This was found to be the case at other pressures and temperatures. In general, the effects of pressure and temperature on the behavior of the $\mathrm{MTS} / \mathrm{CO}_{2} / \mathrm{H}_{2}$ system were found to be similar, in a qualitative sense, to those on the $\mathrm{SiCh} / \mathrm{CO}_{2} / \mathrm{H}_{2}$ system. Increasing the pressure or the temperature caused earlier partial equilibration in the gas phase, but the effects of temperature were considerably stronger.

As in the case of $\mathrm{SiCl}_{4}$, the rates of reactions $\mathrm{R} 2$ and $\mathrm{R} 3$ are almost the same in the residence time range where they have high values, and thus, the concentrations of $\mathrm{H}_{2} \mathrm{O}$ and $\mathrm{CO}$ have almost identical values at all residence times. The rates of $\mathrm{R} 2$ and $\mathrm{R} 3$ start to behave differently after they reach a maximum and drop to low values, but this has no noticeable effect on the concentrations of $\mathrm{CO}$ and $\mathrm{H}_{2} \mathrm{O}$. An interesting observation is that R2 and R3 change direction a few times in the region of high residence time (that is, the region of partial equilibrium), and this is also observed for other chemical reactions. A more careful examination of Figure 7 reveals that the major species that are involved in the submechanism of the water-gas-shift reaction (e.g., $\mathrm{H}_{2}$, $\mathrm{CO}$, and $\mathrm{CO}_{2}$ ) reach almost constant values (partial equilibrium) at much lower residence times (by more than one order of magnitude) than the chlorosilane species that result from the decomposition of MTS. This behavior can also be deduced from the results of Figure 8 where it is seen that the reactions that are involved in the water gas-shift reaction reach their maximum values at much smaller residence times than the reactions involved in the decomposition of MTS. This behavior is at variance with what happens when $\mathrm{SiCh}_{4}$ is fed into the reactor, where all major species reach partial equilibrium and all major reactions attain maximum values at about the same time (see Figures 1-4).

The higher rates of the water-gas-shift reaction and of some key steps in the generation of chlorosilane species in the $\mathrm{MTS} / \mathrm{H}_{2} / \mathrm{CO}_{2}$ system lead to very large differences between the concentrations of the various species in the two systems before a situation of partial equilibration is established. These differences occur over a residence time range that covers the residence time values that are encountered in typical CVD 
arrangements, of laboratory or industrial scale, and therefore, one would expect very large differences in the deposition rates of silica from the two chlorosilanes under identical conditions. It has been observed in past studies that the deposition rate of silica with MTS in the feed is by a few orders of magnitude higher than when $\mathrm{SiCl}_{4}$ is used a silicon source, and as we will see later, the complete homogeneous-heterogeneous model is capable of predicting this experimental finding.

The generation of $\mathrm{H}$ radicals in the reactions involved in the decomposition of MTS is the main reason for the faster occurrence of the water-gas-shift reaction. The starting reaction in the decomposition of MTS is reaction R34, which leads to formation of $\mathrm{CH}_{3}$ and $\mathrm{SiCl}_{3}$. This reaction has very low equilibrium constant, and therefore, its rate is controlled by the subsequent destruction of $\mathrm{CH}_{3}$ and $\mathrm{SiCl}_{3}$ in other reactions. As seen in Figure 8, R16 is the main route of $\mathrm{CH}_{3}$ consumption, with $\mathrm{H}$ and $\mathrm{CH}_{4}$ as products. The occurrence of R16 leads to much higher concentrations of $\mathrm{H}$ radicals in the MTS system (compare Figures 2 and 7), and this in turn causes a dramatic increase in the rate of reaction $\mathrm{R} 2$, the starting reaction of the water gas-shift reaction submechanism. Because of the high values of $\mathrm{H}$ concentration, almost all other reactions in which this species is involved proceed in the direction of its consumption (e.g., R1 and R4). Even R16 starts proceeding in the reverse direction after $\mathrm{CH}_{4}$ reaches a state of partial equilibrium (at about $0.25 \mathrm{~s}$ ). $\mathrm{SiCl}_{3}$ is involved in reactions $\mathrm{R} 18, \mathrm{R} 20$, and $\mathrm{R} 21$, all proceeding in the direction of its consumption. $\mathrm{R} 21$ is the main reaction of $\mathrm{SiCl}_{3}$ consumption, and because of the higher concentrations of $\mathrm{SiCl}_{3}$, it proceeds faster than in the $\mathrm{SiCl} / \mathrm{H}_{2} / \mathrm{CO}_{2}$ system (see Figures 1 and 8). This leads to larger rates of production for most of the $\mathrm{Si}$ and $\mathrm{Cl}$ species. As in the case of the $\mathrm{SiCl} / \mathrm{H}_{2} / \mathrm{CO}_{2}$ system, $\mathrm{HCl}$ attains a high concentration at relatively low values of residence time.

The variation of the equilibrium composition of the $\mathrm{MTS} / \mathrm{H}_{2} / \mathrm{CO}_{2}$ system with the temperature at the conditions of Figures 7 and 8 is shown in Figure 5. Comparing the results of Figure 5 at $1273 \mathrm{~K}$ with the concentrations of the various species at large residence times (region of partial equilibrium) show that, the partial equilibrium concentrations differ significantly from those at complete thermodynamic equilibrium. As in the $\mathrm{SiCh} / \mathrm{H}_{2} / \mathrm{CO}_{2}$ system, this is mainly due to the very low rate of $\mathrm{SiO}$ formation, which is the main silicon-containing species under equilibrium conditions. Thermodynamic equilibrium concentrations without allowing for $\mathrm{SiO}$ in the gas phase 
(see Figure 6) yield equilibrium concentrations that are closer to the concentrations predicted by the mathematical model at high residence times. The results of Figure 5 and 6 show that the equilibrium concentrations of the major species do not differ significantly between the $\mathrm{MTS} / \mathrm{H}_{2} / \mathrm{CO}_{2}$ and $\mathrm{SiCl} / \mathrm{H}_{2} / \mathrm{CO}_{2}$ systems. From the comparison of Figures 2 and 7 , it is concluded that this is also true for the concentrations a high residence times, that is, at partial equilibrium.

$\mathrm{CH}_{4}$ is present at relatively high concentrations in the $\mathrm{MTS} / \mathrm{H}_{2} / \mathrm{CO}_{2}$ system at all residence times even though it is practically absent in the $\mathrm{SiCl} / \mathrm{H}_{2} / \mathrm{CO}_{2}$ system. This leads to significant concentrations for several other hydrocarbons (see Figure 9). R17, $\mathrm{R} 31$, and R16 - before it reverses direction - are the main routes of $\mathrm{CH}_{4}$ formation from the $\mathrm{CH}_{3}$ radicals that are formed from the decomposition of MTS (R34). Several other hydrocarbons are predicted to be present at relatively high concentrations. It is apparent from the results of Figure 9 that a state of partial equilibrium exists among the various hydrocarbons for residence times above $200 \mathrm{~s}$. The concentrations in Figure 9 are by a few orders magnitude higher than the corresponding concentrations at conditions of complete thermodynamic equilibrium in the $\mathrm{MTS} / \mathrm{H}_{2} / \mathrm{CO}_{2}$ mixture (see Figures 5 and 6 for $\mathrm{CH}_{4}$ ). The slow approach of the hydrocarbons to complete equilibrium is mainly due to the low rates of the reactions that involve hydrocarbons and oxygen species, a consequence of the very low concentrations of highly reactive oxygen-containing species, such as $\mathrm{O}$ and $\mathrm{OH}$. The occurrence of these reactions is needed to bring the carbon contained in the $\mathrm{CH}_{3}$ radicals that result from the decomposition of MTS to the $\mathrm{CO}$ and $\mathrm{CO}_{2}$ forms that are favored to exist at equilibrium. The adsorption of hydrocarbons on the substrate could lead to incorporation of carbon in the deposit. However, since the analysis of the deposits that were obtained in our experiments did not reveal the existence of carbon of them, it was decided not to include these species in the heterogeneous chemistry model. It should be noted that because of its stable form and symmetric structure, $\mathrm{CH} 4$, the most abundant of the hydrocarbons, exhibits low reactivity towards the surface [67].

A screening procedure was applied to determine the importance of the various reaction steps of the homogeneous chemistry model in the $\mathrm{SiCl} / \mathrm{CO}_{2} / \mathrm{H}_{2}$ and $\mathrm{MTS} / \mathrm{CO}_{2} / \mathrm{H}_{2}$ systems. The rates of the forward and reverse steps of each of the reactions Table 3 were calculated at the feed conditions and at conditions of complete equilibrium 
in the gas phase (see Figure 5) at several temperatures around $1300 \mathrm{~K}$ and several pressures around 100 Torr. A threshold was defined relative to the fastest forward or reverse step rate at the considered sets of conditions, and those reactions whose forward or reverse step rate was not above that threshold at any set of conditions was omitted from the homogeneous chemistry model. Computations were carried out using the reduced set, and the results showed that any reaction with forward and reverse step rates that were by a factor of $10^{10}$ smaller than the rate of the fastest step had practically no effect on the computed concentrations of the major species in the gas phase and of the species that were included in the heterogeneous chemistry model. (For the reaction rate values of Figures 1,4 and 8 , this translates to an absolute rate limit of $10^{-15} \mathrm{kmol} /\left(\mathrm{m}^{3} \cdot \mathrm{s}\right)$.) Superscripts $\mathrm{a}$ and $\mathrm{b}$ are used on the reactions of Table 3 to indicate those reactions that are important for the $\mathrm{SiCh} / \mathrm{CO}_{2} / \mathrm{H}_{2}$ and $\mathrm{MTS} / \mathrm{CO}_{2} / \mathrm{H}_{2}$ systems, respectively, at the conditions that are of interest for the present study. It was decided to leave all reactions in Tables 3 and 4 since some of those that do not play an important role at the conditions used in our computations may prove to have a significant contribution at conditions of interest to other investigators.

\section{Overall Model}

Figures 10-16 presents results on the evolution of the deposition rate, the surface coverages of some of the adsorbed species, and the gas phase composition with the residence time when the heterogeneous chemistry model of Table 5 is used together with the reactor model and the homogeneous chemistry model. It is assumed that the reactor operates isothermally and has $15 \mathrm{~mm}$ internal diameter, the same as the reactor used in the CVD experiments we carried out. This gives a value of $267 \mathrm{~m}^{-1}$ for parameter $a_{R}$ (lateral (deposition) surface area to volume ratio for the reactor), used in the mathematical model to express the heterogeneous reaction rates per unit of reactor volume (see equation (12)). The results are again presented as functions of the space time of the mixture in the reactor at the conditions at the inlet, which for isothermal operation and small changes in the molar flow rate is almost identical to the residence time of the mixture.

Results on the effect of the pressure of operation on the variation of the deposition rate with the residence time in the $\mathrm{SiCh} / \mathrm{CO}_{2} / \mathrm{H}_{2}$ system are presented in Figure 10, 
whereas Figure 11 presents the effect of temperature on the deposition rate when either $\mathrm{SiCh}_{4}$ or MTS is employed as silicon source. In all cases and for both systems, the deposition rate increases with the residence time, going eventually through a maximum beyond which it decreases to zero. The variation of the gas phase composition with the residence time is presented in Figure 12 for the $\mathrm{SiCl}_{4} / \mathrm{CO}_{2} / \mathrm{H}_{2}$ system at $1273 \mathrm{~K}$ and 100 Torr and in Figure 13 for the $\mathrm{MTS} / \mathrm{CO}_{2} / \mathrm{H}_{2}$ system at 100 Torr and 1272 and $1373 \mathrm{~K}$. Species with mole fraction above $10^{-10}$ are shown in Figure 12, whereas only species that participate in the heterogeneous chemistry model are included in Figure 13. It is seen in Figure 12 and 13 that at the point where the deposition rate starts to decrease to zero, the mole fractions of all Sicontaining species also decrease approaching very low values. This is a clear indication that the dramatic decrease of the deposition rate at residence times above that corresponding to the maximum is a consequence of depletion of the gas phase from $\mathrm{Si}$ species. The mole fraction of all species do not change significantly after the deposition rate becomes zero, and this points to the conclusion that the gas phase is at a condition of partial equilibrium at which the deposition of $\mathrm{SiO}_{2}$ is not feasible. In others words, the concentrations of the gas phase species are such that the sequence of reactions that leads to $\mathrm{SiO}_{2}$ production is equilibrated.

The mole fractions of the Si-containing species that are included in the surface reaction mechanism ( $\mathrm{SiCl}_{2}$ and $\mathrm{SiCl}_{3}$ ) evolve in the same qualitative manner as the deposition rate in the residence time range before the maximum in the deposition. This is also true for the concentrations of gas phase species that are responsible for oxygen incorporation in the deposit $\left(\mathrm{H}_{2} \mathrm{O}\right.$ and $\left.\mathrm{OH}\right)$. Therefore, it is impossible to conclude from the results of Figures 12 and 13 whether the rate of incorporation of silicon or the rate of incorporation of oxygen in the deposit is the factor that limits the deposition rate. The results of Figures 14 and 15 on the variation of the coverages of the various surface species with the residence time in the $\mathrm{SiCl} / \mathrm{CO}_{2} / \mathrm{H}_{2}$ and $\mathrm{MTS} / \mathrm{CO}_{2} / \mathrm{H}_{2}$ systems are more helpful in extracting conclusions on which is the limiting factor in the $\mathrm{SiO}_{2}$ deposition process. Whereas in the first system the coverage of $[\mathrm{OH}]_{\mathrm{s}}$ is considerably higher than those of the $\mathrm{Si}$ species at residence times smaller than that corresponding to the maximum, the opposite situation is encountered when MTS is used as silicon source. This observation suggests that the limiting factor in the deposition of $\mathrm{SiO}_{2}$ from $\mathrm{SiCh}_{4}$ is the supply of Si species to the surface, while at the same conditions but with MTS in the 
feed, the process is limited by the supply of $\mathrm{O}$ species, that is, the rate of hydroxylation of the surface.

The homogeneous model results that were presented in the preceding section showed that the gas phase attained a situation of partial equilibrium faster when MTS was used as silicon source. As a result, the concentrations of all gas phase species that are included in the heterogeneous chemistry mechanism are by several orders magnitude in the case of MTS before partial equilibrium is reached (see Figures 2 and 7). From the evolution of the rates of the elementary reactions in the homogeneous chemistry mechanism, it was concluded in the preceding section that the higher concentrations of $\mathrm{Si}$ containing species were caused by the faster decomposition of MTS. On the other hand, the higher concentrations of deposition precursors that lead to $[\mathrm{OH}]_{\mathrm{s}}$ formation on the surface (that is, of $\mathrm{OH}$ and $\mathrm{HO}$ ) were due to the positive influence on the water-gas-shift reaction of the production of $\mathrm{H}$ radicals in some of the elementary steps of the decomposition of MTS. Figures 12 and 13 show that the above observations also hold when reactions leading to solid deposition are allowed to take place.

A careful examination of the results of Figures 12 and 13 reveals that the effect of the replacement of $\mathrm{SiCh}_{4}$ in the feed with MTS is much stronger for the concentration of $\mathrm{SiCl}_{2}$ and $\mathrm{SiCl}_{3}$ than for those of $\mathrm{OH}$ and $\mathrm{H}_{2} \mathrm{O}$. This is the reason for which the deposition of $\mathrm{SiO}_{2}$ from MTS is limited by the formation of $[\mathrm{OH}]_{\mathrm{s}}$ on the surface despite the much higher concentrations of $\mathrm{OH}$ and $\mathrm{H}_{2} \mathrm{O}$ in the gas phase than in the case of $\mathrm{SiCh}_{4}$. Figures 14 and 15 show that when the deposition of $\mathrm{SiO}_{2}$ drops to zero, the surface coverage of $[\mathrm{OH}]_{\mathrm{s}}$ becomes almost unity and those of the $\mathrm{Si}$ species reach very low values. This is in agreement with the conclusion that the drop in the deposition rate is caused by the reduction of the Si loading of the gas phase. Since the concentration of $\mathrm{OH}$ is much lower than that of $\mathrm{H}_{2} \mathrm{O}$ in both systems and at all residence times, with or without solid formation, reaction RS2 turns out to be a rather unimportant source of $[\mathrm{OH}]_{\mathrm{s}}$ in the heterogeneous surface mechanism. The high concentrations of $\mathrm{H}_{2} \mathrm{O}$ in the gas phase are in accordance with the results of the analysis of the gas phase of silicon oxide CVD reactors using spectroscopic methods $[68,69]$.

Strong effects of pressure and temperature on the deposition rate are manifested in the results of Figures 10 and 11. This is a direct consequence of the strong influence of these operating parameters on the gas phase composition. Because of its positive effect 
on the rates of all elementary reactions in the homogeneous and heterogeneous chemistry mechanisms, an increase in the temperature leads to higher concentrations of radical species in the gas phase and higher deposition rates (see Figure 11) at relatively low residence times (before the appearance of a maximum). The higher deposition rates cause faster consumption of the $\mathrm{Si}$ species, and thus, the residence time at which a maximum is attained moves towards lower residence times as the temperature is increased. An increase in the pressure of operation leads to higher concentrations of the deposition precursors in the gas phase, and thus, it also increase the deposition rate (see Figure 10 for $\mathrm{SiCh}_{4}$ ). Since most reaction steps in the homogeneous mechanism are not monomolecular, the pressure effect on their rates is at least of second order, and thus, depletion of the $\mathrm{Si}$ species from the gas phase occurs at lower residence times. For residence times greater than that at the deposition rate maximum at the lowest pressure or temperature, the deposition rate increases with decreasing pressure or temperature, that is, it behaves in the opposite manner from that at residence times below the deposition rate maximum at the highest pressure or temperature. For residence times between these two values, the deposition rate exhibits non-monotonic variation with the temperature or pressure.

Figure 11 shows that at the same operating conditions, the deposition rate from MTS is much higher for residence times below the deposition rate maximum. For the same reasons as in the effects of pressure and temperature (Figures 10 and 11), the residence time at which the deposition rate maximum is encountered is shifted towards smaller values in the case of MTS. Thus, at locations in the reactor that correspond to residence times greater than that at the maximum deposition rate for MTS, it is possible

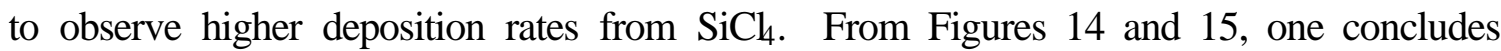
that the very large differences in the deposition rates between MTS and $\mathrm{SiCh}_{4}$ are due to the higher surface concentrations of $\mathrm{Si}$ adsorbed species. This is also suggested by the results of Figures 2 and 7 and 12 and 13 for the concentrations in the gas phase with and without solid formation reactions, respectively. A region of rather weak variation of the deposition rate precedes the maximum in the case of MTS, and therefore, it may be possible to have a situation where the deposition rate does not change significantly over the length of the reactor. As we will see in the following section, the differences in the 
rates of silica deposition from $\mathrm{MTS}$ and $\mathrm{SiCh}_{4}$ are in agreement with the experimental results $[1,66]$.

Since $\mathrm{Si}$ is transferred to the walls of the reactor (deposition surfaces), $\mathrm{Cl}$ contained in the chlorosilane feed is converted to hydrogen chloride. This is why the mole fraction of $\mathrm{HCl}$ under conditions of solid product formation (Figures 12 and 13) is much higher (by more than an order of magnitude) than in the absence of heterogeneous reactions (Figures 2 and 7). The very large concentrations of $\mathrm{HCl}$, in combination with the very low concentrations of Sicontaining species in the gas phase, lead to equilibration of the solid deposition reaction for residence times above the deposition rate maximum. The parameter that controls the contribution of the heterogeneous reactions to the overall rate of production or consumption of the gas phase species is $a_{R}$, the ratio of deposition surface area to reactor volume. Results on the effect of this parameter on the deposition rate vs. residence time curve are shown in Figure 16 for $\mathrm{SiCh}_{4}$ as silicon source. Similar qualitative behavior was exhibited by experimental results for MTS. The dashed curve gives the deposition rate that would be obtained under conditions of negligible contribution of the heterogeneous reactions to the rates of consumption or production of the gas phase species, that is, for negligible deposition surface area. It is seen in Figure 16 that as the deposition surface area is decreased, the deposition rate decreases in the range of low residence times. The reason for this apparently discrepant behavior is that the occurrence of the heterogeneous reactions (see Table 5) not only causes consumption of gas phase species that introduce $\mathrm{Si}$ and $\mathrm{O}$ in the deposit but also produces species (e.g., H) that play a key role in the production of those species in the gas phase reactions. As the comparison of Figures 2 and 12 shows, the concentration of $\mathrm{SiCl}_{2}$, one of the two gaseous species that yield Sicontaining surface species in the proposed heterogeneous chemistry mechanism, is larger for residence times between 0.01 and $1 \mathrm{~s}$ when deposition of $\mathrm{SiO}_{2}$ is allowed to take place.

\section{Comparison of Model and Experiment}

The predictions of the overall (homogeneous and heterogeneous) model are compared with experimental data obtained in CVD experiments in our laboratory. Some of these results were presented in $[1,66]$, and information is provided there on the experimental arrangement and the procedures used in the experiments. Experiments were 
carried out using $\mathrm{SiCh}_{4}$ or MTS in the feed, and deposition rate data were measured by using gravimetric monitoring of the deposition rate on small substrates or by determining the deposition rate profile on thin refractory wires traversing the axis of the tubular reactor. The reactor was a vertical quartz tube with $15 \mathrm{~mm}$ internal diameter, the same as that of the reactor used to obtain the theoretical results of the previous section. Since an experimental reactor cannot be isothermal, the axial temperature profile in the reactor tube was measured at various set point temperatures, and the obtained results were used to find the temperature in the mathematical model along the axis of the reactor. Some of the measured temperature profiles are in Figure 17, where it can be seen that there is a region of about $22-23 \mathrm{~cm}$ in the reactor, starting at about the top of the heating zone (0 $\mathrm{cm}$ location in the reactor), where the temperature is very close to the set point value. The temperature profile in the CVD reactor is also discussed in [70].

Results on the comparison of model and experiment for the effects of temperature are presented in Figures 18 and 19 for $\mathrm{SiCh}_{4}$ and MTS, respectively, as silicon source. Excellent agreement is observed to exist between model and experiment for both silicon sources. This is a remarkable achievement considering that at the conditions of Figures 18 and 19, the deposition rate from $\mathrm{SiCh}_{4}$ is lower than that from MTS by more than one order of magnitude at $1373 \mathrm{~K}$ and by more than three orders of magnitude at $1223 \mathrm{~K}$. The deposition experiments were carried out at different locations in Figures 18 and 19 (4 vs. $7 \mathrm{~cm}$ ), but both of these locations lie within the isothermal zone of the reactor (see Figure 17), and therefore, the reasons for the different deposition rates are the same as those mentioned in the previous section during the discussion of the deposition rate vs. residence time curves for the two chlorosilane species. The effect of temperature on the deposition rate is clearly stronger in the case of $\mathrm{SiCh}_{4}$ especially in the lower end of the temperature range. This is a reflection of the strong effects of temperature on the concentrations of $\mathrm{SiCl}_{2}$ and $\mathrm{SiCl}_{3}$ in the gas phase, which, as it was pointed out before, are the species that control the deposition rate when $\mathrm{SiCh}_{4}$ is used as silicon source. For both silicon sources, the results of Figures 18 and 19 indicate that the activation energy values that may be extracted from the deposition rate vs. temperature results decrease with increasing temperature. This decrease is not the result of increasing mass transport limitations - as it is the usual explanation in the literature - since the model does not consider mass transport limitations from the gas phase to the deposition surface. This 
conclusion is consistent with the observation made in our experiments that the local geometry of the deposition surface (i.e., whether it was a flat substrate or a thin wire) did not affect the measured deposition rate at a given axial location.

Results on the effect of flow rate on the deposition rate for $\mathrm{SiCl}_{4}$ as silicon source at the conditions of Figure 18 are shown in Figure 20. The deposition rate decreases with increasing flow rate, and the agreement between model and experiment is again excellent. The behavior seen in Figure 20 is in agreement with that in Figures 10 and 11 for residence times below the maximum in the deposition rate since for fixed deposition location an increase in the flow rate brings about a decrease in the residence time. It must be noted that the results of Figure 20 lend further support to the conclusion that there are no significant mass transport limitations in the process inasmuch as the mass transfer coefficient from the gas phase to the deposition surface increases with increasing flow rate. The results of Figure 10 showed that an increase in the pressure of operation increases the deposition rate for residence times below the maximum deposition rate. However, for fixed deposition location, an increase in the pressure causes a proportional increase in the residence time (space time) of the mixture in the reactor for fixed temperature profile. Therefore, the pressure effect on the deposition rate at fixed deposition location can be stronger than that seen in Figure 10 at fixed residence time if deposition is carried out in the region where the pressure has a positive effect on the deposition rate, that is, at residence times below the maximum. Experimental and theoretical results on the effect of pressure on the deposition rate from $\mathrm{SiCh}_{4}$ at $4 \mathrm{~cm}$ location are shown in Figure 21. The pressure is seen to affect strongly the deposition rate, having a positive effect on it over the whole range covered in the figure, and this behavior is very well described by the mathematical model.

The distance from the entrance of the reactor, that is, the location of deposition, is the other parameter that has a direct effect on the residence time of the reactive mixture in the reactor. Figure 22 shows the evolution of deposition rate profile at $1300 \mathrm{~K}$ and 100 Torr for a reactive mixture of 0.004 MTS mole fraction and 0.072 carbon dioxide mole fraction in hydrogen. This deposition rate profile was obtained from a single experiment by using as substrate a thin refractory wire traversing the axis of the tubular reactor. The agreement between the experimental and theoretical deposition rate profiles is very good, with both profiles showing a maximum in the deposition rate at about $11 \mathrm{~cm}$ from the 
beginning of the isothermal zone. This maximum occurs within the isothermal zone of the deposition reactor, and it is therefore due to the same reasons as the peaks seen in the theoretical results on the variation of the deposition rate with the residence time in isothermal reactors (Figures 10 and 11), the most important of which are the decrease of the concentrations of $\mathrm{Si}$ species in the gas phase and the increase of the concentrations of $\mathrm{HCl}$.

Experimental results that demonstrate clearly the inhibitory effect of $\mathrm{HCl}$ on the deposition rate of $\mathrm{SiO}_{2}$ are shown in Figure 23 for MTS as silicon source. The mathematical model appears to preform very satisfactorily in reproducing the negative effect of $\mathrm{HCl}$ on the deposition rate. For the MTS mole fraction value used in the experiments of Figure 23, $\mathrm{HCl}$ would be produced at a mole fraction of about 0.03 for complete conversion of the chlorine contained in MTS to $\mathrm{HCl}$. It is seen that at this level of $\mathrm{HCl}$ addition in the feed, the deposition rate is reduced by about $50 \%$ relative to the value it has zero $\mathrm{HCl}$ addition. Since the formation of $\mathrm{HCl}$ in the reactor is accompanied by removal of $\mathrm{Si}$ from the gas phase, one expects the effects of the increase of the concentration of $\mathrm{HCl}$ in the gas phase on the deposition rate to be much stronger than those observed in Figure 23. This is exactly what happens in Figure 22 after the deposition rate goes through a maximum.

\section{Summary}

Detailed homogeneous and heterogeneous kinetic mechanisms for the deposition of $\mathrm{SiO}_{2}$ from $\mathrm{SiCh} / \mathrm{CO}_{2} / \mathrm{H}_{2}$ and $\mathrm{MTS} / \mathrm{CO}_{2} / \mathrm{H}_{2}$ mixtures were formulated in this study. Since formation of the species that are required for the incorporation of oxygen atoms in the film takes place through the pathways of the water-gas-shift reaction, a complete kinetic model for this process was incorporated as a submodel in the homogeneous chemistry model. Information obtained from the analysis of the thermodynamic equilibrium in the gas phase of the reacting mixture and from past experimental and theoretical studies was employed to determine which reaction pathways could play an important role in the overall deposition process. The surface reaction mechanism involved all reactive compounds encountered in significant quantities in the gas phase of the $\mathrm{Si} / \mathrm{C} / \mathrm{Cl} / \mathrm{H} / \mathrm{O}$ system at thermochemical equilibrium. All reactions were treated as reversible in order for the model to be capable of accounting for the inhibitory effects of 
reaction products (e.g., $\mathrm{HCl}$ ) on the deposition process. The overall (homogeneous and heterogeneous) kinetic model was introduced into the transport and reaction model of a tubular, hot-wall CVD reactor. Computations were carried out to investigate the dependence of the spatial variation of the deposition rate, the gas phase composition, and the surface coverages of the adsorbed species on the operating conditions and the reactor parameters. The predictions of the overall model were compared with experimental data obtained in a CVD reactor in our laboratory.

The results showed that the type of the chlorosilane ( $\mathrm{SiCh}_{4}$ or MTS) present in the feed has strong effects on the variation of the concentrations of the gas phase species both with and without reactions leading to solid formation. For both chlorosilane species, the deposition rate increases initially with the residence time of the reactor, but after it reaches a maximum, it decreases to zero. From the gas and adsorbed species concentrations, it was concluded that the drop in the reaction rate is due to the depletion of the gas phase from $\mathrm{Si}$ species and the equilibration of the solid formation reaction because of the high concentration of $\mathrm{HCl}$. When MTS is employed as silicon source, the concentrations of $\mathrm{Si}$ species and $\mathrm{O}$ species that participate in the heterogeneous chemistry mechanism of $\mathrm{SiO}_{2}$ deposition evolve much faster towards their equilibrium concentrations in the absence of solid deposition reactions. Since these species are not present in the feed but are formed in the gas phase, their concentrations are much higher in the case of MTS, and this in turn leads to larger deposition rates in the region of low residence times. Since larger deposition rates imply larger rates of $\mathrm{Si}$ consumption, the maximum in the deposition rate appears at lower residence times in the $\mathrm{MTS} / \mathrm{H}_{2} / \mathrm{CO}_{2}$ system at a given set of reaction conditions. As a result, the deposition rate from $\mathrm{SiCl}_{4}$ becomes greater than that from MTS above some value of residence time.

From the evolution of the gas phase concentrations and the surface coverages of the adsorbed species, it was concluded that the deposition of $\mathrm{SiO}_{2}$ is limited by the rate of $\mathrm{Si}$ incorporation in the deposit in the $\mathrm{SiCl} / \mathrm{CO}_{2} / \mathrm{H}_{2}$ system and by the rate of incorporation of $\mathrm{O}$ in the case of MTS. The higher rates of formation of Si precursor species are caused by the higher rate of decomposition of MTS, whereas the faster formation of $\mathrm{O}$ donor species $\left(\mathrm{H}_{2} \mathrm{O}\right.$ and $\left.\mathrm{OH}\right)$ is due to the effects of the $\mathrm{H}$ radicals formed in the decomposition of MTS on the elementary steps of the water-gas-shift reaction. Regardless of which species was used as silicon source (MTS or $\mathrm{SiCh}_{4}$ ), the residence 
time required for attainment of equilibrium is much larger than the typical residence times encountered in chemical vapor deposition reactors, industrial or laboratory. This result indicates that that the results of thermochemical equilibrium analysis of the gas phase are useful for extracting qualitative conclusions on the effects of operating parameters on the operation of $\mathrm{SiO}_{2}$ deposition reactors.

The temperature and the pressure have positive effects on the deposition rate in the range of low residence times, but because of the increased consumption of $\mathrm{Si}$ in the gas phase, the maximum is shifted towards smaller values of residence time with increasing temperature or pressure. Because of this, for residence times above that corresponding to the maximum in the deposition rate at the lower limit of a temperature or pressure range, the deposition rate may decrease with increasing temperature or may vary in a non-monotonic fashion. These observations agreed with those made in experiments on $\mathrm{SiO}_{2}$ deposition from $\mathrm{SiCh} / \mathrm{CO}_{2} / \mathrm{H}_{2}$ or $\mathrm{MTS} / \mathrm{CO}_{2} / \mathrm{H}_{2}$ mixtures. The overall model was found to be capable of predicting satisfactorily, both qualitatively and quantitatively, the effects of the various operating parameters on the deposition process, including the much higher, by more than an order of magnitude, deposition rate from MTS and the strong inhibitory effect of $\mathrm{HCl}$ addition in the feed on the deposition rate.

\section{ACKNOWLEDGMENTS}

This research was supported by a grant from the U.S. Department of Energy.

\section{LITERATURE CITED}

1. Nitodas, S. F., and Sotirchos, S. V., Chem. Vapor Deposition (Adv. Mater.), 5, 219 (1999).

2. Tsapatsis, M., and Gavalas, G. R., AIChE J., 38, 847 (1992).

3. George, S. M., Sneh, O., Dillon, A. C., Wise, M. L., Ott, A. W., Okada, L. A., and Way, J. D., Appl. Surf. Sci., 82/83, 460 (1994).

4. Armistead, C. G., and Hockey, J. A., T. Faraday Soc., 63, 2549 (1967).

5. Hair, M. L., and Hertl, W., J. Phys. Chem., 77, 2372 (1973).

6. Suski, L., and Wutke, A., B. Pol. Acad. Sci.-Chem., 34, 463 (1986).

7. Bradford, B. W., J. Chem. Soc., 1557 (1933). 
8. Warnatz, J., Combustion Chemistry (Ed.: Gardiner, W. C. Jr.), Springer-Verlag Publishers, New York (1984).

9. Vandooren, J., Peeters, J., and Van Tiggelen, P. J., Symp. Int. Combust. Proc., 15, 745 (1975).

10. Miller, J. A., and Kee, R. J., J. Phys. Chem., 81, 2534 (1977).

11. Baulch, D. L., Cobos, C. J., Cox, R. A., Esser, C., Frank, P., Just, T., Kerr, J. A., Pilling, M. J., Troe, J., Walker, R. W., and Warnatz, J., J. Phys. Chem. Ref. Data, 21, 411 (1992).

12. Sutherland, J. W., Michael, J. V., Pirraglia, A. N., Nesbitt, F. L., and Klemm, R. B., Symp. Int. Combust. Proc., 21, 929 (1988).

13. Davidson, D. F., and Hanson, R. K., Combust. Flame, 82, 445 (1990).

14. Germann, T. C., and Miller, W. H., J. Phys. Chem. A, 101, 6358 (1997).

15. Azatyan, V. V., Aleksandrov, E. N., and Troshin, A. F., Kinet. Catal., 16, 306 (1975).

16. Koike, T., Bull. Chem. Soc. Jpn., 62, 2480 (1989).

17. Arustamyan, A. M., Smakhnazaryan, I. K., Philipossyan, A. G., and Nalbandyan, A. B., Int. J. Chem. Kin., 12, 55 (1980).

18. Tsang, W., and Hampson, R. F., J. Phys. Chem. Ref. Data, 15, 1087 (1986).

19. Westbrook, C. K., and Pitz, W. J., Comb. Sci. Tech., 37, 117 (1984).

20. Berry, R. J., Ehlers, C. J., Burgess, D. R., Jr., Zachariah, M. R., and Marshall, P., Chem. Phys. Lett., 269, 107 (1997).

21. Forst, W., J. Phys. Chem., 95, 3612 (1991).

22. Catoire, L., Woiki, D., and Roth, P., Int. J. Chem. Kinet., 29, 415 (1997).

23. Adusei, G. Y., and Fontijn, A., Symp. Int. Combust. Proc., 25, 801 (1994).

24. Ashen, D. J., Bromberger, G. C., and Lewis, T. J., J. Appl. Chem., 18, 348 (1968).

25. Sirtl, E., Hunt, L. P., and Sawyer, D. H., J. Electrochem. Soc., 121, 919 (1974).

26. Arthur, N. L., Potzinger, P., Reimann, B., and Steenbergen, H. P., J. Chem. Soc. Faraday Trans. 2, 85, 1447 (1989).

27. Swihart, M. T., and Carr, R. W., J. Phys.Chem. A., 102, 1542 (1998).

28. Wittbrodt, J. M., Schlegel, H. B., Chem. Phys. Lett., 265, 527 (1997).

29. Cagliostro, D. E., and Riccitiello, S. R., J. Am. Ceram. Soc., 76, 49 (1993). 
30. Serdvuk, N. K., Strunin, V. P., Chesnokov, E. N., and Panfilov, V. N., Khim. Fiz. (1983).

31. Kerr, J. A., Stephens, A., and Young, J. C., Int. J. Chem. Kinet., 1, 339 (1969).

32. Jasinski, J. M., Becerra, R., and Walsh, R., Chem. Rev., 95, 1203 (1995).

33. Zachariah, M. R., and Tsang, W., J. Phys. Chem., 99, 5308 (1995).

34. Singleton, D. L., and Cvetanovic, R. J., Int. J. Chem. Kinet., 13, 945 (1981).

35. Pritchard, H. O., Pyke, J. B., and Trotman-Dickenson, A. F., J. Am. Chem. Soc., 76, 1201 (1954).

36. Manion, J. A., and Louw, R., J. Chem. Soc. Perkin Trans. 2, 1547 (1988).

37. Dean, A. M., and Westmoreland, P. R., Int. J. Chem. Kinet., 19, 207 (1987).

38. Osterheld, T. H., Allendorf, M. D., and Melius, C. F., J. Phys. Chem., 98, 6995 (1994).

39. Papasouliotis, G. D., "Kinetic Investigation of the Chemical Vapor Deposition of Silicon Carbide through Thermal Decomposition of Methyltrichlorosilane", Ph.D Dissertation, University of Rochester, Rochester, NY (1998).

40. Burgess, J. N., and Lewis, T. J., Chemistry and Industry, 76 (1974).

41. Manory, R., Avni, R., and Grill, A., Plasma Chem. Plasma P., 7, 169 (1987).

42. Gupta, P., Coon, P. A., Koehler, B. G., and George, S. M., J. Chem. Phys., 93, 2827 (1990).

43. Gao, Q., Dohnalek, Z., Cheng, C. C., Choyke, W. J., and Yates, J. T. Jr., Surf. Sci., 302, 1 (1994).

44. Bruno, G., Capezzuto, P., Cicala, G., and Cramarossa, F., Plasma Chem. Plasma P., 6, 109 (1986).

45. Aoyama, T., Inoue, Y., and Suzuki T., J. Electrochem. Soc., 130, 203 (1983).

46. Nishizawa, J., and Saito, M., J. Cryst. Growth, 52, 213 (1981).

47. Bogart, K. H. A., Cushing, J. P., and Fisher, E. R., Chem. Phys. Lett., 267, 377 (1997).

48. Nitodas S. F., Sotirchos S. V., to be submitted in Adv. Mater.

49. Ranke, W., Surf. Sci., 369, 137 (1996).

50. Ranke, W., and Xing., Y. R., Surf. Sci., 381, 1 (1997).

51. Chabal, Y. J., Proc. 10th Inter. Conf. On Chem. Vap. Dep. (Ed.: Cullen, G. W.), 1 (1987).

52. Jacobi, K., and Myler, U., Surf. Sci., 284, 223 (1993). 
53. Ezzehar, H., Stauffer, L., Leconte, J., and Minot, C., Surf. Sci., 388, 220 (1997).

54. Wise, M. L., Koehler, B. G., Gupta, P., Coon, P. A., and George, S. M., Surf. Sci., 258, 166 (1991).

55. Froitzheim, H., Köhler, U., and Lammering, H., J. Phys. C Solid State, 19, 2767 (1986).

56. Ohshita, Y, Ishitani, A., and Takada, T., J. Cryst. Growth, 108, 499 (1991).

57. Wise, M. L., Okada, L. A., Sneh, O., and George, S. M., J. Vac. Sci. Technol. A, 13, $1853(1995)$.

58. Nitodas, S. F., and Sotirchos, S. V., J. Electrochem. Soc., 147, 1050 (2000).

59. Hill, C. G., Jr., An Introduction to Chemical Engineering Kinetics and Reactor Design, John Wiley \& Sons, New York (1977).

60. Hindmarsh, A. C., in Scientific Computing, (Ed.: Stepleman, R. S.), Amsterdam, North Holland, 55 (1983).

61. Petzold, L. R., Siam. J. Sci. Stat. Comp., 4, 136 (1983).

62. Tingey, G. L., J. Phys. Chem., 70, 1406 (1966).

63. Graven, W. M., and Long, F. J., J. Am. Chem. Soc., 76, 2602 (1954).

64. Walkup, R. E., and Raider, S. I., Appl. Phys. Lett., 53, 888 (1988).

65. Buss, R. J., Ho, P., and Weber, M.E., Plasma Chem. Plasma P., 13, 61 (1993).

66. Nitodas, S. F., and Sotirchos, S. V., J. Electrochem. Soc., 147, 1050 (2000).

67. Papasouliotis, G. D., and Sotirchos, S. V., J. Electrochem. Soc., 141, 1599 (1994).

68. Wolf, R., and Wandel, K., Surf. Coat. Technol., 74-5, 522 (1995).

69. Courtney, C. H., Smith, B. C., and Lamb, H. H., J. Electrochem. Soc., 145, 3957 (1998).

70. Papasouliotis, G. D., and Sotirchos, S. V., J. Electrochem. Soc., 142, 3834 (1995). 


\section{LIST OF FIGURES}

Figure 1. Homogeneous reaction rates vs. residence time at $1273 \mathrm{~K}$ and 100 Torr for $\mathrm{SiCh}_{4}$ in the feed. Solid lines: the reaction proceeds in the forward direction; dotted lines: the reaction proceeds in the reverse direction; +: reaction R18 is not included in the mechanism.

Figure 2. Variation of mole fractions with the residence time at the conditions of Figure 1 .

Figure 3. Variation of mole fraction with residence time at $1373 \mathrm{~K}$ and 100 Torr for $\mathrm{SiCl}_{4}$ in the feed.

Figure 4. Homogeneous reaction rates vs. residence time at the conditions of Figure 3. Solid lines: the reaction proceeds in the forward direction; dotted lines: the reaction proceeds in the reverse direction.

Figure 5. Variation of the equilibrium mole fractions with the temperature for $\mathrm{SiCh}_{4}$ or MTS in the feed.

Figure 6. Variation of the equilibrium mole fractions with the temperature for $\mathrm{SiCh}_{4}$ or MTS in the feed without $\mathrm{SiO}$ in the gas phase.

Figure 7. Variation of mole fractions with the residence time at $1273 \mathrm{~K}$ and 100 Torr for MTS in the feed.

Figure 8. Homogeneous reaction rates vs. residence time at the conditions of Figure 7. Solid lines: the reaction proceeds in the forward direction; dotted lines: the reaction proceeds in the reverse direction. 
Figure 9. Variation of the mole fractions of hydrocarbon species at the conditions of Figure 7.

Figure 10. Variation of the deposition rate with the residence time at $1273 \mathrm{~K}$ at various pressures with $\mathrm{SiCl}_{4}$ in the feed.

Figure 11. Variation of the deposition rate with the residence time at 100 Torr and various temperatures with $\mathrm{SiCl}_{4}$ or MTS in the feed.

Figure 12. Evolution of gas phase mole fractions at $1273 \mathrm{~K}$ and 100 Torr with $\mathrm{SiCh}_{4}$ in the feed. Surface reactions are included in the model.

Figure 13. Evolution of gas phase mole fractions at 100 Torr and 1273 or $1373 \mathrm{~K}$ with MTS in the feed. Surface reactions are included in the model.

Figure 14. Surface coverages vs. residence time at the conditions of Figure 12.

Figure 15. Surface coverages vs. residence time at the conditions of Figure 13 at 1273 K.

Figure 16. Dependence of the variation of the deposition rate with residence time on the deposition surface area to reactor volume ratio at $1273 \mathrm{~K}$ and 100 Torr with $\mathrm{SiCl}_{4}$ in the feed.

Figure 17. Temperature profiles in the experimental CVD reactor at various set point temperatures.

Figure 18. Comparison of model and experiment for the variation of the deposition rate with the temperature at 100 Torr and deposition location at $4 \mathrm{~cm}$ with $\mathrm{SiCh}_{4}$ in the feed. 
Figure 19. Comparison of model and experiment for the variation of the deposition rate with the temperature at 100 Torr and deposition location at $7 \mathrm{~cm}$ with MTS in the feed.

Figure 20. Comparison of model and experiment for the variation of the deposition rate with the flow rate at 100 Torr and $1323 \mathrm{~K}$ with $\mathrm{SiCl}_{4}$ in the feed at $4 \mathrm{~cm}$ location.

Figure 21. Comparison of model and experiment for the variation of the deposition rate with the pressure at $1273 \mathrm{~K}$ at $4 \mathrm{~cm}$ location with $\mathrm{SiCl} 4$ in the feed.

Figure 22. Comparison of model and experiment for the deposition rate vs. distance profile in the reactor at $1300 \mathrm{~K}$ and 100 Torr with MTS in the feed.

Figure 23. Comparison of model and experiment for the effects of $\mathrm{HCl}$ mole fraction on the deposition rate at 100 Torr, 1223 and $1273 \mathrm{~K}$, and $4 \mathrm{~cm}$ location with MTS in the feed. 
Table 1. Major gas phase species of the thermodynamic analysis.

$\begin{array}{ll}\mathrm{CH}_{4} & \mathrm{SiCl}_{2} \\ \mathrm{CO} & \mathrm{SiCl}_{3} \\ \mathrm{CO}_{2} & \mathrm{SiCl}_{4} \\ \mathrm{H}_{2} & \mathrm{SiO} \\ \mathrm{HCl} & \mathrm{SiHCl}_{3} \\ \mathrm{H}_{2} \mathrm{O} & \mathrm{SiH}_{2} \mathrm{Cl}_{2} \\ \mathrm{H} & \mathrm{MTS}\left(\mathrm{CH}_{3} \mathrm{SiCl}_{3}\right)\end{array}$


Table 2. Additional gas phase species included in the homogeneous chemistry.

$\begin{array}{ll}\mathrm{CH}_{2} \mathrm{O} & \mathrm{O} \\ \mathrm{CH}_{3} & \mathrm{OH} \\ \mathrm{HCO} & \mathrm{O}_{2} \\ \mathrm{HO}_{2} & \mathrm{SiHCl} \\ \mathrm{Cl} & \mathrm{SiH}_{3} \mathrm{Cl} \\ \mathrm{Cl}_{2} & \mathrm{SiO}_{2} \\ \mathrm{C}_{2} \mathrm{H}_{6} & \mathrm{C}_{2} \mathrm{H}_{5} \\ \mathrm{C}_{2} \mathrm{H}_{4} & \mathrm{C}_{2} \mathrm{H}_{3} \\ \mathrm{C}_{2} \mathrm{H}_{2} & \end{array}$


Table 3. Homogeneous chemistry for $\mathrm{SiCl}_{4} / \mathrm{CO}_{2} / \mathrm{H}_{2}$ and $\mathrm{MTS} / \mathrm{CO}_{2} / \mathrm{H}_{2}$ deposition systems.

$$
\begin{aligned}
& \mathrm{R} 1^{\mathrm{a}, \mathrm{b}} \cdot H_{2}+M \rightarrow 2 H+M \\
& \mathrm{R} 2{ }^{\mathrm{a}, \mathrm{b}} . \mathrm{CO}_{2}+\mathrm{H} \rightarrow \mathrm{CO}+\mathrm{OH} \\
& \text { R3 }{ }^{\mathrm{a}, \mathrm{b}} \cdot \mathrm{H}_{2}+\mathrm{OH} \rightarrow \mathrm{H}_{2} \mathrm{O}+\mathrm{H} \\
& \mathrm{R} 4{ }^{\mathrm{a}, \mathrm{b}} \cdot \mathrm{H}+\mathrm{OH}+\mathrm{M} \rightarrow \mathrm{H}_{2} \mathrm{O}+\mathrm{M} \\
& \mathrm{R}^{\mathrm{a}}{ }^{\mathrm{a} b} . \mathrm{OH}+\mathrm{OH} \rightarrow \mathrm{O}+\mathrm{H}_{2} \mathrm{O} \\
& \mathrm{R}^{\mathrm{a}, \mathrm{b}} \cdot \mathrm{H}_{2}+\mathrm{O} \rightarrow \mathrm{OH}+\mathrm{H} \\
& \text { R7. } O+O+M \rightarrow O_{2}+M \\
& \text { R8. } \mathrm{H}_{2}+\mathrm{O}_{2} \rightarrow \mathrm{OH}+\mathrm{OH} \\
& \text { R9. } \mathrm{H}_{2}+\mathrm{O}_{2} \rightarrow \mathrm{HO}_{2}+\mathrm{H} \\
& \text { R10. } \mathrm{H}+\mathrm{O}_{2}+\mathrm{M} \rightarrow \mathrm{HO}_{2}+\mathrm{M} \\
& \text { R11. } \mathrm{H}+\mathrm{O}_{2} \rightarrow \mathrm{OH}+\mathrm{O} \\
& \text { R12. } \mathrm{HO}_{2}+\mathrm{H}_{2} \rightarrow \mathrm{H}_{2} \mathrm{O}+\mathrm{OH} \\
& \mathrm{R} 13^{\mathrm{b}} \cdot \mathrm{H}+\mathrm{CO}+\mathrm{M} \rightarrow \mathrm{HCO}+\mathrm{M} \\
& \mathrm{R} 14^{\mathrm{b}} \text {. } \mathrm{HCO}+\mathrm{H}_{2} \rightarrow \mathrm{CH}_{2} \mathrm{O}+\mathrm{H} \\
& \text { R15 }{ }^{\mathrm{b}} \text {. } \mathrm{CH}_{2} \mathrm{O}+\mathrm{H} \rightarrow \mathrm{CH}_{3}+\mathrm{O} \\
& \text { R16 }{ }^{\mathrm{b}} . \mathrm{CH}_{3}+\mathrm{H}_{2} \rightarrow \mathrm{CH}_{4}+\mathrm{H} \\
& \text { R17 }{ }^{\mathrm{b}} . \mathrm{CH}_{4}+\mathrm{M} \rightarrow \mathrm{CH}_{3}+\mathrm{H}+\mathrm{M} \\
& \mathrm{R} 18^{\mathrm{a}, \mathrm{b}} \cdot \mathrm{SiCl}_{4}+\mathrm{M} \rightarrow \mathrm{SiCl}_{3}+\mathrm{Cl}+\mathrm{M} \\
& \mathrm{R} 19^{\mathrm{a}, \mathrm{b}} \cdot \mathrm{H}_{2}+\mathrm{Cl} \rightarrow \mathrm{H}+\mathrm{HCl} \\
& \mathrm{R} 20^{\mathrm{a}, \mathrm{b}} \cdot \mathrm{SiCl}_{4}+\mathrm{H} \rightarrow \mathrm{SiCl}_{3}+\mathrm{HCl} \\
& \mathrm{R} 21^{\mathrm{a}, \mathrm{b}} \cdot \mathrm{SiCl}_{3}+\mathrm{H}_{2} \rightarrow \mathrm{SiHCl}_{3}+\mathrm{H}
\end{aligned}
$$




\section{Table 3 (contd.)}

$$
\begin{aligned}
& \mathrm{R} 22^{\mathrm{a}, \mathrm{b}} . \mathrm{SiHCl}_{3} \rightarrow \mathrm{SiCl}_{2}+\mathrm{HCl} \\
& \mathrm{R} 23^{\mathrm{a}, \mathrm{b}} . \mathrm{SiCl}_{2}+\mathrm{H}_{2} \rightarrow \mathrm{SiH}_{2} \mathrm{Cl}_{2} \\
& \mathrm{R} 24^{\mathrm{a}, \mathrm{b}} . \mathrm{SiH}_{2} \mathrm{Cl}_{2} \rightarrow \mathrm{SiHCl}+\mathrm{HCl} \\
& \mathrm{R} 25^{\mathrm{a}, \mathrm{b}} . \mathrm{SiHCl}_{3}+\mathrm{H}_{2} \rightarrow \mathrm{SiH}_{2} \mathrm{Cl}_{2}+\mathrm{HCl} \\
& \mathrm{R} 26^{\mathrm{a}, \mathrm{b}} \cdot \mathrm{SiHCl}_{3}+\mathrm{Cl} \rightarrow \mathrm{HCl}+\mathrm{SiCl}_{3} \\
& \text { R27. } \mathrm{CH}_{3}+\mathrm{SiHCl}_{3} \rightarrow \mathrm{CH}_{4}+\mathrm{SiCl}_{3} \\
& \mathrm{R} 28^{\mathrm{a}, \mathrm{b}} \cdot \mathrm{SiCl}_{2}+\mathrm{O} \rightarrow \mathrm{SiO}+\mathrm{Cl}_{2} \\
& \mathrm{R} 29 . \mathrm{OH}+\mathrm{SiO} \rightarrow \mathrm{SiO}_{2}+\mathrm{H} \\
& \text { R30. } \mathrm{O}+\mathrm{HCl} \rightarrow \mathrm{OH}+\mathrm{Cl} \\
& \text { R31. } \mathrm{CH}_{3}+\mathrm{HCl} \rightarrow \mathrm{CH}_{4}+\mathrm{Cl} \\
& \text { R32. } \mathrm{CH}_{2} \mathrm{O}+\mathrm{H}_{2} \rightarrow \mathrm{CH}_{3}+\mathrm{OH} \\
& \mathrm{R} 33^{\mathrm{a}, \mathrm{b}} \cdot \mathrm{SiHCl}+\mathrm{H}_{2} \rightarrow \mathrm{SiH}_{3} \mathrm{Cl} \\
& \mathrm{R} 34^{\mathrm{b}} \text {. } \mathrm{CH}_{3} \mathrm{SiCl}_{3} \rightarrow \mathrm{CH}_{3}+\mathrm{SiCl}_{3} \\
& \mathrm{R} 35^{\mathrm{b}} . \mathrm{CH}_{3}+\mathrm{CH}_{3} \rightarrow \mathrm{C}_{2} \mathrm{H}_{6} \\
& \mathrm{R} 36^{\mathrm{b}} . \mathrm{C}_{2} \mathrm{H}_{6}+\mathrm{H} \rightarrow \mathrm{C}_{2} \mathrm{H}_{5}+\mathrm{H}_{2} \\
& \mathrm{R} 37^{\mathrm{b}} . \mathrm{C}_{2} \mathrm{H}_{5}+\mathrm{M} \rightarrow \mathrm{C}_{2} \mathrm{H}_{4}+\mathrm{H}+\mathrm{M} \\
& \mathrm{R} 38^{\mathrm{b}} . \mathrm{C}_{2} \mathrm{H}_{4}+\mathrm{H} \rightarrow \mathrm{C}_{2} \mathrm{H}_{3}+\mathrm{H}_{2} \\
& \mathrm{R} 39^{\mathrm{b}} \text {. } \mathrm{C}_{2} \mathrm{H}_{3}+\mathrm{M} \rightarrow \mathrm{C}_{2} \mathrm{H}_{2}+\mathrm{H}+\mathrm{M} \\
& \mathrm{R} 40^{\mathrm{b}} . \mathrm{C}_{2} \mathrm{H}_{3}+\mathrm{H} \rightarrow \mathrm{C}_{2} \mathrm{H}_{2}+\mathrm{H}_{2} \\
& \mathrm{R} 41^{\mathrm{b}} . \mathrm{CH}_{3}+\mathrm{CH}_{3} \rightarrow \mathrm{C}_{2} \mathrm{H}_{5}+\mathrm{H}
\end{aligned}
$$

${ }^{a}$ Affects significantly the deposition process for $\mathrm{SiCl} / \mathrm{CO}_{2} / \mathrm{H}_{2}$ feed.

${ }^{\mathrm{b}}$ Affects significantly the deposition process for $\mathrm{MTS} / \mathrm{CO}_{2} / \mathrm{H}_{2}$ feed. 
Table 4. Homogeneous reaction rate constants.

$k=A x T^{n} x \exp (-E / R T)$; Units: kgmol, kJ, $\mathrm{m}^{3}, \mathrm{~s}, \mathrm{~K}$.

\begin{tabular}{|c|c|c|c|}
\hline Reaction & $A$ & $E$ & $n$ \\
\hline R1* & $6.407 \times 10^{11}$ & 0 & -1 \\
\hline $\mathrm{R} 2$ & $8.269 \times 10^{11}$ & 101 & 0 \\
\hline $\mathrm{R} 3$ & $1.0 \times 10^{8}$ & 13.8 & 1.6 \\
\hline $\mathrm{R} 4$ & $1.403 \times 10^{17}$ & 0 & -2 \\
\hline $\mathrm{R} 5$ & $1.504 \times 10^{6}$ & 0.42 & 1.14 \\
\hline R6 & $1.87 \times 10^{11}$ & 56.98 & 0 \\
\hline $\mathrm{R} 7$ & $1.001 \times 10^{11}$ & 0 & -1 \\
\hline $\mathrm{R} 8$ & $1.9 \times 10^{11}$ & 181.99 & 0 \\
\hline R9 & $4.1 \times 10^{13}$ & 284.98 & 0 \\
\hline R10 & $7.009 \times 10^{11}$ & 0 & -0.8 \\
\hline R11 & $1.77 \times 10^{11}$ & 69.663 & 0 \\
\hline $\mathrm{R} 12$ & $9.63 \times 10^{7}$ & 96 & 0 \\
\hline $\mathrm{R} 13$ & $6.9 \times 10^{8}$ & 7 & 0 \\
\hline R14 & $1.802 \times 10^{3}$ & 74.59 & 2 \\
\hline $\mathrm{R} 15$ & $8.43 \times 10^{10}$ & 0 & 0 \\
\hline R16 & $7.71 \times 10^{4}$ & 55.5 & 1.97 \\
\hline $\mathrm{R} 17^{*}$ & $2.298 \times 10^{21}$ & 5.28 & -2.98 \\
\hline R18 & $4.8 \times 10^{13}$ & 340.5 & 0 \\
\hline $\mathrm{R} 19 *$ & $1.363 \times 10^{5}$ & 13.24 & 1.63 \\
\hline R20 & $1.4 \times 10^{10}$ & 39.91 & 0 \\
\hline $\mathrm{R} 21$ & $2.47 \times 10^{9}$ & 10.64 & 0 \\
\hline $\mathrm{R} 22$ & $5 \times 10^{14}$ & 300 & 0 \\
\hline $\mathrm{R} 23 *$ & $7.94 \times 10^{13}$ & 321 & 0 \\
\hline $\mathrm{R} 24 *$ & $7.94 \times 10^{14}$ & 314 & 0 \\
\hline $\mathrm{R} 25^{*}$ & $2.49 \times 10^{29}$ & 207.5 & 0 \\
\hline R26 & $7.23 \times 10^{9}$ & 0 & 0 \\
\hline
\end{tabular}


Table 4 (contd.)

\begin{tabular}{lccc} 
Reaction & $A$ & $E$ & $n$ \\
\hline R27 & $6.76 \times 10^{7}$ & 17.98 & 0 \\
R28 & $4.638 \times 10^{9}$ & 0 & 0 \\
R29 & $1.798 \times 10^{7}$ & 5.1 & 0.78 \\
R30 & $3.06 \times 10^{9}$ & 26.3 & 0 \\
R31 & $3.16 \times 10^{8}$ & 3.89 & 0 \\
R32* & $3.195 \times 10^{9}$ & 45.23 & -0.53 \\
R33* & $1.0 \times 10^{15}$ & 288.38 & 0 \\
R34 & $1.0 \times 10^{18}$ & 407.92 & 0 \\
R35 & $8.91 \times 10^{9}$ & 0 & 0 \\
R36 & 0.54 & 21.76 & 3.5 \\
R37* & $2.79 \times 10^{12}$ & 3.16 & 0 \\
R38 & $1.51 \times 10^{4}$ & 25.1 & 2 \\
R39 & $3.9 \times 10^{11}$ & 158.8 & 0 \\
R40 & $2 \times 10^{10}$ & 10.46 & 0 \\
R41 & $2.8 \times 10^{10}$ & 56.87 & 0
\end{tabular}

*The parameters given refer to the reverse step. 
Table 5. Surface reaction mechanism for $\mathrm{SiCl}_{4} / \mathrm{CO}_{2} / \mathrm{H}_{2}$ and $\mathrm{MTS} / \mathrm{CO}_{2} / \mathrm{H}_{2}$ deposition systems.

RS1. $\mathrm{H}_{2} \mathrm{O}+[\mathrm{S}] \rightarrow \mathrm{H}+[\mathrm{OH}]_{S}$

$\mathrm{RS} 2 . \mathrm{OH}+[\mathrm{S}] \rightarrow[\mathrm{OH}]_{S}$

RS3. $\mathrm{SiCl}_{2}+[\mathrm{S}] \rightarrow\left[\mathrm{SiCl}_{2}\right]_{S}$

RS4. $\mathrm{SiCl}_{3}+[\mathrm{S}] \rightarrow\left[\mathrm{SiCl}_{3}\right]_{S}$

RS5. $\left[\mathrm{SiCl}_{3}\right]_{S}+\mathrm{H} \rightarrow\left[\mathrm{SiCl}_{2}\right]_{S}+\mathrm{HCl}$

RS6. $\left[\mathrm{SiCl}_{2}\right]_{S}+[\mathrm{OH}]_{s} \rightarrow[\mathrm{SiClO}]_{S}+[\mathrm{S}]+\mathrm{HCl}$

RS7. $[\mathrm{SiClO}]_{S}+[\mathrm{OH}]_{S} \rightarrow \mathrm{SiO}_{2}+2[\mathrm{~S}]+\mathrm{HCl}$ 
Table 6. Surface reaction rate constants.

$k=A x T^{n} x \exp (-E / R T) ;$ Units: kgmol, $\mathrm{kJ}, \mathrm{m}^{2}, \mathrm{~s}, \mathrm{~K}$.

\begin{tabular}{ccccccc} 
& & Forward Step & & \multicolumn{3}{c}{ Reverse Step } \\
Reaction & $A$ & $E$ & $n$ & $A$ & $E$ & $n$ \\
\cline { 2 - 5 } RS1 & $8.57 \times 10^{-2 *}$ & 0 & 0.5 & 5.82 & 0 & 0.5 \\
RS2 & 8.82 & 0 & 0.5 & $1.14 \times 10^{9}$ & 511 & 0 \\
RS3 & 3.7 & 0 & 0.5 & $7.22 \times 10^{5}$ & 280 & 0 \\
RS4 & 3.14 & 0 & 0.5 & $5.80 \times 10^{5}$ & 280 & 0 \\
RS5 & 36.4 & 0 & 0.5 & 6.02 & 102 & 0.5 \\
RS6 & $2.04 \times 10^{6}$ & 274 & 0 & 200 & 119 & 0 \\
RS7 & $4.57 \times 10^{6}$ & 274 & 0 & $1.2 \times 10^{-3}$ & 119 & 1.5
\end{tabular}

*The parameters given correspond to a sticking coefficient of 0.01 . 


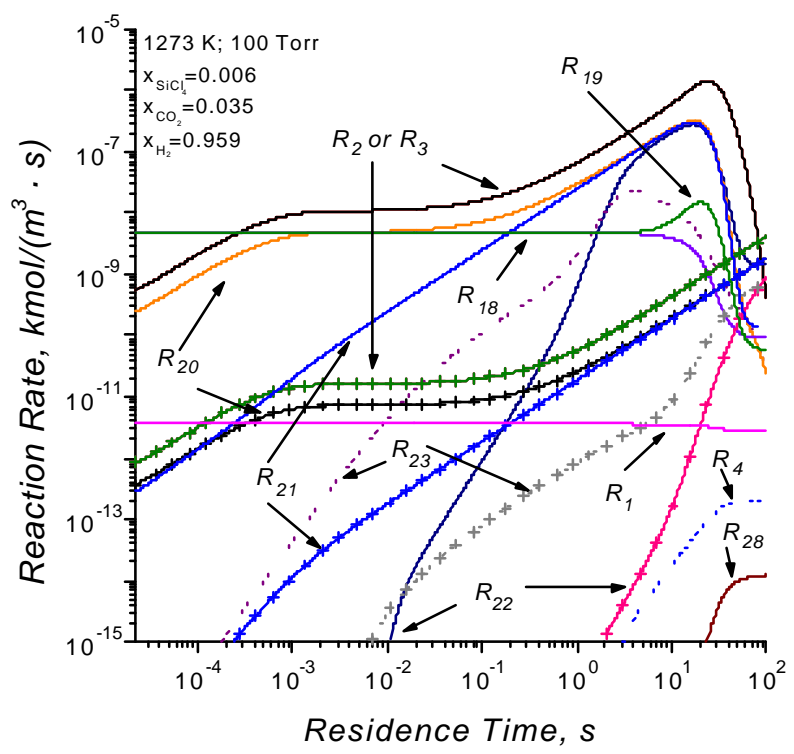

FIGURE 1 


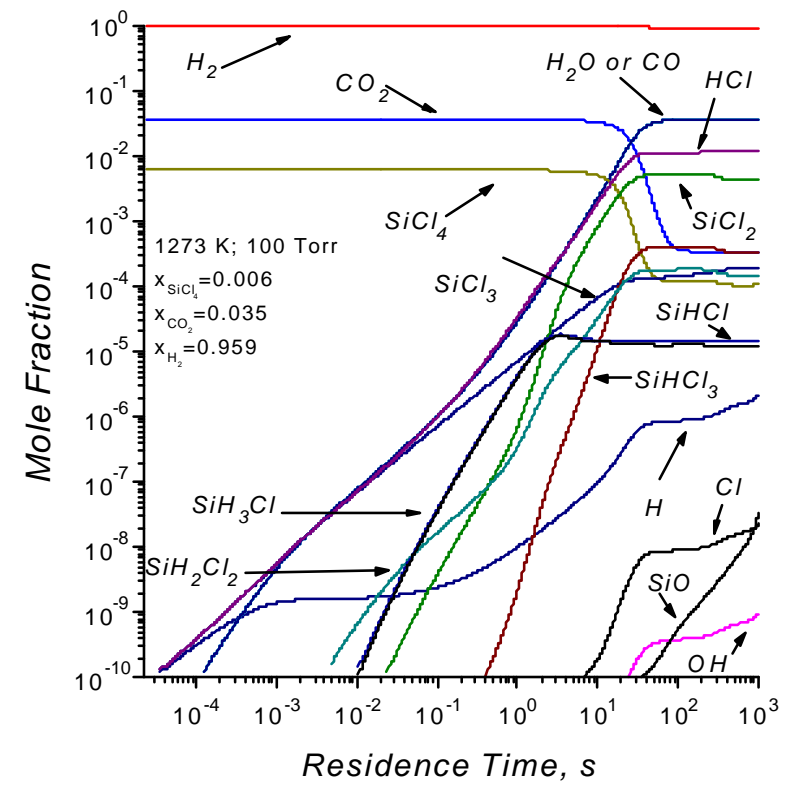

FIGURE 2 


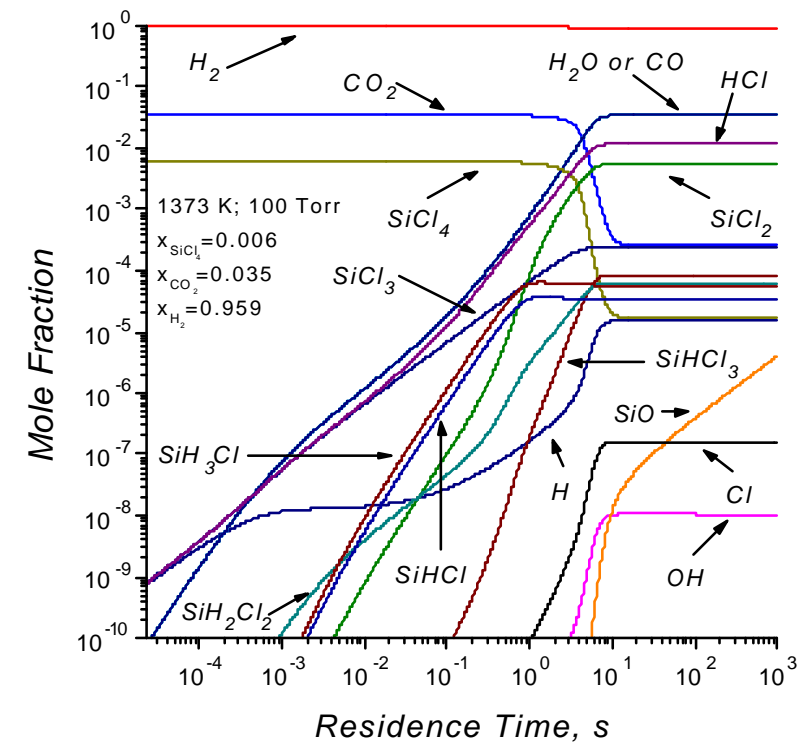

FIGURE 3 


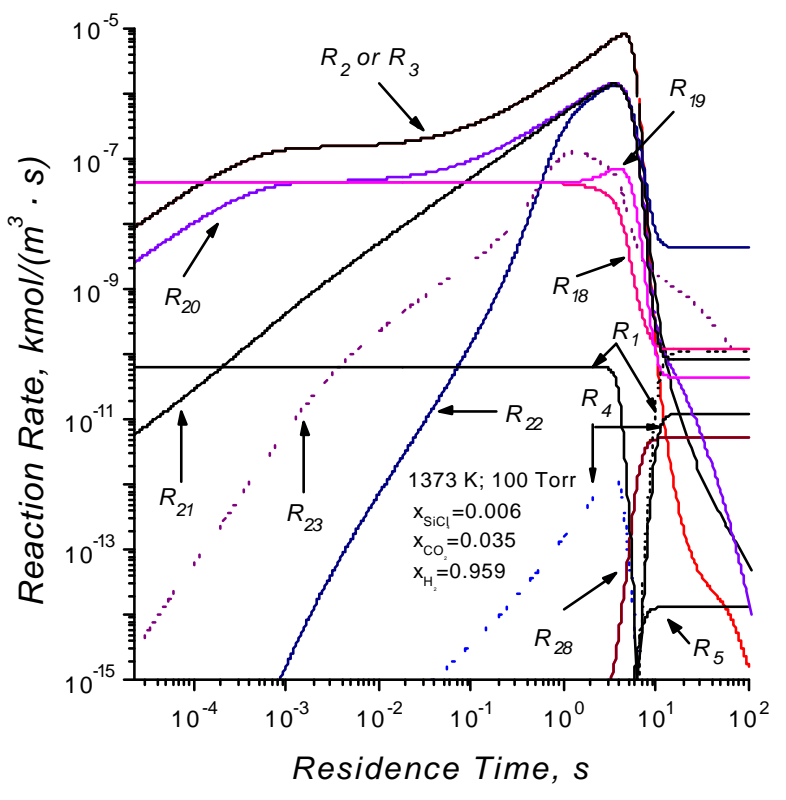

FIGURE 4 


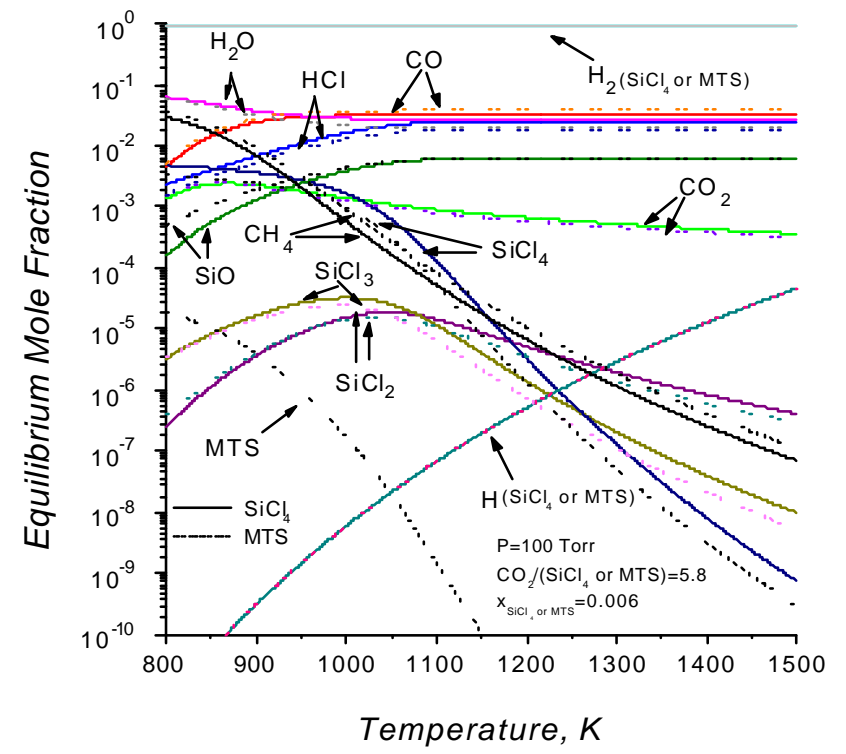

FIGURE 5 


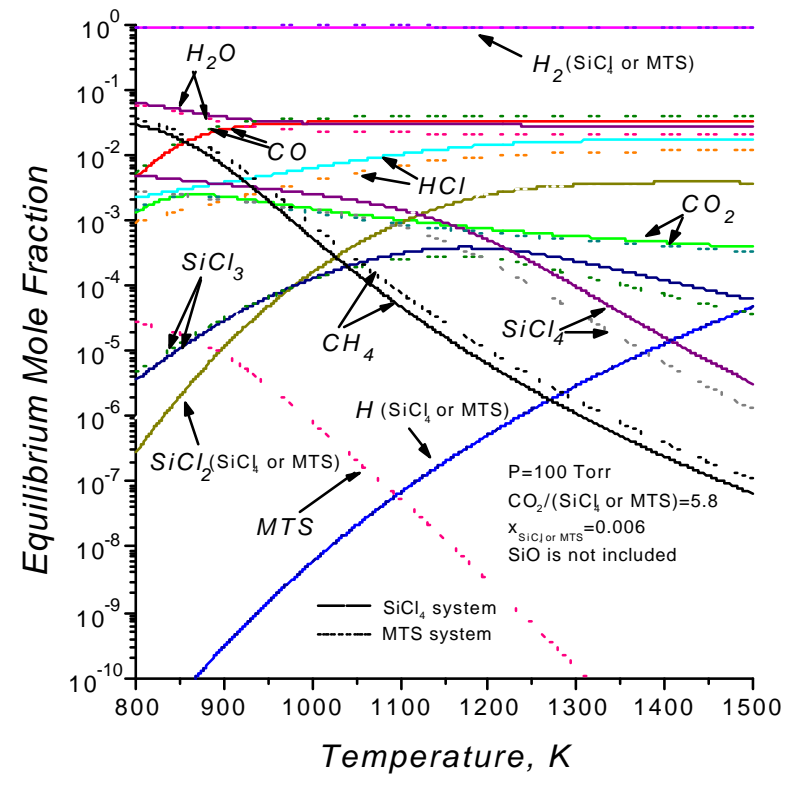

FIGURE 6 


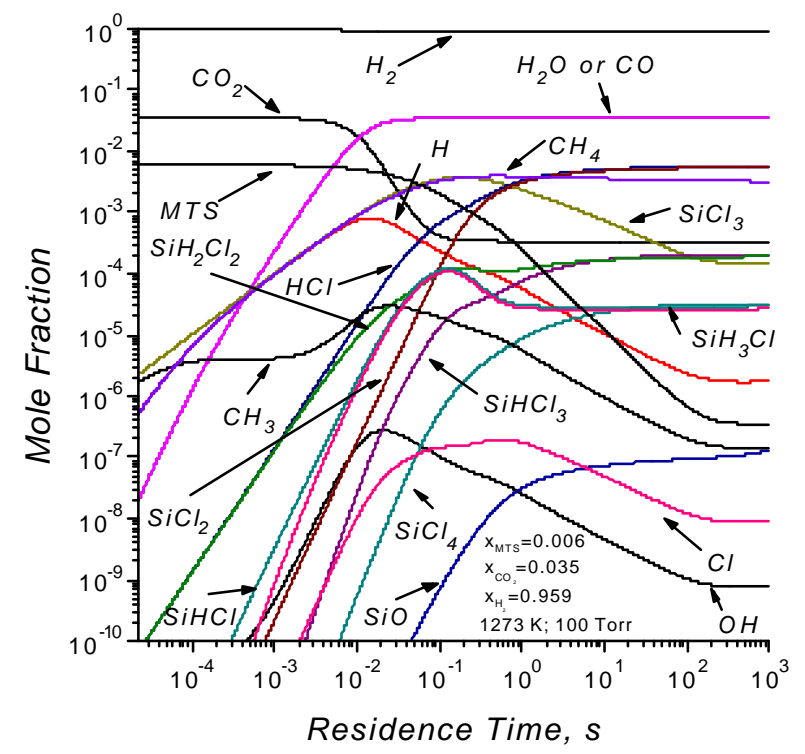

FIGURE 7 


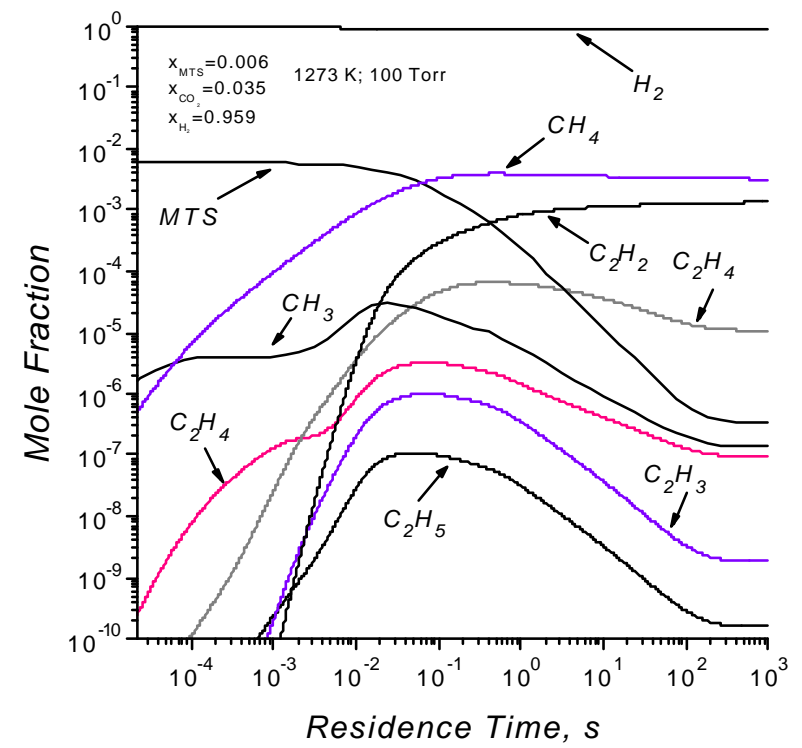

FIGURE 8 


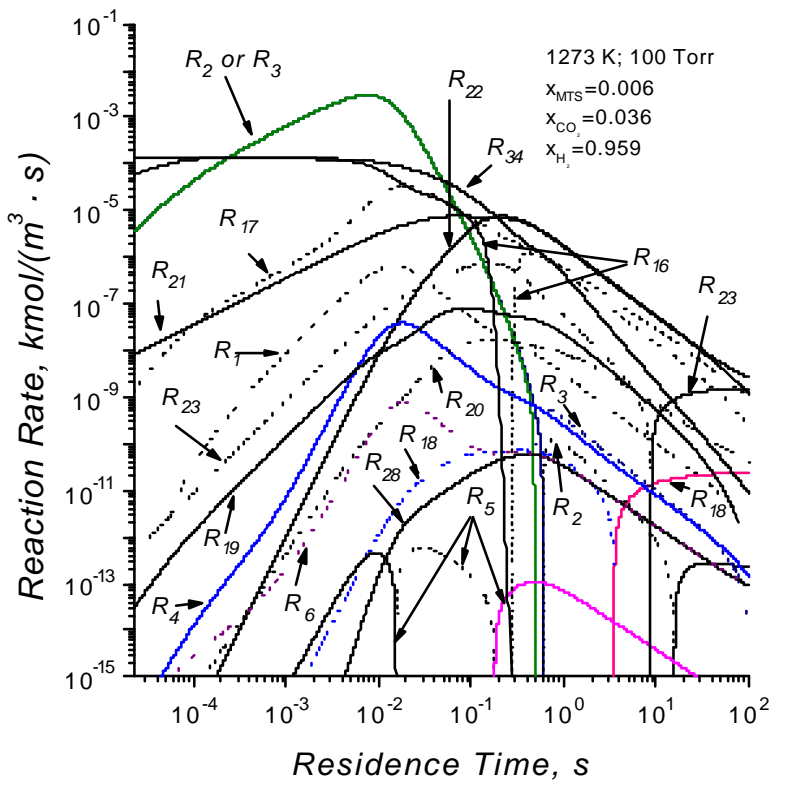

FIGURE 9 


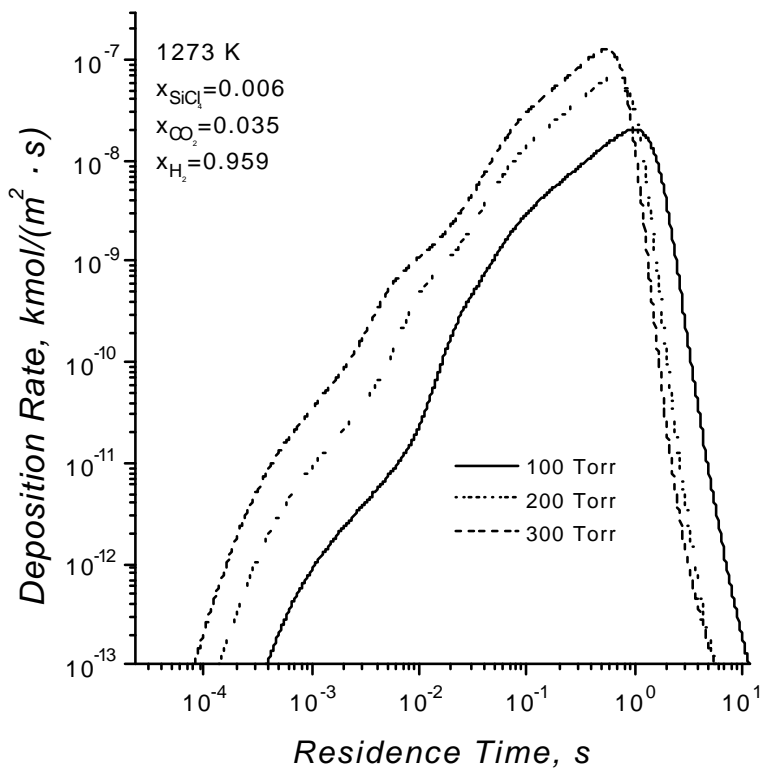

FIGURE 10 


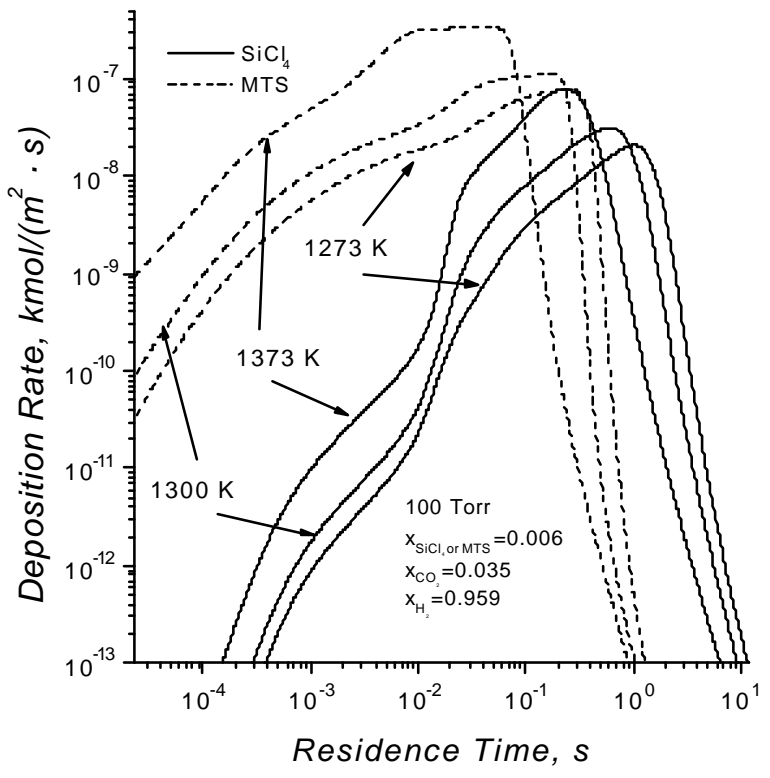

FIGURE 11 


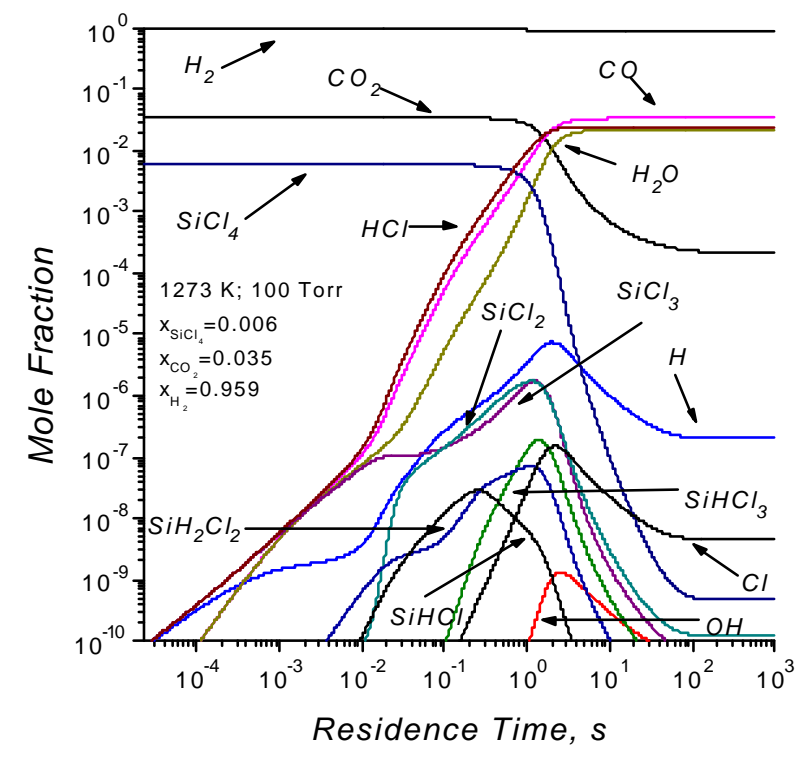

FIGURE 12 


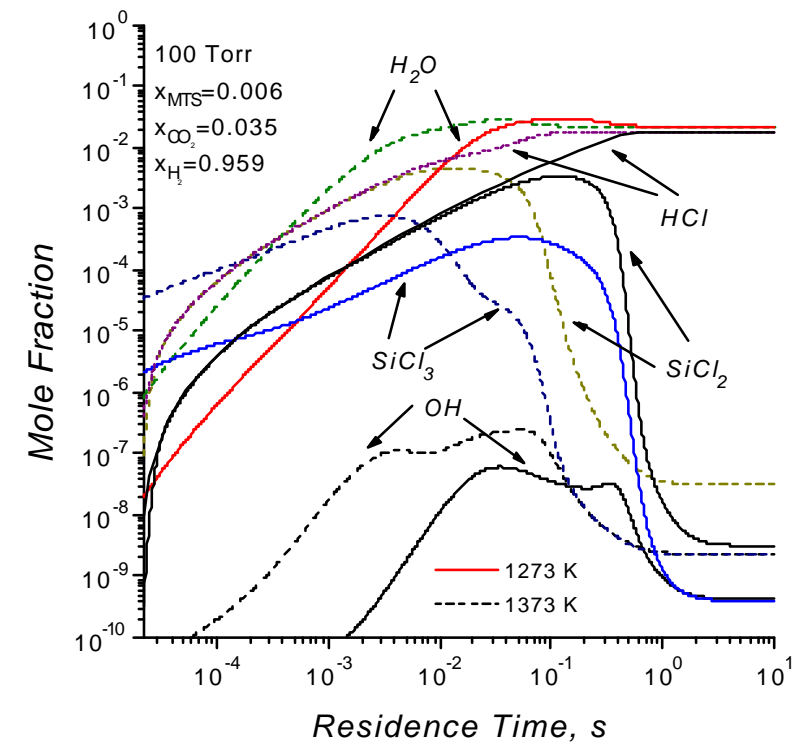

FIGURE 13 


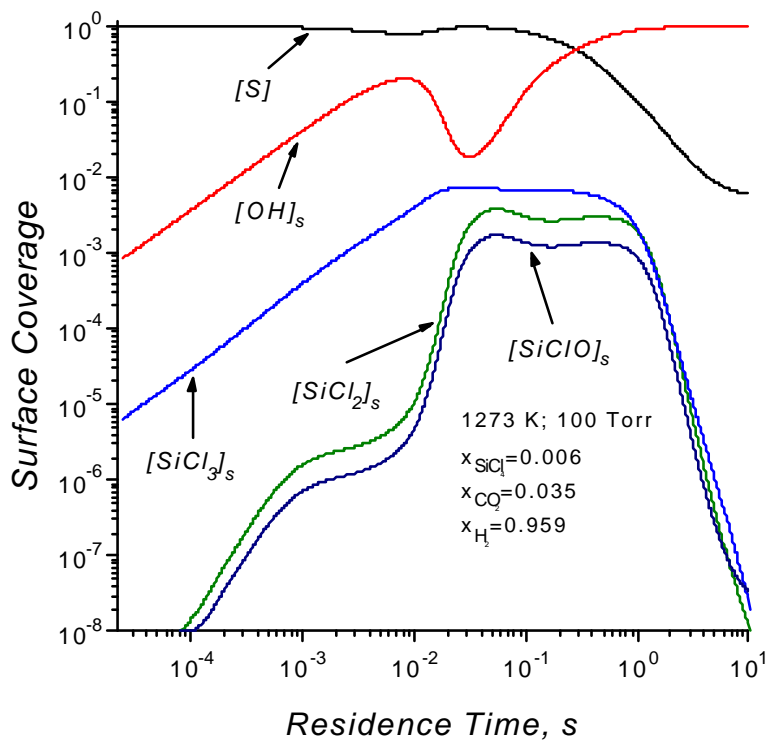

FIGURE 14 


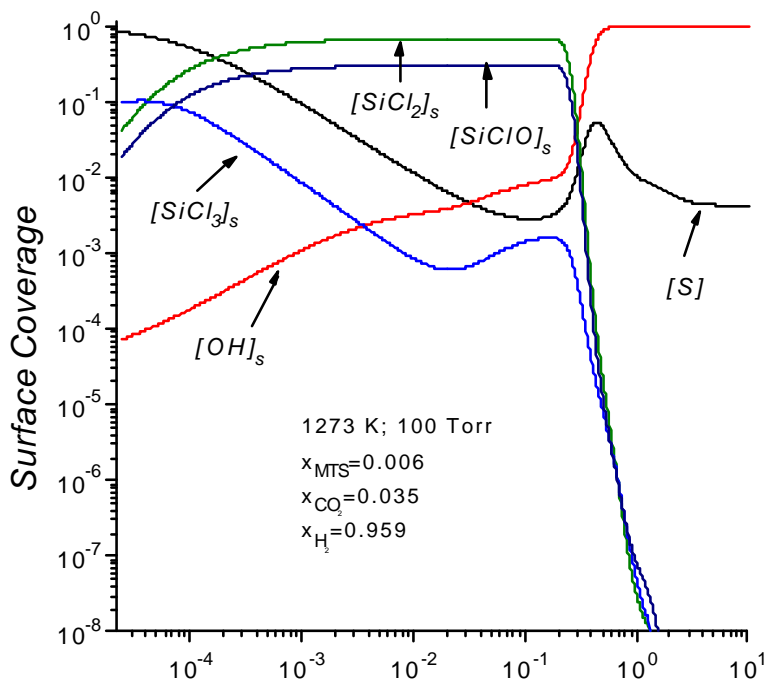

Residence Time, $s$ 


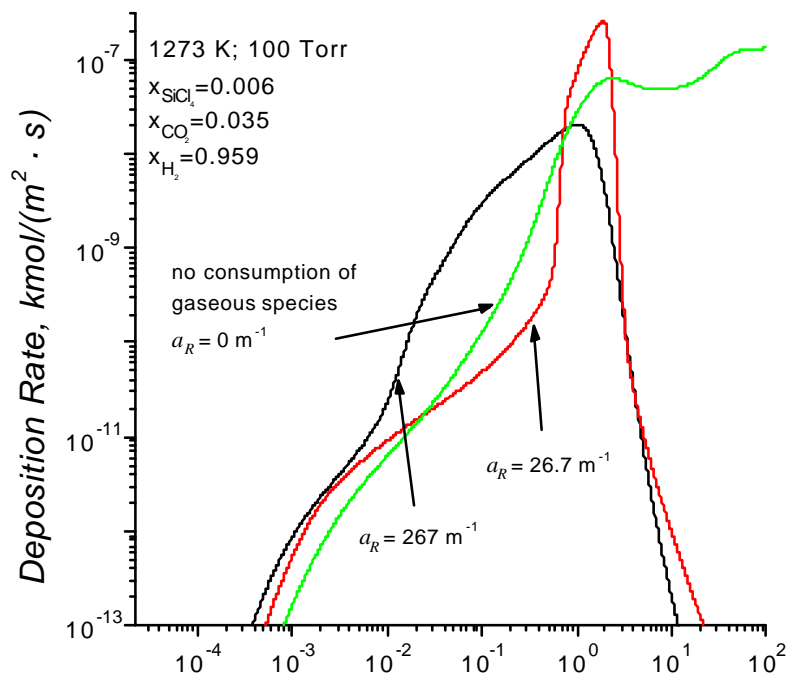

Residence Time, $s$ 


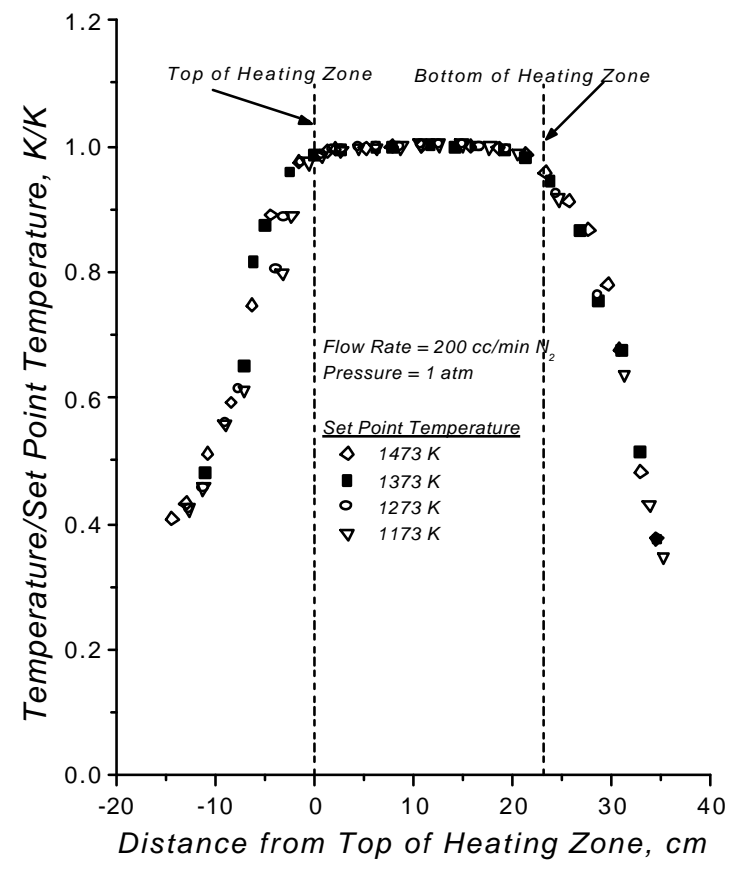




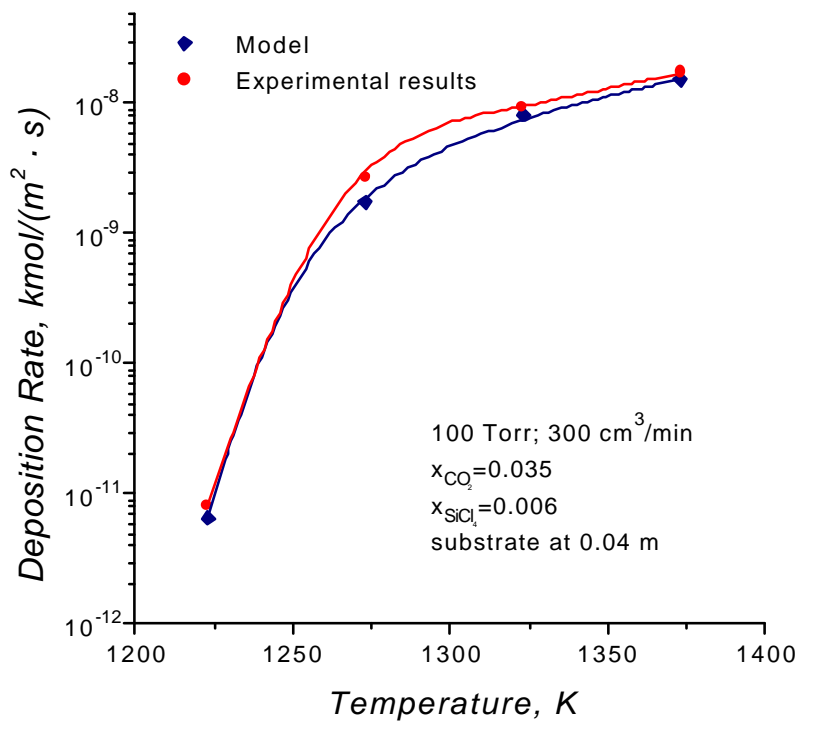

FIGURE 18 


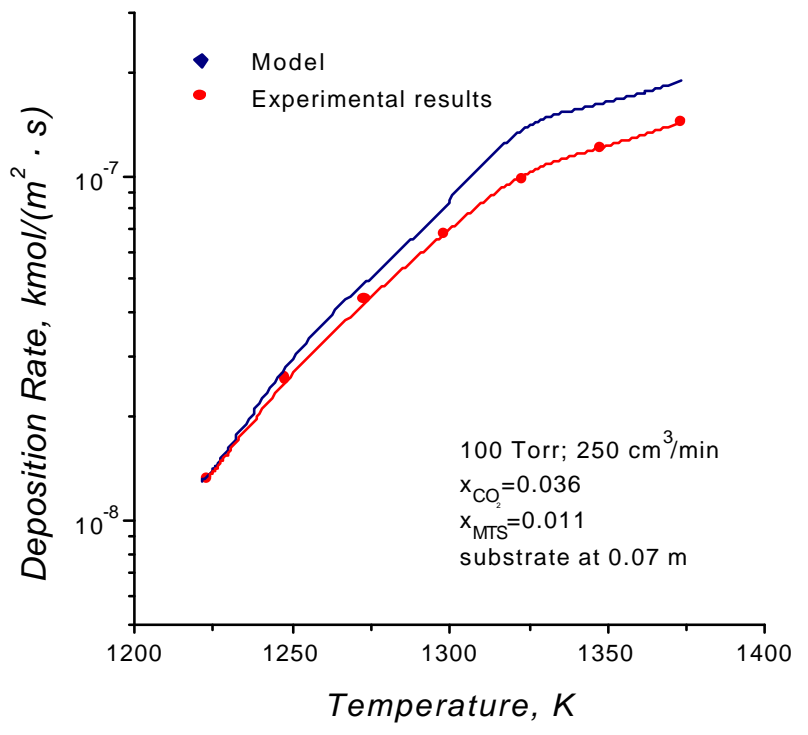

FIGURE 19 


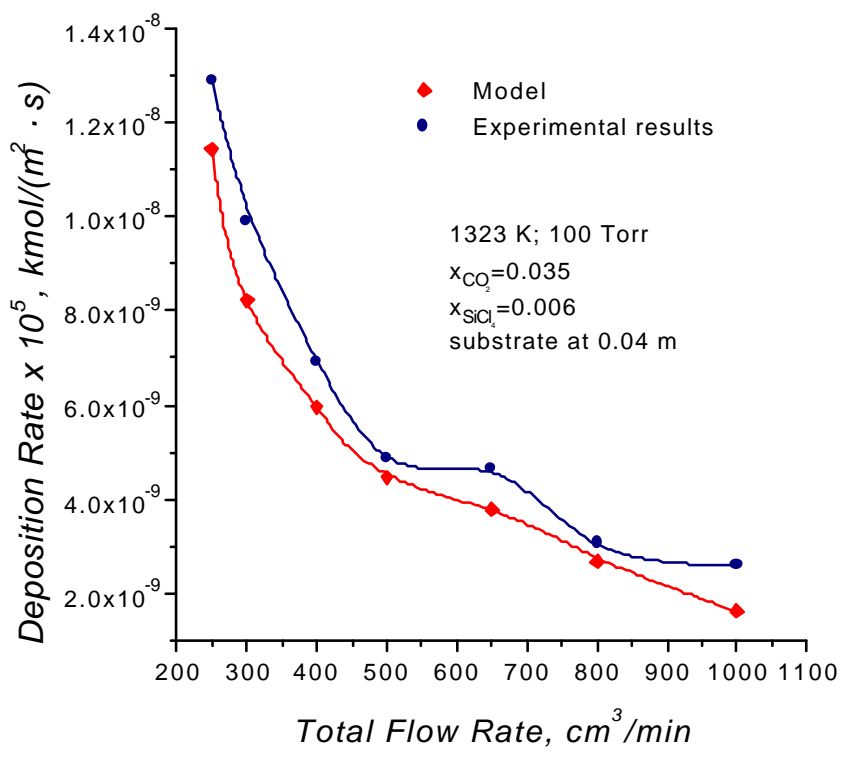

FIGURE 20 


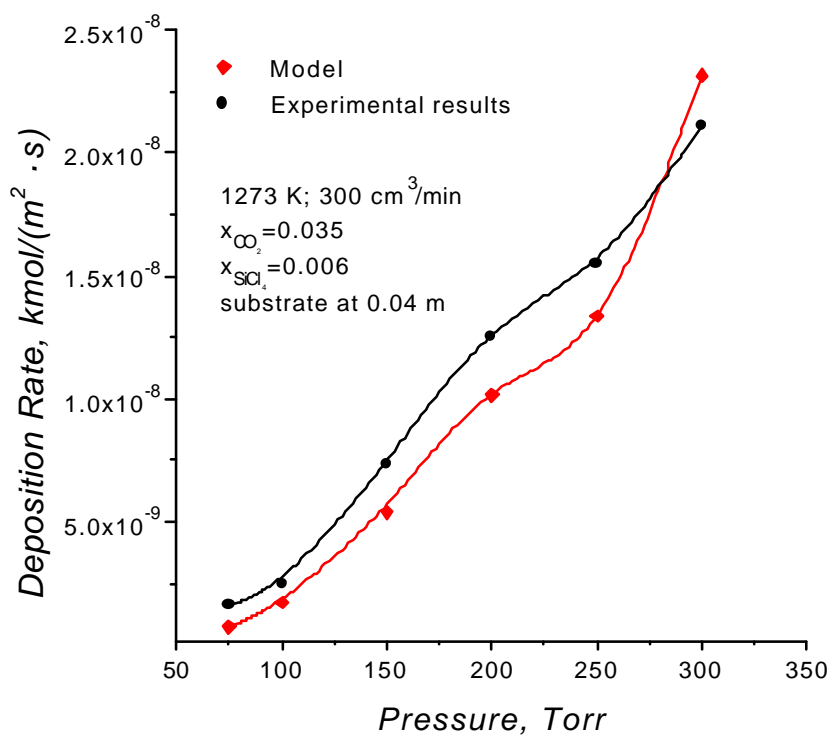

FIGURE 21 


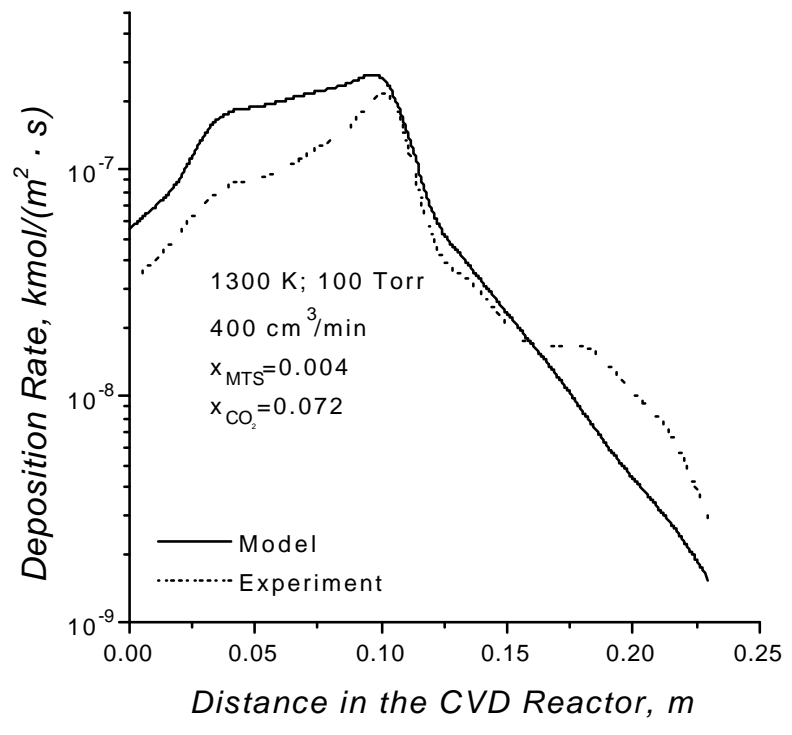

FIGURE 22 


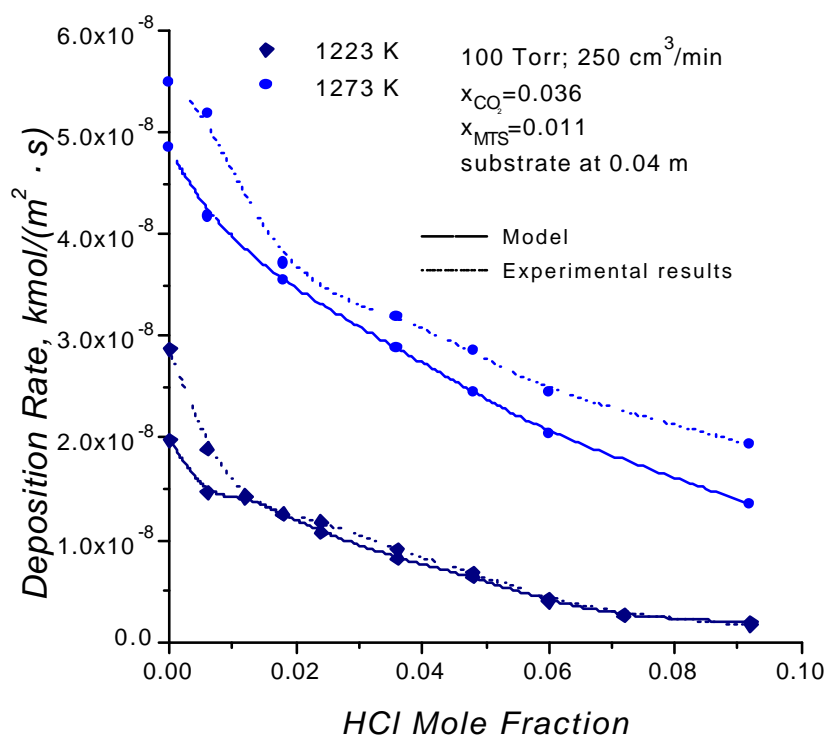

FIGURE 23 


\section{Development and Validation of a Mathematical Model for the Chemical Vapor Deposition of $\mathrm{Al}_{2} \mathrm{O}_{3}$ from Mixtures of $\mathrm{AlCl}_{3}, \mathrm{CO}_{2}$, and $\mathrm{H}_{2}$}

Stephanos F. Nitodas and Stratis V. Sotirchos *

Department of Chemical Engineering

University of Rochester

Rochester, NY 14627

* to whom correspondence should be addressed 


\begin{abstract}
Detailed homogeneous and heterogeneous chemistry models are formulated for the chemical vapor deposition of alumina from mixtures of aluminum trichloride, hydrogen, and carbon dioxide. Since formation of the species that are required for the incorporation of oxygen atoms in the film (primarily $\mathrm{H}_{2} \mathrm{O}$ and $\mathrm{OH}$ ) takes place through the pathways of the water gas-shift reaction, a complete kinetic model for this process is incorporated as a submodel in the homogeneous chemistry model. Information obtained from the analysis of the thermodynamic equilibrium in the gas phase of the reacting mixture and from past experimental and theoretical studies is employed to determine which elementary reaction steps play an important role in the overall deposition process. The kinetic model is introduced into the transport and reaction model of a tubular, hotwall CVD reactor, and it is employed to obtain results on the effects of the operating conditions on the variation of the gas phase composition, deposition rate and surface species coverages with residence time, under conditions typically encountered in aluminum oxide chemical vapor deposition. Experimental data obtained in a tubular, hotwall CVD reactor in our laboratory are used to validate the predictions of the overall model. The model is found to be capable of reproducing successfully the experimental data and the various behavior patterns observed in the experiments, such as the occurrence of a maximum in the variation of the deposition rate with parameters that affect strongly the residence time of the mixture in the reactor.
\end{abstract}

Keywords: alumina; $\mathrm{AlCl}_{3}$; chemical vapor deposition; water-gas-shift reaction; mathematical modeling; experimental study 


\section{Introduction}

Aluminum oxide $\left(\mathrm{Al}_{2} \mathrm{O}_{3}\right)$ is characterized by many attractive properties, such as good corrosion resistance, high dielectric strength, fracture toughness, and high resistance to impurity diffusion. Because of these properties, it is attractive for use in various applications, such as protective coatings for semiconductor components and components of silicon ceramics and coatings for the improvement of the wear resistance and life of cemented carbide cutting tools [1-6]. Alumina is also used in the microelectronics industry for the fabrication of metal-oxide semiconductor field effect transistors (MOSFETs) [7-9], in the synthesis of permselective membranes for use in hightemperature gas separations [10], and as catalytic support for various catalytic materials [11-13].

Among the various methods that are used to prepare aluminum oxide films, chemical vapor deposition (CVD) offers easy composition and microstructure control and yields dense, uniform and well-adherent coatings. The hydrolysis of volatile chlorides (e.g., $\mathrm{AlCl}_{3}$ ) in a mixture of hydrogen and carbon dioxide is one of the most frequently employed methods for the chemical vapor deposition of alumina, and it has been the subject of many studies [6,14-17]. Formation of $\mathrm{H}_{2} \mathrm{O}$ usually takes place through the water-gas-shift reaction (WGSR),

$$
\mathrm{CO}_{2}+\mathrm{H}_{2} \rightarrow \mathrm{H}_{2} \mathrm{O}+\mathrm{CO}
$$

and the deposition of alumina proceeds according to the reaction

$$
2 \mathrm{AlCl}_{3}+3 \mathrm{H}_{2} \mathrm{O} \rightarrow \mathrm{Al}_{2} \mathrm{O}_{3}+6 \mathrm{HCl}
$$

Equations (1) and (2) represent overall mass balances and not the actual reaction pathways. Understanding of the kinetics of $\mathrm{Al}_{2} \mathrm{O}_{3}$ deposition requires the development of a detailed gas phase and surface reaction mechanism. The homogeneous reactions are responsible for the generation of the actual deposition precursors, whereas the heterogeneous reactions are those that lead to the formation of solid species on the deposition surfaces.

The formulation of a fundamental model has not been considered in any of the past studies that deal with the alumina deposition process. Most of these studies present growth rate data at different operating conditions or correlate the measured deposition 
rate data with the concentrations of the reactants fed into the chemical reactor $\left(\mathrm{AlCl}_{3}\right.$ and $\mathrm{H}_{2} \mathrm{O}$ or $\mathrm{CO}_{2}$ and $\mathrm{H}_{2}$ ) using power-law rate expressions with Arrhenius-type temperature dependence. A detailed homogeneous and heterogeneous chemistry model for the deposition of $\mathrm{Al}_{2} \mathrm{O}_{3}$ from mixtures of aluminum trichloride, carbon dioxide, and hydrogen is developed in the present work. A procedure used in past study to develop a kinetic model for $\mathrm{SiO}_{2}$ deposition from mixtures of chlorosilanes, carbon dioxide, and hydrogen [18] is used to set up the kinetic mechanism and determine the values of the kinetic parameters. Thermodynamic equilibrium analysis is used to identify from a large number of gas phase species those that exist in considerable amounts in the $\mathrm{AlCl} / \mathrm{CO}_{2} / \mathrm{H}_{2}$ system under equilibrium conditions, and thus may play a significant role in the deposition process. A set of reversible reactions that can adequately describe the homogeneous and heterogeneous chemistry of the system is then formulated for the reduced set of gas phase species. The kinetic parameters of the homogeneous reactions are obtained from several kinetic studies. Estimates of collision frequencies and sticking coefficients are used to find some of the kinetic constants of the heterogeneous reactions, and equilibrium relationships that do not involve adsorbed surface species are employed to obtain a set of equations than can reduce the unknown parameters further. The values of the remaining parameters are then estimated by fitting the model predictions to the experimental data.

Experimental data obtained in a hot-wall, tubular chemical vapor deposition reactor in our laboratory are used to validate the predictions of the overall (homogeneous and heterogeneous) model. The diameter of the reactor is much smaller than its length, and thus, a plug-flow reactor [18,19] is used to model it. A detailed study of the effects of the operating conditions on the spatial variation of the gas phase composition, deposition rate and surface species coverages is conducted under conditions typically encountered in aluminum oxide chemical vapor deposition.

\section{Homogeneous Chemistry Mechanism}

The homogeneous chemistry mechanism encompasses species that either are encountered in significant quantities in the equilibrium composition of the gas phase [1] or participate in important pathways that lead to the generation of the deposition 
precursors. The reactions that model the homogeneous chemistry of the $\mathrm{AlCl} / \mathrm{CO}_{2} / \mathrm{H}_{2}$ system are treated as reversible and are presented in Table 1. The reaction rate constants, obtained from the literature, are summarized in Table 2. Symbol M stands for any other component of the gas mixture apart from those participating in the reaction steps where $\mathrm{M}$ appears. The rate constant of the forward step is given for reactions R2-R16, R18, R19, R21, R22, and R26-R30, whereas the rate constants of reactions R1, R17, R20, R23-R25, and R31 are for the reverse step. The equilibrium constants that are needed for the computation of the rate constant of the other step (reverse or forward) were calculated from thermodynamic data.

The reactions that are denoted with an asterisk $(*)$ are those that have been found to proceed at significant forward or reverse step rate (above $10^{-15} \mathrm{kmol} /\left(\mathrm{m}^{3} \cdot \mathrm{s}\right)$ ) at several feed concentrations of $\mathrm{AlCl}_{3}, \mathrm{CO}_{2}$, and $\mathrm{H}_{2}$ or at the equilibrium composition of the gas phase. The computations showed that when only these reactions were included in the homogeneous chemistry model, the obtained results were almost identical to those obtained from the complete kinetic model. However, it was decided to report the kinetic parameters we estimated for all reaction steps in the proposed mechanism since other researchers may employ reaction conditions where some of the other reactions are important. The first 12 reactions represent the mechanism of the water gas-shift reaction, which provides the species needed for the incorporation of oxygen in the deposit. Detailed information on the kinetic studies from which the rate constants of these reactions were obtained is given in [18]. The same reference also provides data for the kinetic pathway of methane formation (reactions R13-R19). (Methane was included in the mechanism since it was found to exist in appreciable amounts in the equilibrium composition of the gas phase [1].)

There is not much information available in the literature on the gas phase decomposition of $\mathrm{AlCl}_{3}$. Videnov et al. [20] studied the thermal decomposition of aluminum trichloride at 473-773 K, but they did not propose a kinetic route for the process. Reaction R22 serves as the initiation step of the generation of the aluminum deposition precursors. Its activation energy was obtained from [20], whereas its preexponential factor was treated as model parameter, and a first estimate for its value was obtained by requiring that it gives in the vicinity of $1300 \mathrm{~K}$ rate similar to that of the 
decomposition of $\mathrm{SiCh}_{4}$ [18]. The recombination of $\mathrm{AlCl}$ with $\mathrm{HCl}$ (reverse step of reaction R23) was proposed by Slavejkov and Fontijn [21], and its recombination with $\mathrm{Cl}_{2}$ by Rogowski et al. [22]. In these two studies, the rate coefficients were measured with the high-temperature fast-flow reactor (HTFFR) technique. The rate constant of R25 was obtained from the study of Mayer et al. [23], while those of R26 and R27 from Pasternack and Rice [24] and Belyung et al. [25], respectively. The study of Pasternack and Rice [24] was also the source for the kinetic parameters of reactions R28 and R29.

Since there were not any kinetic data available in the literature for reaction R30, kinetic data for the recombination of $\mathrm{AlO}$ with $\mathrm{O}_{2}$ [26] were used to approximate its rate constant. If reaction $\mathrm{R} 30$ is not included in the homogeneous mechanism, $\mathrm{AlHO}_{2}$ can only be generated through reaction R29. Preliminary computations showed that in that case $\mathrm{AlHO}_{2}$ is produced at concentrations hat are several orders of magnitude lower than the equilibrium concentration value obtained from thermodynamic analysis. The inclusion of the generation reaction of $\mathrm{AlHO}_{2}$ from $\mathrm{AlOH}$ (reaction R30) leads to faster attainment of equilibrium for the former. The equilibrium between the monomeric and dimeric aluminum trichloride (reaction R31) has been investigated by several authors. According to Konings and Booij [27], aluminum trichloride consists predominantly of dimeric molecules $\left(\mathrm{Al}_{2} \mathrm{Cl}_{6}\right)$ at low temperatures, whereas at temperatures above $650 \mathrm{~K}$ the two modifications coexist. The molar enthalpy of the dissociation of $\mathrm{Al}_{2} \mathrm{Cl}_{6}$ at the temperature range of 650-1100 K [27] was used as the activation energy of the reverse step of reaction $\mathrm{R} 31$. The preexponential factor of the latter was treated as model parameter.

\section{Heterogeneous Chemistry Mechanism}

The decomposition of aluminum trichloride does not take place only in the gas phase. Oya et al. [28] have established that the surface decomposition of $\mathrm{AlCl}_{3}$ plays an important role in the formation of $\mathrm{Al}_{2} \mathrm{O}_{3}$ films from $\mathrm{AlCl}_{3}$ and $\mathrm{O}_{2}$ at temperatures between 873 and $1073 \mathrm{~K}$. Using scanning tunneling microscopy and atomic force microscopy, some studies showed that $\mathrm{AlCl}_{3}$ molecules adsorb dissociatively on surfaces, yielding $\mathrm{Cl}$ atoms and $\mathrm{AlCl}_{\mathrm{x}}$ fragments [29,30]. Radical species, such as $\mathrm{OH}, \mathrm{AlCl}$, and $\mathrm{AlOH}$, which are encountered in significant quantities in the composition of the gas 
phase, also adsorb on the deposition surface. The presence of $\mathrm{OH}$ groups has been determined by IR spectroscopy in alumina films grown using $\mathrm{AlCl}_{3}$-2-methyl-2-propanol [31] and in films deposited from $\mathrm{AlCl}_{3}$ and $\mathrm{H}_{2} \mathrm{O}$ [32]. The surface chemistry model proposed in this study is presented in Table 3. All reactions are treated as reversible in a thermodynamically consistent manner. Adsorbed species are denoted by a bracket, [ ], with subscript $s$, and $[S]$ denotes free active surface sites. Each gas phase species is assumed to adsorb on one surface site. The adsorbed species concentrations are expressed as fractional coverages in the formulation of the rate expressions of the heterogeneous reactions. The kinetic parameters of the various surface reactions are shown in Table 4.

The rate constants of the forward and reverse steps of the surface reactions were determined using the experimental kinetic data for $\mathrm{Al}_{2} \mathrm{O}_{3}$ deposition [1,14], literature information and estimates of the sticking coefficients of the gas phase species on the surface, and the collision frequencies of the gaseous species with the deposition surface. Thermodynamic consistency required that the equilibrium constants of the surface reaction steps be consistent with the equilibrium constants of gas-solid reactions involving gas phase species and bulk solid species $\left(\mathrm{Al}_{2} \mathrm{O}_{3}\right)$. Literature information on the heats of reaction of some gas-solid reactions was used to reduce the set of unknown parameters further. The rate constants of the steps involving adsorption of a radical species or reaction of a radical species with an adsorbed surface species were set equal to the collision frequency factor of the radical species. This is equivalent to using sticking coefficient equal to unity for the gas phase species involved in the reaction step. This procedure was followed for the forward steps of reactions RS2, RS5, RS6, RS8, and RS9, and the reverse steps of RS3, RS7, RS10, and RS11.

The oxygen needed for the formation of $\mathrm{Al}_{2} \mathrm{O}_{3}$ is supplied by the adsorption of $\mathrm{H}_{2} \mathrm{O}$ molecules and $\mathrm{OH}$ radicals. The surface reaction mechanism was formulated based on the results of several studies [33-35], according to which when $\mathrm{Al}_{2} \mathrm{O}_{3}$ is deposited with $\mathrm{O}$ supplied by $\mathrm{H}_{2} \mathrm{O}$, the deposition surface is hydroxylated. Detailed information on the dissociative adsorption of water (reaction RS1) and the rate constants of the forward and reverse steps of RS1 and RS2 is provided in [18]. As it has been already mentioned, adsorbed $\mathrm{AlCl}_{\mathrm{x}}$ and $\mathrm{Cl}$ atoms are formed by the dissociative adsorption of $\mathrm{AlCl}_{3}$. Since 
no reports were found in the literature on $\mathrm{Cl}_{2}$ formation on the surface, the starting reaction of the surface decomposition was written as

$$
\mathrm{AlCl}_{3}+2[\mathrm{~S}] \rightarrow\left[\mathrm{AlCl}_{2}\right]_{\mathrm{s}}+[\mathrm{Cl}]_{\mathrm{s}}
$$

The desorption of $\mathrm{Cl}$ from the surface,

$$
[\mathrm{Cl}]_{\mathrm{S}} \rightarrow \mathrm{Cl}+[\mathrm{S}]
$$

occurs very fast at temperatures greater than $873 \mathrm{~K}$ [36], and therefore, equations (3) and (4) can be written as reaction RS3.

Hydrogen was considered to exist only in the gas phase because absence of adsorbed hydrogen atoms from the substrate surface has been reported by several investigators $[37,38]$. Alumina is assumed to be formed through the reaction of $[\mathrm{AlClO}]_{\mathrm{s}}$ and $\left[\mathrm{AlHO}_{2}\right]_{\mathrm{S}}$ (reaction RS12). The role of adsorbed aluminum hydroxides in the deposition of alumina has been established by George et al. [39] and that of $[\mathrm{AlClO}]_{\mathrm{s}}$ by Schierling et al. [40]. $[\mathrm{AlClO}]_{\mathrm{s}}$ is formed from the reaction of $[\mathrm{AlCl}]_{\mathrm{s}}$ and $[\mathrm{OH}]_{\mathrm{s}}$ (reaction RS7), whereas $\left[\mathrm{AlHO}_{2}\right]_{\mathrm{s}}$ is formed from the adsorption of $\mathrm{AlHO}_{2}$ on the surface (reaction RS9) and the reaction of $[\mathrm{AlOH}]_{\mathrm{S}}$ and $[\mathrm{OH}]_{\mathrm{s}}$ (reaction RS11). Because of the low concentration of $\mathrm{AlHO}_{2}$ in the gas phase, RS11 turns out to be the principal route of $\left[\mathrm{AlHO}_{2}\right]_{\mathrm{s}}$ formation. The reverse step of reaction RS12 proceeds through the dissociative chemisorption of $\mathrm{HCl}$ molecules on the surface. Since $\mathrm{HCl}$ is a product of the solid formation reaction, its presence in the gas phase should have an inhibitory effect on the rate of $\mathrm{Al}_{2} \mathrm{O}_{3}$ deposition.

The pre-exponential factor of the forward step of reaction RS3 was set equal to the collision frequency of $\mathrm{AlCl}_{3}$ with the surface and its activation energy was taken from the study of Cadoret [41]. The adsorption of $\mathrm{GaCl}_{3}$ was studied in [41], but it was decided to use the reported activation energy for $\mathrm{AlCl}_{3}$ adsorption because of the similar structure of the two chlorides. RS3 and RS5 may be combined as RS3-RS5 to give

$$
\mathrm{AlCl}_{3} \rightarrow \mathrm{AlCl}+\mathrm{Cl}
$$

Thermodynamic consistency required that the equilibrium constants of RS3 and RS5 be related to the equilibrium constant of reaction (A) through the equation 


$$
\left(\begin{array}{l}
k_{s 3, f} \\
k_{s 3, r}
\end{array}\right) /\left(\frac{k_{s 5, f}}{k_{s 5, r}}\right)=K_{c A}
$$

where $K_{c A}$ is the concentration-based equilibrium constant of reaction (A), and $k_{s i, f}$ and $k_{s i, r}$ the forward and reverse rate constant, respectively, of surface reaction RSi. Since equation (5) must be valid at all temperatures, it can be used to determine the values of a preexponential factor, an activation energy, and an exponent of $T$ for reactions RS3 and RS5 if the values of the other parameters are known.

The collision frequency of $\mathrm{HCl}$ with the deposition surface was used as the preexponential factor of the reverse step of RS4, whereas the activation energy of the reaction was set equal to the heat of reaction of the overall reaction

$$
\mathrm{AlCl}+\mathrm{HCl} \rightarrow \mathrm{AlCl}_{2}+\mathrm{H}
$$

The linear combination of RS3, RS4, and RS6 as RS3+RS4-RS6 yields the overall reaction

$$
\mathrm{AlCl}_{3}+\mathrm{H} \rightarrow \mathrm{AlCl}+\mathrm{HCl}+\mathrm{Cl}
$$

Thermodynamic consistency requires that

$$
\left(\frac{k_{s 3, f}}{k_{s 3, r}}\right)\left(\frac{k_{s 4, f}}{k_{s 4, r}}\right) /\left(\frac{k_{s 6, f}}{k_{s 6, r}}\right)=K_{c C}
$$

Equation (6) was used to determine the preexponential factor of the reverse step of reaction RS6 and its activation energy. In order to reduce the number of the model parameters, the activation energy of the forward step of RS7 was assumed to be equal to the activation energy of the forward steps of RS10 and RS11. Combining reactions RS2, RS8, RS9, and RS11, we obtain the overall reaction

$$
\mathrm{AlOH}+\mathrm{OH} \rightarrow \mathrm{AlHO}_{2}+\mathrm{H}
$$

as (D) = RS2+RS8-RS9+RS11. Reactions RS2, RS4, RS5, RS7, RS9, and RS12 can also be combined as RS2 + RS4 + RS5 + RS7 + RS9 + RS12 to yield the overall reaction

$$
\mathrm{AlCl}+\mathrm{AlHO}_{2}+\mathrm{OH} \rightarrow \mathrm{Al}_{2} \mathrm{O}_{3}+2 \mathrm{HCl}
$$

Finally, the reaction

$$
\mathrm{AlCl}+\mathrm{OH} \rightarrow \mathrm{AlOH}+\mathrm{Cl}
$$

can be obtained as $(\mathrm{F})=\mathrm{RS} 2+\mathrm{RS} 6-\mathrm{RS} 8+\mathrm{RS} 10$. 
Reactions (D), (E), and (F) yield equations similar to (5) and (6), namely,

$$
\begin{gathered}
\left(\frac{k_{s 2, f}}{k_{s 2, r}}\right)\left(\frac{k_{s 8, f}}{k_{s 8, r}}\right)\left(\frac{k_{s 11, f}}{k_{s 11, r}}\right) /\left(\frac{k_{s 9, f}}{k_{s 9, r}}\right)=K_{c D} \\
\left(\frac{k_{s 2, f}}{k_{s 2, r}}\right)\left(\frac{k_{s 4, f}}{k_{s 4, r}}\right)\left(\frac{k_{s 5, f}}{k_{s 5, r}}\right)\left(\frac{k_{s 7, f}}{k_{s 7, r}}\right)\left(\frac{k_{s 9, f}}{k_{s 9, r}}\right)\left(\frac{k_{s 12, f}}{k_{s 12, r}}\right)=K_{c E} \\
\left(\frac{k_{s 2, f}}{k_{s 2, r}}\right)\left(\frac{k_{s 6, f}}{k_{s 6, r}}\right)\left(\frac{k_{s 10, f}}{k_{s 10, r}}\right) /\left(\frac{k_{s 8, f}}{k_{s 8, r}}\right)=K_{c F}
\end{gathered}
$$

After assigning to the reverse step of RS12 the value of the activation energy used for the reverse step of $\mathrm{SiO}_{2}$ deposition reaction in [18], that is $119 \mathrm{~kJ} / \mathrm{mol}$, equations (7), (8), and (9) can be solved for the values of the remaining activation energies.

The deposition rate data close to the entrance of our CVD reactor were employed to determine the value of the forward constant of the $\mathrm{Al}_{2} \mathrm{O}_{3}$ generation reaction by assuming that, because of the low concentration of $\mathrm{HCl}$, the reverse rate of reaction $\mathrm{RS} 12$ was relatively small there. The preexponential factors of the forward steps of RS7 and RS10, which were set equal to each other, and those of the reverse steps of RS8 and RS9 were treated as model parameters. The remaining preexponential factors were determined from equations (7), (8), and (9). The equilibrium constants of reactions (A)-(F) were assumed to be given by the formula $K_{d 1300 K} \exp \left(\frac{-E}{R}\left(\frac{1}{T}-\frac{1}{1300 K}\right)\right)$. The values of exponent $n$ in the adsorption steps and in steps involving reaction of a gaseous species with an adsorbed species (0.5) resulted from the collision frequency. The value of $n$ in the reverse steps of reactions RS5 and RS6 (0.5) was determined from equations (5) and (6), respectively. 


\section{Transport and Reaction Model and Computational Aspects}

To model a CVD reactor, the surface reaction mechanism must be coupled with the proposed homogeneous reaction mechanism and the entire mechanism must be incorporated into an appropriate reaction and transport model. For the simple plug-flow reactor configuration that we employed in our experimental study the transport and reaction model is given by

$$
\begin{gathered}
\frac{d x_{i}}{d z}=\frac{A}{\hat{F}} \frac{P_{i}-x_{i} P_{T}}{f} \\
\frac{d f}{d z}=\frac{A}{\hat{F}} P_{T} \\
P_{s i}=\underset{\rho^{\prime}}{\sum} v_{i \rho^{\prime}}^{S} R_{s \rho^{\prime}}=0 \\
\sum_{i} \theta_{i}=1
\end{gathered}
$$

where $F$ is the molar flow rate of the gas mixture, $A$ the area of the cross section of the reactor, $z$ the axial distance in the reactor, $x_{i}$ the mole fraction of species $i, \hat{F}$ the molar flow rate of the gas mixture at the entrance of the reactor, $f$ a dimensionless quantity which is equal to $F / \hat{F}$, and $\theta_{i}$ is the surface coverage of the $i$ surface species.

$P_{i}$ and $P_{T}$ are the production rate of species $i$ and the overall (molar) production rate in the gas phase, and they are given by

$$
\begin{gathered}
P_{i}=\sum_{\rho} v_{i \rho} R_{\rho}+a_{R} \sum_{\rho^{\prime}} v_{i \rho^{\prime}}^{G} R_{s \rho^{\prime}} \\
P_{T}=\sum_{i}\left(\sum_{\rho} v_{i \rho} R_{\rho}+a_{R} \sum_{\rho^{\prime}}^{\sum} v_{i \rho^{\prime}}^{G} R_{s \rho^{\prime}}\right)
\end{gathered}
$$

$R_{\rho}$ is the rate of homogeneous reaction $\rho, R_{s \rho^{\prime}}$ is the rate of heterogeneous reaction $\rho^{\prime}$, $v_{i \rho}$ is the stoichiometric coefficient of gaseous species $i$ in the $\rho$ homogeneous reaction, 
$v_{i \rho^{\prime}}^{G}$ the stoichiometric coefficient of gaseous species $i$ in the $\rho^{\prime}$ heterogeneous reaction, and $a_{R}$ is the area of the wall of the reactor per unit volume. The summation over $\rho$ in equations (14) and (15) involves summation over all homogeneous reactions and that over $\rho^{\prime}$ is taken over all heterogeneous reactions. The summation over $i$ in equation (15) involves all gas phase species.

When only homogeneous reactions are allowed to take place, the model is described by equations (10) and (11), and thus an ordinary differential equation solver suffices for the solution. The complete model comprises differential equations (equations (10) and (11)) and algebraic equations (equations (12) and (13)), and thus, a differentialalgebraic solver must be employed. However, the computations showed that a more robust behavior of the numerical integrator could be obtained by integrating (10) and (11) for $x_{i}$ and using an ordinary differential equation solver, and solving equations (12) and (13) for the coverages of the surface species at every set of mole fractions of the gas phase species using a Newton-Raphson scheme. The transport and reaction model does not include an energy balance equation because the heat effects associated with the alumina deposition process are negligible. This does not mean that the reactor is treated as isothermal when comparison is made with experimental data. In this case, the temperature profile obtained in our experiments is used to find the temperature at each location in the reactor.

\section{Results for Uniform Temperature in the Reactor}

\section{Homogeneous Chemistry}

The results presented and discussed in this section refer to the case in which only homogeneous reactions are allowed to take place. Such results can help us understand the dynamics of the gas phase reactions independently of those of the heterogeneous reactions, and thus determine which elementary reaction steps in the homogenous chemistry mechanism play an important role in the overall deposition process. The reactor is assumed to operate at 100 Torr with uniform temperature over its length, and the feed is assumed to contain $\mathrm{AlCl}_{3} / \mathrm{CO}_{2} / \mathrm{H}_{2}$ at a ratio of $0.09 / 0.36 / 9.55$. The results are 
presented in terms of the space time of the mixture in the reactor at the inlet conditions, which is practically equal to the residence time.

The evolution of the gas phase species concentration profiles at $1273 \mathrm{~K}$ and 100 Torr is shown in Figure 1. The concentrations of water and carbon monoxide have almost identical values throughout the reactor, and this indicates that these two species are generated at the same rate in the chemical reactor. As the results of Figure 2 show, reaction $\mathrm{R} 2$ is the only route leading to formation of $\mathrm{CO}$, whereas reaction $\mathrm{R} 3$ is the main pathway for the generation of $\mathrm{H}_{2} \mathrm{O}$ at relatively low residence times $(<1$ s). Reaction sequence R1-R3 is the most widely accepted mechanism for the generation of water from hydrogen and carbon dioxide. Other routes have also been suggested (reactions R4, R5, R12), and, as it can be seen in Figure 2, reaction R4 becomes the main pathway for $\mathrm{H}_{2} \mathrm{O}$ generation at residence times greater than $1.5 \mathrm{~s}$. Above this residence time value, reaction $\mathrm{R} 3$ proceeds in the reverse direction. The comparison of the results of Figure 2 with those given by Figure 3 at a higher temperature (1273 vs. $1373 \mathrm{~K})$ indicates that the time needed for water and carbon dioxide mole fractions to level off decreases with increasing temperature, but the values they attain do not change significantly with the temperature. It should be noted that the constant values reached by the various species at large residence times should be viewed as partial equilibrium values since as Figures 1 and 3 show, several of the components of the gas phase are not at equilibrium even at the largest residence time shown in the figures.

The results of Figure 3 show that several species, such as $\mathrm{H}$ and $\mathrm{OH}$, that do not appear to reach equilibrium at $1273 \mathrm{~K}$ within the residence time range of the figures, do so at $1373 \mathrm{~K}$. Hydrogen radicals can be generated at time zero only by reaction R1, but according to the results of Figure 2, $\mathrm{R} 1$ proceeds in the direction of $\mathrm{H}_{2}$ formation even at very low residence times. The generation of hydrogen radicals, therefore, must take place through other pathways, and since $\mathrm{H}$ is produced or consumed by many reactions, the evolution of its concentration profile is the result of the competition between the rates of the pathways that produce it (reactions R3, R20, and R6) and the rates of the routes that consume it (reactions R1, R2, R4, and R6).

Reaction R3 plays an important role not only in the supply of hydrogen radicals in the system but also in determining values of the concentrations of the other major species 
of the WGSR mechanism (that is, $\mathrm{H}_{2} \mathrm{O}, \mathrm{OH}$, and $\mathrm{CO}$ ) and how fast they reach equilibrium. When reaction R3 is not included in the kinetic mechanism (see Figure 4), the mole fractions of $\mathrm{H}_{2} \mathrm{O}$ and $\mathrm{CO}$ increase monotonically without reaching equilibrium within the residence time window shown in the figures, and they are by about one order of magnitude lower than those in Figure 1. The concentration of $\mathrm{OH}$ is by a few orders of magnitude higher in Figure 4 than in Figure 1, but it is still lower than the concentration of $\mathrm{H}_{2} \mathrm{O}$. In view of the above results, one would expect that the omission of reaction $\mathrm{R} 3$ from the kinetic model to lead to lower deposition rates in the overall model because of the lower overall concentration of O-containing surface reactive species. As it will be seen in the discussion of the surface reaction mechanism, the incorporation of oxygen in the deposit is mainly due to the adsorption of $\mathrm{HO}$ in the surface. The results of Figure 4 imply that the $\mathrm{OH}$ radicals not only are consumed in the $\mathrm{H}_{2} \mathrm{O}$-yielding pathways but also contribute significantly to the generation of molecular oxygen (reaction R8), the concentration of which is by 6-7 orders of magnitude higher than that obtained under the conditions of Figure 1.

$\mathrm{AlCl}$ and $\mathrm{AlCl}$ are the most abundant aluminum-bearing radicals in the gas phase in Figures 1, 3, and 4. The results of Figure 2 indicate that aluminum dichloride is mainly generated by the decomposition of aluminum trichloride (reaction R22), whereas the source of $\mathrm{AlCl}$ radicals is reaction $\mathrm{R} 23$. The local maximum and minimum in the concentration profile of aluminum dichloride are the result of the competition among $\mathrm{AlCh}_{2}$-consuming reactions ( $\left.\mathrm{R} 23\right)$ and $\mathrm{AlCh}_{2}$-producing reactions ( $\mathrm{R} 22$ and $\left.\mathrm{R} 24\right)$. Both radicals reach partial equilibrium at lower residence times as the temperature increases. $\mathrm{AlCl}$ equilibrates much faster than $\mathrm{AlCl}_{2}$ (see Figures 1 and 3), and it attains equilibrium at about the same residence time as $\mathrm{H}_{2} \mathrm{O}$ and $\mathrm{CO}$. This indicates that the hydrogen radicals, which are needed for the formation of $\mathrm{AlCl}$ through $\mathrm{R} 23$, must be generated in the system via the main route of water formation, that is, reaction R3. The elementary steps of the WGSR, therefore, play a role not only in the formation of $\mathrm{O}$ precursors but also on the generation of aluminum-containing radicals.

The thermochemical equilibrium analysis of the $\mathrm{Al} / \mathrm{Cl} / \mathrm{C} / \mathrm{O} / \mathrm{H}$ system has shown that there are also two other aluminum-bearing species that exist in appreciable quantities (see Figure 5) in the equilibrium composition of the gas phase, namely $\mathrm{AlOH}$ and $\mathrm{AlHO}_{2}$. 
The concentrations of these species increase monotonically throughout the reactor, and they are significantly affected by the operating temperature. As any Al-bearing radical present in significant, in relative terms, amounts in the gas phase, $\mathrm{AlOH}$ and $\mathrm{AlHO}_{2}$ are assumed to contribute to the incorporation of $\mathrm{Al}$ in the deposit under conditions of solid formation. Reaction R23 has been found to be vital for the presence of these two radicals in amounts that are comparable to their equilibrium mole fractions (see Figure 5). As it can be seen in Figure 6, in the absence of R23 the concentrations of $\mathrm{AlOH}$ and $\mathrm{AlHO}_{2}$ take values, which are not above the threshold mole fraction considered in the computations $\left(10^{-10}\right)$. The concentration of $\mathrm{AlCl}$ is also affected significantly by reaction $\mathrm{R} 23$, and it is by five orders of magnitude lower in the absence of R23 (compare Figures 1 and 6). The comparison of the equilibrium mole fraction values found from Figure 5 with those at which the various species appear to be equilibrated in Figures 1, 3, 4, and 6 show that in all cases, the corresponding values differ significantly. This indicates that even at large residence times, not all reactions in the gas phase are equilibrated; in other words, a situation of partial equilibrium prevails in the gas phase.

Because of the Arrhenius dependence of the reaction rate constants, most reaction rates increase by about one order of magnitude, on average, when the temperature is changed from 1273 to $1373 \mathrm{~K}$ (Figure 7). The faster occurrence of reactions may lead to higher concentrations of the deposition precursors, but it also leads to an increase in the mole fraction of $\mathrm{HCl}$, which is a product of the deposition process. Reaction $\mathrm{R} 20$, which proceeds at relatively high rates, is one of the major pathways for the production of hydrogen chloride. The concentration of $\mathrm{HCl}$ is relatively high and it levels off at about the same residence time as the concentration of $\mathrm{H}_{2} \mathrm{O}$.

Methane was included in the gas phase chemistry because it existed in relatively high concentrations in the gas phase at thermochemical equilibrium (see Figure 5). No results are shown for methane in the mole fraction vs. residence time results of Figures 1, 3 , 4, and 6 because the computed mole fraction value was below the lower limit of the range shown in the figures. Since the generation rates of the various gas phase species differ significantly the residence times that are needed for partial equilibration to be attained by these species cover a very broad range of values. Even at the high temperature (Figure 3), the residence time needed for most of the gas phase species (with the 
exception of $\mathrm{AlOH}$ and $\mathrm{AlHO}_{2}$ ) to reach partial equilibrium is of the order of $10^{4} \mathrm{~s}$. This value is by more than two orders of magnitude larger than the residence time encountered in typical experimental chemical vapor deposition reactors, which seldom exceeds a few seconds. This result implies that $\mathrm{Al}_{2} \mathrm{O}_{3}$ deposition from mixtures of $\mathrm{AlCl}_{3}, \mathrm{CO}_{2}$, and $\mathrm{H}_{2}$ takes place away from a situation of gas phase equilibrium, and therefore, the results of the thermochemical equilibrium analysis may only be useful for the derivation of qualitative conclusions. It should be noted that for several species the concentrations in the "plateau" region of Figures 1, 3, 4, and 6 differ significantly from the equilibrium values in Figure 5. For example, the mole fraction of $\mathrm{HCl}$ in Figures 1 and 3 is much higher than the equilibrium value at 1273 and $1373 \mathrm{~K}$, respectively, in Figure 5.

\section{Overall Model}

The proposed surface reaction mechanism of Table 3 was coupled with the homogeneous reaction model, and the entire mechanism was incorporated into the reaction and transport model of a cylindrical, hot-wall plug-flow reactor of $0.015 \mathrm{~m}$ internal diameter (equations (10)-(13)). We discuss in this section some results on the effects of the occurrence of the heterogeneous reactions on the concentrations of the gas phase species and the dependence of the deposition profile on the operating conditions. In addition to the residence time (space time), the ratio of the surface area of deposition to the reactor volume ( $a_{R}$ in Equation (14)) is needed to specify the configuration of the plug-flow reactor. For a reactor with $0.015 \mathrm{~m}$ diameter and deposition on the wall, $a_{R}=$ $267 \mathrm{~m}^{-1}$.

The evolution of the deposition rate profile at various temperatures and pressures is shown in Figure 8 for a feed of $\mathrm{AlCl}_{3} / \mathrm{CO}_{2} / \mathrm{H}_{2}$ set at $0.09 / 0.36 / 9.55$. The reaction rate initially increases with the residence time, but eventually, it exhibits two local maxima, separated by a shallow minimum, which shift towards lower residence times with increasing temperature or decreasing pressure. After the second maximum, the deposition rate decreases to zero. The concentration profiles of the major gas phase species at $1273 \mathrm{~K}$ and 100 Torr are shown in Figure 9 and those at $1373 \mathrm{~K}$ and 100 Torr in Figure 10. Comparing the results of Figures 9 and 10 with those of Figures 1 and 3, 
one readily concludes that the occurrence of surface reactions has a strong effect on the gas phase concentration profiles.

The second maximum and the drop in the deposition rate that follows it coincide with a decrease in the concentrations of Al-containing radicals and stable species in the gas phase (see Figures 9 and 10). This result indicates that the decrease in the deposition rate results from depletion of the gas phase from Al-containing compounds. As the pressure or the temperature increases, the reaction rates of the homogeneous reactions and the concentrations of the surface reactive species in the gas phase at a given residence time increase (see Figures 9 and 10 for the temperature effect), and this leads to higher reaction rates at residence times smaller than the value at which the deposition rate decreases to an almost zero value. The higher reaction rates and the higher deposition rates lead to faster production of deposition precursors in the gas phase and faster reduction of the $\mathrm{Al}$ loading of the gas phase, respectively. The concentration of the silicon precursor in the feed is inversely proportional to temperature, and thus, the higher deposition rates lead $\mathrm{b}$ earlier reduction of the Si content of the gas phase to low levels, causing the maxima in the deposition rate to move towards smaller values of residence time. On the other hand, when the pressure is varied, the concentration changes proportionally with it, and this is why the deposition rate drops to zero at higher residence times as the pressure is increased even though it increases with the increasing pressure at residence times below the maximum.

The variation of the surface coverages of the adsorbed species with the residence time at the conditions of Figure 9 is portrayed in Figure 11. It is seen that the maximum in the deposition rate of Figure 8 is accompanied by a maximum in the variation of the surface coverage of $\left[\mathrm{AlHO}_{2}\right]_{\mathrm{s}}$, one of the two surface species that appear in the forward step of the $\mathrm{Al}_{2} \mathrm{O}_{3}$ formation reaction in the heterogeneous chemistry mechanism. At the point where the deposition rate starts to decrease to zero, the coverages of the various $\mathrm{Al}$ species on the surface go to zero, and this observation is in accordance with the decrease of the concentrations of the $\mathrm{Al}$ species in the gas phase. The first maximum and the minimum in the variation of the concentration of $\left[\mathrm{AlHO}_{2}\right]_{\mathrm{s}}$ is accompanied by a minimum in the variation of the concentration of $[\mathrm{OH}]_{\mathrm{s}}$, and this indicates that the supply of oxygen to the surface, through $[\mathrm{OH}]_{\mathrm{s}}$ and reactions RS7, RS10 and RS11 that lead to 
$[\mathrm{AlClO}]_{\mathrm{s}}$ and $\left[\mathrm{AlHO}_{2}\right]_{\mathrm{s}}$ formation, controls the deposition process before the deposition rate starts to decrease towards zero.

The low concentrations of $\mathrm{Al}$ species in the gas phase cause low surface coverages of $\mathrm{Al}$ species on the surface, and as a result, the surface coverage of $[\mathrm{OH}]_{\mathrm{s}}$ becomes almost unity. The increased rate of formation of $[\mathrm{OH}]_{\mathrm{s}}$ after the second maximum decreases the concentrations of $\mathrm{H}_{2} \mathrm{O}$ and $\mathrm{OH}$ in the gas phase significantly (see Figure 9). The occurrence of surface reactions increases the concentrations of $\mathrm{AlOH}$ and $\mathrm{AlHO}_{2}$ in the gas phase (compare Figures 1 and 9) at residence times below the second maximum. This happens because reactions RS8 and RS9 occur in the reverse direction, that is, in the direction of production of $\mathrm{AlOH}$ and $\mathrm{AlHO}_{2}$, respectively. The concentration of $\mathrm{OH}$ in Figure 9 is larger than that in Figure 1 for residence times in the range between the maxima in the deposition rate. This indicates that reaction RS2 proceeds in the reverse direction in that range, and therefore, the only source of $[\mathrm{OH}]_{\mathrm{s}}$ is $\mathrm{H}_{2} \mathrm{O}$. It should be noted that the effects of the occurrence of reactions RS8 and RS9 on the behavior of the process are negligible in most cases we examined in this study.

The results we presented in Figures 8-11 were for a reactor with deposition surface area to volume ratio, $a_{R}$, equal to $267 \mathrm{~m}^{-1}$, which for a hot-wall, tubular reactor corresponds to $1.5 \mathrm{~cm}$ internal diameter. Figure 12 presents results on the dependence of the deposition rate vs. residence time on the value of $a_{R}$. The dashed curve is for $a_{R}$ equal to $0 \mathrm{~m}^{-1}$, that is, it corresponds to the case in which the radius of the chemical reactor is infinite. Since in that case no removal of $\mathrm{Al}$ or $\mathrm{O}$ from the gas phase takes place, the variation of mole fractions of the gas phase species with the residence time is that shown in Figure 1. From Figures 1 and 9, it is found that the mole fractions of the Al and $\mathrm{O}$ species that play an important role in the heterogeneous chemistry model $\left(\mathrm{AlCl}_{\mathrm{x}}\right.$ and $\mathrm{H}_{2} \mathrm{O}$ ) are not affected significantly at low residence times by the occurrence of the surface reactions. As a result, the deposition rate is the same for all cases in the region of low residence times. As the reaction surface area (i.e., $a_{R}$ ) is increased, the rate of $\mathrm{Al}$ and O removal from the gas phase also increases, leading to earlier deviation of the deposition rate from that without $\mathrm{Al}$ and $\mathrm{O}$ consumption and shifting of the maxima in the deposition rate vs. residence time curve to smaller residence times. 


\section{Comparison of Model and Experiment}

Experimental data were obtained in a tubular, hot-wall reactor, coupled to a microbalance for continuous monitoring of the deposition rate. Deposition was carried out on small substrates to obtain local reaction rates and on refractory wires aligned along the reactor axis to obtain deposition rate profiles. The actual temperature profile in the reactor is used in the mathematical model. Temperature profiles for four set point temperatures are shown in Figure 13. Similar results were obtained for other pressures and other gases and flow rates. It $\dot{\mathrm{s}}$ seen that starting from the beginning of the heating zone, there is a range of about $22-23 \mathrm{~cm}$ over which the temperature does not differ by more than $5{ }^{\circ} \mathrm{C}$ from the set point value. Since the actual deposition precursors are not the species fed into the chemical reactor but those formed in the homogeneous reactions, preliminary computations showed that the part of the reactor before the heating zone that is at relatively high temperature plays a very important role in determining the deposition rate at locations within the isothermal zone.

Experimental results on the effects of temperature for deposition at a fixed location are shown in Figure 14, where they are compared with the predictions of the mathematical model. The model is obviously capable of predicting, both qualitatively and quantitatively, the influence of temperature on the deposition rate. Similar results were obtained for other operating conditions. We saw in Figure 8 that when it is applied to a CVD reactor of uniform temperature, the mathematical model predicts that the deposition rate increases with increasing pressure from 100 to 300 Torr at all locations (residence time) before the gas phase is depleted of Al-containing species. The same behavior was also observed in the experiments. Figure 15 presents results on the effect of pressure on the deposition rate at $4 \mathrm{~cm}$ deposition location for three temperatures $(1273,1323$, and $1373 \mathrm{~K}$ ), and 0.027 and $0.08 \mathrm{AlCl}_{3}$ mole fraction and $\mathrm{CO}_{2}$ mole fraction, respectively. At 1273 and $1323 \mathrm{~K}$, the agreement between model and experiment is very good, both in the values of the deposition rate at individual pressures and in the trend of its variation. Very good agreement is also observed at $1373 \mathrm{~K}$ for pressures lower than 250 Torr. Above this pressure, the model predicts stronger influence of pressure on the deposition rate than the experiment, but the difference in the two values is still less than $30 \%$. It should be noted that depending on the experimental conditions in a CVD system and the location of the 
deposition surface, the deposition rate may have a complex dependence on pressure. With the feed composition and the temperature kept constant, an increase in the operating pressure increases both the concentrations of the reactants and the residence time in the reactor. The former leads, in general, to faster occurrence of homogeneous and surface reactions and, therefore, higher deposition rates, but the latter results in greater consumption of reactive species upstream of the deposition site. Thus, at a fixed deposition location, there should be a pressure at which the positive effect of increased feed concentration is counterbalanced or even offset by the effect of increased residence time.

The experimental data showed that a maximum could be present in the variation of the alumina deposition rate with the total flow rate. Figure 16 shows results on the effect of the total gas flow rate on the deposition rate at two temperatures (1273 and 1373 $\mathrm{K})$ and 100 Torr total pressure. Very good agreement is seen to exist between model and experiment. The model appears to be capable of reproducing the maximum and other trends in the variation of the deposition rate. The maximum in the rate is shifted towards larger flow rate values or, equivalently, smaller residence time values as the temperature increases. Since the mass transport coefficient from the bulk of the gas phase to the deposition surface increases with increasing the flow rate of the gaseous mixture, the negative effect of flow rate on the deposition rate at values greater than $400 \mathrm{~cm}^{3} / \mathrm{min}$ at $1273 \mathrm{~K}\left(500 \mathrm{~cm}^{3} / \mathrm{min}\right.$ at $\left.1373 \mathrm{~K}\right)$ suggests that the influence of mass transport limitations on the deposition process is not important. For uniform temperature in the reactor, the variation in the total flow rate affects only the residence time of the mixture in the reactor, with the two quantities being inversely proportional to each other. Therefore, the presence of a maximum in the variation of the deposition rate with the flow rate is directly related with the maxima in the deposition rate vs. residence time curve in Figure 8.

Another parameter that has a direct influence on the residence time of the mixture in the reactor, being proportional to it for uniform temperature profile, is the distance from the entrance of the reactor. Experimental and theoretical results in the evolution of the deposition rate with the distance in the reactor are shown in Figure 17. The agreement between model and experiment is very good except at the two limits of the isothermal 
zone. It was noted before that the actual temperature profile was used in the computations. Temperature measurements in the reactor showed that the temperature profile at the two limits of the isothermal zone was strongly influenced by how the insulating material was placed at the two openings of the furnace around the process tube. Therefore, the relative differences between model predictions and experimental results at the two ends of the isothermal zone could reflect differences between the actual temperature profile and the profile (see Figure 13) used in the computations.

\section{Summary}

A kinetic model was formulated for the homogeneous and heterogeneous chemistry of the deposition of $\mathrm{Al}_{2} \mathrm{O}_{3}$ from mixtures of $\mathrm{AlCl}_{3}, \mathrm{CO}_{2}$, and $\mathrm{H}_{2}$. The kinetic parameters of the homogeneous reactions were extracted from various sources of the literature, while those of the heterogeneous reactions were determined using collision frequency estimates, thermodynamic data for gas phase and solid species, and experimental data obtained in a tubular, hot-wall CVD reactor. The model was coupled with the transport and reaction model of a plug-flow, hot-wall CVD reactor to study the spatial variation of the gas phase composition under conditions typically used to carry out chemical vapor deposition of aluminum oxide and investigate the effect of different reaction pathways on the generation of the actual deposition precursors.

The results showed that the mechanism used for the water-gas-shift reaction influenced not only the generation of $\mathrm{O}$-donor species but also of aluminum deposition precursors. The various species of the kinetic mechanism reached partial equilibrium over a wide range of residence times, and for several of them their partial equilibrium concentrations differed significantly from the values at complete thermochemical equilibrium. The residence time required for most of the major species to reach partial equilibrium was much larger (by more than two orders of magnitude) than the residence times encountered in CVD reactors (typically of the order of a few seconds). This led to the conclusion that the deposition of aluminum oxide takes place far away from a situation of complete thermochemical equilibrium in the gas phase.

When the heterogeneous chemistry model was included in the overall model, the concentrations of the gas phase species were different than those obtained with 
homogeneous reactions only. For uniform temperature profile in the CVD reactor, the deposition rate was found to first increase with increasing residence time and then go through two maxima separated by a relatively shallow minimum. Beyond the second maximum, it decreased to zero. From the variation of the concentrations of the gas phase species and of the coverages of the adsorbed species with residence time, it was concluded that this drop was caused by depletion of the gas phase from Al-bearing species and increase of the concentration of $\mathrm{HCl}$. When it was applied to the reaction

conditions used in $\mathrm{Al}_{2} \mathrm{O}_{3}$ CVD experiments, the overall model was found to be capable of reproducing satisfactorily the deposition rate and the trends observed in the dependence on the operating conditions and the distance in the CVD reactor.

\section{ACKNOWLEDMENTS}

This work was supported by a grant from the U.S. Dept. of Energy.

\section{LITERATURE CITED}

1. Nitodas, S. F., and Sotirchos, S. V., Chem. Vapor Deposition, 5, 219 (1999).

2. Colmet, R., and Naslain, R., Wear, 80, 221 (1982).

3. Kamoshida, M., Mitchell, I. V., and Mayer, J. W., Appl. Phys. Lett., 18, 292 (1971).

4. Iida, K., and Tsujide, T., Jap. J. App. Phys., 11, 840 (1972).

5. Lindström, J. N., and Johanesson, R. T., J. Electrochem. Soc., 123, 555 (1976).

6. Lux, B., Colombier, C., Altena, H., and Stjernberg, K., Thin Solid Films, 138, 49 (1986).

7. Ishida, M., Yamaguchi, S., Masa, Y., Nakamura, T., and Hikita, Y., J. Appl. Phys., 69, 8408 (1991).

8. Snow, E. S., Campbell, P. M., Rendell, R. W., Buot, F. A., Park, D., Marrian, C. R., and Magno, R., Appl. Phys. Lett., 72, 3071 (1998).

9. Kimura, T., Yaginuma, H., Sengoku, A., Moriyasu, Y., and Ishida, M., Jpn. J. Appl. Phys. Part 1, 37, 1285 (1998).

10. Tsapatsis, M., Kim, S, Nam S. W., and Gavalas, G., Ind. Eng. Chem. Res., 30, 2152 (1991).

11. Knözinger, H., and Ratnasamy, P., Catal. Rev. Sci. Eng., 17, 31 (1978). 
12. Cubeiro, M. L., Morales, H., Goldwasser. M. R., Perez-Zurita, M. J., GonzalezJimenez., F., and De Caribay, U., Appl. Catal. A, 189, 87 (1999).

13. Masters, S. G., and Chadwick., D., Appl. Catal. B, 23, 235 (1999).

14. Nitodas, S. F., and Sotirchos, S. V., J. Electrochem. Soc., 147, 1050 (2000).

15. Colmet, R., Naslain, R., Hagenmuller, P., and Bernard, C., J. Electrochem. Soc., 129, 1367 (1982).

16. Bae, Y.W., Lee, W.Y., Besmann, T.M., Cavin, O.B., and Watkins, T.R., J. Am. Ceram. Soc., 81, 1945 (1998).

17. Park, C.S., Kim, J.G., and Chun, J.S., J. Vac. Sci. Technol. A, 1, 1820 (1983).

18. Nitodas. S. F., and Sotirchos, S. V., in preparation (2000).

19. C. G. Hill, Jr., An Introduction to Chemical Engineering Kinetics and Reactor Design, John Wiley \& Sons, New York (1977).

20. Videnov, N., Bozadzhiev, P., Mikhailov, B., and Gochev, V., Bulg. God. Vissh. Khim.-Tekhnol. Inst. Sofia, 23, 241 (1977).

21. Slavejkov, A. G., and Fontijn, A., Chem. Phys. Lett., 165, 375 (1990).

22. Rogowski, D., Marshall, P., and Fontijn, A., J. Phys. Chem., 93, 1118 (1989).

23. Mayer, S. W., Schieler, L., and Johnston, H. S., Symp. Int. Combust. Proc., 11, 837 (1967).

24. Pasternack, L., and Rice, J. K., J. Phys. Chem., 95, 8701 (1991).

25. Parnis, J. M., Mitchell, S. A., Kanigan, T. S., and Hackett, P. A., J. Phys. Chem., 93, 8045 (1989).

26. Belyung, D. P., and Fontijn, A., J. Phys. Chem., 99, 12225-12230 (1995).

27. Konings, R. J. M., and Booij, A. S., J. Chem. Thermodynamics, 24, 1181 (1992).

28. Oya, G., and Sawada, Y., Acta Polytechn. Scand. Chem. Tech. Ser., 195, 185 (1990).

29. Takiguchi, T., Katsuhiro, U., Yoshimura, M., and Yao, T., Appl. Surf. Sci., 82/83, 428 (1994).

30. Uesugi, K., Takiguchi, T., Izawa, M., Yoshimura, M., and Yao, T., Jpn. J. Appl. Phys., 32, 6200 (1993).

31. Leskelä, M., Niinisto, L., Nykänen, E., Soinimen, P., and Tiitta, M., Acta Polytechn. Scand. Chem. Techn. Ser., 195, 193 (1990). 
32. Aarik, J., Aidla, A., Jack, A., and Kiisler, A. A., Tartu Ulik. Toim, 964, 4 (1993).

33. Maeland, A. J., Rittenhouse, R., Lahar, W., and Romano, P. V., Thin Solid Films, 21, 67 (1974).

34. Mertens, F. P., Surf. Sci., 71, 161 (1978).

35. Kaltchev, M, and Tysoe, W. T., Surf. Sci., 430, 29 (1999).

36. Uesugi, K., Takiguchi, T., Yoshimura, M., and Yao, T., J. Vac. Sci. Technol. B, 12, 2008 (1994).

37. Froitzheim, H., Köhler, U., and Lammering, H., J. Phys. C Solid State Phys., 19, 2767 (1986).

38. Wise, M. L., Koehler, B. G., Gupta, P., Coon, P. A., and George, S. M., Surf. Sci., 258, 166 (1991).

39. George, S. M., Sneh, O., Dillon, A. C., Wise, M. L., Ott, A. W., Okada, L. A., and Way, J. D., Appl. Surf. Sci., 82/83, 460 (1994).

40. Schierling, M, Zimmermann, E., and Neuschutz, D., J. de Phys. IV, 9, 85 (1999).

41. Cadoret, R., J. Cryst. Growth, 205, 123 (1999). 


\section{LIST OF FIGURES}

Figure 1. Variation of the mole fractions with the residence time at $1273 \mathrm{~K}$ and 100 Torr.

Figure 2. Homogeneous reaction rates vs. residence time at the conditions of Figure 1. Solid lines: the reaction proceeds in the forward direction, dotted lines: the reaction proceeds in the reverse direction.

Figure 3. Variation of the mole fractions with the residence time at $1373 \mathrm{~K}$ and 100 Torr.

Figure 4. Variation of the mole fractions with the residence time at $1273 \mathrm{~K}$ and 100 Torr. R3 is not included in the mechanism.

Figure 5. Variation of the equilibrium mole fractions with the temperature at 100 Torr.

Figure 6. Variation of the mole fractions with the residence time at $1273 \mathrm{~K}$ and 100 Torr when R23 is not included in the mechanism.

Figure 7. Homogeneous reaction rates vs. residence time at $1373 \mathrm{~K}$ and 100 Torr. Solid lines: the reaction proceeds in the forward direction, dotted lines: the reaction proceeds in the reverse direction.

Figure 8. Dependence of the variation of the deposition rate with the residence time on the temperature and the pressure.

Figure 9. Variation of the gas phase concentrations with the residence time at $1273 \mathrm{~K}$ and 100 Torr when solid deposition takes place. 
Figure 10. Variation of the gas phase concentrations with the residence time at $1373 \mathrm{~K}$ and 100 Torr when solid deposition takes place.

Figure 11. Variation of the fractional surface coverage of the adsorbed species at the conditions of Figure 9.

Figure 12. Dependence of the variation of the deposition rate with residence time on the deposition surface area to reactor volume ratio at $1273 \mathrm{~K}$ and 100 Torr.

Figure 13. Temperature profiles in the experimental CVD reactor at various set point temperatures.

Figure 14. Comparison of model and experiment for the variation of the deposition rate with the temperature at 100 Torr, $\mathrm{AlCl}_{3} / \mathrm{CO}_{2} / \mathrm{H}_{2}=0.12 / 0.36 / 9.52$, and deposition location at $4 \mathrm{~cm}$.

Figure 15. Comparison of model and experiment for the variation of the deposition rate with the pressure for $\mathrm{AlCl}_{3} / \mathrm{CO}_{2} / \mathrm{H}_{2}=0.27 / 0.8 / 8.93$ and deposition at $4 \mathrm{~cm}$.

Figure 16. Comparison of model and experiment for the variation of the deposition rate with the total flow rate for $\mathrm{AlCl}_{3} / \mathrm{CO}_{2} / \mathrm{H}_{2}=0.27 / 0.8 / 8.93$ and deposition at $4 \mathrm{~cm}$.

Figure 17. Comparison of model and experiment for the deposition rate vs. distance profile in the reactor at $1248 \mathrm{~K}, 100$ Torr, $400 \mathrm{~cm}^{3} / \mathrm{min}$, and $\mathrm{AlCl}_{3} / \mathrm{CO}_{2} / \mathrm{H}_{2}=$ $0.12 / 0.72 / 9.16$. 
Table 1. Homogeneous chemistry mechanism for the $\mathrm{AlCl}_{3} / \mathrm{CO}_{2} / \mathrm{H}_{2}$ deposition system.

$* \mathrm{R} 1 . \mathrm{H}_{2}+\mathrm{M} \rightarrow 2 \mathrm{H}+\mathrm{M}$

* R2. $\mathrm{CO}_{2}+\mathrm{H} \rightarrow \mathrm{CO}+\mathrm{OH}$

* R3. $\mathrm{H}_{2}+\mathrm{OH} \rightarrow \mathrm{H}_{2} \mathrm{O}+\mathrm{H}$

* R4. $\mathrm{H}+\mathrm{OH}+\mathrm{M} \rightarrow \mathrm{H}_{2} \mathrm{O}+\mathrm{M}$

* R5. $\mathrm{OH}+\mathrm{OH} \rightarrow \mathrm{O}+\mathrm{H}_{2} \mathrm{O}$

* R6. $\mathrm{H}_{2}+\mathrm{O} \rightarrow \mathrm{OH}+\mathrm{H}$

R7. $O+O+M \rightarrow O_{2}+M$

R8. $\mathrm{H}_{2}+\mathrm{O}_{2} \rightarrow \mathrm{OH}+\mathrm{OH}$

R9. $\mathrm{H}_{2}+\mathrm{O}_{2} \rightarrow \mathrm{HO}_{2}+\mathrm{H}$

R10. $\mathrm{H}+\mathrm{O}_{2}+\mathrm{M} \rightarrow \mathrm{HO}_{2}+\mathrm{M}$

R11. $\mathrm{H}+\mathrm{O}_{2} \rightarrow \mathrm{OH}+\mathrm{O}$

R12. $\mathrm{HO}_{2}+\mathrm{H}_{2} \rightarrow \mathrm{H}_{2} \mathrm{O}+\mathrm{OH}$

$*$ R13. $\mathrm{H}+\mathrm{CO}+\mathrm{M} \rightarrow \mathrm{HCO}+\mathrm{M}$

* R14. $\mathrm{HCO}+\mathrm{H}_{2} \rightarrow \mathrm{CH}_{2} \mathrm{O}+\mathrm{H}$

* R15. $\mathrm{CH}_{2} \mathrm{O}+\mathrm{H} \rightarrow \mathrm{CH}_{3}+\mathrm{O}$

* R16. $\mathrm{CH}_{3}+\mathrm{H}_{2} \rightarrow \mathrm{CH}_{4}+\mathrm{H}$

* R17. $\mathrm{CH}_{4}+\mathrm{M} \rightarrow \mathrm{CH}_{3}+\mathrm{H}+\mathrm{M}$

* R18. $\mathrm{CH}_{3}+\mathrm{HCl} \rightarrow \mathrm{CH}_{4}+\mathrm{Cl}$

R19. $\mathrm{CH}_{2} \mathrm{O}+\mathrm{H}_{2} \rightarrow \mathrm{CH}_{3}+\mathrm{OH}$

* R20. $\mathrm{H}_{2}+\mathrm{Cl} \rightarrow \mathrm{H}+\mathrm{HCl}$

R21. $\mathrm{O}+\mathrm{HCl} \rightarrow \mathrm{OH}+\mathrm{Cl}$ 
Table 1. (cntd.)

* R22. $\mathrm{AlCl}_{3}+\mathrm{M} \rightarrow \mathrm{AlCl}_{2}+\mathrm{Cl}+\mathrm{M}$

* R23. $\mathrm{AlCl}_{2}+\mathrm{H} \rightarrow \mathrm{AlCl}+\mathrm{HCl}$

* R24. $\mathrm{AlCl}_{2}+\mathrm{Cl} \rightarrow \mathrm{AlCl}+\mathrm{Cl}_{2}$

* R25. $\mathrm{AlCl}+\mathrm{H} \rightarrow \mathrm{AlH}+\mathrm{Cl}$

R26. $\mathrm{AlH}+\mathrm{O}_{2} \rightarrow \mathrm{AlO}+\mathrm{OH}$

* R27. $\mathrm{AlO}+\mathrm{H}_{2} \rightarrow \mathrm{AlOH}+\mathrm{H}$

* R28. $\mathrm{AlH}+\mathrm{H}_{2} \mathrm{O} \rightarrow \mathrm{AlOH}+\mathrm{H}_{2}$

R29. $\mathrm{AlH}+\mathrm{O}_{2} \rightarrow \mathrm{AlHO}_{2}$

* R30. $\mathrm{AlOH}+\mathrm{OH} \rightarrow \mathrm{AlHO}_{2}+\mathrm{H}$

R31. $2 \mathrm{AlCl}_{3} \rightarrow \mathrm{Al}_{2} \mathrm{Cl}_{6}$

* Indicates reactions that play an important role at the conditions examined in this study. 
Table 2. Homogeneous reaction rate constants.

$k=A x T^{n} x \exp (-E / R T)$; Units: kgmol, $\mathrm{kJ}, \mathrm{m}^{3}, \mathrm{~s}, \mathrm{~K}$.

\begin{tabular}{|c|c|c|c|}
\hline Reaction & $A$ & E & $n$ \\
\hline $\mathrm{R} 1 *$ & $6.407 \times 10^{11}$ & 0 & -1 \\
\hline $\mathrm{R} 2$ & $8.269 \times 10^{11}$ & 101 & 0 \\
\hline R3 & $1.0 \times 10^{8}$ & 13.8 & 1.6 \\
\hline $\mathrm{R} 4$ & $1.403 \times 10^{17}$ & 0 & -2 \\
\hline R5 & $1.504 \times 10^{6}$ & 0.42 & 1.14 \\
\hline R6 & $1.87 \times 10^{11}$ & 56.98 & 0 \\
\hline $\mathrm{R} 7$ & $1.001 \times 10^{11}$ & 0 & -1 \\
\hline $\mathrm{R} 8$ & $1.9 \times 10^{11}$ & 181.99 & 0 \\
\hline R9 & $4.1 \times 10^{13}$ & 284.98 & 0 \\
\hline R10 & $7.009 \times 10^{11}$ & 0 & -0.8 \\
\hline $\mathrm{R} 11$ & $1.77 \times 10^{11}$ & 69.663 & 0 \\
\hline $\mathrm{R} 12$ & $9.63 \times 10^{7}$ & 96 & 0 \\
\hline $\mathrm{R} 13$ & $6.9 \times 10^{8}$ & 7 & 0 \\
\hline R14 & $1.802 \times 10^{3}$ & 74.59 & 2 \\
\hline $\mathrm{R} 15$ & $8.43 \times 10^{10}$ & 0 & 0 \\
\hline R16 & $7.71 \times 10^{4}$ & 55.5 & 1.97 \\
\hline $\mathrm{R} 17^{*}$ & $2.298 \times 10^{21}$ & 5.28 & -2.98 \\
\hline R18 & $3.16 \times 10^{8}$ & 3.89 & 0 \\
\hline R19 & $3.195 \times 10^{9}$ & 45.23 & -0.53 \\
\hline $\mathrm{R} 20 *$ & $1.363 \times 10^{5}$ & 13.24 & 1.63 \\
\hline $\mathrm{R} 21$ & $3.06 \times 10^{9}$ & 26.3 & 0 \\
\hline $\mathrm{R} 22$ & $4.8 \times 10^{8}$ & 38 & 0 \\
\hline $\mathrm{R} 23^{*}$ & $6.62 \times 10^{9}$ & 109 & 0 \\
\hline $\mathrm{R} 24 *$ & $5.75 \times 10^{10}$ & 5.1 & 0 \\
\hline $\mathrm{R} 25^{*}$ & $2.7 \times 10^{8}$ & 5.85 & 0 \\
\hline R26 & $9.51 \times 10^{8}$ & 0 & 0 \\
\hline
\end{tabular}


Table 2 (contd.)

\begin{tabular}{cccc} 
Reaction & $A$ & $E$ & $n$ \\
\hline R27 & $3 \times 10^{7}$ & 0 & 0 \\
R28 & $1.86 \times 10^{10}$ & 0 & 0 \\
R29 & $9.51 \times 10^{8}$ & 0 & 0 \\
R30 & $4.63 \times 10^{11}$ & 83.2 & 0 \\
R31* & $1 \times 10^{15}$ & 127 & 0
\end{tabular}

* The constants are given for the reverse step. 
Table 3. Surface reaction mechanism for the $\mathrm{AlCl}_{3} / \mathrm{CO}_{2} / \mathrm{H}_{2}$ deposition system

$$
\begin{aligned}
& \text { RS1. } \mathrm{H}_{2} \mathrm{O}+[\mathrm{S}] \rightarrow \mathrm{H}+[\mathrm{OH}]_{S} \\
& \text { RS2. } \mathrm{OH}+[\mathrm{S}] \rightarrow[\mathrm{OH}]_{S} \\
& \text { RS3. } \mathrm{AlCl} l_{3}+[\mathrm{S}] \rightarrow\left[\mathrm{AlCl}_{2}\right]_{S}+\mathrm{Cl} \\
& \text { RS4. }\left[\mathrm{AlCl}_{2}\right]_{S}+\mathrm{H} \rightarrow[\mathrm{AlCl}]_{S}+\mathrm{HCl} \\
& \text { RS5. } \mathrm{AlCl} l_{2}+[\mathrm{S}] \rightarrow[\mathrm{AlCl}]_{S} \\
& \text { RS6. } \mathrm{AlCl}+[\mathrm{S}] \rightarrow[\mathrm{AlCl}]_{S} \\
& \text { RS7. }[\mathrm{AlCl}]_{S}+[\mathrm{OH}]_{S} \rightarrow\left[\mathrm{AlClO}_{S}+[\mathrm{S}]+\mathrm{H}\right. \\
& \text { RS8. } \mathrm{AlOH}+[\mathrm{S}] \rightarrow[\mathrm{AlOH}]_{S} \\
& \text { RS9. } \mathrm{AlHO} \mathrm{H}_{2}+[\mathrm{S}] \rightarrow\left[\mathrm{AlHO}_{2}\right]_{S} \\
& \text { RS10. }[\mathrm{AlCl}]_{S}+[\mathrm{OH}]_{S} \rightarrow\left[\mathrm{AlOH}_{S}+[\mathrm{S}]+\mathrm{Cl}\right. \\
& \text { RS11. }[\mathrm{AlOH}]_{S}+[\mathrm{OH}]_{S} \rightarrow\left[\mathrm{AlHO}_{2}\right]_{S}+[\mathrm{S}]+\mathrm{H} \\
& \text { RS12. }[\mathrm{AlClO}]_{S}+[\mathrm{AlHO}]_{S} \rightarrow \mathrm{Al}_{2} \mathrm{O}_{3}+2[\mathrm{~S}]+\mathrm{HCl}
\end{aligned}
$$


Table 4. Surface reaction rate constants.

$k=A x T^{n} x \exp (-E / R T)$; Units: kgmol, $\mathrm{kJ}, \mathrm{m}^{2}, \mathrm{~s}, \mathrm{~K}$.

Forward Step

$\underline{\text { Reverse Step }}$

\begin{tabular}{ccccccc} 
Reaction & $A$ & $E$ & $n$ & $A$ & $E$ & $n$ \\
\hline RS1 & $8.57 \times 10^{-2} *$ & 0 & 0.5 & 5.82 & 0 & 0.5 \\
RS2 & 8.82 & 0 & 0.5 & $1.14 \times 10^{9}$ & 511 & 0 \\
RS3 & 0.63 & 47 & 0.5 & 6.11 & 0 & 0.5 \\
RS4 & 1.82 & 0 & 0.5 & 6.02 & 91 & 0.5 \\
RS5 & 0.74 & 0 & 0.5 & $1.22 \times 10^{6}$ & 377 & 0.5 \\
RS6 & 0.23 & 0 & 0.5 & $1.65 \times 10^{5}$ & 377 & 0.5 \\
RS7 & $1 \times 10^{-2}$ & 69 & 0 & 3.64 & 0 & 0.5 \\
RS8 & 5.48 & 0 & 0.5 & $1 \times 10^{29}$ & 893 & 0 \\
RS9 & 4.7 & 0 & 0.5 & $1 \times 10^{8}$ & 540 & 0 \\
RS10 & $1 \times 10^{-2}$ & 69 & 0 & 6.11 & 0 & 0.5 \\
RS11 & 3.64 & 69 & 0 & 36.4 & 0 & 0.5 \\
RS12 & $9.2 \times 10^{2}$ & 81 & 0 & $8 \times 10^{-14}$ & 119 & 0.5 \\
$*$ It corresponds to a sticking coefficient equal to 0.01. & & &
\end{tabular}




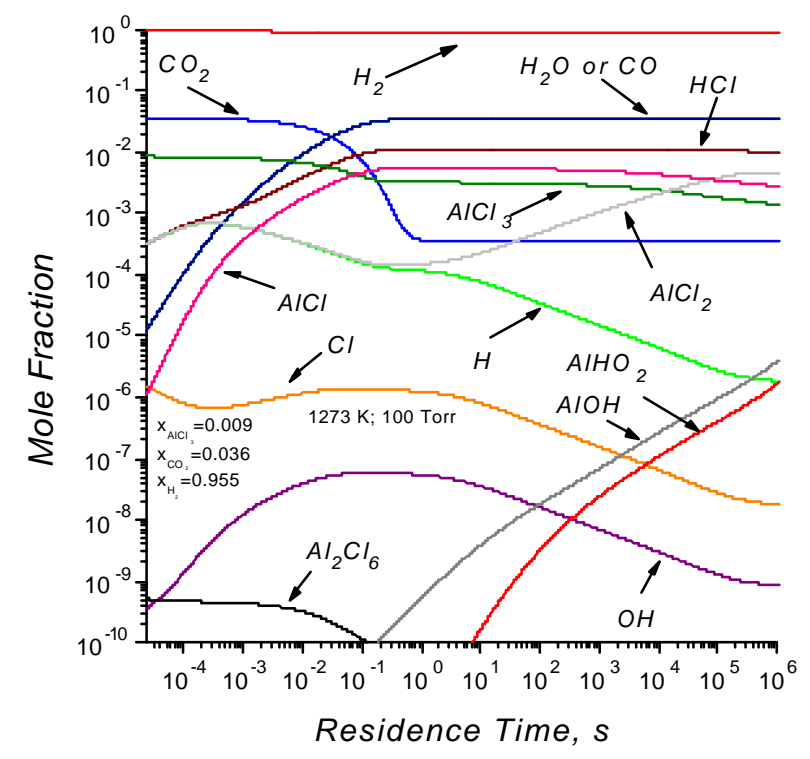

FIGURE 1 


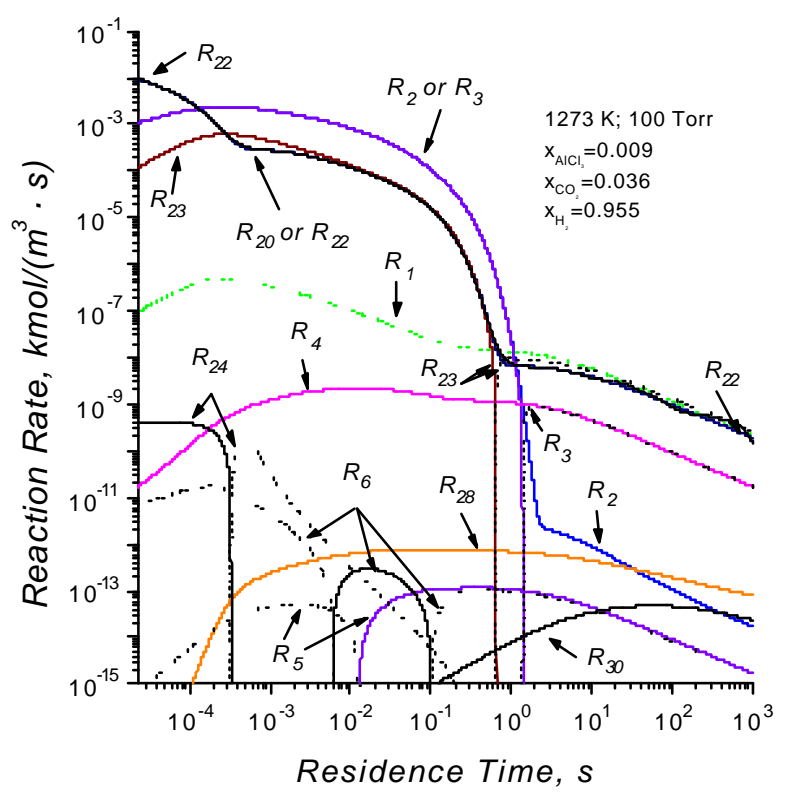

FIGURE 2 


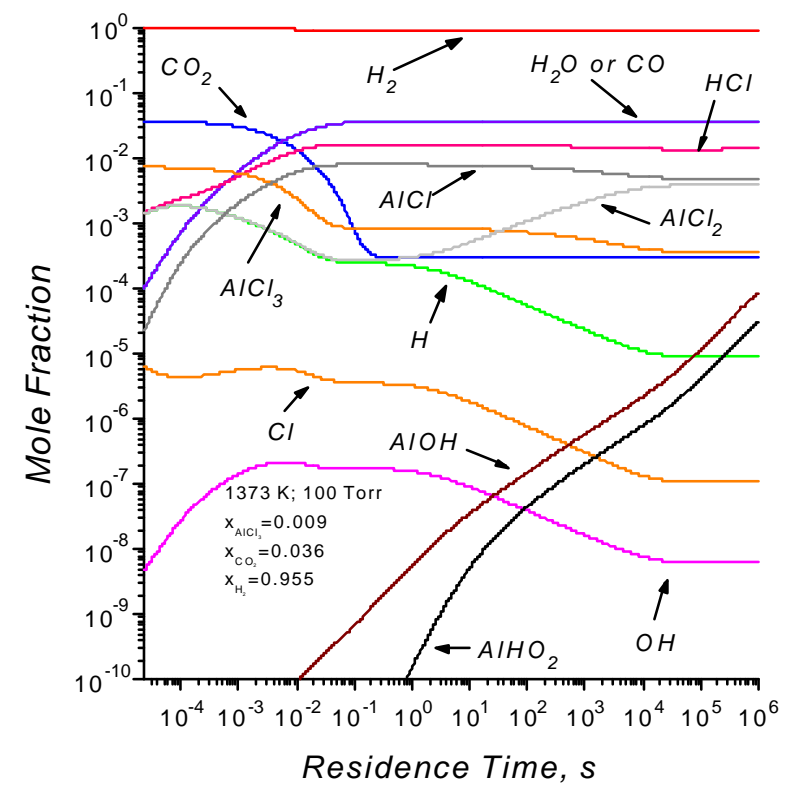

FIGURE 3 


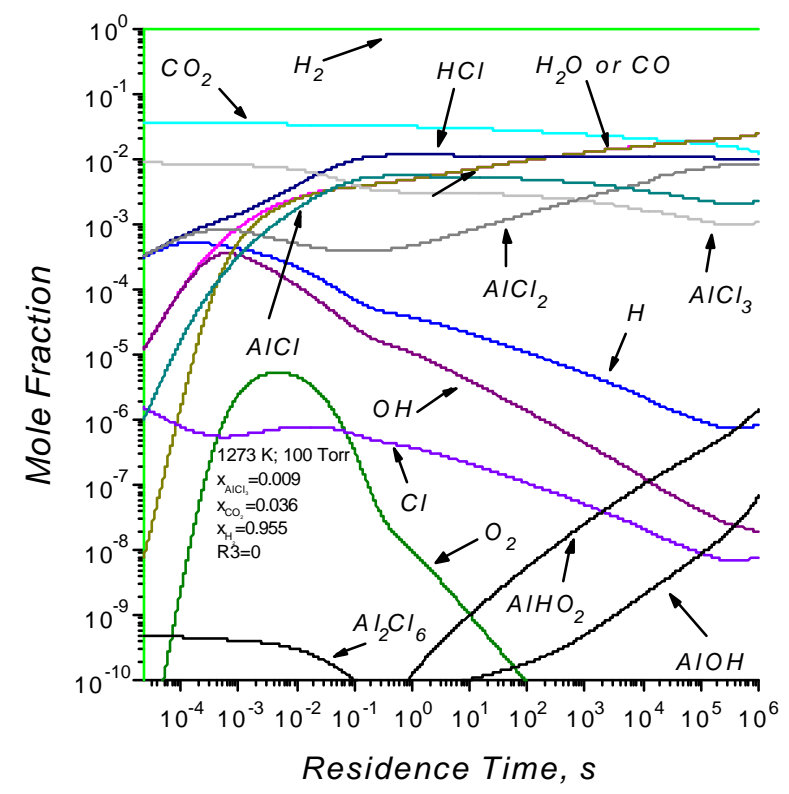

FIGURE 4 


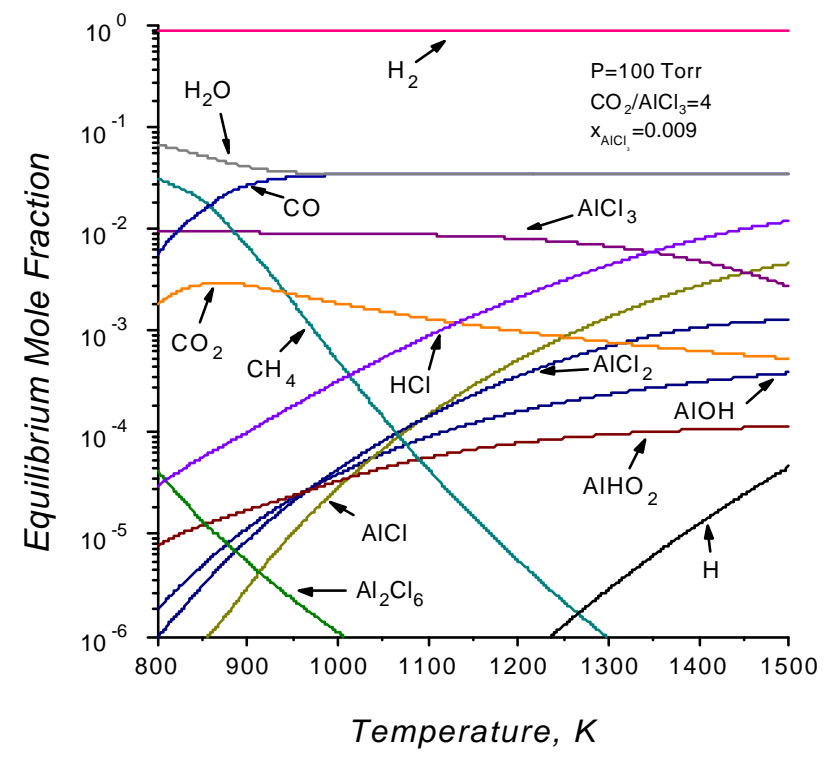

FIGURE 5 


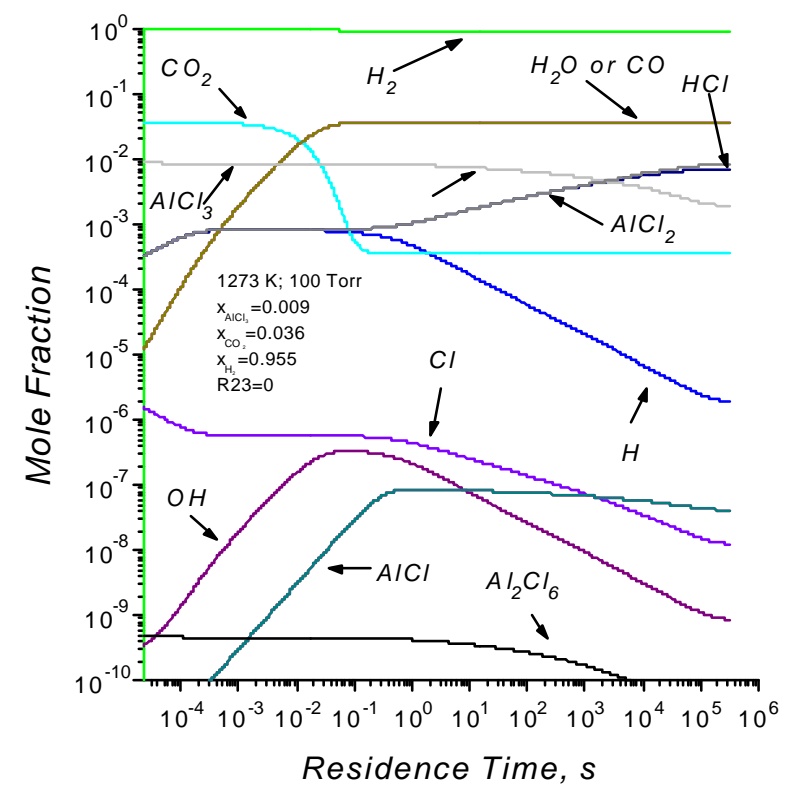

FIGURE 6 


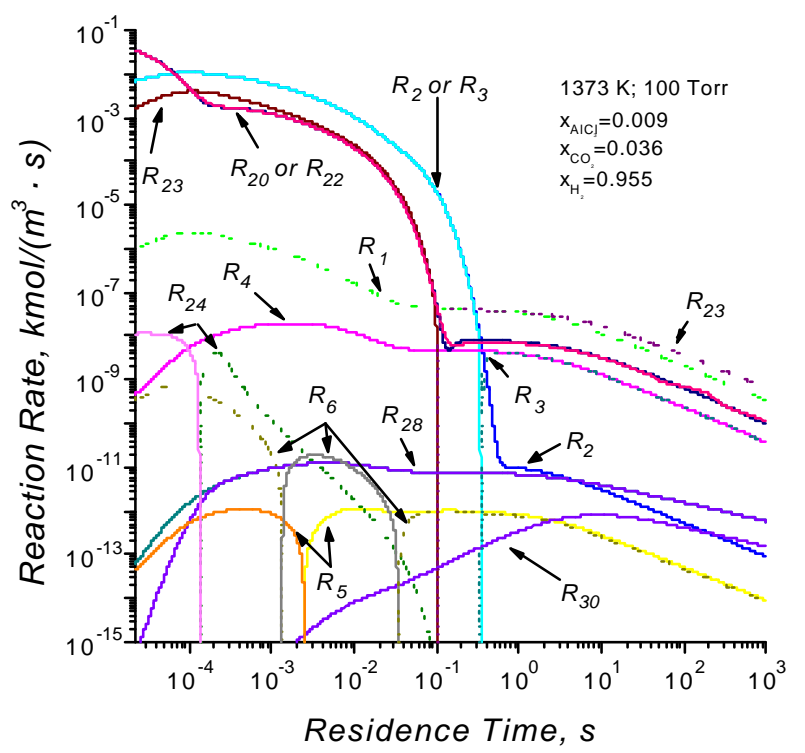

FIGURE 7 


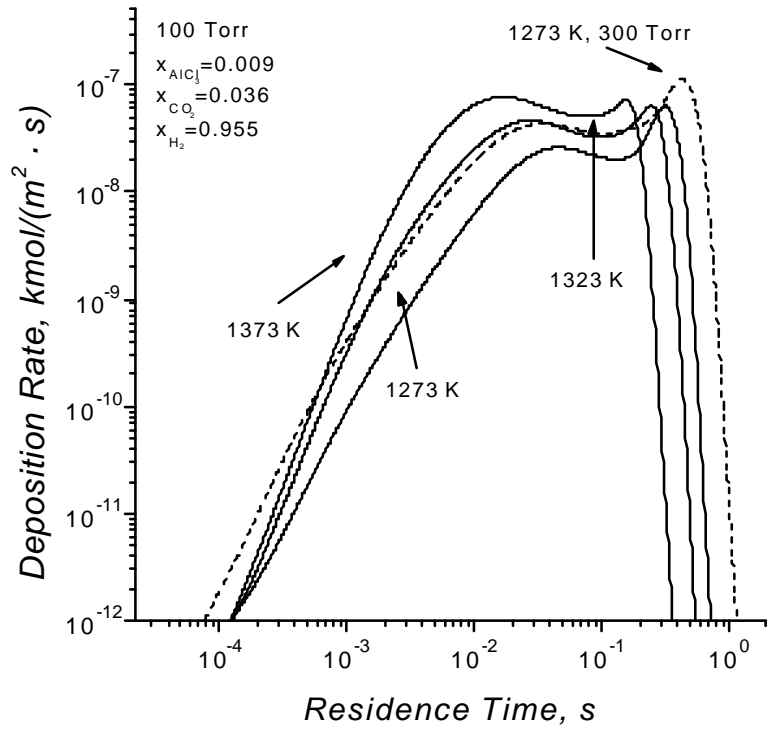

FIGURE 8 


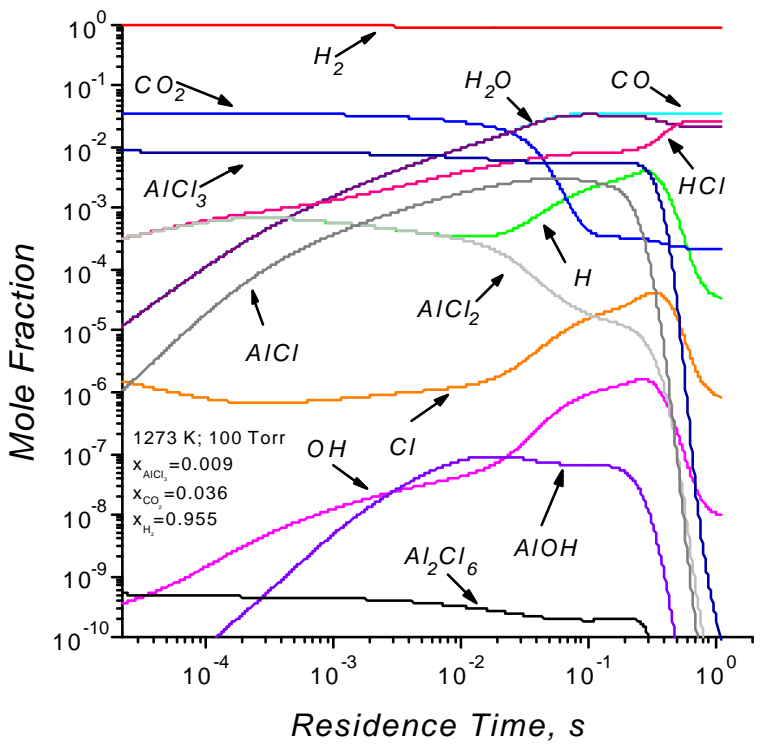

FIGURE 9 


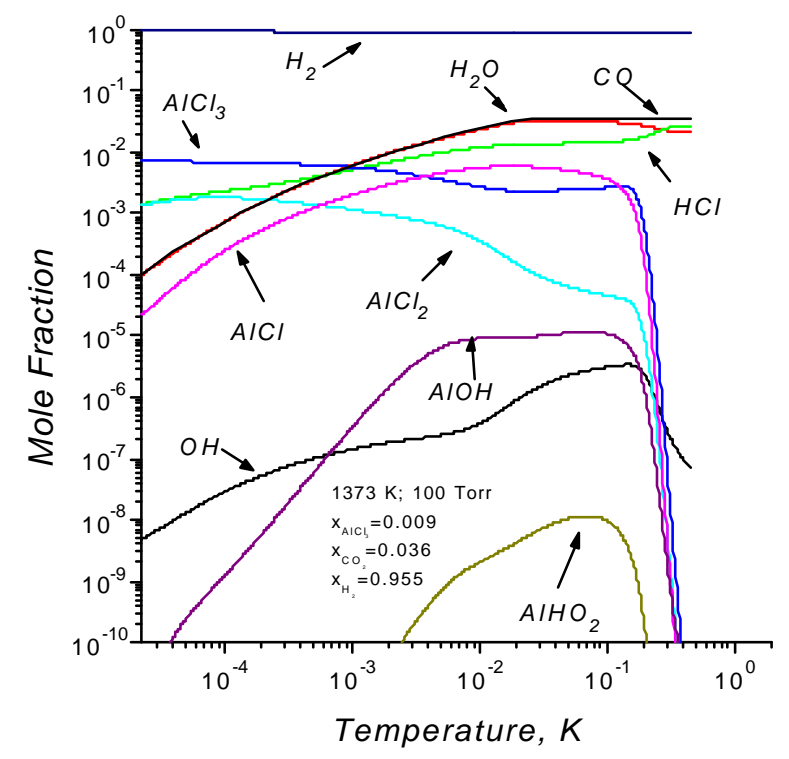

FIGURE 10 


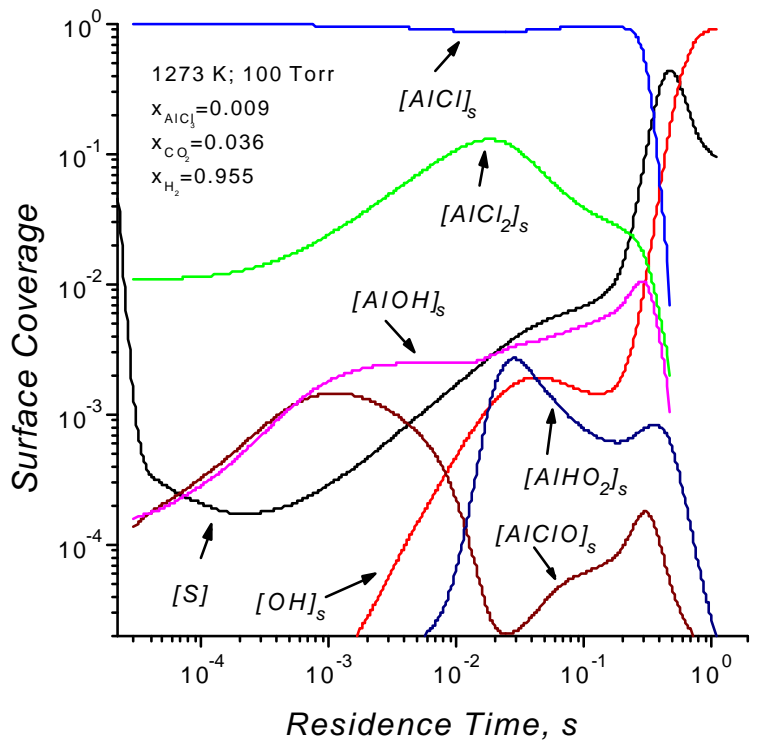

FIGURE 11 


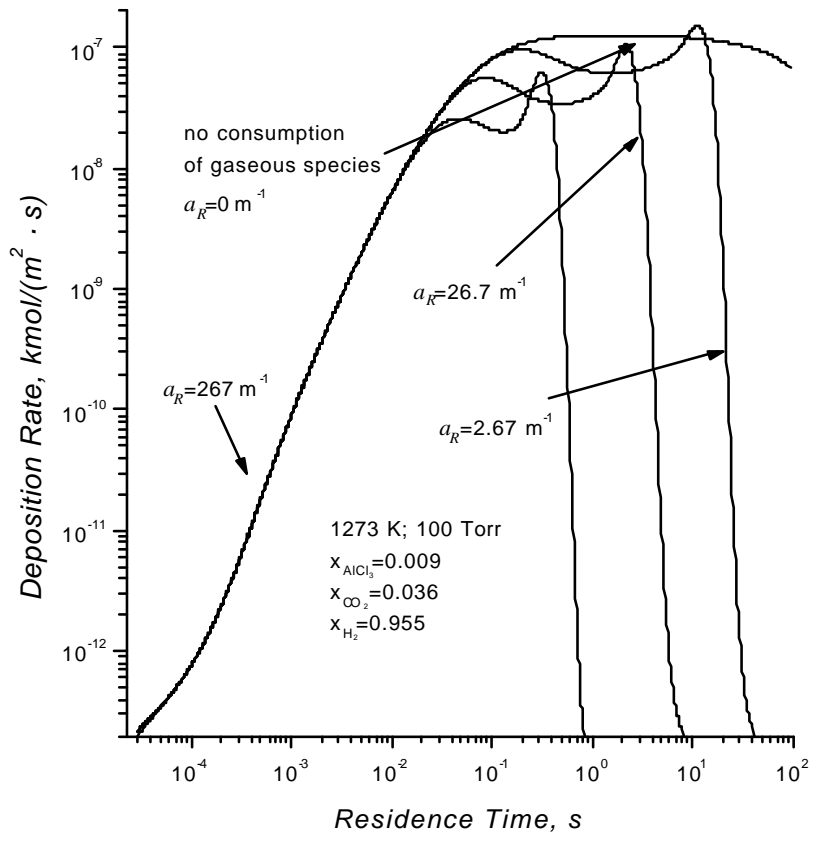

FIGURE 12 


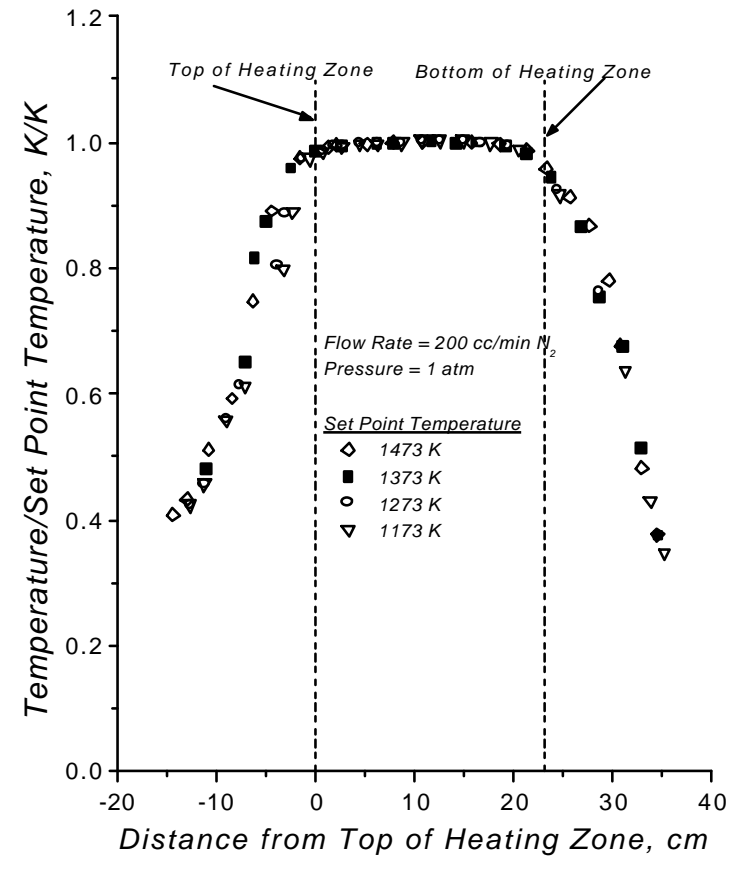

FIGURE 13 


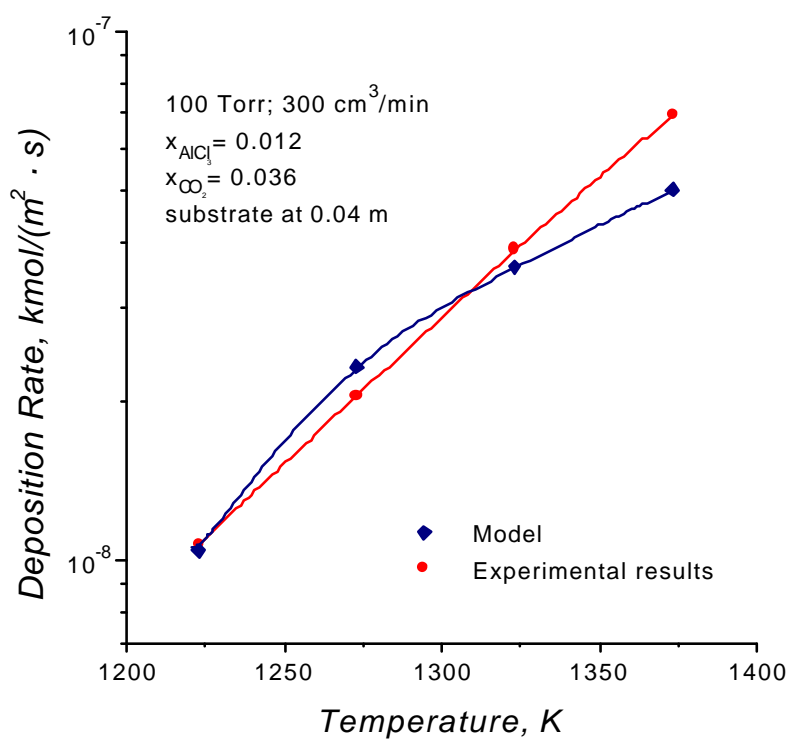

FIGURE 14 


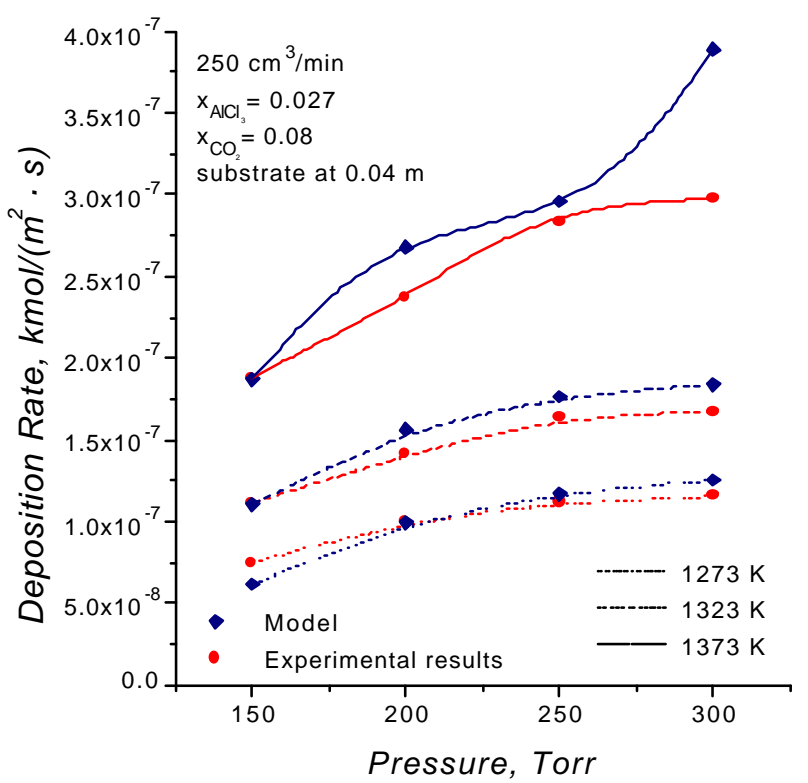

FIGURE 15 


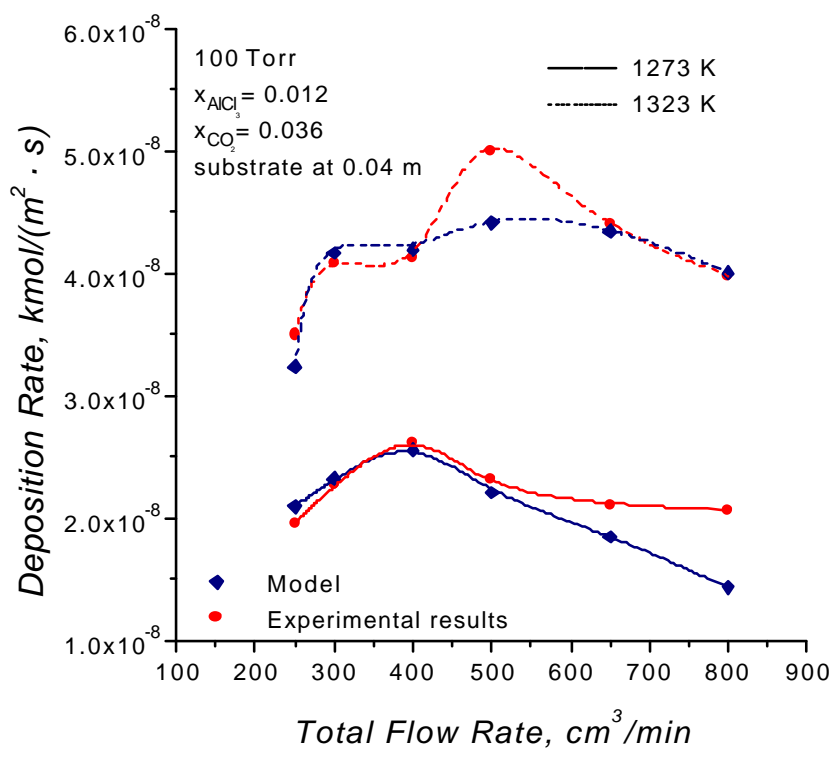

FIGURE 16 


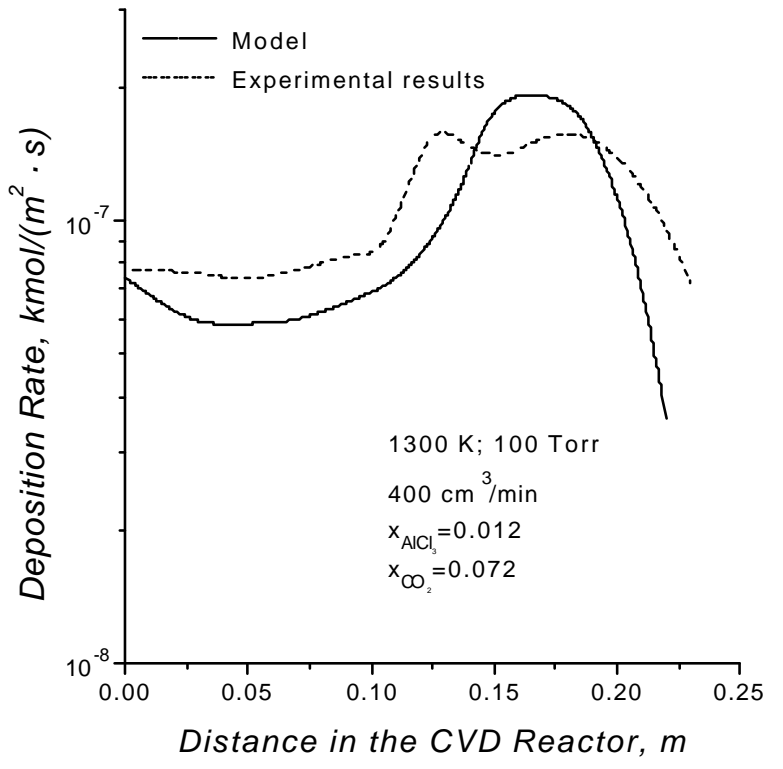

FIGURE 17 


\title{
Factors Influencing the Preparation of Mullite Coatings from Metal Chloride Mixtures in $\mathrm{CO}_{2}$ and $\mathrm{H}_{2}$
}

\author{
Stephanos F. Nitodas and Stratis V. Sotirchos * \\ Department of Chemical Engineering \\ University of Rochester \\ Rochester, NY 14627 \\ e-mail: svs2@che.rochester.edu
}

* Corresponding Author 


\begin{abstract}
The preparation of mullite coatings through chemical vapor deposition from mixtures of silicon tetrachloride, aluminum trichloride, carbon dioxide, and hydrogen is addressed in this study. The results of past experimental studies on the kinetics of this deposition system and the predictions of a mathematical model that involves detailed homogeneous and heterogeneous chemistry mechanisms for the codeposition process are used to identify operating conditions where deposition of coatings consisting of mullite or alumina-rich mullite is possible. Deposition experiments are carried out in a hot-wall reactor using as substrates both small thin plates and refractory wires traversing the centerline of the reactor. Results are presented on the dependence of the film composition in silica and alumina on temperature, pressure, and residence time of the reactive mixture in the reactor. The results showed that the alumina content of the deposits increased towards the entrance of the reactor, exceeding in many cases the value that corresponds to stoichiometric mullite. The microstructure and surface morphology of the deposit depended strongly on the operating conditions. In general, the deposition of material having the composition of mullite $\left(2 \mathrm{SiO}_{2} \cdot 3 \mathrm{Al}_{2} \mathrm{O}_{3}\right)$ or alumina-rich mullite was found to be favored by low operating pressures, high Si:Al feed ratios, and low residence times in the CVD reactor.
\end{abstract}

Keywords: chemical vapor deposition (CVD); mullite; alumina; silicon tetrachloride; aluminum trichloride 


\section{Introduction}

Mullite is a material with chemical composition ranging from $3 \mathrm{Al}_{2} \mathrm{O}_{3} \cdot 2 \mathrm{SiO}_{2}$ to $2 \mathrm{Al}_{2} \mathrm{O}_{3} \cdot \mathrm{SiO}_{2}$, which crystallizes in the orthorhombic system [1]. Its composition (70 to $82 \% \mathrm{Al}_{2} \mathrm{O}_{3}$, on a weight basis (wt)) has been found to be dependent on the method of synthesis [2]. High purity and dense mullite $\left(3 \mathrm{Al}_{2} \mathrm{O}_{3} \cdot 2 \mathrm{SiO}_{2}\right)$ ceramics have been prepared by sintering of mullite powder of submicron size $[3,4]$ or plasma spraying [5,6]. Mullite ceramics exhibit very attractive properties for a number of applications, such as low thermal expansion coefficient [7], high thermal resistance (melting point of about $2123 \mathrm{~K}$ ) [8], good hot corrosion resistance [9-12], and high bending strength [13]. They are used in the metallurgical industries as electric-furnace roofs, hot mixers, and low-frequency induction furnaces [1]. Mullite is also an ideal candidate material for the protection of silicon carbide $(\mathrm{SiC})$ in high temperature applications because it matches rather well its thermal expansion coefficient (CTE); the CTE of mullite is $5 \times 10^{-6} /^{\circ} \mathrm{C}$ and that of $\mathrm{SiC} 4.7 \times 10^{-6} /^{\circ} \mathrm{C}[14]$.

Aluminosilicate compounds in powder or film form may be formed through the exposure of silicon and aluminum chlorides (e.g., $\mathrm{SiCl}_{4}$ and $\mathrm{AlCl}_{3}$ ) to an oxidizing, high temperature environment. Mullite powder was produced by Itatani et al. $[15,16]$ from $\mathrm{SiCl}_{4}-\mathrm{AlCl}_{3}-\mathrm{O}_{2}$ mixtures, and conditions for obtaining crystalline mullite were determined. Mullite coatings were prepared through chemical vapor deposition from $\mathrm{SiCl}_{4}-\mathrm{AlCl}_{3}-\mathrm{CO}_{2}-\mathrm{H}_{2}$ mixtures by Auger and Sarin [17], and they were found to form effective barrier to corrosion in high temperature corrosive environments, such as $\mathrm{Na}_{2} \mathrm{SO}_{4}$ and $\mathrm{O}_{2}$. The same conclusion was also reached by Haynes et al. [9] and Haynes et al. [11]. Mullite was produced in these studies by chemical vapor deposition from mixtures of $\mathrm{SiCl}_{4}, \mathrm{AlCl}_{3}, \mathrm{CO}_{2}, \mathrm{H}_{2}$ and $\mathrm{Ar}$ on $\mathrm{Si}_{3} \mathrm{~N}_{4}$ substrates. The obtained coatings provided excellent protection from corrosion during short-term exposure to $\mathrm{Na}_{2} \mathrm{SO}_{4}$ and good resistance to oxidation in highpressure water vapor. High-density CVD mullite has also been prepared by Besmann et al. [18] and was found to remain intact after exposure $\mathbf{b} \mathrm{Na}_{2} \mathrm{SO}_{4}$ for 100 hours at 1273 K. Phase diagrams and kinetic rate considerations were used to identify initial 
process parameters for the growth of mullite from mixtures $\mathrm{SiCl}_{4}, \mathrm{AlCl}_{3}, \mathrm{CO}_{2}, \mathrm{H}_{2}$ and Ar by Mulpuri and Sarin [10], but no information on the reactant concentrations employed for the deposition of mullite was provided.

The preparation of mullite coatings through chemical vapor codeposition from mixtures of $\mathrm{SiCl}_{4}, \mathrm{AlCl}_{3}, \mathrm{CO}_{2}$, and $\mathrm{H}_{2}$ is the subject of the present study. Past studies $[19,20]$ on the deposition of metal oxides from mixtures of chlorosilanes (MTS or $\mathrm{SiCh}_{4}$ ), aluminum trichloride, carbon dioxide, and hydrogen revealed that the presence of $\mathrm{AlCl}_{3}$ in the feed has a catalytic effect on the incorporation of $\mathrm{Si}$ in the deposit and that, on the contrary, the presence of $\mathrm{SiCh}_{4}$ in the feed caused a suppression in the deposition rate of the $\mathrm{Al}_{2} \mathrm{O}_{3}$ component of the deposit. Because of these two effects, even at conditions at which $\mathrm{Al}_{2} \mathrm{O}_{3}$ was deposited at rates much higher than $\mathrm{SiO}_{2}$ from mixtures containing one metal chloride only, the deposit obtained in the codeposition process contained more than $90 \% \mathrm{SiO}_{2}$. The catalytic effect on the deposition rate of $\mathrm{SiO}_{2}$ was so strong that the deposition rate in the codeposition process could be by almost an order of magnitude higher than the sum of the deposition rates of $\mathrm{SiO}_{2}$ and $\mathrm{Al}_{2} \mathrm{O}_{3}$ in independent deposition experiments at the same conditions. However, further studies revealed that that manipulation of the temperature and pressure of the reaction and of the residence time of the mixture in the reactor offered a way to control the composition of the codeposited films in alumina and silica and shift the composition towards alumina. When MTS was employed as silicon source, the $\mathrm{Al}_{2} \mathrm{O}_{3}$ content of the deposit increased towards the entrance of the reactor, and it could reach close to the beginning of the hot-zone of the reactor values close to that of mullite. Lowering the deposition temperature and pressure was also found to have a positive effect on the relative rate of incorporation of alumina in the deposit. In the films codeposited from $\mathrm{SiCl}_{4}$, the $\mathrm{Al} / \mathrm{Si}$ ratio increased with increasing distance from the entrance of the reactor, reaching a maximum in the middle of the hot zone (i.e., at $~ 10$ $\mathrm{cm})$. It also increased with increasing operating temperature.

A mathematical model that includes detailed mechanistic submodels for the heterogeneous and homogeneous chemistries of the deposition process from mixtures 
of aluminum and silicon chlorides in $\mathrm{CO}_{2}$ and $\mathrm{H}_{2}$ was formulated by Nitodas [21] for the analysis and interpretation of the results of the experimental studies [19, 20]. The mathematical model could successfully reproduce all the behavior patterns observed in the experimental studies [19,20], including those of enhanced deposition rate relative to the deposition rates of silica and alumina in independent deposition experiments, enhanced rate of incorporation of $\mathrm{Si}$ in the deposit, and suppressed rate of incorporation of $\mathrm{Al}_{2} \mathrm{O}_{3}$. This model, in combination with the aforementioned experimental results, is employed in this study to formulate processing routes for depositing films rich in $\mathrm{Al}_{2} \mathrm{O}_{3}$ (e.g., mullite). It was decided to use only $\mathrm{SiCh}_{4}$ as silicon source since this chlorosilane leads to lower incorporation rates of $\mathrm{Si}$ in the deposit than MTS [21]. Several combinations of feed composition, temperature, and pressure are examined. Conditions that lead to relatively high alumina contents in the deposit are employed in the experiments, which are carried out in a hot-wall dhemical vapor deposition (CVD) reactor of tubular configuration. The effects of the operating parameters (e.g., pressure and temperature) on the deposition of mullite are studied, and the results are discussed in the context of other experimental studies.

\section{Experimental}

Chemical vapor deposition experiments were carried out in a vertical hot-wall reactor, made of quartz, with $15 \mathrm{~mm}$ internal diameter. The reactor is coupled to an electronic microbalance ( $1 \mu \mathrm{g}$ sensitivity) for continuous monitoring of the weight of the deposit. Aluminum trichloride is formed in situ in a packed-bed reactor (chlorinator), loaded with high purity aluminum granules and kept at a temperature above $250^{\circ} \mathrm{C}$ in order to achieve complete conversion of $\mathrm{HCl}$ to $\mathrm{AlCl}_{3}$ [22]. The pressure in the deposition chamber is measured at the inlet of the reactor using a capacitance manometer, and it is regulated by a throttling valve controlled by a pressure controller. Subambient pressures are generated using a mechanical vacuum pump. The pump and the control valve are protected by using a liquid nitrogen trap, a soda lime trap, and a particulate filter. The reactor tube and the substrate are heated 
with a high temperature single-zone resistance furnace, which provides about $25 \mathrm{~cm}$ of heating zone. Temperature measurements in the reactor showed that the part of the reactor tube that lies in the heating zone is almost isothermal [23], with the temperature being within $\pm 5^{\circ} \mathrm{C}$ of the set point value within a $23 \mathrm{~cm}$ region starting from the top of the heating zone .

Local deposition rates were measured using small silicon substrates (typically, $1.35 \mathrm{~cm}$ length, $0.75 \mathrm{~cm}$ width, and $0.20 \mathrm{~mm}$ thickness) obtained by depositing silicon carbide or silicon from mixtures of silicon tetrachloride/hydrogen or methyltrichlorosilane/hydrogen on substrates cut from high-density graphite blocks. The substrates were hung from the sample arm of the microbalance and placed within the heating zone, with the deposition surface parallel to the flow of the reactive mixture, which enters the chemical reactor from the top. Experiments were also carried out on thin molybdenum wires placed along the centerline of the tubular reactor in order to obtain information on the profiles of deposition rate and deposit composition along the reactor. At each set of experimental conditions, the deposition process was allowed to occur for a period of time that was sufficient to accurately extract the deposition rate from the slope of the weight vs. time curve.

\section{Results and Discussion}

\section{Model Predictions vs. Experiment}

The overall chemical reaction for mullite deposition from $\mathrm{SiCh}, \mathrm{AlCl}_{3}, \mathrm{CO}_{2}$, and $\mathrm{H}_{2}$ is:

$$
2 \mathrm{SiCl}_{4}+6 \mathrm{AlCl}_{3}+13 \mathrm{CO}_{2}+13 \mathrm{H}_{2} \rightarrow \mathrm{Al}_{6} \mathrm{Si}_{2} \mathrm{O}_{13}+26 \mathrm{HCl}+\mathrm{CO}
$$

The mechanism of the deposition process is much more involved than what equation (1) suggests. The deposition process involves a very large number of gas phase species and surface adsorbed species, which participate in several homogeneous and heterogeneous reactions. A mathematical model has been formulated by Nitodas [21] 
for the description of the various phenomena that take place during chemical vapor deposition of metal oxides from mixtures of metal chlorides, $\mathrm{CO}_{2}$, and $\mathrm{H}_{2}$. The model includes detailed submodels for the mechanisms of the homogeneous and heterogeneous reactions. The rate parameters (preexponential factor, exponent of temperature in the preexponential factor, and activation energy) were determined using information reported in the literature, such as kinetic constants, rate date, and thermodynamic data for the species that participate in the reactions. The corresponding parameters for the heterogeneous reactions were estimated using reported values for the sticking coefficients of the gas phase species involved in them, thermodynamic data of the literature for the gas phase and bulk solid species, and experimental deposition rate data obtained in our laboratory. Overall, the kinetic model consists of 51 homogeneous and 20 heterogeneous reactions. The key gas phase species in the heterogeneous mechanism that play an important role in the deposition process at all conditions we have covered in our experimental studies are $\mathrm{SiCl}_{\mathrm{x}}, \mathrm{AlCl}_{\mathrm{x}}$, and $\mathrm{H}_{2} \mathrm{O}$, but several other species (such as, $\mathrm{OH}$ ) are involved in it.

The reactions that are responsible for solid deposition are:

$$
\begin{gathered}
{[\mathrm{SiClO}]_{\mathrm{s}}+[\mathrm{OH}]_{\mathrm{s}} \rightarrow \mathrm{SiO}_{2}+2[\mathrm{~S}]_{\mathrm{SiO}_{2}}+\mathrm{HCl}} \\
{[\mathrm{AlClO}]_{\mathrm{s}}+\left[\mathrm{AlHO}_{2}\right]_{\mathrm{s}} \rightarrow \mathrm{Al}_{2} \mathrm{O}_{3}+2[\mathrm{~S}]_{\mathrm{A}_{2} \mathrm{O}_{3}}+\mathrm{HCl}} \\
{[\mathrm{SiClO}]_{\mathrm{s}}+\left[\mathrm{AlHO}_{2}\right]_{\mathrm{s}} \rightarrow \mathrm{SiO}_{2}+[\mathrm{OH}]_{\mathrm{SiO}_{2}}+[\mathrm{AlCl}]_{\mathrm{s}}}
\end{gathered}
$$

$[\cdot]_{\mathrm{s}}$ denotes an adsorbed species on the surface, $[\mathrm{S}]$ denotes an active site, and subscript $\mathrm{SiO}_{2}$ or $\mathrm{Al}_{2} \mathrm{O}_{3}$ is used to indicate sites or adsorbed species on active sites belonging to the $\mathrm{SiO}_{2}$ or the $\mathrm{Al}_{2} \mathrm{O}_{3}$ components of the deposit. It is assumed that once formed, $\mathrm{SiO}_{2}$ and $\mathrm{Al}_{2} \mathrm{O}_{3}$ are combined in further (relatively fast) steps to form the mixed oxides that are stable at the conditions of deposition (e.g., mullite). Of the three deposition reactions that are given above, it is the third reaction (equation (4)) 
that occurs only in the codeposition process and is responsible for the enhancement of the overall deposition rate and of the rate of incorporation of $\mathrm{SiO}_{2}$. The suppression of the deposition rate of $\mathrm{Al}_{2} \mathrm{O}_{3}$ is mainly the result of the interaction of the three deposition reactions among themselves and with the other surface reactions in the model that lead to formation of the surface species that participate in them from the surface species formed from the adsorption of the gas phase species. More information on the kinetic model is provided in [21].

In our previous studies [19,20], deposition experiments where carried out using mixtures with $\mathrm{AlCl}_{3}$ and $\mathrm{SiCl}_{4}$ contents that did not differ by a very large factor. However, when $\mathrm{AlCl}_{3}$ and $\mathrm{SiCl}_{4}$ are introduced in the feed at a ratio of approximately 15:1, the model predicts a significant increase in the deposition rate of alumina. As it can be seen in Figure 1, the $\mathrm{Al}_{2} \mathrm{O}_{3}$ fraction in the deposit at $1248 \mathrm{~K}$ is 0.57 (or equivalently, the $\mathrm{Al} / \mathrm{Si}$ deposit ratio is approximately 1.6). Increasing temperature has a positive effect on the incorporation of alumina in the film, resulting in an $\mathrm{Al} / \mathrm{Si}$ deposit ratio of 4.7 at $1323 \mathrm{~K}$.

The results of Figure 1 suggest that it may be possible to obtain experimentally coatings with high alumina content. The conditions of Figure 1 were employed in experiments at three temperatures of operation, 1273, 1323, and $1373 \mathrm{~K}$. The morphology and the composition of the deposits were examined using scanning electron microscopy (SEM) and energy dispersive X-ray analysis (EDXA), respectively. The films were found to be dense and uniform in thickness, having nodular structure. Figure 2 shows SEM micrographs of films formed at $7 \mathrm{~cm}$ location at 1273 and $1323 \mathrm{~K}$. The size of the nodules increased with increasing the temperature. An average nodule size of about $7.5 \mu \mathrm{m}$ was observed at $1273 \mathrm{~K}$, while at $1323 \mathrm{~K}$ the deposit consisted of nodules of about $10 \mu \mathrm{m}$.

The increase in temperature also had a positive effect on the alumina content of the deposit. The bulk Al/Si ratio of coatings formed at $1273 \mathrm{~K}$ was found to be 1.52, whereas the corresponding values at 1323 and $1373 \mathrm{~K}$ were 2.25 and 2.65, respectively. These values are lower than those predicted by the model, but they show 
that by increasing the $\mathrm{Al} / \mathrm{Si}$ feed ratio it is possible to increase the relative rate of incorporation of $\mathrm{Al}_{2} \mathrm{O}_{3}$ in the deposit at the expense of that of $\mathrm{SiO}_{2}$, and in this way circumvent the effects of the enhancement of $\mathrm{SiO}_{2}$ deposition observed in [20]. In addition to using very large values of $\mathrm{Al} / \mathrm{Si}$ feed ratio, the feed mole fraction of $\mathrm{CO}_{2}$ and the total flow rate of the reactive mixture in the reactor were increased. This was done on the basis of observations made in [20], according to which increasing these parameters led to a decrease in the deposition of silica in the single species deposition experiments and an increase in the codeposition rate.

Figure 3 compares reactivity results obtained in [20] with those at the conditions of Figure 1. It is seen that at the conditions of Figure 1 the incorporation rate of $\mathrm{Al}_{2} \mathrm{O}_{3}$ is by about one order of magnitude greater, and that the deposition of $\mathrm{SiO}_{2}$ is reduced significantly at 1323 and $1373 \mathrm{~K}$. For this reason, it was decided to employ in our subsequent experiments temperatures lying in the upper part of the temperature range that was covered in our studies. Since the $\mathrm{Al} / \mathrm{Si}$ ratio of the deposit was also increased by a decrease in the residence time of the mixture of the reactor, and this parameter is decreased (almost linearly) by decreasing the pressure operations, deposition experiments were carried out at pressures lower than 100 Torr.

\section{Effects of Pressure, Temperature, and Residence Time}

The analysis of the composition of coatings formed in our reactor at 0.0005 $\mathrm{SiCl}_{4}$ feed mole fraction, $6 \mathrm{~cm}$ location, $1323 \mathrm{~K}$, and 75 Torr on $\mathrm{SiC}$ substrates showed that the $\mathrm{Al} / \mathrm{Si}$ ratio in the deposit was 3.9, a value which is much higher than that of the stoichiometric mullite $\left(\mathrm{A} 1 / \mathrm{Si}_{\text {(mullite) }}=3\right)$. X-ray diffraction $(\mathrm{XRD})$ analysis revealed that the only crystalline phase present in the coating was mullite. The XRD results are shown in Figure 4. (Peaks corresponding to the SiC substrate are marked with an S.) Incorporation of various modifications of $\mathrm{Al}_{2} \mathrm{O}_{3}$ has been encountered in the mullite coatings formulated in other studies. For instance, Itatani et al. [15] found that mullite powder produced by chemical vapor deposition contained a small amount of $\gamma-\mathrm{Al}_{2} \mathrm{O}_{3}$. This difference could be a result of the different reactor configuration, 
temperature, and flow rates used in their experiments. The deposition of crystalline mullite coatings at 75 Torr is in agreement with the results of Haynes et al. [9], who reported that CVD crystalline mullite coatings were deposited from $\mathrm{SiCh}-\mathrm{AlCl}_{3}-\mathrm{CO}_{2}-$ $\mathrm{H}_{2}$-Ar mixtures at operating pressures lower than 100 Torr.

Since the pressure was found to have a strong influence on the incorporation of alumina in the deposit, its effect at various positions in the reactor was examined. Experiments were performed at 75 and 100 Torr on refractory wires placed along the centerline of the CVD reactor. Silicon carbide was deposited on the wires prior to the deposition of the oxides. Figure 5 presents the variation of the $\mathrm{Al}_{2} \mathrm{O}_{3}$ content (wt\%) of the deposit with the distance in the reactor. It is clear that the alumina content decreases as the distance from the entrance of the reactor increases. Alumina-rich films are obtained at locations close to the top of the heating zone. The films are much richer in $\mathrm{Al}_{2} \mathrm{O}_{3}$ when the smaller operating pressure is employed. At 75 Torr, coatings with greater alumina content than that corresponding to stoichiometric mullite are formed even at positions in the reactor far from the entrance. High incorporation rates of alumina are also encountered at positions before the beginning of the heating zone.

The operating pressure and the residence time of the reactive mixture (position in the reactor) had a strong effect of the morphology of the coatings. Significant variations in the microstructure with the distance in the reactor were observed. Coatings of $72 \%$ or higher $\mathrm{Al}_{2} \mathrm{O}_{3}$ content, formed at locations prior to the middle of the heating zone, exhibited faceted crystalline structure. The length of the reactor over which faceted crystalline structures were obtained increased with decreasing pressure. Figures 6 and 7 show SEM micrographs of crystalline mullite and alumina-rich mullite coatings prepared at 100 and 75 Torr, respectively, at the conditions of Figure 5. At both pressures of operation, the size of the crystals decreased with increasing distance in the reactor or, equivalently, increasing residence time. The average crystal size at $1 \mathrm{~cm}$ location and 75 Torr was about $7 \mu \mathrm{m}$, whereas at 3 and $5 \mathrm{~cm}$ the coatings consisted of much smaller crystals, around 3.4 and 
2.5 $\mu \mathrm{m}$, respectively. The variation of the crystal size along the reactor, combined with the results of Figure 5, leads to the conclusion that larger crystals and larger growth rates are associated with higher alumina contents. This result is in agreement with the results of our previous study [20], according to which high codeposition rates promote the incorporation of the alumina in the deposit.

At some distance from the entrance of the reactor (about $6 \mathrm{~cm}$ at the conditions of Figures 5-7), the morphology of the deposit changed smoothly from faceted crystalline, of relatively large crystals, to microcrystalline nodular or grainy nodular. This change in the morphology can be seen in the AFM (atomic force microscopy) topography pictures of Figure 8. These images correspond to a coating prepared at $1323 \mathrm{~K}, 75$ Torr, and $6.5 \mathrm{~cm}$ location. Crystals are still present in the coating (Figure 8b), but, as seen in smaller magnification, they are arranged into nodules, giving the surface of the film a microscopic nodular morphology (Figure 8a). It should be noted that even at $5 \mathrm{~cm}$ deposition location, the crystals are not as well defined as at smaller distances from the entrance (compare Figure 7c with Figures 7a and $7 \mathrm{~b}$ ). At locations much farther than $6.5 \mathrm{~cm}$, the surface morphology resembled that of the grainy nodular structure shown in Figure 2. In general, the appearance of nodular structures was accompanied by a decrease in the alumina content of the deposit below that of the stoichiometric mullite.

The size of the crystals was also affected, to some extent, by pressure changes. At $1 \mathrm{~cm}$ location and 100 Torr (Figure 6b) an average crystal size of $6.2 \mu \mathrm{m}$ was observed, which is lower than that measured at 75 Torr. This indicates that lowering the operating pressure leads to larger mullite crystals. This was also verified by experiments carried out at 50 Torr and $1323 \mathrm{~K}$. In this case, the average crystal size was measured at $3 \mathrm{~cm}$ location and it was found to be about $3.7 \mu \mathrm{m}$, that is, slightly bigger than the $3.4 \mu \mathrm{m}$ value obtained at 75 Torr and $1323 \mathrm{~K}$ at the same location.

Figure 9 presents the variation of the alumina content in the deposit within the first $3.5 \mathrm{~cm}$ of the reactor for operation at various conditions. These experiments were conducted on $\mathrm{SiC}$ or $\mathrm{Si}$ plates. At the beginning of the reactor $(0 \mathrm{~cm}$ position $)$, the 
crystalline coatings consisted mainly of $\mathrm{Al}_{2} \mathrm{O}_{3}$. It is interesting to point out that aluminosilicate structures with $\mathrm{Al} / \mathrm{Si}$ deposit ratios as high as 10 were obtained, and this value is among the highest $\mathrm{Al} / \mathrm{Si}$ ratios found in coatings developed by other investigators. At 50 Torr, an increase in the temperature results in higher incorporation rates of $\mathrm{Al}_{2} \mathrm{O}_{3}$ in the deposit. The same conclusion is also derived by comparing the curve at $1273 \mathrm{~K}$ with that at $1323 \mathrm{~K}$ and 75 Torr in Figure 5.

The crystal size was also increased by increasing the deposition temperature. Figures 10 and 11 present SEM micrographs at $3 \mathrm{~cm}$ location for operation at 75 and 50 Torr, respectively. The average size of the crystals at 75 Torr decreased from 3.4 to $1.8 \mu \mathrm{m}$ by changing the temperature from 1323 to $1273 \mathrm{~K}$. A slight increase in the crystal size was observed at 50 Torr as the temperature was changed from 1323 to $1373 \mathrm{~K}$. The positive effect of increasing temperature on the crystal size and the $\mathrm{Al} / \mathrm{Si}$ deposit ratio during preparation of CVD mullite was also reported by Mulpuri [2].

The fact that the coatings of Figures 6 and 7 were formed on refractory wires, whereas those of Figures 10 and 11 were deposited on flat substrates indicates that the microstructure of the mullite coatings does not depend on the local geometry of the substrate. The thickness of the obtained films ranged from $2-10 \mu \mathrm{m}$, depending on the process conditions and the deposition time. Figure 12 presents AFM topography images for a crystalline coating prepared at the conditions of Figure 10b. The AFM images clearly show that formation of highly oriented, faceted crystals takes place. This result is in agreement with the X-ray diffraction analysis results (Figure 4), which show much higher intensities for a few peaks in the spectrum. X-ray analysis results for a coating prepared at the same conditions as in Figure 4, but at a lower temperature and at a much shorter distance from the entrance of the reactor are shown in Figure 13. (The substrate peaks have been removed from the graph of Figure 13.) In both cases (Figures 4 and 13), the (120)/(210) peak is the most intense one, but the relative intensity of the other peaks varies, an indication that the preferred orientation of the crystals in the deposit depends on the operating conditions. For example, in Figure 4 there is a strong (111) peak, whereas in Figure 13 a sharp peak in the (110) 
direction is observed. In Figure 13 the (120)/(210) peak is relatively much more intense than the other peaks, relative to what happens in Figure 4. This observation lends further support to the conclusion that lower residence times tend to give deposits with better defined faceted crystalline structure and higher $\mathrm{Al}_{2} \mathrm{O}_{3}$ content. It should be noted that the deposition temperature was lower in the preparation of the deposit of Figure 13 (1273 K vs. 1323 K in Figure 4).

\section{Discussion}

Thermodynamic equilibrium calculations were carried out in [19] on the $\mathrm{Si} / \mathrm{C} / \mathrm{Cl} / \mathrm{H} / \mathrm{O}, \quad \mathrm{Al} / \mathrm{C} / \mathrm{Cl} / \mathrm{H} / \mathrm{O}, \quad$ and $\mathrm{Al} / \mathrm{Si} / \mathrm{C} / \mathrm{Cl} / \mathrm{H} / \mathrm{O}$ systems using a computational scheme based on free energy minimization. The thermodynamic computations were carried out in two steps. The free energy minimization code was first used to compute the equilibrium of the gas phase in the absence of chemical reactions. The feasibility of the deposition of a solid species was then examined in a second step by computing the equilibrium constants of reactions leading to deposition of that species. The results showed that the deposition of $\mathrm{SiO}_{2}, \mathrm{Al}_{2} \mathrm{O}_{3}$, and of mixed oxides (such as, $\mathrm{Al}_{2} \mathrm{SiO}_{5}$ and $\left.\mathrm{Al}_{6} \mathrm{Si}_{2} \mathrm{O}_{13}\right)$ is allowed to take place from the equilibrated gas phase for a very broad range of compositions of the feed mixture over the whole temperature that is typically of interest in CVD applications (800 to $1500 \mathrm{~K}$ ). The analysis of the phase equilibrium of the solid phase species revealed that for $\mathrm{Al}_{2} \mathrm{O}_{3}$ ratios in the deposit above 3:2, that is, for ratios corresponding to alumina-rich mullite, the stable composition of the deposit would involve only mullite and $\mathrm{Al}_{2} \mathrm{O}_{3}$ for temperatures above $1128 \mathrm{~K}$ and $\mathrm{Al}_{2} \mathrm{SiO}_{5}$ (andalusite) and $\mathrm{Al}_{2} \mathrm{O}_{3}$ for temperatures below that value. Even though this result was based on theoretical results obtained by considering pure solid phases, it is in agreement with the result of experimental and other thermodynamic studies [1]. It is also in agreement with the results of the present study, which showed that at the temperatures used in our experiments - in all cases the temperature we used was above $1128 \mathrm{~K}$ - mullite was the only aluminosilicate 
present in the films (see Figures 4 and 13) for $\mathrm{Al}_{2} \mathrm{O}_{3}$ to $\mathrm{SiO}_{2}$ ratios in the range of alumina-rich mullite $\left(\mathrm{Al}_{2} \mathrm{O}_{3}: \mathrm{SiO}_{2}\right.$ above $\left.3: 2\right)$.

The results from the thermochemical equilibrium computations in the gas phase in [19] showed that many species (most of them having radical form) are present in the gas phase. Among the species with the highest concentrations is $\mathrm{HCl}$. This species appears as a product in the overall deposition reaction (equation (1)), and it is a product of the homogeneous (gas phase) reactions that lead to formation of the species that act as direct precursors for metal incorporation in the deposit $\left(\mathrm{SiCl}_{\mathrm{x}}\right.$ and $\mathrm{AlCl}_{\mathrm{x}}$ ). Moreover, it is a product of the reactions that are assumed to be the solid formation steps under single oxide deposition conditions (silica or alumina) in the model we formulated (see equations (2) and (3)). One would therefore expect an increase in the concentration of $\mathrm{HCl}$ to have an inhibitory effect on the rates of formation of metal chloride radical species in the gas phase and on the deposition of $\mathrm{SiO}_{2}$ and $\mathrm{Al}_{2} \mathrm{O}_{3}$ through reactions (2) and (3).

Since $\mathrm{HCl}$ is a product of the deposition process, its concentrations increases away from the entrance of the reactor. This is also the case for the other species formed in the gas phase of the reactor in the entrance region of the reactor, but the concentrations of those that participate as reactants in the heterogeneous reactions or in homogeneous reactions may present a maximum at some distance in the reactor. The strong effects of the location of deposition (distance from the entrance of the reactor, i.e., the beginning of the isothermal zone) may therefore be a manifestation of the effects of the varying composition of the gas phase along the length of the reactor. Both the thermochemical equilibrium analysis of the gas phase and the results obtained from the mathematical model [21] have shown that for comparable mole fractions of $\mathrm{AlCl}_{3}$ and $\mathrm{SiCl}_{4}$ in the feed, the gas phase concentration of $\mathrm{HCl}$ in the codeposition process is at a similar level as that in the $\mathrm{SiCl} / \mathrm{CO}_{2} / \mathrm{H}_{2}$ system but much higher than that in the $\mathrm{AlCl} / \mathrm{CO}_{2} / \mathrm{H}_{2}$ system, for all three systems at the same conditions. Therefore, the reduction of the molar fraction of $\mathrm{SiCh}_{4}$ in the feed not only leads to lower deposition rates of $\mathrm{SiO}_{2}$ by lowering the coverages of the $\mathrm{Si}$ 
containing surface species in the $\mathrm{SiO}_{2}$-generating reactions (equations (2) and (4)), but also enhances the rate of incorporation of $\mathrm{Al}_{2} \mathrm{O}_{3}$ in the deposit and brings the $\mathrm{Al}_{2} \mathrm{O}_{3}$ content to the levels seen for deposition from mixtures of $\mathrm{AlCl}_{3}, \mathrm{CO}_{2}$, and $\mathrm{H}_{2}$ by reducing the mole fraction of $\mathrm{HCl}$ in the gas phase.

It was noted in the presentation of the experimental results that the effects of several experimental parameters, such as pressure, flow rate, and location of deposition, are closely related to the effects of residence time. Allowing the gas mixture to spend more time in the high temperature environment of the reactor before it reaches the deposition sites leads to higher concentrations of $\mathrm{HCl}$ in the vicinity of the deposition location and, hence, lower rates of $\mathrm{Al}_{2} \mathrm{O}_{3}$ incorporation in the deposit and lower $\mathrm{Al}$ to $\mathrm{Si}$ ratios. Experiments on the effects of $\mathrm{HCl}$ on the deposition of $\mathrm{SiO}_{2}$ [21] revealed a strong inhibitory effect of that species on the deposition rate. However, the enhancement in the incorporation rate of $\mathrm{SiO}_{2}$ in the deposit in the presence of $\mathrm{AlCl}_{3}$ in the feed points to the existence of additional $\mathrm{SiO}_{2}$ generation steps in the codeposition process, such as the step postulated by Nitodas [21] in the codeposition model (see equation (4)). Since this step does not involve $\mathrm{HCl}$ as a product, its rate is affected not directly by that species as those of reactions (2) and (3). Therefore, the progressive shift of the composition of the deposit towards $\mathrm{SiO}_{2}$ along the length of the reactor is most probably due to the weaker influence of the concentration of $\mathrm{HCl}$ on the rates of $\mathrm{SiO}_{2}$-generating steps that do not involve it as a product.

The very strong dependence of the deposition rate and of the composition of the deposit on the residence time of the mixture in the reactor indicates that the design of a chemical vapor deposition reactor that could be used to deposit uniform (in thickness, composition, and morphology) coatings of mullite or alumina-rich mullite on objects of complex shape would be a challenging problem. Since the strong effects of residence time are in turn connected with the effects of the composition of the mixture on the deposition rate, one concludes that the reactor must be designed in such a way that the composition of the reactive mixture should be almost uniform 
over all surfaces that must be coated. This could be achieved by appropriate placement of multiple feeding and withdrawal ports of the reactive mixture. Of course, the temperature in the reactor should be uniform as well since, as we have also seen in the results we presented in the present study, its effects on deposition rate, coating composition, and coating morphology are very strong. Another factor that must be taken into account in designing an industrial reactor is the requirement to have relatively low residence times of the mixture in the high temperature environment of the reactor in order to obtain deposits with high $\mathrm{Al}_{2} \mathrm{O}_{3}$ content. In addition to the obvious solutions of using high flow rates, inert gases in the feed mixture, or low operating pressures, another option may be to employ a cold-wall configuration, in which the reactive mixture experiences high temperatures only in the vicinity of the deposition surface.

\section{Conclusions}

The formulation of processing routes for the fabrication of mullite coatings through chemical vapor deposition from mixtures of $\mathrm{SiCl}_{4}, \mathrm{AlCl}_{3}, \mathrm{CO}_{2}$, and $\mathrm{H}_{2}$ was addressed in this study. The results of past theoretical and experimental studies were used to identify a range of operating conditions where deposits with $\mathrm{Al} / \mathrm{Si}$ ratio close to that of mullite or higher could be obtained. Experiments were carried out in a tubular, hot-wall CVD reactor, equipped with an electronic microbalance. Mullite coatings were deposited onto $\mathrm{SiC}$ and $\mathrm{Si}$ plates, and onto refractory wires placed along the centerline of the reactor. The effects of temperature, pressure, and residence time on the composition and morphology of the films were studied, and the deposits were analyzed using a variety of methods.

The composition of the coatings was found to depend strongly on the concentration of $\mathrm{SiCl}_{4}$. In order to obtain $\mathrm{Al} / \mathrm{Si}$ deposit ratios close to that of stoichiometric mullite, $\mathrm{AlCl}_{3} / \mathrm{SiCh}_{4}$ feed ratios of $25: 1$ were employed in the experiments, combined with a relatively high total gas flow rate to reduce the residence time of the reactive mixture in the reactor. The results on the profiles of the 
composition of the deposit in the reactor showed that the content in $\mathrm{Al}_{2} \mathrm{O}_{3}$ increased towards the entrance of the reactor, obtaining values above $90 \%$ by weight in the vicinity of the beginning of the heating zone. The microstructure of the deposit varied significantly depending on the process conditions and residence time. Crystalline mullite films, of well-defined faceted structure, were obtained at positions located in the entrance region of the reactor, with the average size of the crystals decreasing with increasing residence time. A change in the morphology from faceted crystalline to microcrystalline or grainy nodular was observed away from the entrance of the reactor. This was accompanied by a decrease in the alumina content below the value that corresponds to stoichiometric mullite.

The operating pressure and the temperature also had a very strong influence on the composition and the structure of the mullite films. Increasing temperature and decreasing pressure resulted in an increase in the alumina content of the coatings and the size of the crystals. In general, the results of this study suggested promising ways to suppress the enhancement of silica deposition observed in our past experimental studies, and shift the composition of the films codeposited from $\mathrm{SiCh}-\mathrm{AlCl}_{3}-\mathrm{CO}_{2}-\mathrm{H}_{2}$ mixtures towards mullite and alumina-rich mullite. By manipulating the pressure and temperature of the deposition process, stoichiometric mullite could be obtained at 46

cm locations, whereas alumina-rich aluminosilicates were deposited at positions close to the entrance of the CVD reactor.

\section{ACKNOWLEDGEMENTS}

This research was supported by a grant from the Department of Energy. The authors also acknowledge the help Ms. Corinna Skartsila of the Institute of Chemical Engineering and High Temperature Chemical Processes (Patras, Greece) with the AFM characterization of the films.

\section{REFERENCES}

1. Davis, R. F., and Pask, J. A., "Mullite", in High Temperature Oxides. Part IV, Ed.: Alper, A.M., Academic Press, New York, pp. 37-76 (1971). 
2. Mulpuri, R., "Chemical Vapor Deposition of Mullite Coatings on Silicon Based Ceramics for High Temperature Applications", Ph.D. Dissertation, Boston Univ., Boston (1996).

3. Aksay, I. A., Dabbs, D. M., and Sarikaya, M., J. Am. Ceram. Soc., 74, 23432358 (1991).

4. Kara, F., and Little, J. A., J. Mater. Sci., 28, 1323-1326 (1993).

5. Lee, K. N., and Miller, R. A., J. Am. Ceram. Soc., 79, 620-626 (1996).

6. Lee, K. N., and Miller, R. A., Surf. Coat. Tech., 87-88, 142-148 (1996).

7. Schneider, H., and Eberhard, E., J. Am. Ceram. Soc., 73, 2073-2076 (1990).

8. Aramaki, S., and Roy, R., J. Am. Ceram. Soc., 45, 229 (1962).

9. Haynes, J. A., Cooley, K. M., Stinton, D. P., and Lowden, R. A., $23^{\text {rd }}$ Annual Conference on Composites, Advanced Ceramics, Materials, and Structures: B, 20, 355-362 (1999).

10. Mulpuri, R. P., and Sarin, V. K., J. Mater. Res., 11, 1315-1324 (1996).

11. Haynes, J. A., Lance, M. J., Cooley, K. M., Ferber, M. K., Lowden, R. A., and Stinton, D. P., J. Am. Ceram. Soc., 83, 657-659 (2000).

12. Fritze, H., Jojic, J., Witke, T., Ruscher, C., Weber, S., Scherrer, S., Weiss, R., Schultrich, B., and Borchardt, G., J. Eur. Ceram. Soc., 18, 2351-2364 (1998).

13. Kanzaki, S., Tabata, H., Kumazawa, T., and Ohta, S., J. Am. Ceram. Soc., 68, C6-C7 (1985).

14. CRC Materials Science and Engineering Handbook, Shackelford, J. F., ed., 2nd Edition, CRC Press, Boca Raton, FL (1994).

15. Itatani, K., Kubozono, T., Howell, F. S., Kishioka, A., and Kinoshita, M, J. Mater. Sci., 30, 1158-1165 (1995).

16. Itatani, K., Kubozono, T., Howell, F. S., Kishioka, A., and Kinoshita, M, J. Mater. Sci., 30, 1196-1202 (1995).

17. Auger, M. L. and Sarin, V. K., Surf. Coat. Technol., 94-95, 46-52 (1997).

18. Besmann, T. M., Haynes, J. A., Cooley, K. M., Vaubert, V. M., and Lee, W. Y., MRS Proc., 555, 109-118 (1999). 
19. Nitodas, S. F., and Sotirchos, S. V., Chem. Vapor Deposition (Adv. Mater.), 5, 219 (1999).

20. Nitodas, S. F., and Sotirchos, S. V., J. Electrochem. Soc., 147, 1050 (2000).

21. Nitodas, S. F., Ph.D. Dissertation, Univ. of Rochester, Rochester, NY (1999).

22. Fredriksson, E., and Carlsson, J.-O., J. Chem. Vap. Dep., 1, 333 (1993).

23. Papasouliotis, G. D., and Sotirchos, S. V., J. Electrochem. Soc., 142, 3834 (1995). 


\section{LIST OF FIGURES}

Figure 1. Model predictions for shifting the composition of the aluminosilicate coatings towards $\mathrm{Al}_{2} \mathrm{O}_{3}$.

Figure 2. SEM micrographs of CVD aluminosilicate films prepared at 100 Torr, 400 $\mathrm{cm}^{3} / \mathrm{min}$ total flow rate, and $7 \mathrm{~cm}$ location with $x_{\mathrm{SiCl} 4}=0.0008, x_{\mathrm{AlCl} 3}=0.0125$, $x_{\mathrm{CO} 2}=0.0875$. Deposition temperature: (a) $1273 \mathrm{~K}$; (b) $1323 \mathrm{~K}$.

Figure 3. Effect of process conditions on the rates of incorporation of $\mathrm{SiO}_{2}$ and $\mathrm{Al}_{2} \mathrm{O}_{3}$ in the deposit. Solid curves: 100 Torr, $400 \mathrm{~cm}^{3} / \mathrm{min}$, substrate at $7 \mathrm{~cm}, \mathrm{X}_{\mathrm{SiCl} 4}=0.0008$, $\mathrm{x}_{\mathrm{AlCl} 3}=0.0125$, and $\mathrm{x}_{\mathrm{CO} 2}=0.0875$; dashed curves: 100 Torr, $300 \mathrm{~cm}^{3} / \mathrm{min}$, substrate at $4 \mathrm{~cm}, \mathrm{x}_{\mathrm{SiCl} 4}=0.006, \mathrm{x}_{\mathrm{AlCl} 3}=0.012$, and $\mathrm{x}_{\mathrm{CO} 2}=0.035$.

Figure 4. XRD pattern of CVD mullite coating prepared at $1323 \mathrm{~K}, 75$ Torr, 400 $\mathrm{cm}^{3} / \mathrm{min}$ total flow rate, and $6 \mathrm{~cm}$ location with $x_{\mathrm{SiCl} 4}=0.0005, x_{\mathrm{AlCl} 3}=0.0125$, and $x_{\mathrm{CO} 2}=0.0875$.

Figure 5. Effect of position in the reactor on the $\mathrm{Al}_{2} \mathrm{O}_{3}$ content of the deposit at 75 and 100 Torr.

Figure 6. SEM micrographs of CVD mullite films prepared at $1323 \mathrm{~K}, 100$ Torr, and $400 \mathrm{~cm}^{3} / \mathrm{min}$ total flow rate with $x_{\mathrm{SiCl} 4}=0.0005, x_{\mathrm{AlCl} 3}=0.0125$, and $x_{\mathrm{CO} 2}=0.0875$. Deposition location: (a) entrance of the reactor $(0 \mathrm{~cm})$; (b) $1 \mathrm{~cm}$.

Figure 7. SEM micrographs of CVD mullite films prepared at $1323 \mathrm{~K}, 75$ Torr, and $400 \mathrm{~cm}^{3} /$ min total flow rate with $x_{\mathrm{SiCl} 4}=0.0005, x_{\mathrm{AlCl} 3}=0.0125$, and $x_{\mathrm{CO} 2}=0.0875$. Deposition location: (a) $1 \mathrm{~cm}$; (b) $3 \mathrm{~cm}$; (c) $5 \mathrm{~cm}$. 
Figure 8. AFM images of CVD mullite film prepared at $1323 \mathrm{~K}, 75$ Torr, 400 $\mathrm{cm}^{3} / \mathrm{min}$ total flow rate, and $6.5 \mathrm{~cm}$ location with $x_{\mathrm{SiCl} 4}=0.0005, x_{\mathrm{AlCl} 3}=0.0125$, and $x_{\mathrm{CO} 2}=0.0875$.

Figure 9. Variation of the $\mathrm{Al}_{2} \mathrm{O}_{3}$ content of mullite coatings with the distance from the entrance (beginning of the isothermal zone) of the CVD reactor.

Figure 10. SEM micrographs of CVD mullite films prepared at 75 Torr, $400 \mathrm{~cm}^{3} / \mathrm{min}$ total flow rate, and $3 \mathrm{~cm}$ location with $x_{\mathrm{SiCl} 4}=0.0005, x_{\mathrm{AlCl} 3}=0.0125$, and $x_{\mathrm{CO} 2}=$ 0.0875. Deposition temperature: (a) $1273 \mathrm{~K}$; (b) $1323 \mathrm{~K}$.

Figure 11. SEM micrographs of CVD mullite films prepared at 50 Torr, $400 \mathrm{~cm}^{3} / \mathrm{min}$ total flow rate, and $3 \mathrm{~cm}$ location with $x_{\mathrm{SiCl} 4}=0.0005, x_{\mathrm{AlCl} 3}=0.0125$, and $x_{\mathrm{CO} 2}=$ 0.0875. Deposition temperature: (a) $1323 \mathrm{~K}$; (b) $1373 \mathrm{~K}$.

Figure 12. AFM images of CVD mullite film prepared at $1323 \mathrm{~K}, 75$ Torr, 400 $\mathrm{cm}^{3} / \mathrm{min}$ total flow rate, and $3 \mathrm{~cm}$ location with $x_{\mathrm{SiCl} 4}=0.0005, x_{\mathrm{AlCl} 3}=0.0125$, and $x_{\mathrm{CO} 2}=0.0875$.

Figure 13. XRD pattern of CVD mullite coating prepared at $1273 \mathrm{~K}, 75$ Torr, 400 $\mathrm{cm}^{3} /$ min total flow rate, and $1 \mathrm{~cm}$ location with $x_{\mathrm{SiCl} 4}=0.0005, x_{\mathrm{AlCl} 3}=0.0125$, and $x_{\mathrm{CO} 2}=0.0875$. 


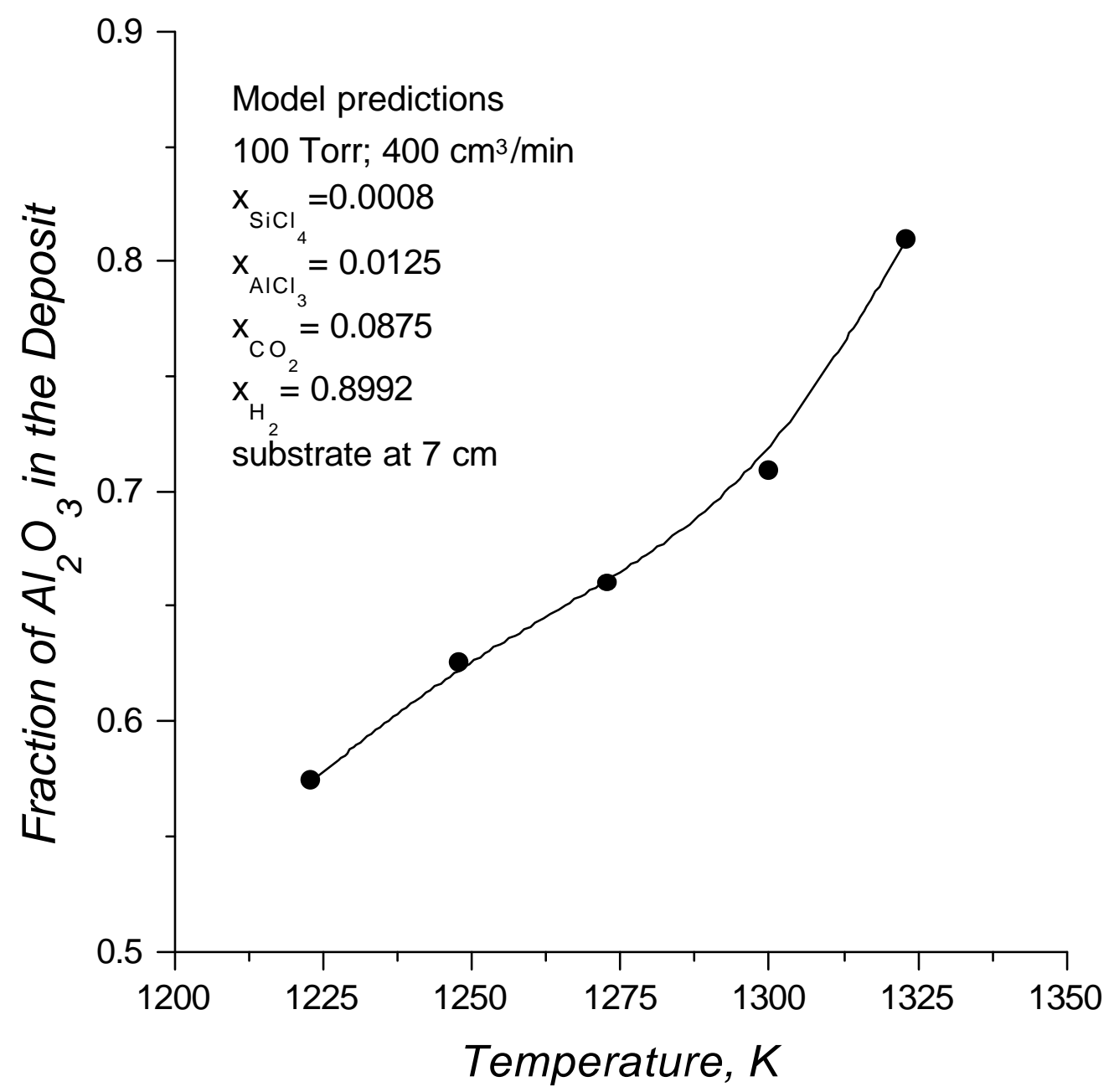




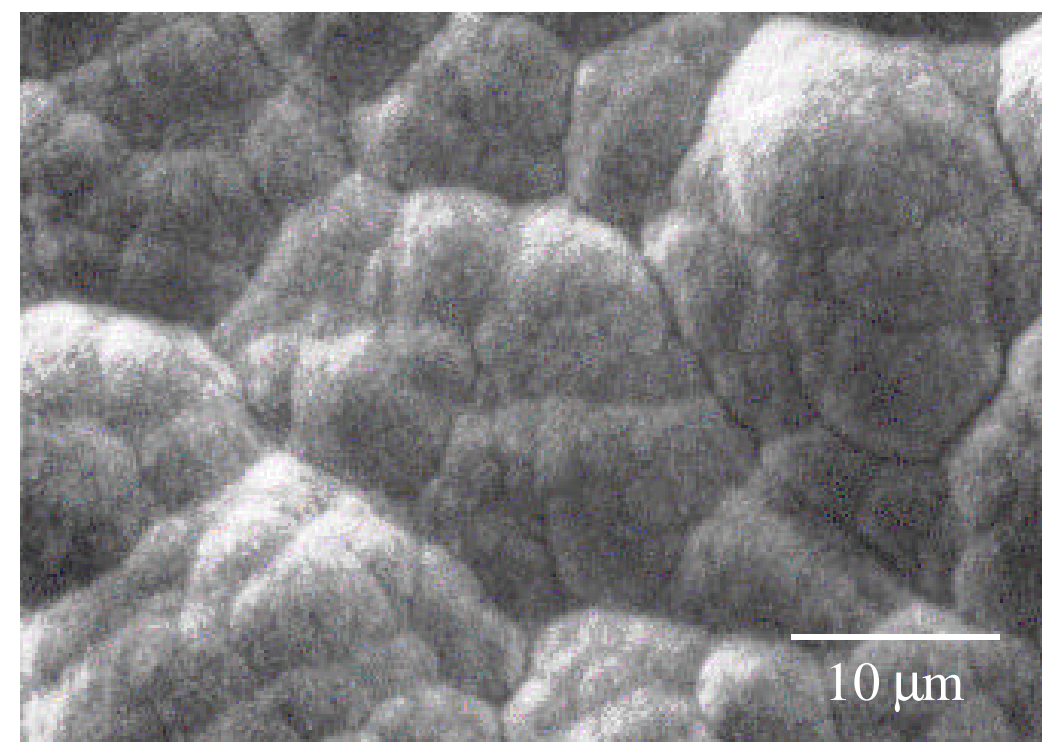

(a)

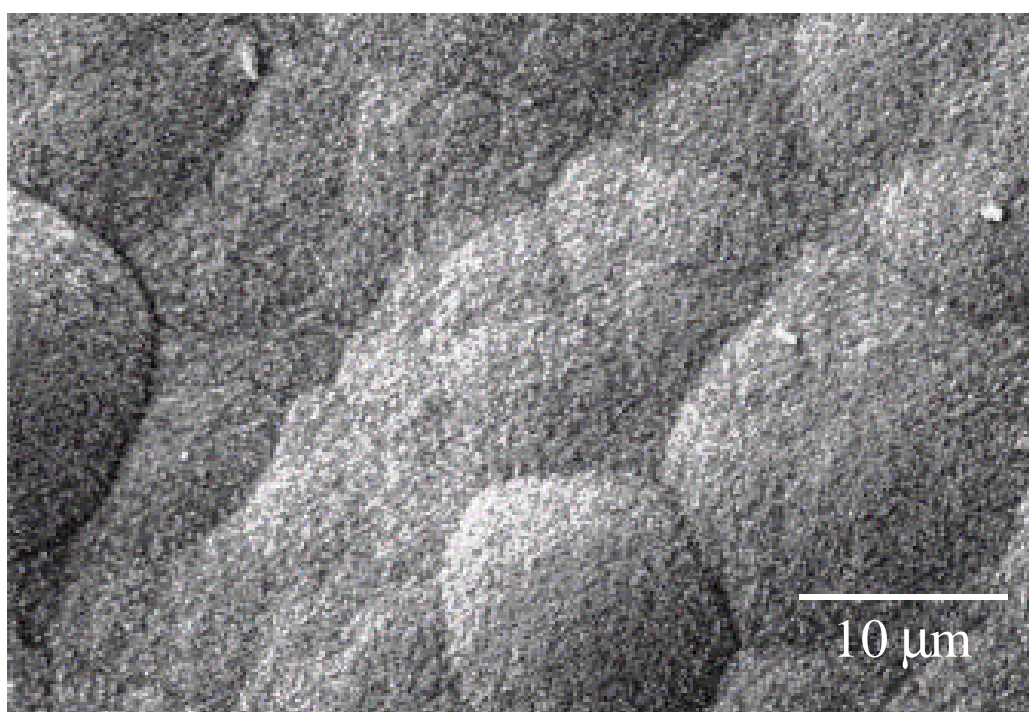

(b) 


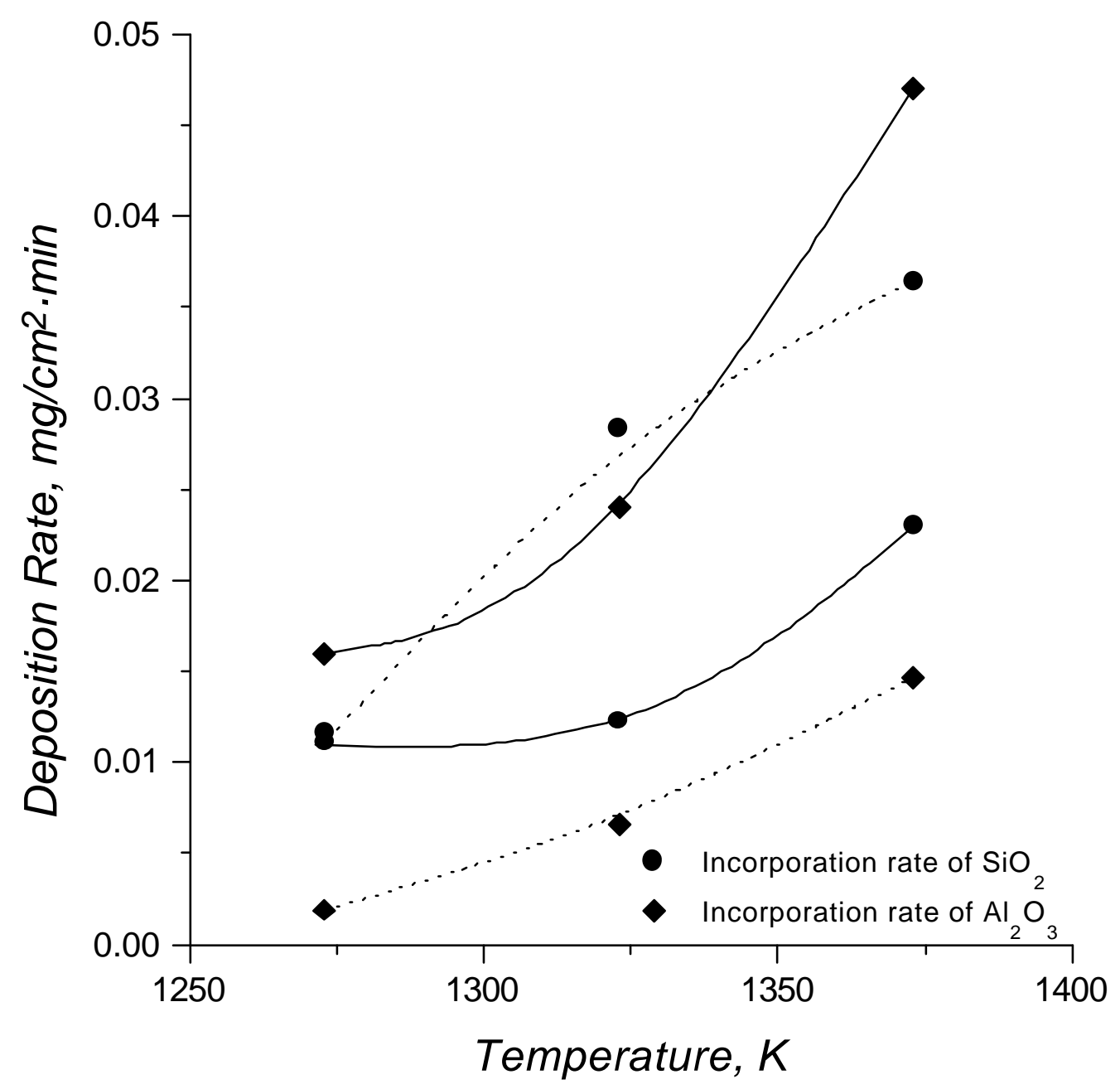




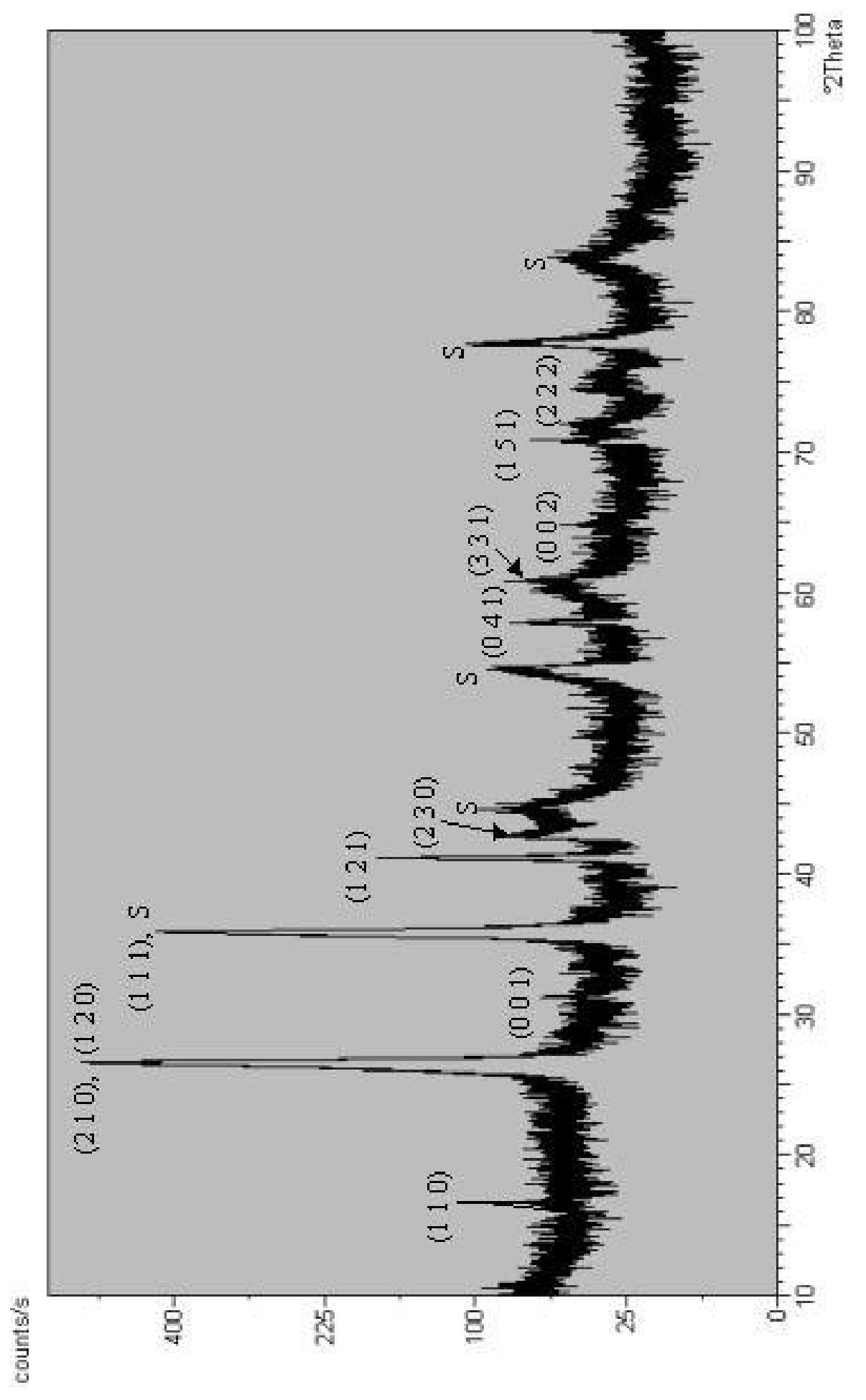

Nitodas and Sotirchos

FIGURE 4 


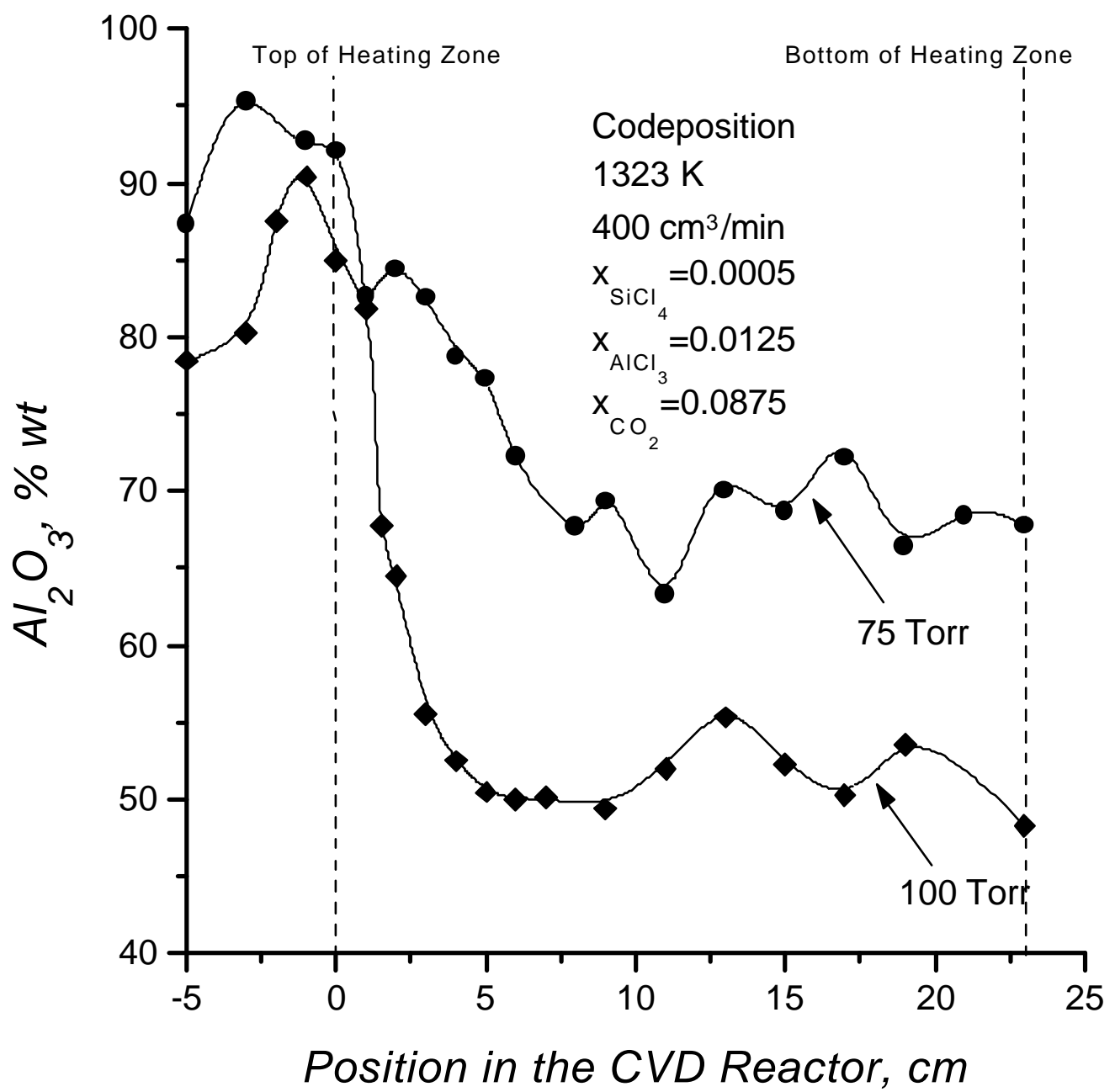




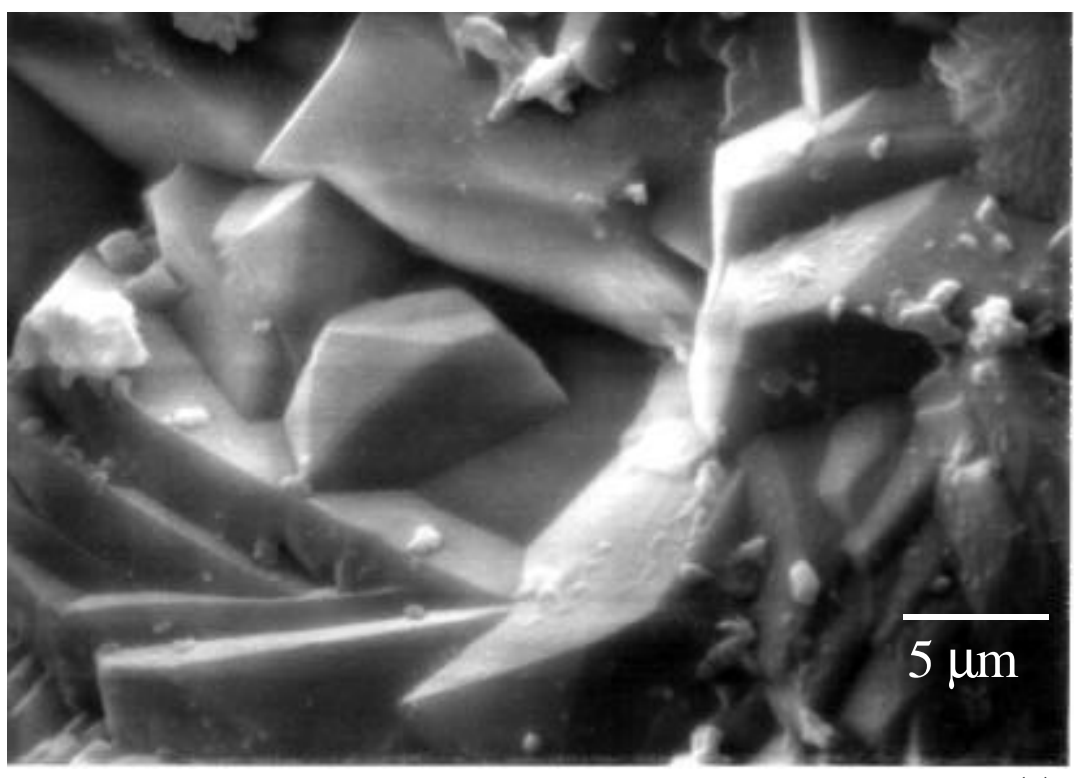

(a)

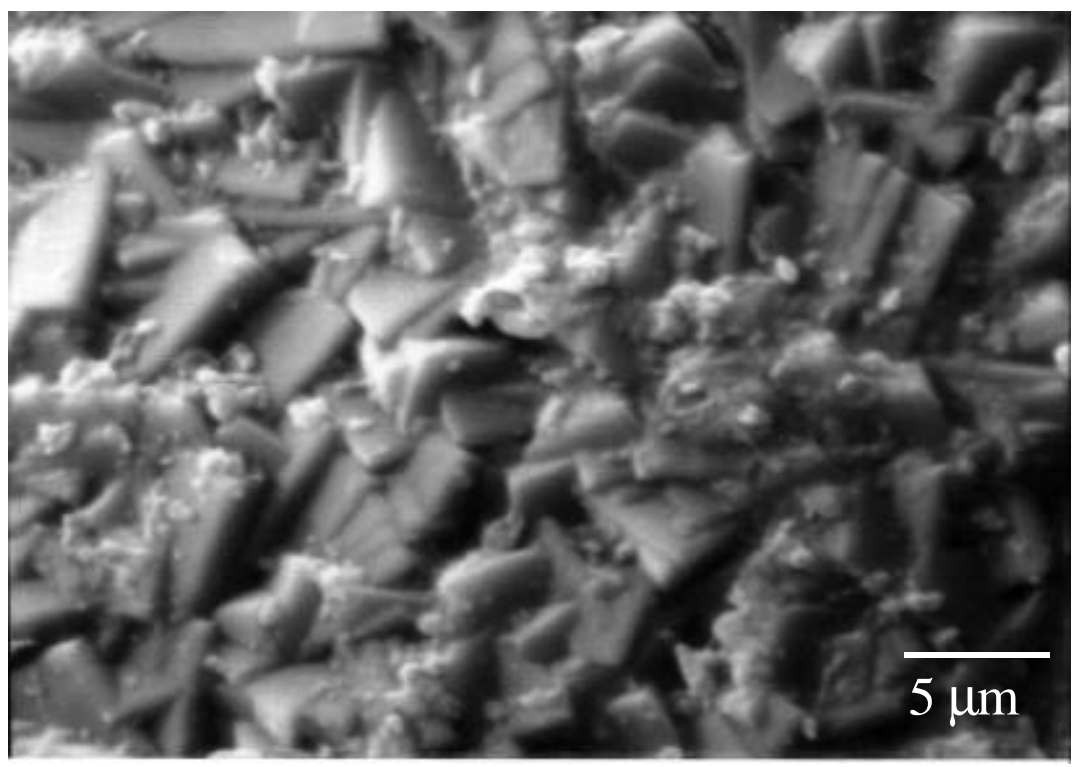

(b) 


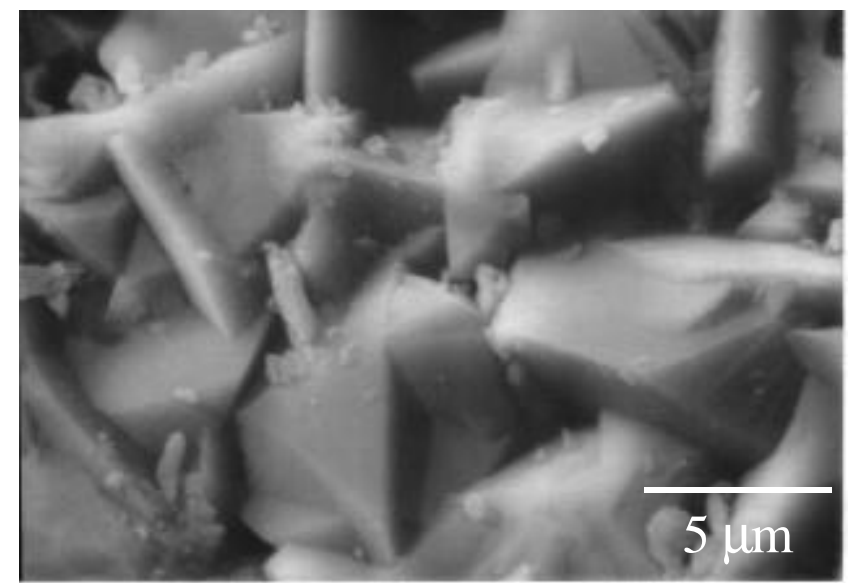

(a)

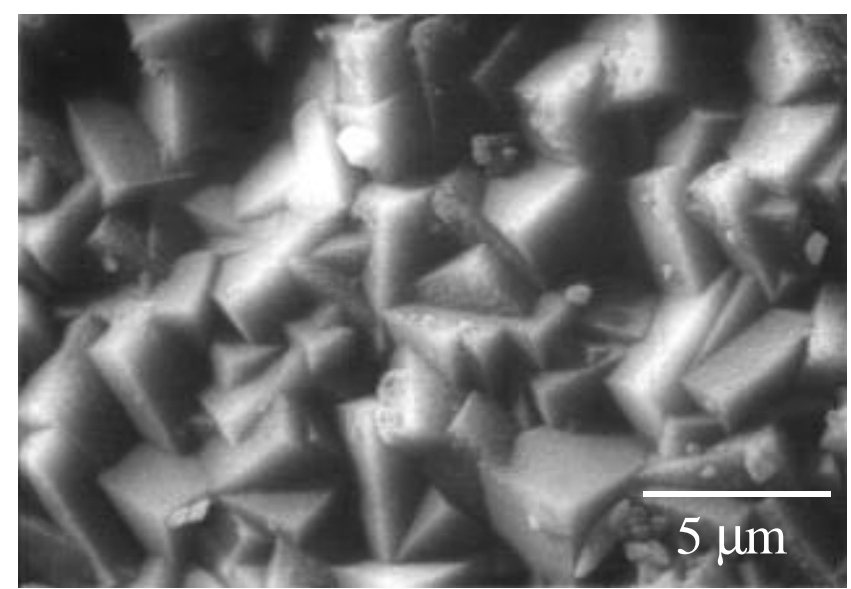

(b)

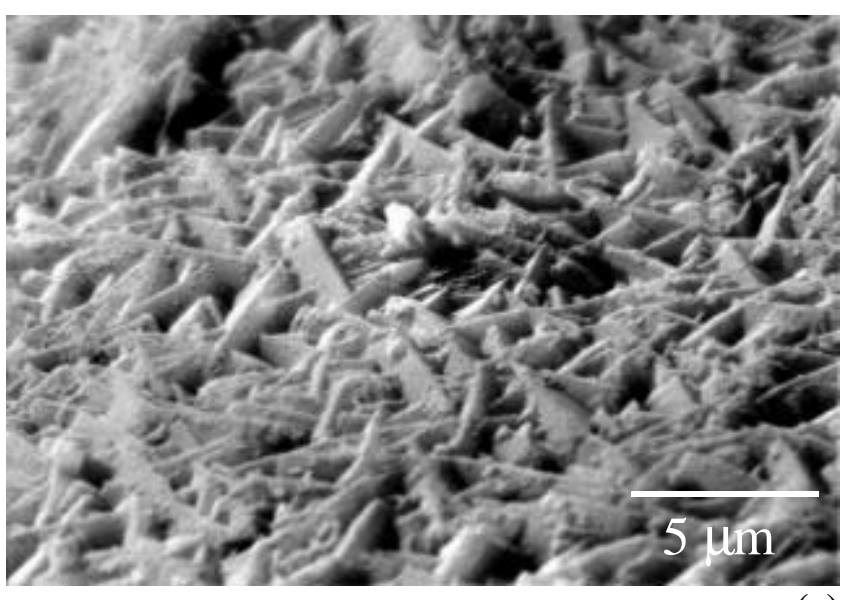

(c) 

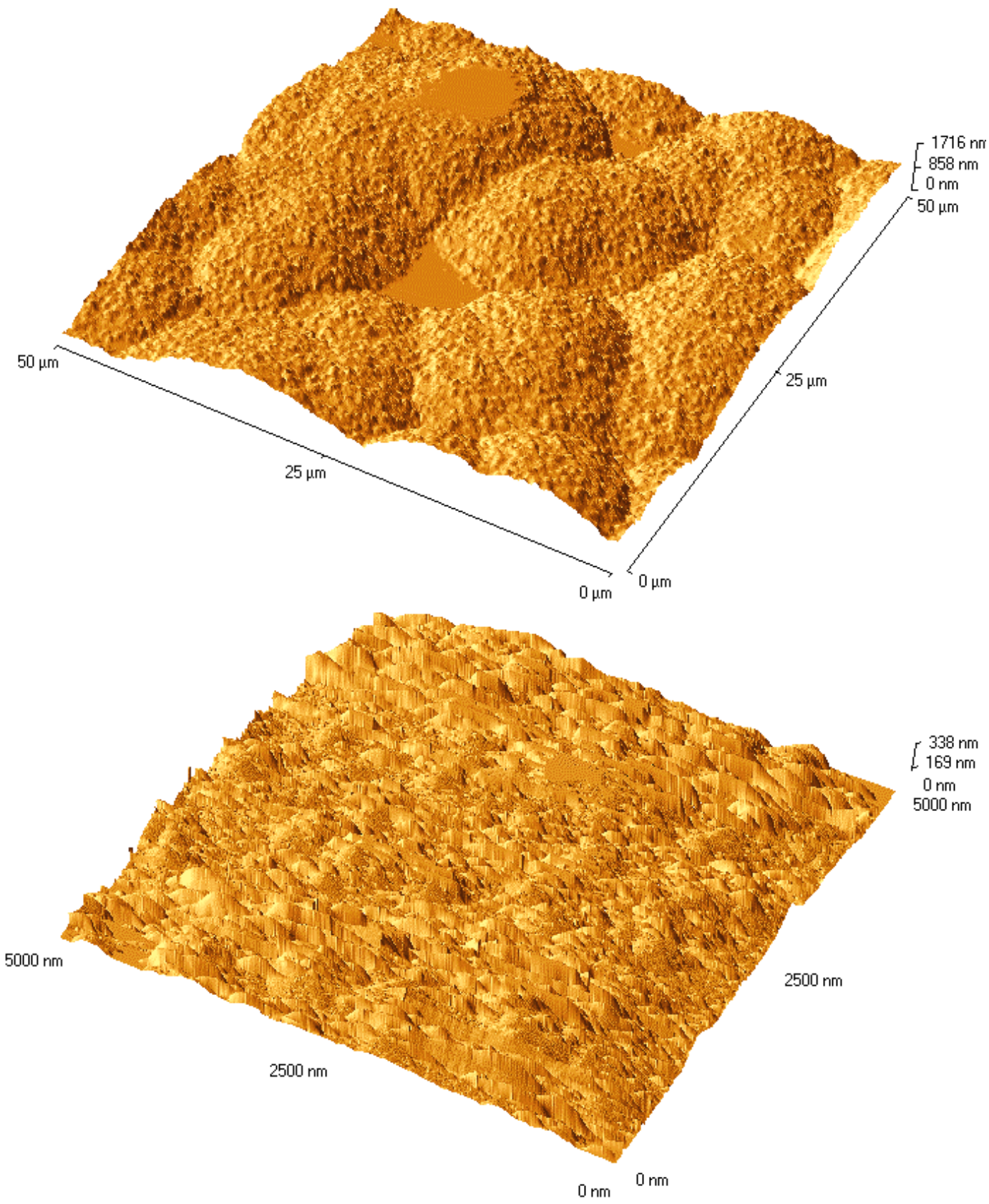


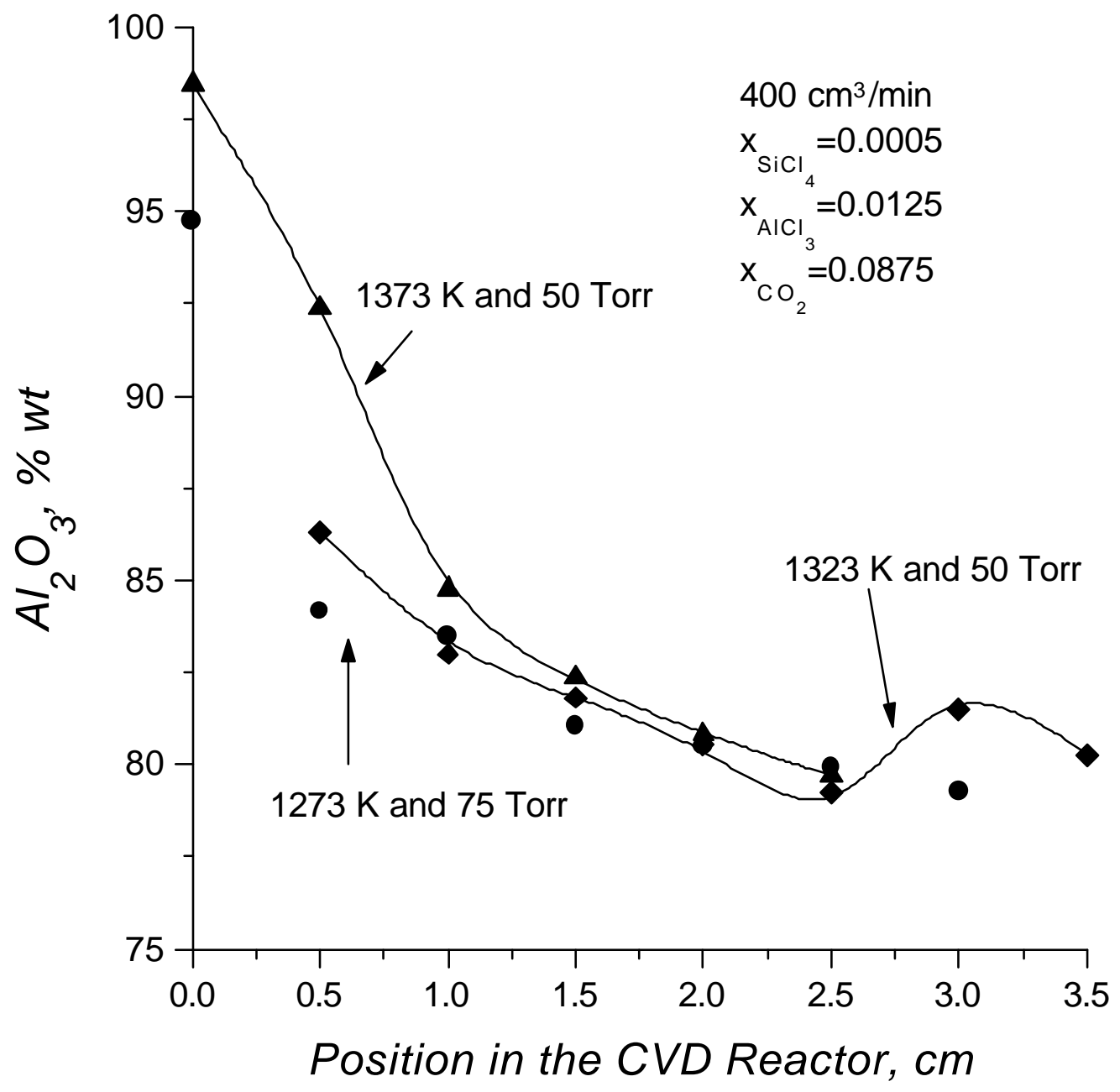




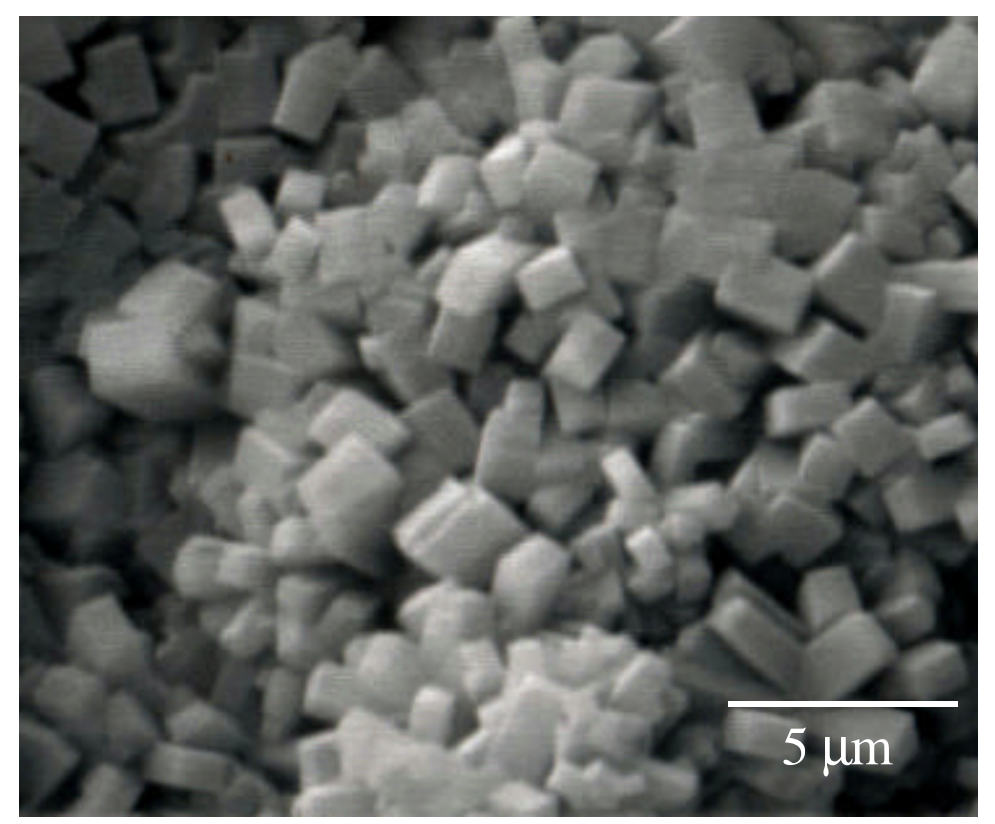

(a)

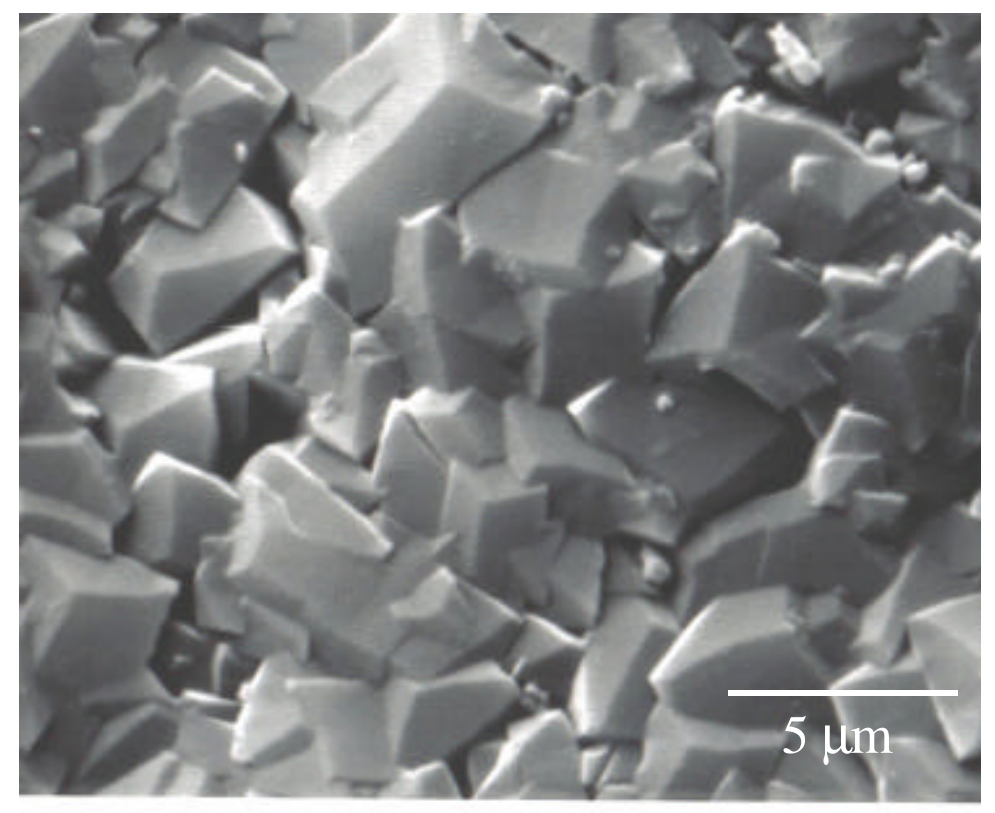

(b) 


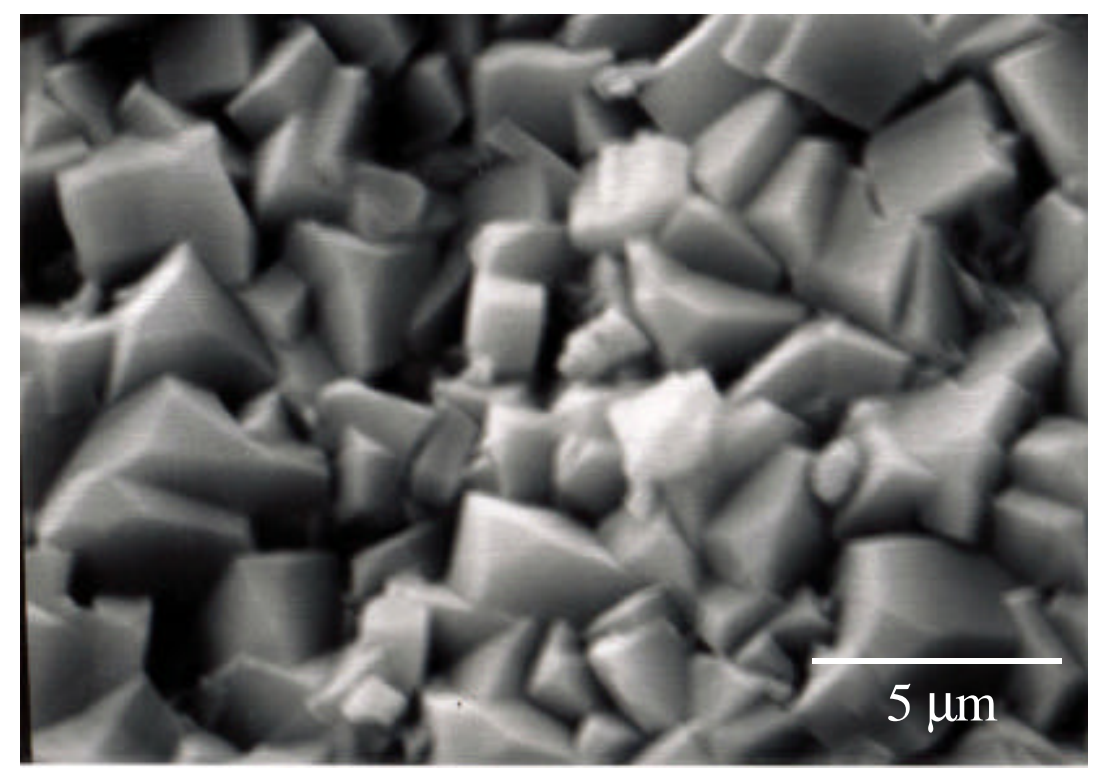

(a)

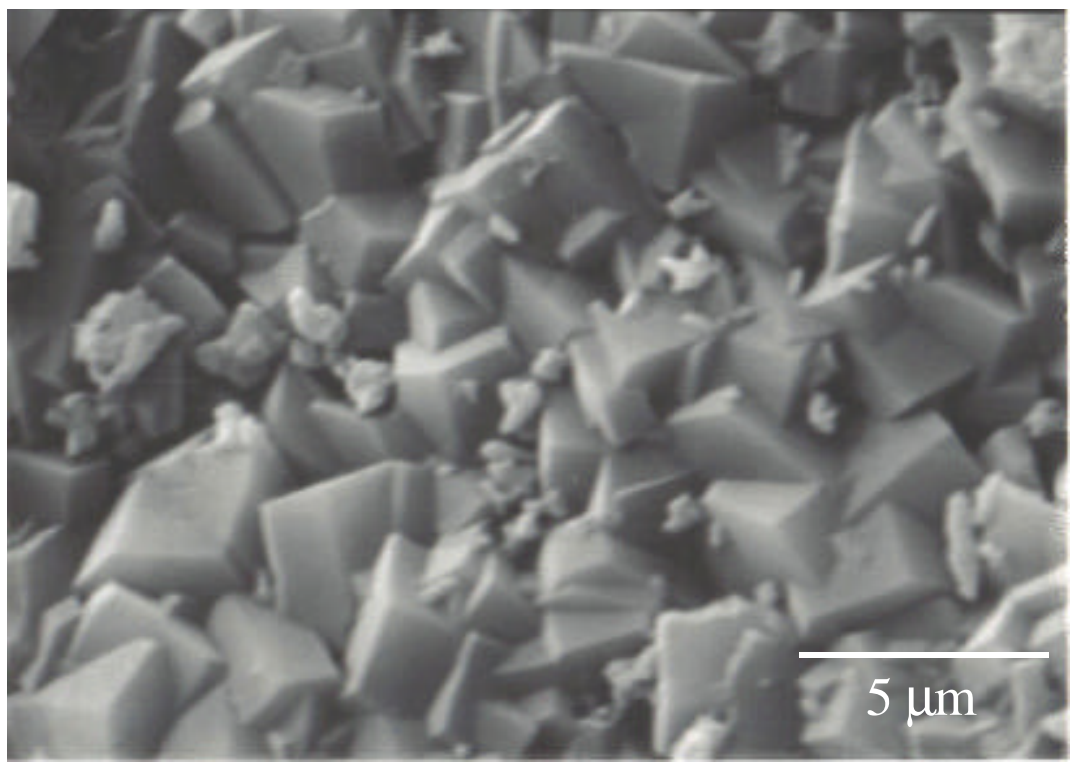

(b) 

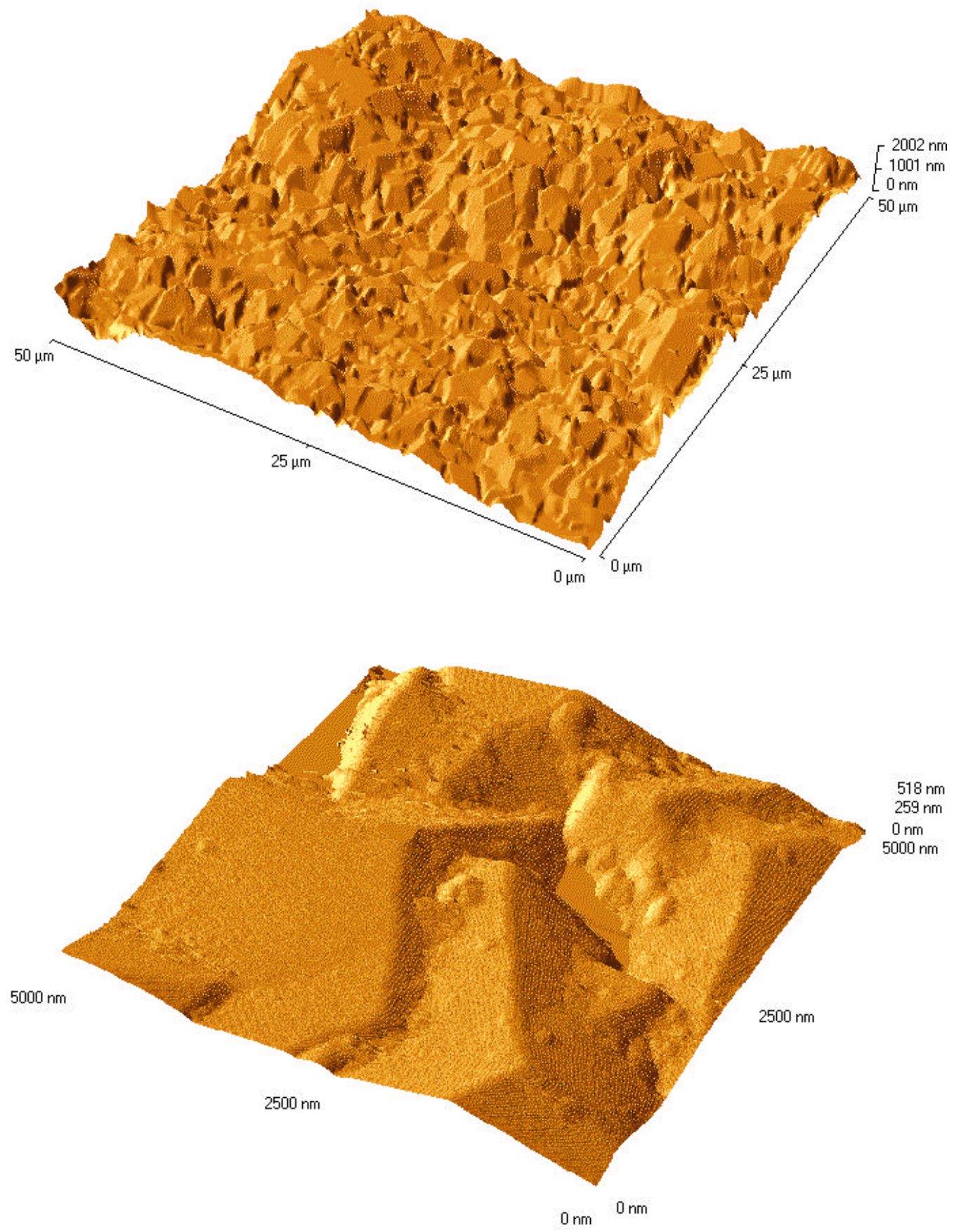


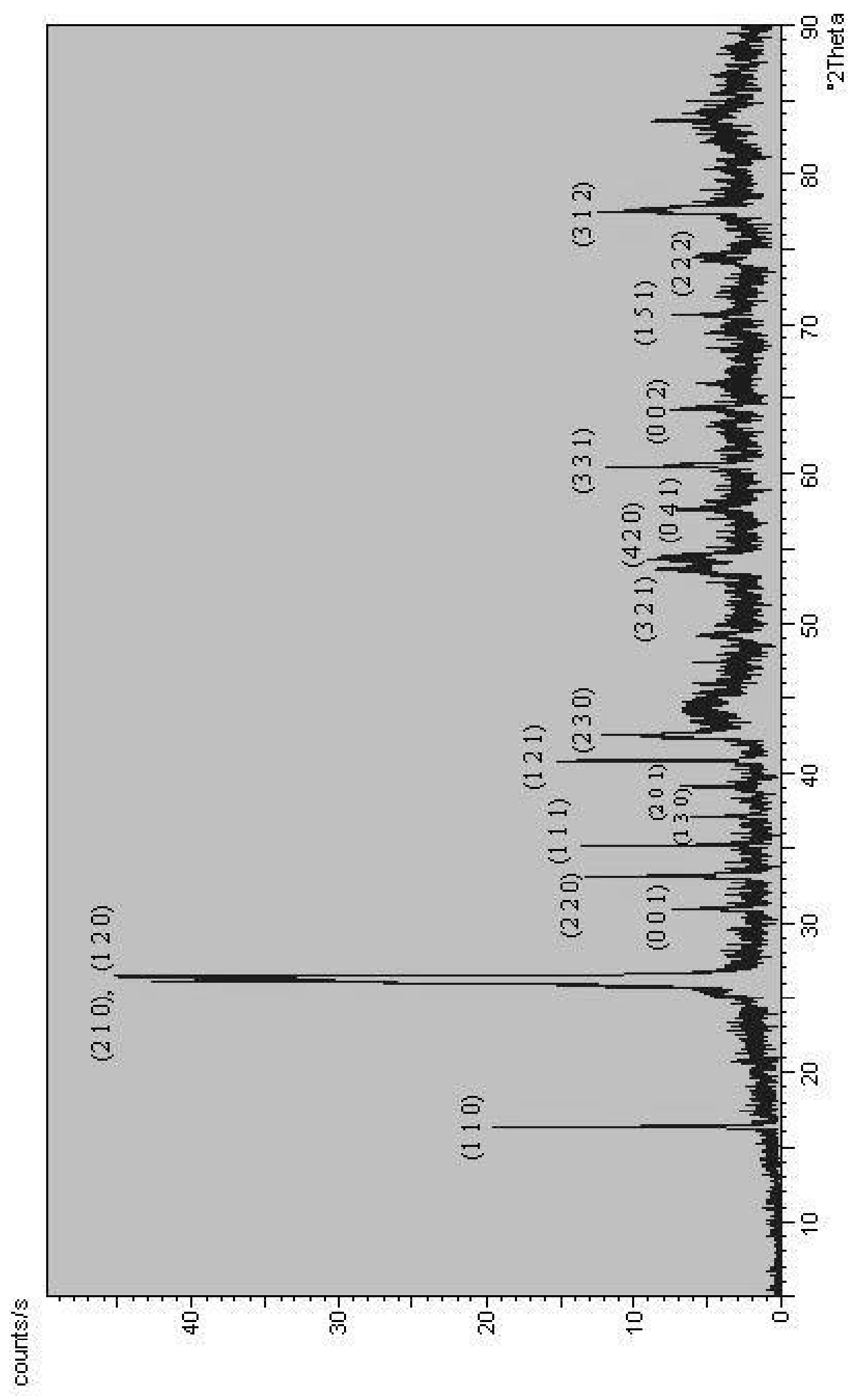

Nitodas and Sotirchos

FIGURE 13 